\title{
Jörg Ebding
}

\section{Tendenzen der Entwicklung des sowjetischen satirischen Romans 1919-1931}

Verlag Otto Sagner München · Berlin · Washington D.C.

Digitalisiert im Rahmen der Kooperation mit dem DFG-Projekt „Digi20“

der Bayerischen Staatsbibliothek, München. OCR-Bearbeitung und Erstellung des eBooks durch den Verlag Otto Sagner:

http://verlag.kubon-sagner.de

( $)$ bei Verlag Otto Sagner. Eine Verwertung oder Weitergabe der Texte und Abbildungen, insbesondere durch Vervielfältigung, ist ohne vorherige schriftliche Genehmigung des Verlages unzulässig. 


\title{
Slavistische Beiträge
}

\author{
BEGRÜNDET VON \\ ALOIS SCHMAUS \\ HERAUSGEGEBEN VON \\ JOHANNES HOLTHUSEN · HEINRICH KUNSTMANN \\ PETER REHDER · JOSEF SCHRENK \\ REDAKTION \\ PETER REHDER \\ Band 145
}

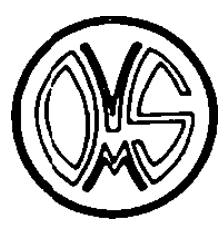

VERLAG OTTO SAGNER

MÜNCHEN 


\section{JÖRG EBDING}

\section{TENDENZEN DER ENTWICKLUNG DES SOWJETISCHEN SATIRISCHEN ROMANS (1919 - 1931)}

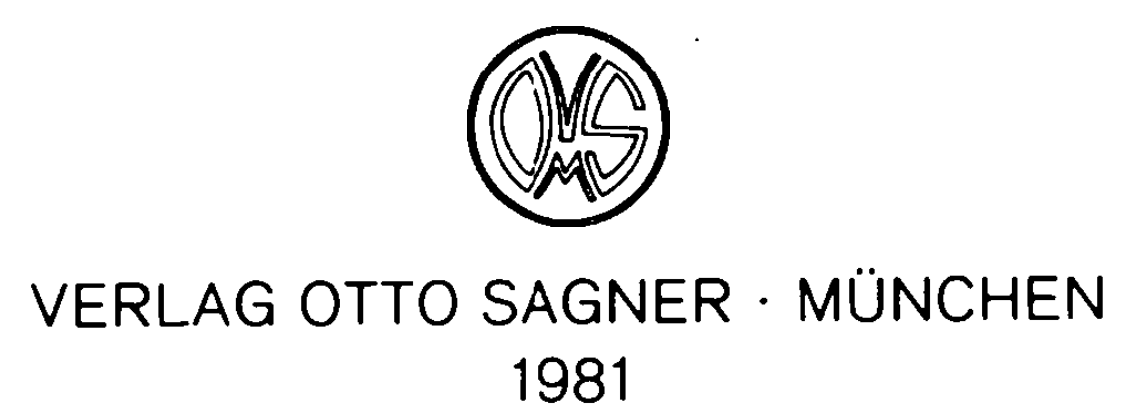


ISBN 3-87690-194-4

Copyright by Verlag Otto Sagner, München 1981 Abteilung der Firma Kubon \& Sagner, München

Druck: Alexander Grossmann

Fäustlestr. 1, D-8000 München 2

\section{Bayerischo \\ Matsbibliothok \\ München}


INHALT

ERSTER TEIL : VORAUSSETZUNGEN

1.1. Zur Forschungssituation 1

1.2. Intention 3

1.3. Vorgehen 3

1.4. Gegenstandseinengung 5

1.5. Der sowjetische Satire-Begriff 7

1.6. Beschreibungskategorien 12

ZWEITER TEIL : SATIRE DES AUBEN-BEREICHS (Kapitalismus)

2.1. Grobcharakterisierung/Grobgliederung der 'Satire des AuBen-Bereichs' 19

2.2. Satire der aristokratischen Agonie 21

2.3. Satire der kapitalistischen Endzeit 28

V.Giršgorn i I.Keller : 'Sorvanec Džo...'

M.Kozyrev : 'Nculovimyj vrag...'

2.3.1. Modifikations- und Uberwindungsansätze 44

V.Kataev : 'Ostrov Erendorf...'

B.Lavrenev : 'Krǚenie Respubliki Itl' '

2.4. Satire der bourgeois-faschistischen Fratze So

S.Beljaev : 'Kak Ivan Ivanyč ot bol'ševikov begal'

I.Zlobin : 'Zemlja $v$ pautine...'

L.Nikulin: 'Prodavcy tajn'

P.Suchotin : 'Viöni dlja kompota'

A. ̌́iško: 'Gospodin Antichrist'

A. ̌́ǐ̌ko: 'Konec zdravogog smysla...'

2.4.1. Modifikations- und Uberwindungsansatz

V.Ivanov: 'Cudesnye pochozdenija portnogo Fokina'

DRITTER TEIL : SONDERFALL ERENBURG - DESORIENTIERTE SATIRISCHE REVUE

3.1. I.Erenburg : 'Chulio Churenito...' 87

3.2. V.Kataevs Anti-Erenburg-Polemik : 'Ostrov Erendorf..' 99

3.3. I.Erenburg : 'Trèst D.E. ...' 101

3.4. I.Erenburg : 'Lazik Rojẗśvanec...': 104 
4.1. Grobcharakterisierung/Grobgliederung der

'Satire des Binnen-Bereichs'

4.2. Satire des Sumpfes

A.Buchov : 'Istorija trech svjatych...'

I.Lukašin : 'Gorod Perepljuj...'

N.Nikitin : 'o byv'šem kupce Chropove...'

Ju.Slezkin : 'Kozel v ogorode...'

4.3. Exkurs : Antiklerikale Satire

A.Buchov : 'Istorija trech svjatych...' (Dritter Teil)

4.4. Nö́p - und Apparatschik-Satire

Ju.Berzin : 'Ford...'

L.Grabar' : 'Lachudrin pereulok...'

4.5. Intellektuellen-Satire

S.Zajaickij: "Zizneopisanie Stepana Aleksandroviča..."

FUNFTER TEIL : SATIRE DES INNEN - BEREICHS (EIGENER BEWU:TSEINS-HAUSHALT)

5.1. Satire der Ideal-zerstörung

205

A.Tolstoj : 'Ibikus...'

V.Kataev : 'Rastratčiki...'

5.2. Satire der Ideologie-Zerstörung

M.Barkanov : 'Povest' o tom kak pomirilsja...'

SECHSTER TEIL : SATIRISCHE TOTALISIERUNG . DIE ROMANE VON I.IL'F UND

E.PETROV

6.1. I.Il'f i E.Petrov : 'Dvenadcat' stul'ev'

6.2 .

I.II'f i

E.Petrov : 'Zolotoj telenok'

Uberlegungen zum 'Positiven in der Satire'

Zus ammen fassung. Sch lußbemerkung

Anmerkungen.Zit atnachweise .Originalzitate

Literaturverzeichnis

Anmerkungen : 1)Alle Etiketten wie 'Satire der kapitalistischen Endzeit' etc. stammen vom Verfasser

2) Die vollständigen russischen Titel der bearbeiteten Primärtexte sind dem Literaturverzeichnis zu entnehmen. In den Analysen werden die Titel übessetstr gegeben2: 88 und dies bei ihrem erstendulfoten wodbständ igo isn 5:21:17 AM weiteren Verlauf meist abgekurzt. 
Erster Teil: Voraussetzungen

\subsection{Zur Forschungssituation}

Im Jahre 1965 legte A. Vulis ${ }^{1)}$ die erste und bislang einzige der Entwicklung des sowjetischen satirischen Romans gewidmete Monographie vor. In dieser Arbeit charakterisiert A. Vulis die damalige Forschungssituation folgendermaßen: "der sowjetische satirische Roman ist bis auf den heutigen Tag das wohl am wenigsten erforschte Gebiet unserer Literatur" ${ }^{2}$ ). Daran habe auch L. Eršovs funf Jahre zuvor publizierte Arbeit 'Die sowjetische satirische Prosa der 20-er Jahre.3) wenig geändert: "Der Autor bringt eine Reihe vergessener Namen und Titel ins wissenschaftliche Gespräch und bemint sich, das enorme Faktenmaterial zu systematisieren und zu analysieren. L. Erłovs Buch ist der flüchtige Beginn eines Gesprächs, das lange vor seinem Erscheinen in aller Ausfürlichkeit hätte geführt werden müssen" ${ }^{4}$ ).

Dem bleibt nur hinzuzufügen: auch A. Vulis hat zu einer 'Vertiefung' des 'Gesprächs' über die Entwicklung des sowjetischen satirischen Romans kaum beigetragen ${ }^{5)}$. Auch A. Vulis hat aber durch eine beträchtliche Erweiterung der Materialbasis einen überaus wichtigen Beitrag zur wissenschaftlichen Darstellung der Geschichte des sowjetischen satirischen Romans geleistet: ohne die (weit über das von Eršov, Ozmitel' und anderen Gebotene hinausgehende) Fülle an (freilich völlig unsystematisch über die ganze Arbeit verstreuten) Hinweisen auf sonst nirgendwo erwähnte Satiriker und satirische Romane des zu untersuchenden Zeitraums wäre die hier vorliegende Arbeit, die sich erstmals um eine systematische, methodisch reflektierte Bewältigung des 'enormen Faktenmaterials' zur Geschichte des sowjetischen satirischen Romans bemuiht, keinesfalls möglich gewesen!

Die Ausgangssituation dieser Arbeit also: eine quantitativ überaus bescheidene, qualitativ bedenkliche Literatur zur Geschichte des sowjetischen satirischen Romans einerseits - ein wahrhaft 
'enormes' (nämlich Dutzende von Primär-Titeln umfassendes) 'Faktenmaterial' andererseits. Die Bewältigung dieser Materialfülle machte eine eindeutige Gewichtungsentscheidung erforderlich: auf einen Bericht über die den sowjetischen satirischen Roman tangierende Forschung wird ebenso verzichtet wie (weitestgehend) auf die Einarbeitung von Meinungen aus Kritik und Literaturgeschichtsschreibung in die eigenen Analysen. Sowohl ein Forschungsbericht als auch die durchgehende Präsentierung von Meinungen zu bestimmten Autoren und Texten wären nur dann sinnvoll (und nicht nur eine - methodisch fragwïrdige und viel Raum beanspruchende - literaturwissenschaftiche Pflichtübung), wenn sie in eine eingehende Darstellung der jahrzehntelangen sowjetischen Satire-Diskussion eingebettet wären. In die detaillierte Darstellung einer SatireDiskussion nämlich, die sich häufig mit der Frage befaßte, ob die von Klassenantagonismen (angeblich) freie sozialistische Gesellschaft die Satire überhaupt noch benötige und die diese Frage (sofern sie - V. Bljum, 'Theorie der Konfliktlosigkeit' s.u. die Satire nicht pauschal ablehnte) fast durchgehend mit normativen Festlegungen (mögliche Angriffsobjekte, kausale Begründung gesellschaftlicher Negativität, Nachweis von Möglichkeiten zur Bewältigung dieser Negativität, figurale oder argumentative Einarbeitung des 'Positiven') beantwortete. Und nur eine Darstellung schließlich, die auch das persönliche und professionelle Schicksal vieler sowjetischer Satiriker ${ }^{6}$ und sich mit Satire befassender Kritiker und Wissenschaftler (für beide Gruppen hat sich Satire häufig als existentieller oder zumindest professioneller 'Schleudersitz' erwiesen) miteinbeziehen würde, wäre dazu angetan, die Beurteilungsunsicherheiten, die offensichtlichen Fehlurteile, das kontinuierliche Pochen auf Normen etc., die die Arbeiten aller sowjetischen Satiretheoretiker und Satirehistoriker charakterisieren, nicht einfach polemisch abzufertigen - sie viel. mehr (diachronisch differenzierend) zurückzuführen auf spezifika der Literaturpolitik, der Ideologiediskussion, der Wissenschaftspolitik, der Editionspolitik in der Sowjetunion. Eine derartige Darstellung aber könnte nicht mehr den Rang von Präliminarien zum 'eigentlichen' Gegenstand haben; eine derartige Darstellung wäre 
(wollte sie sich nicht auf oberflächliches Generalisieren und Pauschalieren beschränken!) vielmehr nur im Rahmen einer umfangreichen Monographie zur Geschichte (nicht des sowjetischen satirischen Romans, sondern) der sowjetischen Satire-Diskussion zu leisten. Letztere ist aber nicht 'eigentlicher' Gegenstand $d i$ e $s$ e Arbeit.

\subsection{Intention}

Zentrale Intention dieser Untersuchung ist vielmehr die Herausarbeitung der Entwicklung des sowjetischen satirischen homans von 1919 bis 1931, vom ersten feststellbaren Text also bis zum 'Goldenen Kälbchen' von I.Il'f und E. Petrov, das eine der Gipfellejstungen des sowjetischen satirischen Romans darstellt und zugleich weitestgehend den (vorläufigen) Schlußpunkt seiner Entwicklung markiert.

Die Entwicklungstendenzen werden hierbei prioritär verdeutlicht an den Veränderungen, denen der Bestand an Angriffsobjekten und die Konstitution dieser Angriffsobjekte während dieses Zeitraums unterworfen waren, sowie am Wandel der zu interpolierenden kommunikativen Funktionen des sowjetischen satirischen Romans der 'zwanziger Jahre'.

\subsection{Vorgehen}

Alle Textanalysen werden vorgenommen nach $e i n$ e Beschreibungsmodell, nach $e i n$ e unten vorzustellenden Katalog von Beschreibungskategorien. Dieser Katalog lehnt sich an an den zu diesem Zweck (!) kurz in seinen wichtigsten Positionen unkritisch referierten sowjetischen satirebegriff und nimmt implizit einige ergänzende satiretheoretische Überlegungen mit herein. Dieser Katalog von Beschreibungskategorien ist keine (etwa dem zuvor vorgestellten sowjetischen Satirebegriff opponierte) Satiretheorie; er soll auch keine Kriterien fur die qualitative Beurteilung satirischer Texte zur Verfüung stellen! Dieser Katalog von Beschreibungskategorien wird vielmehr als geeigneter Frage- 
horizont zur Bearbeitung von Texten sozialistischer Satire erachtet. Allerdings werden es die nach Maßgabe dieses Fragehorizonts gewonnenen Analyse-Ergebnisse ermöglichen, eine der umstrittensten Fragen der sowjetischen Satirediskussion - die nach dem 'Positiven in der Satire' - einer kommunikationstheoretischen Beantwortung zumindest anzunähern (während diese Frage von sowjetischen Satire-'Theoretikern' in aller Regel durch rezeptionspsychologisch unreflektierte Norm-Setzungen liquidiert wird). Ohne selbst eine Theorie zu sein, wird dieser Fragehorizont also theoretische Konsequenzen haben.

Diese Arbeit entstand in zwei Phasen. In einer ersten Phase wurde versucht, die Entwicklung des sowjetischen satirischen Romans von 1919-1931 anhand derjenigen Texte darzustellen, die in westdeutschen Bibliotheken zugänglich sind; anhand also der 'Klassiker' des sowjetischen satirischen Romans (I. Érenburg, V. Kataev, B. Lavrenev, I. Ilf und E. Petrov): eine (mit etwa zehn Titeln) noch übersichtliche Materialbasis - relativ eingehende Einzelanalysen schienen noch möglich und sinnvoll. Ein völlig verändertes Bild ergab sich während eines Arbeitsaufenthaltes in der Sowjetunion, der die urspruingliche Materialbasis um ein Vielfaches erweiterte und während dessen in der Kiewer Bibliothek der Akademie der Wissenschaften der USSR und in der Moskauer Lenin-Bibliothek eine große Zahl von Texten zugänglich wurde, die in bisherigen Darstel. lungen der Sowjetliteratur keine Erwähnung oder gar Beschreibung fanden.

Ein sich an Einzelanalysen orientierender Darstellungsmodus war mit dieser unvorhergesehenen Material-Explosion selbstverständlich hinfällig geworden. Statt dessen wird nun die gesamte ermittelte und zugänglich gewordene Produktion an satirischen Romanen der 'Zwanziger Jahre' einer doppelten Gliederung unterzogen. Nämlich erstens einer Grobgliederung nach Maßgabe der Wirklichkeitsbereiche, denen die satirischen Darstellungsobjekte korreliert sind (wobei der sowjetische Leser der 20-er Jahre die Zuordnungsperspektive 1 iefert): 
I Außen-Bereich (der Zeit, des Raums und der Zeit, des Raums )

II Binnen-Bereich (des eigenen Sozialhaushaltes)

III Innen-Bereich (des eigenen Bewußtseinshaushaltes)

Die Verdeutlichung dieser Etiketten (I-III) wird 'vor ort', im Rahmen der Textbeschreibungen erfolgen.

Diese Großgruppen ('Satire des AuBen-Bereichs', 'Satire des Binnen-Bereichs' etc.) werden zweitens einer Feingliederung unterzogen; diese Feingliederung faßt Texte mit gemeinsamen Darstellungsobjekten, gemeinsamen Konstitutionsverfahren, gemeinsamen kommunikativen Funktionen etc. zu Untergruppen zusammen, die in Abhängigkeit vom Klischierungsgrad der Texte und der Anzahl der jeweils eine Untergruppe bildenden Romane als 'Paradigmen', als 'typologische Erscheinungsformen' dargestellt werden - oder aber als Einzeltexte, die sich entweder um Überwindung, Modifikation etc. bestehender Paradigmen etc. bemihen oder aber gänzlich isoliert stehen. In keinem einzigen Fall wird eine 'exemplarische' Darstellung vorgenommen, die einen Einzeltext 'stellvertretend' für eine vielzahl von Texten präsentiert.

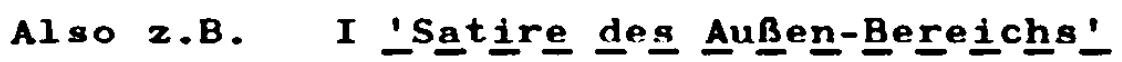

- 1. typologische Erscheinungsform: 'Satire der aristokratischen Agonie'

- 1. Paradigma: 'Satire der kapitalistischen Endzeit'

- Versuche der überwindung des ersten Paradigmas

- 2. Paradigma: 'Satire der bourgeois-faschistischen Fratze'

- Versuch der überwindung des zweiten Paradigmas

\subsection{Gegenstandse inengung}

\footnotetext{
'Tendenzen der Entwicklung des $s$ w $j$ e $t i s h$ e $n$ s a$t i r i s c h$ e $R \circ m$ a $s^{\prime}$ : Was wird in dieser Arbeit unter 'sowjetischem (1) satirischem (2) Roman (3)' verstanden? m.a.W.: Welche Texte werden als diesem Genre zuschlagbar erachtet, welche werden als sich nicht auf das Untersuchungsfeld dieser Arbeit erstreckend angesehen und folglich nicht berücksichtigt? Diese Fragen seien hier sehr lapidar geklärt.
} 
ad 1): Grundsätzlich werden nur Texte vorgestellt, die zumindest einmal in der Sowjetunion erschienen sind: Emigrantenliteratur (ob 'antisowjetisch' oder nicht) bleibt also ausgeklammert.

ad 2): Des weiteren konzentriert sich die Arbeit auf Texte, die ohne weiteres als 'satirisch' apostrophiert werden können, die von ihren Autoren als 'Satiren' gekennzeichnet wurden, bezüglich deren 'Satire'-Spezifik in wissenschaftlicher Literatur und Kritik Konsens herrscht: Romane, die zwar unbestreitbar 'satirische Elemente' aufweisen, in denen das 'Satirische' aber nicht den gesamten Text charakterisierendes Konstitutionsmerkmal ist, bleiben also ausgeklammert (z.B. die Romane Ju. Olešas).

ad 3): Schließlich ist in aller Kürze und ohne jede theoretische Prätention zu klären, welche Texte aus dem unübersehbaren Bestand an satirischen 'Großerzählungen' dem 'satirischen $R$ o m a $n$ ' zugeschlagen werden. Auch hier kommen verschiedene Kriterien zur Geltung: alle (verfügbaren) Texte, denen ihre Autoren den Untertitel 'satirischer Roman' gaben, werden berücksichtigt (auch wenn manche dieser 'satirischen Romane' nur 50 Druckseiten aufweisen); desgleichen alle Texte, die Forschung und Kritik weitgehend einmütig als 'satirische Romane' klassifizieren; und schließlich werden aus der enormen Produktion an 'satirischen povesti' (die oft wesentlich umfangreicher als die 'satirischen Romane' sind) jene als 'satirische Romane' 'akzeptiert', die als Einzeldrucke in Buchform erschienen. (Dieses letzte Kriterium verfolgt lediglich die Intention einer Materialeinengung: zum einen wird sich unten herausstellen, daß - zumindest für den untersuchten Zeitraum - eine starre Scheidung zwischen 'satirischem Roman' und 'satirischer povest" nicht durchführbar ist; und zum anderen sind auch viele der vorgestellten'satirischen Romane' zuerst in Zeitschriften erschienen). Grundsätzlich nicht berührt werden hin gegen Satiren, die zweifelsfrei anderen satirischen Genres zuzuordnen sind (satirisches Feuilleton, satirische Fabel, satirische Kurzerzählung etc.): deren (bei Vulis gang und gäbe) Subsumtion unter den 'sowjetischen satirischen Roman' ergäbe (s.u. unter 'Bürokraten-Satire') ein völlig verzerrtes Bild (zwar nicht der 
'Entwicklung der sowjetischen Satire' - aber doch) der 'Entwicklung des sowjetischen satirischen Romans'.$$
+++
$$

\subsection{Der sowjetische Satire-Begriff}

Mit seiner 1957 erschienenen Satiretheorie ('Fragen der Theorie der Satire') leistete Ja. El'sberg ${ }^{7}$ den bislang wichtigsten Beitrag zur sowjetischen Satiretheorie; die Bedeutung dieser Arbeit resultiert einerseits daraus, daß sie die russische und sowjetische Satirediskussion aufarbeitet, andererseits daraus, daß sie sich darum bemüht, einen Schlußstrich zu ziehen unter die seit 1929 nicht aussetzenden Versuche, der Satire ein Heimatrecht in der sowjetischen Literatur abzusprechen.

Él'sberg definiert die Satire als "spezifisches ideell-künstlerisches Prinzip der Darstellung der Wirklichkeit" ${ }^{8}$, das eine spezifische Relation Wirklichkeit:Text:Leser herstellt und zu deren Realisierung spezifische Darstellungsverfahren und Konstitutionsprinzipien einsetzt.

I $n h$ a $l t ~ l i c h$ wird die Satire charakterisiert durch die Auswahlstrategie, die sie bezüglich der darzustellenden Wirklichkeit verfolgt: aus einer komplexeren gesellschaftlichen Realität isoliert sie fast ausschlieblich negative Erscheinungen, zeigt sie "wie unter einem Vergrößerungsglas"9).

Thre $I n t$ e $t i$ o $n$ ist Decouvrierung, Verspottung, Verlachung eben dieser negativen - oft als positiv maskierten - Erscheinungen; ihre Angriffsobjekte sind generell solche Erscheinungen, die der Entwicklung einer gegebenen Gesellschaft zu dem dem Satiriker vorschwebenden gesellschaftlichen Ideal im Wege stehen und deren überwindung die Satire verfolgt.

Hieraus - d.h. aus der Decouvrierungs- und Aggressionsintention der Satire - resultiert ihre strategie, resultieren ihre zentralen $D$ a $r$ s $e^{\prime} l$ u $n$ gs-Prinzipien: Humor, Ironie und insbesondere Komik ${ }^{10}$ ); deren Funktion ist aber nicht nur in. der Entlarvung des den Rezipienten bedrohenden gesellschaftichen 
Negativen zu sehen (d.h. in der Herstellung eines Problembewußtseins), sondern auch darin, ihm ein Superioritätsbewußtsein gegenüber dieser Bedrohung zu vermitteln, ihm das Bewußtsein sie meistern zu können zu suggerieren; d.h. aber letztlich: ihn zu ihrer überwindung zu aktivieren.

Näher bestimmt sich dieses als satirisches Angriffsziel ausgewiesene gesellschaftliche Negative durch die 'Qualität des Komischen', dessen Basisdefinition $\dot{E} 1$ 'sberg von C̈ernÿsevskij übernimmt: Das Komische ist "innere Leere und Nichtigkeit, die sich unter einem Äußeren verbergen, das Anspruch auf Gehalt und echte Bedeutung erhebt"11) - es resultiert also aus der Nichtübereinstimmung von Idee und Form, Schein und Sein, Anspruch und Einlösungsvermögen.

Das so beschriebene Komische ist aber nur sekundär ästhetische Qualität; primär ist es objektive "Qualität bestimmter gesellschafticher Erscheinungen und historischer Personen, die jenen objektiv aufgrund historischer Ursachen eignet"12) - und nur dieses im soziohistorischen Raum vorfindliche Komische ist für die satirische Darstellung relevant.

Zur Beantwortung der Frage, wann negative soziohistorische Erscheinungen objektiv komisch, wann objektiv tragisch seien, bietet $\dot{E}^{\prime}$ 'sberg zwei sehr verschiedene Kriterien an: zum einen das Selbstverständnis der Träger des Negativen. (Dieses Selbstverständnis sei in der Feudalgesellschaft mit ihrem festgefüten Wertesystem intakt gewesen - in ihr vorfindlicher gesellschaftlicher Negativität müsse also die objektive Qualität 'tragisch' zugewiesen werden; in der spätbürgerlichen Gesellschaft hingegen schützten die Träger des gesellschaftlich Negativen ein intaktes Selbstverständnis nur mehr vor - sie seien folglich objektiv 'komisch'). Als zweites Kriterium dient $\dot{E}_{1}$ 'sberg die erwiesene "Machtlosigkeit (der Träger des Negativen j.e.) vor dem Antlitz des historischen Prozesses"13) - dieses Kriterium weist Hitler (im Gegensatz etwa zu Dschingischan) als 'komische' 'historische Person' aus. 
Dieses überhistorische Satireverständnis erfährt für die Belange der sowjetischen Satire Präzisierung und Modifikationen, die im Ergebnis bei $\dot{b}_{1}$ 'sberg freilich eher Normen für eine künftige sowjetische Satireproduktion aufstellen, als aus der Analyse der vorliegenden Produktion gewonnene Charakteristika darstellen. Angriffsobjekte der sowjetischen Satire: ihre "Spitze muß gegen alle wie auch immer gearteten bürokratischen Entartungserscheinungen, gegen Gleichgültigkeit gegenüber den Interessen der Werktätigen, gegen Unterdrückung der Kritik, gegen Verstöße gegen die sozialistische Gesetzlichkeit und andere Folgen des Personenkultes gerichtet sein"14). Ihr Hauptziel ist der Bürokrat als Repräsentant einer gesellschaftlichen Gruppe, die aus einem grundlegend negativen gesellschaftichen system negative Arbeitsgewohnheiten in eine grundlegend positive Gesellschaft verschleppte und so im Verein mit der gleichfalls aus der Vergangenheit oder den kapitalistischen Ländern 'importierten' Gruppe der Karrieristen, Magnaten, Kriecher, Spießer, Raffer, Gecken, Dandys etc. die endgülige Ausformung des sozialistischen gesellschaftichen Ideals behindert. D.h. aber: die sowjetische Satire zielt wesentlich nicht auf von der sozialistischen Gesellschaft produziertes Negatives, nicht auf Decouvrierung und überwindung von strukturschwächen dieser Gesellschaft, vielmehr auf die 'überbleibsel' (perezitki') einer bereits überwundenen Gesellschaftsordnung: der 'peré̌itok' ist die Zentralkategorie des sowjetischen Satirebegriffs !

Nach diesen von gesellschaftlichen $G r$ u $p$ e repräsentierten oder an bestimmte Gruppen und $s$ o $i$ a $l$ e $T$ y $p$ e gebundenen Angriffszielen nennt El'sberg die "überbleibsel der alten Welt des Privatbesitzes im $B$ e $u$ $b$ e $i n$ der Menschen"15) sowie die "bürgerliche Ideologie in den kapitalistischen Ländern selbst" 16 ).

Aber - geändert gegenüber der vorrevolutionären Gesellschaft haben sich nicht nur die negativen Erscheinungen selbst, geändert hat sich vor allem auch ihr objektiver Charakter: während die 'Ausbeutergesellschaft' den Menschen (und zwar Unterdruickten wie 
Unterdrücker) durch objektive Strukturfehler dieser Gesellschaft pervertierte - subjektives Fehlverhalten und objektive Bedingtheit dieses Fehlverhaltens also kein Schuldbewußtsein aufkommen ließen, muß in der nachrevolutionären Satire gerade die persönliche Verantwortlichkeit des die Norm Verletzenden herausgearbeitet werden.

Diese Änderung des 'objektiven Charakters' des Negativen wirkt sich insbesondere auf die Figuren-Typisierungsverfahren der sowjetischen Satire aus. Generell ist die satirische Figur konstituiert als auf stärkere Individualisierung verzichtender 'merkmalhaltiger' ('naricatel'ny.j') Charakter, der sich vom 'typischen' Charakter durch die scharfe Herausarbeitung meist nur einer negativen Dimension unterscheidet: er ist der 'bekannte Unbekannte', der - da in ihm das negative Allgemeine gegenüber dem individualisierenden Besonderen uberwiegt - unmittelbare Identifikation mit einer Vielzahl 'sozialer Typen', d.h. Menschen gleicher (negativen) klassen-bzw. gruppenspezifischer Merkmaldominanz ermöglicht.

Die Satire konzentriert sich auf Altes, Überlebtes; die satirische Typisierung unterstreicht also nicht nur die (negative) Eindimensionalität der satirisch generalisierten Träger des Negativen, sondern auch ihre Statik und Entwicklungsunfähigkeit: sie sind 'innerlich leer' - folglich lernunfähig, unfähig, ihre 'Idee' mit der ihr inadäquaten Realität in übereinstimmung zu bringen.

Anders als die vorrevolutionäre hat - nach $\dot{1} l$ 'sbergs Auffassung die sowjetische Satire aber verstärkt die Möglichkeit, Eindimensionalität und statik früherer satirischer Typen dahingehend zu modifizieren, daß die Typisierung e $i$ n e negative ('Überbleibsel'-) Qualität sich von einem insgesamt positiven Fond abheben läßt - was weiterhin die Möglichkeit eröffnet, satirische Figuren zu dynamisieren, ihnen eine die Eliminierung dieser Negativ-Qualität unter dem Einfluß einer positiven gesellschaftlichen Realität beinhaltende Biographie zuzuschreiben. 
Daraus, daß die Existenz dieser 'positiven gesellschaftlichen Realität' in der sowjetischen Satire nicht nur als im Erfahrungshorizont des Rezipienten verankert gesetzt, in der Satire vielmehr dargestellt werden soll, resultiert die tiefgreifendste - postulierte - Modifikation gegenüber der vorrevolutionären Satire: Für Saltykov-Š́cedrin z.B. war das Positive (das gesellschaftliche Ideal) aufgrund der fehlenden 'demokratischen und revolutionären Reife' seiner Zeitgenossen figural kaum darstellbar, konnte im Text also nur indirekt - als die gesteuerte Reaktion des Rezipienten auf das dargestellte Negative - präsent sein; die sowjetische Satire hingegen kann durchaus gerade den Durchschnittsmenschen als Positiv-Figur den negativen Figuren opponieren. Mit diesem Abrücken von der Auffassung, der positive Held sei der Satire unangemessen, da er grundsätzlich anders-als satirische Figuren konstituiert und der Realisierung der von der

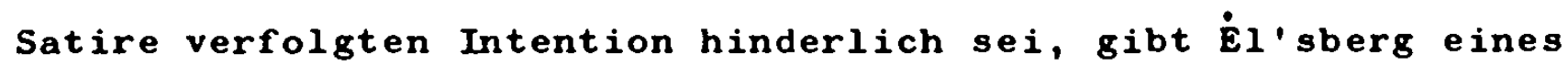
der zentralen Merkmale der Satire auf: ihre das Negative isolierende Auswahlstrategie.

1929 artikuliert $V$. Bljum in einem Aufsatz in der 'Literaturnaja gazeta' eine Meinung, die schon 1923 - anläßlich der Diskussion um das satirische Feuilleton - und in den folgenden Jahren wiederholt laut wurde und die über fast dreißig Jahre nicht nur Stimme in der sowjetischen Satirediskussion hatte, sondern sich auch bestimmend auf die Satire-Produktion auswirken und zur Folge haben sollte, daß diese Produktion phasenweise weitgehend zum Stillstand kam. Unter dem Titel 'Kommt eine Renaissance der Satire?' vertritt er die Auffassung, diese Wiedergeburt werde und düfe nicht stattfinden, denn: "das sowjetische Volk braucht die Satire nicht"17). Als Begründung für diese Auffassung - die insbesondere im Widerspruch steht zu Majakovskijs wiederholter Klage uber den desastreusen Zustand der sowjetischen Satire sowie zu seinem Ruf nach dem Satiriker als "Prokuror des Alten und Verteidiger des Aufbaus" ${ }^{18}$ ) - führt Bljum an, unter der Diktatur des Proletariats könne die Satire nicht existieren, da sie "ihren Staat und ihre Gesellschaft vernichten muß"19). In den fol- 
genden Jahren wird diese Auffassung - nicht nur von Bljum selbst häufig wiederholt; und noch die 1949 stattfindende 'Allunionskonferenz uber Satire und Humor', in der Positionen der 'Theorie der Konfliktlosigkeit' dominieren, verweist die Satire in die Vergangenheit: in einer Gesellschaft ohne Klassenkonflikte sei Satire 'Allchemie' und 'Magie'; der Satiriker setze sich folglich dem Vorwurf der Verunstaltung und Verleumdung der wirklichkeit aus 20 ).

Wiederholt - und diese Auffassung schlägt noch in El'sbergs Satiretheorie durch - wird die Meinung geäußert, Satire sei zwar nötig, müsse in der Sowjetgesellschaft aber, da diese keine antagonistischen Klassen kenne, ein 'lächelndes, gütiges Gesicht' zeigen - d.h. aber: auf jede Angriffsschärfe verzichten, das Positive zur Dominanz führen. M.a.W.: die Satire muisse aufhören Satire zu sein! Erst Éventov ${ }^{21}$ ) verweist diesen 'Kompromiß' des Feldes, da er richtig erkennt, daß dieser normativ wirkende Satirebegriff zu einem guten Teil das vielbeklagte Ausbleiben einer satirischen Literatur auch nach dem stalinismus bedingt.

\subsection{Beschreibungskategorien}

1.6.1. Negativ-Position

Die Kategorie 'Negativ-Position' umschreibt die beiden - zu korrelierenden $u n d$ zu trennenden - Ebenen der satirischen Darstellungs-objekte (intratextuell) einerseits, der ihnen korrelierten satirischen Angriffs-objekte (extratextuell) andererseits.

Die Notwendigkeit der $K \circ r \quad r$ e $l$ a $i n$ von satirischen Darstellungs-Objekten und satirischen Angriffs-Objekten bedarf keiner Erläuterung. Nicht gleichermaßen evident ist die Notwendigkeit ihrer $T r$ en $n$ n: Angriffs-objekte der Satire sind nicht generell (wenngleich im Bereich der sowjetischen Satire auch vorwiegend) im sozio-politischen Raum un- 
mittelbar 'personifiziert' vorfindliche Objekte (z.B. militärische Gegner, Klassenfeinde in der fremden oder eigenen Gesellschaft, schädliche Gruppen und Typen in der eigenen Gesellschaft etc.) - $d i$ e $s$ Angriffs-Objekte sind unmittelbar darstellbar. Anders verhält es sich, wenn Angriffs-Objekte der Satire beim Rezipienten selbst angesetzte Denkmuster sind: Denkmuster (z.B. bügerliche Ideologien, vergangenheitslastige Idealkonzeptionen) sind zwar direkt ansprechbar (benennbar), aber nicht direkt darstellbar. In diesem Fall muß der Satiriker also dem "gesichtslos Drohende( $(n) " 22$ ) Angriffs-Objekt ein DarstellungsOujekt zuordnen, welches das den Bewußtseinshaushalt des Rezipienten (und damit - über das von diesem Bewußtsein abhängige Sozialverhalten des Rezipienten - auch die Gesellschaft) belastende (bedrohende) Negative repräsentiert. Dieser $g$ e $t$ e i$g$ e $r$ e Repräsentanzcharakter (gesteigert, denn: eine Repräsentanz liegt natülich auch dann vor, wenn die Angriffs-objekte im sozio-politischen Bereich liegen) muß signalisiert werden $(\mathbf{s . u})$.

\subsubsection{Figuren-Bestand}

a) Welchem gesellschaftlichen Großraum (kapitalistische, sozialistische Gesellschaft), welchen gesellschaftlichen Klassen, Gruppen (der anderen oder eigenen Gesellschaft) gehören die dargestellten Figuren an?

b) Ist (Im Falle: 'eigene Gesellschaft') die Klassen- bzw. Gruppenzugehörigkeit einer Figur spezifiziert?

Die Beantwortung dieser Frage ist relevant für die Beurteilung 1. der Generalisierbarkeit der dargestellten Negativität, 2. des Grades des Repräsentanzwertes dieser Figur: je schwächer die Signalisierung der Gruppenzugehörigkeit etc. ausgeprägt ist, desto größer 1. die Generalisierbarkeit, 2. und folglich der Repräsentanzwert für e $i g$ e $\mathrm{s}$ Denken, e i g e n s Sozial-Verhalten.

c) Sind der geopolitische Raum (z.B. nicht 'kapitalistische Gesellschaft überhaupt', sondern 'französische kapitalistische Gesellschaft') und der Zeitraum (z.B. nicht 'kapitalistische Gesellschaft überhaupt', sondern 'kapitalistische Gesellschaft 
jetzt/in hundert Jahren; oder: 'kapitalistische Gesellschaft in der Inkubationsphase des Faschismus), in dem die dargestellten Figuren stehen, spezifiziert?

Auch die Beantwortung dieser Frage ist relevant für die Beurteilung der Generalisierbarkeit der dargestellten Negativität ( in Raum und Zeit!).

\subsubsection{Figuren-Konstitution}

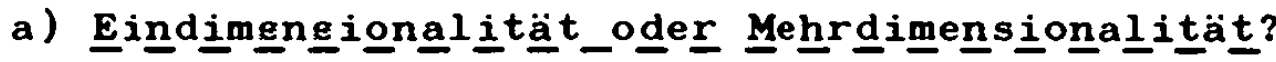

Im Zusammenhang mit anderen Kriterien relevant für die Beurteilung des Repräsentanzwertes der Figuren, d.h. für die Beantwortung der Frage: liegen die Angriffsobjekte $p r i$ o $r$ $t \ddot{a} r$ auf der Ebene gesellschaftlichen Seins und Verhaltens a $n$ d e $r$ e oder $p r i \circ r i t \ddot{a} r$ auf der Ebene des Bewußtseinshaushaltes des Rezipienten ('prioritär: es versteht sich von selbst, daß die Satire in beiden Fällen eine steigerung der Bewußtheit des Rezipienten intendiert. Im ersten Fall ist es aber eine Steigerung der Bewußtheit bezüglich der Negativität anderer, im zweiten Fall bezüglich der eigenen partiellen Negativität. S.u. 'Kommunikative Funktion').

b) Merkmale sozialen Seins, Verhaltens und Denkens (anderer)? Anvisierte 'eigene' Denkmuster (Idealkonzeptionen, Ideologien ctc.), eventuelle anvisierte 'eigene' soziale verhaltensweisen

c) Darstẹllung und

D.h. - wie konstituiert sich die dargestellte Negativität, wie konstituiert sie sich als komische Negativität?

- ergeben sich Negativität und Komik mittelbar aus der Konstituierung der Figuren (Einführung, Aufbau, Destruierung, Opposition zu anderen Figuren etc.) oder/und erfolgt (zusätzlich) eine direkte Etikettierung der Negativität ('Bourgeois', 'Spießer' etc.), eine direkte Benennung der Lächerlichkeit ('steht auf verlorenem Posten', 'gibt sich als vollwertiger Mensch, ist aber faktisch eine Wanze' etc.)?

- damit direkt gekoppelt ist die Frage nach der

d) Deçouvvrierungs=strâteggie?

- Werden die Figuren (intratextuell s.u.) als $n$ e $g$ a $i v$ decouvriert oder werden sie - wenn ihre Negativität als evident gesetzt ist - als 1 a cher li ch etc. decouvriert? 
M.a.W.: bedeutet 'Decouvrierung - Decouvrierung der Negativität oder/und - Decouvrierung der Lächerlichkeit?

- Welche Strategien werden zur Decouvrierung der Negativität, zur Decouvrierung der Lächerlichkeit (Verlachung) eingesetzt? $++$

\subsubsection{Positive Gegenposition}

1.6.2.1. Ist die Positive Gegenposition (das 'Ideal' etc. des Satirikers) im Text ii b e $r$ a $u$ p repräsentiert?

1.6.2.2. Wenn ja: ist die Positive Gegenposition (auch oder nur) $f i g$ u a 1 oder (auch/nur) a $r$ u m $n t a t i v$ repräsentiert?

1.6.2.3. Bei $f i g u r$ a $l$ e $r$ Repräsentierung:

a) Figurenbestand-, Konstitution etc.

b) Stellt die figurale Positive Gegenposition dem (sowjetischen zeitgenössischen) Rezipienten Identifikationsangebote, Orientierungsangebote zur Verfügung?

1.6.2.4. Bei (auch) a $r$ u m $\mathrm{m} t$ a $t$ i $v r$ Repräsentierung:

a) Wer formuliert welche 'Argumente'?

b) Ergehen (direkte/implizite) Aktionsappelle?

\subsubsection{Historische Perspektive}

1.6.3.1. Die dargestellte Negativität gehört für die eigene Gesellschaft der Vergangenheit an?

1.6.3.2. Die dargestellte Negativität befindet sich in der eigenen oder fremden Gesellschaft in der (Auto-) Liquidationsphase?

1.6.3.3. Die dargestellte Negativität hat in der eigenen oder fremden Gesellschaft Bestand? Kein Nachweis kurzfristiger (Auto-) Liquidationsmöglichkeit? 


\subsubsection{Kommunikative Funktion}

Vorliegende satiretheoretische und historische Arbeiten behandeln das Problem der zu interpolierenden kommunikativen Funktion satirischer Texte zumeist pauschal unter dem Aspekt: 'Was will (sowjetische) Satire generell?'. So sinnvoll derartige überlegungen für die Gewinnung eines groben Satirebegriffs (in Abgrenzung zu anderen Möglichkeiten der Textkonstituierung) sein mögen, so ungeeignet - weil eben zu pauschal-undifferenziert - sind sie für die Erstellung eines Modells zur Beschreibung konkreter satirischer Texte und Textgruppen.

Hier müssen also zusätzliche Beschreibungskategorien entwickelt werden, was an dieser stelle methodisch nicht unproblematisch ist, da einerseits diese Beschreibungskategorien gewonnen wurden aus satiretheoretischen überlegungen (zur Kategorie des 'Positiven in der Satire'), die sich an vorgängige Analysen derselben Texte anschlossen, zu deren Beschreibung sie nun herangezogen werden; die Gefahr eines induktiven Zirkelschlusses ließ sich aber durch überprüfung dieser Kategorien an zahlreichen Texten - auch anderer Genres (Majakovskijs Komödien, Bednyjs Fabeln) der sowjetischen Satire der zwanziger Jahre einwandfrei eliminieren. Andererseits ist die Einfürung dieser Beschreibungskategorien an dieser stelle methodisch insofern problematisch, als sie - da es sich um neu einzuführende Kategorien handelt um verständlich zu werden Analyseergebnisse andeutungsweise mit hereinnehmen muß!

Typologische Möglichkeiten (sowjetische Satire der zwanziger Jahre!

1.6.4.1. Basisfunktion: Bewußtmachung der Negativität des anderen gesellschaftlichen Systems (der eigenen vorrevolutionären gesellschaftlichen Vergangenheit).

Anschlußfunktionen:

a) Nachweis und Demonstration der Agoniesituation der bürgerlichen Gesellschaft.

K o n $\mathrm{s}$ e $\mathrm{q}$ e $\mathrm{n}$ : Propagierung der These von der Unausbleiblichkeit der Weltrevolution bzw. der iso- 
lierten Revolution in allen kapitalistischen Ländern; dies bedeutet zugleich die Legitimierung der eigenen sozio-ökonomischen und politischen situation (s.u.).

b) Nachweis der Häßlichkeit und Gefährlichkeit des kapitalistischen systems.

K $\circ \mathrm{n}$ e q u e $\mathrm{z}$ : Legitimierung (per Kontrast) des eigenen gesellschaftlichen status quo. Daruber hinaus: Stärkung der Bereitschaft zur ideologischen und/oder aufgezwungenen militärischen Auseinandersetzung mit dem 'kapitalistischen Lager'.

1.6.4.2. Basisfunktion: Bewußtmachung, Bewußthaltung der Existenz negativer Gruppen, negativer sozialer Typen in der eigenen Gesellschaft.

Anschlußfunktionen:

a) Verlachung dieser Negativität als einer sich auto-1iquidierenden, vom historischen ProzeB per Selbstreinigung eliminiert werdenden Negativität.

$K \circ n s$ e $q$ u $n z$ : Stärkung des Vertrauens in die positive Entwicklung der eigenen Gesellschaft; Bestätigung der Richtigkeit der eigenen politischen überzeugung; Orientierungshilfe für die Gewinnung der richtigen politischen Überzeugung.

b) Nachweis der überwindbarkeit dieser (für den Rezipienten objektivierbaren) Negativität und Nachweis der (politischen, ökonomischen, administrativen) überwindungs - und Eliminierungsmöglichkeiten.

$K \circ n s$ e $q$ e $n$ z: direkter oder impliziter Aktionsappell zur bewußten Teilnahme an der gesellschaftspolitischen Auseinandersetzung.

1.6.4.3. Basisfunktion: Bewußtmachung der Existenz negativer unmittelbar gesellschaftsrelevanter strukturen des eigenen Bewußtseinshaushaltes ('überbleibsel der Vergangenheit im Bewußtsein'; aber auch für die sozialistische Gesellschaft spezifische negative Bewußtseinsstrukturen).

Anschlußfunktion:

Bewußtmachung der Lächerlichkeit, Unhaltbarkeit, Gefährlichkeit dieser Bewußtseinsstrukturen. 
K o $n s$ e q $u$ e $n z$ : 'Integration' des 'bürgerlichen Schattens' (s.u.); BewuBthaltung und Abwehr der Gefahr $n$ e $u$ e $r$ negativer gesellschaftsrelevanter BewuBtseinsstrukturen ('Komčvanstvo' - Kommunistendükel' etc.) sowie - eventuell - aus innen resultierender eigener negativer sozialer Verhaltensweisen.

\subsubsection{Sujetkonstruktion}

Erklärte literaturhistorische Intention dieser Arbeit ist die Herausarbeitung der Entwicklungstendenzen des sowjetischen satirischen Romans der zwanziger Jahre unter dem Aspekt seiner Angriffsobjekte und seiner kommunikativen Funktionen. Das traditionelle Problem der Sujetfügung, das von gattungsorientierten Nacherzählungsphilologen à la Vulis ohnehin über Gewicht zentriert wird (der satirische Roman als 'Roman-Feuilleton' etc.) interessiert hier also nur beiläufig.

In das Beschreibungsmodell geht nur die Frage nach der story ein: 1.6.5.1. Gibt es eine story oder erfolgt pure Porträt-bzw. Episoden-Reihung?

1.6.5.2. Es gibt eine story: ist sie 'organisch' eingearbeitet oder vor-ein-angeklebt?

1.6.5.3. Es gibt eine story: welche der überhaupt entwickelten Möglichkeiten wurde - eventuell in Kombination mit einer weiteren Möglichkeit - genutzt (Revolutions- und Bürgerkriegsstory, Krimistory, Abenteuer- bzw. Schatzsucherstory)? 
Zweiter Teil: Satire des Außen-Bereichs ('Kapitalismus')

\subsection{Grobcharakterisierung/Grobgliederung}

1919 erschien die 'Russische Geschichte bei Warägern und Vorägern' von O.L. D'Or ${ }^{0}$, der erste sowjetische satirische Roman. Schon er repräsentiert nicht nur die am frühesten einsetzende und bis 1927 eindeutig dominierende - durch weitgehend gemeinsame Angriffsobjekte, Typisierungsverfahren, Decouvrierungsstrategien, figurale und argumentative positive Gegenposition, gemeinsame kommunikative Basisfunktion konstituierte Gruppe sowjetischer satirischer Romane; er repräsentiert zugleich auch die insgesamt mit Abstand produktivste Gruppe: dieser ersten großen Textgruppe sind mit Sicherheit nicht weniger als 40 satirische Romane zuzuschlagen, deren letzte in den Jahren $1927 / 1928$ vorgelegt wurden.

Es handelt sich um $d i$ e Gruppe sowjetischer satirischer Romane, deren Darstellungs- und Angriffsobjekte zeitlich und/oder räumlich a $\mathrm{u}$ e $r$ a $l$ b der Sowjetgesellschaft liegen: 1) im Bereich der eigenen vorrevolutionären sozio-historischen Vergangenheit, 2) im in naher Zukunft angesiedelten Bereich der bürgerlichen Gesellschaft 'der letzten Tage', 3) im Bereich der zeitgenössischen kapitalistischen Staaten Europas und (vereinze1t) Nordamerikas.

Die hier vorgeschlagene Untergliederung dieser Textgruppe, deren objekte generell außerhalb der Sowjetgesellschaft (im 'AußenBereich') liegen, in drei Untergruppen ist aber nicht nur eine differenzierende Typologisierung nach Maßgabe einer Klassifizierung der Darstellungs- und Angriffsobjekte etc-; diese Untergliederung koinzidiert zugleich auch mit einer Periodisierung nach Maßgabe der jeweils dominierenden typologischen Möglichkeit, wobei die Dominanzen sehr eindeutig ausgeprägt sind: ein Konkurrieren dieser drei Untergruppen miteinander ist nicht zu beobachten (wohl aber ein Konkurrieren mit anderen typologischen Möglichkeiten, die der sowjetische satirische Roman für Darstel- 
lungs- und Angriffsobjekte entwickelt hat, die in anderen 'Bereichen' liegen s.u.).

Die früheste typologische Möglichkeit ist diejenige, deren Darstellungsobjekte dem 'Bereich der eigenen vorrevolutionären gesellschaftlichen Vergangenheit' korreliert sind. Diese 'Satire der aristokratischen Agonie (1) - als Beleg steht leider nur O.L. D'Ors 'Russische Geschichte ...' zur Verfügung, so daß hier nur von einer 'typologischen Möglichkeit' (nicht jedoch von einem 'Paradigma') die Rede sein kann - bringt um 1919 (Vulis' Angaben zufolge) nur einige wenige Exemplare hervor. Während der innenpolitisch, ökonomisch überaus schwierigen Jahre des Bürgerkriegs und des Kriegskommunismus entstanden innerhalb der UdSSR (die als solche freilich erst am 30.12.1922 gegründet wurde) keine satirischen Romane mehr; nur I. Érenburg fand im Ausland Muß $₹$ und Distanz zur Abfassung seines 'Julio Jurenito', der sich aber - wie auch die anderen satirischen Romane dieses Autors - einer eindeutigen Einordnung in die generellen Entwicklungstendenzen des sowjetischen satirischen Romans entzieht und einer gesonderten Betrachtung bedarf, die sich um die Herausarbeitung seiner Außerordentlichkeit im Gesamtfeld des sowjetischen satirischen Romans bemuiht (s.u.). Die Satire-Produktion konzentrierte sich während dieser Jahre (1920-1922) ganz auf kleine Genres, die sich leichter für unmittelbar politisch-agitatorische Kommunikationsfunktionen einsetzen ließen: Lubok (meist mit kurzen Texten versehene Bildstreifen, Bildtafeln), Fabel etc. Es sei nuran die 'Okna Rosta' und D. Bednyjs Agit-Fabeln erinnert.

Erst nach dem Beginn der durch relative außen- und innenpolitische stabilisierung und relative ökonomische Konsolidierung charakterisierten Periode der Nöp setzt auch die Produktion satirischer Romane innerhalb der Sowjetunion wieder ein - mit 
der zweiten Untergruppe der großen Textgruppe, deren objekte den 'Außen-Bereich' zuzuordnen sind: zwischen 1922 und 1925 dominiert derjenige satirische Roman, dessen Objekte im Bereich 'nahe Zukunft der bürgerlichen Gesellschaft, des kapitalistischen Systens' liegen und der die bevorstehende Liquidierung des kapitalistischen Systems, die Weltrevolution erzählt, dominiert die 'Satire der kapitalistischen Endzeit' (1. Paradigma).

Schon die letzten Texte der 'Satire der kapitalistischen Endzeit' verlagern - bei weitgehend unverändertem Figurenbestand, Typisierungs- und Handlungsmustern etc. - die Revolution etc. entweder in die ferne Zukunft (Kataev) oder in die jüngte Vergangenheit (Lavrenev) und bereiten so die Ausformung des 2. Paradigmas innerhalb der Großgruppe 'Außen-Bereichs'Satire' vor, des Paradigmas der 'Satire der bourgeois-faschistischen Fratze'.

Das Paradigma der 'Satire der bourgeois-faschistischen fratze' dominiert 1925-1927 und wird dann abgelöst von ganz anderen typologischen Möglichkeiten, die einige Jahre mit der 'Satire der bourgeois-faschistischen Fratze' bereits konkurriert hatten: von den jetzt zur Dominanz gelangenden satirischen Romanen, deren Darstellungs- und Angriffsobjekte im 'Binnen-Bereich' des'eigenen Sozialhaushaltes' liegen.

\subsection{Die 'Satire der aristokratischen Agonie'}

Hauptintention dieser Arbeit ist die Verdeutlichung der Entwicklungstendenzen des sowjetischen satirischen Romans (bis zum 'Goldenen Kälbchen'); sie muß sich also auf Text-Gruppen oder solche Einzel-Texte konzentrieren, die entweder zur Konstruktion und Dokumentation paradigmatischer Zusamenhänge geeignet sind oder aber Versuche der Weiterentwicklung bzw. Überwindung der bisher vorherrschenden Paradigmen darstellen, die zu einem bestimmten Zeitpunkt für impratikabel erachtet wurden: sei es, weil sich die konstruktiven paradigmatischen Versatzstuicke abgeschliffen, zu ästhetischer und inhaltlich-kommunikativer Wir- 
kungslosigkeit automatisiert hatten; sei es, weil die komminative Funktion der jeweils vorhergehenden Paradigmen einer Umbewertung unterworfen - d.h. jetzt für irrelevant oder ideologisch und politisch nicht mehr winschenswert etc. angesehen - wurde. Die 'Russische Geschichte ...' ist der erste und weitgehend isolierte Vertreter des ubergeordneten paradigmatischen Feldes derjenigen satirischen Romane, deren 'Helden' "Todeskandidaten"1) sind; die hier vorzunehmende Präsentierung dieses satirischen Romans wird sich daher konzentrieren auf die Betonung der paradigmatischen Gemeinsamkeiten nit dem übergeordneten Paradigma der 'Satire der kapitalistischen Endzeit'. Auf diese Weise eröffnet die 'Russische Geschichte...' einen ersten Zugang zu den Typisierungs- und Decouvrierungsmöglichkeiten, zur Konstruktion der positiven Gegenposition und zur kommunikativen Funktion dieser Gruppe von Texten.

Dieser erste Zugang wäre möglich an jedem anderen Text dieser Textgruppe. Wenn hier gerade die 'Russische Geschichte ...' gewählt wird, so nicht nur, weil sie der erste nachrevolutionäre Gehversuch des Genres 'satirischer Roman' ist, sondern auch, we 11 kein anderer sowjetischer satirischer Roman (zu Unrecht) so schnell und absolut in Vergessenheit geraten ist.

Die 'Russische Geschichte ...', 1919 in Petrograd im Selbstrerlag des Autors erschienen, nimmt eine satirische Umbewertung, eine vernichtende Neubewertung der Geschichte Rußlands vom 'Anfang ier Rus', (so eine der Kapiteluberschriften, die generell historische Epochen - z.B. 'Das Mongolenjoch', 'Das Moskauer Füstentum' - oder Herrscherpersönlichkeiten nennen) bis zu 'Nikolaj dem 2.' vor: Aus einer - kontinuierlich ironisch zitierten - Geschichte heroischer Feldherrn, genialer strategen, Philosophen, Künstler und Staatsmänner auf dem Zarenthron - wird eine Geschichte von gekrönten Feiglingen, Dummköpfen, Ignoranten, Hurenböcken; eine Geschichte vor allem aber von Ausbeutern, Mördern, Dieben, Rechtsverdrehern unter dem Doppeladler. 
Der (Negativ-) F i $g$ u $r$ e $b$ e $t$ a $n d$ ist damit bereits umrissen: russische Großfüsten und Zaren, daneben sich in Zarendiensten bereitwillig prostituierende Hocharistokraten, sowie - ganz vereinzelt - Bürger, zwangsverdummtes Volk.

Die $r$ i $g$ u $r$ e $k$ o $s t i t u t i o n$ zentriert fast durchgehend nur eine einzige negative Dimension. Auf eine auch nur andeutende Beschreibung des physischen Erscheinungsbildes der Figuren wird hier - im Gegensatz zu den voll entwickelten Paradigmen der Satiren des 'Außen-Bereichs' - generell verzichtet: jede Einzelfigur ist festgelegt auf die Funktion der $D$ e m 0 $s t r$ a $t$ o $n$ einer einzigen als Autokraten - spezifisch ausgewiesenen Negativ-Qualität (Dummeit, Brutalität, Geilheit etc.); diese wird den Figuren nicht als direkt benennende Etikette angeheftet, manifestiert sich vielmehr indirekt (s.u.). Diese negative $E$ i n $i m e n s$ o n $l i t$ a $t$ der Figurenkonstitution wird erst gegen Ende der 'Russischen Geschichte ...' - und damit auch erst in der (Auto-) Liquidationsphase der russischen Monarchie - durchbrochen: die Hocharistokratie verfällt in den Schwanengesang ihrer historischen Agonie und die Negativqualitäten aller früheren Herrscher - die n u $r$ dumm oder $n$ u $r$ blutgierig etc. waren - summieren sich in ihrem letzten Repräsentanten, der sich somit als wahrhaft wüdiger 'dernier cri' seiner Epoche erweist; als krönender Höhe- und Schlußpunkt eines jahrhundertelangen Fäulnisprozesses (als solcher stellt sich die Geschichte des vorrevolutionären Rußlands dar) ist Nikolaj II von 'genialer' Dummeit, 'genialer' Brutalität, 'genialer' Ignoranz etc. $z$ u $g l$ e $i \mathrm{~h}$. Er ist das Negativ-Konzentrat einer ganzen historischen Epoche, auf das nur noch etwas qualitativ völlig Neues folgen kann: die Herrschaft des Volkes, dessen Erwachen als Katalysator der aristokratischen Agonie fungiert.

Die Deco $u$ e $r$ e $r$ u g der Negativität und Lächerlichkeit der Negativfiguren erfolgt in der 'Russischen Geschichte...' nicht benennend-etikettierend, vielmehr indirekt über die Herstellung einer - komischen - Spannung zwischen Sein und Schein, 
Selbstbewertung und Wert, zwischen historischer überlieferung und historischer Faktizität etc.

In diesem Roman sind die Decouvrierung der Negativität und die Decouvrierung der Lächerlichkeit (Verlachung) stets gekoppelt; diese $K \circ p$ e $l u n g$ ist $k$ e $i$ spezifisches Merkmal satirischer Figurenkonstitution. Deren spezifisches Merkmal hingegen ist die Konstitution $n$ e $g t i v$ e Figuren als $k \circ m i s$ c $\mathrm{k} r$ Figuren. Diese beiden Decouvrierungen erfolgen aber zumeist getrennt; die Analyse der Entwicklung der Konstitution der Negativfiguren des sowjetischen satirischen Romans wird zudem ergeben, daß in der zweiten Hälfe des Jahrzehnts unter 'Decouvrierung' in steigendem Maße nur 'Decouvrierung der Lächerlichkeit' (Verlachung) zu verstehen ist, da die Negativität der Figuren und ihrer gesellschaftlichen Korrelate als evident vorausgesetzt und allenfalls noch erinnert wird.

Die häufigsten von der 'Russischen Geschichte ...' eingesetzten Decouvrierungsstrategien sind: 1) Ironisierung durch Herstellung komischer Synonymien; 2) Komische Namensetymologisierung; 3) Parodierung. Letztere erfolgt hier recht originell (die originalität schleift sich innerhalb des Textes durch kontinuierliche wiederholung desselben Verfahrens allerdings rasch ab): Historischen Personen korrelierte Figuren sprechen im Wortlaut diese Personen glorifizierender historischer Dokumente (Chroniken) und literarischer Vorlagen, sehen sich dann dem Vorwurf der Plagiierung dieser Vorlagen ausgesetzt. M.a.W.: die 'regressive' 'Plagiierung' erstellt per Zitat eine 'Identität', die der faktischen Identität nicht entspricht - auch hier also die Etablierung einer komischen Spannung zwischen subjektivem Anspruch und objektivem Einlösungsvermögen.

\section{Beispiele}

ad 1) I $r$ o $i s i$ e $r$ n g: - "Nach dem Brauch der russischen rechtgläubigen Zaren, der Väter ihres Volkes, ließ Nikolaj am Tage seiner Thronbesteigung einige Hundert Menschen erschiessen, einige Hundert aufhängen und einige Hundert in die sibirischen Bergwerke verschicken. (...) Nikolaj Pavlovic, wie alle russischen Imperatorep, liebte sein Volk wahnsinnig und dachte ständig an sein Wohl" "). 
Komische Synonymie-Relation: "liebte sein Volk wahnsinnig und dachte ständig an sein Wohl" = "ließ (...) einige Hundert Menschen erschießen, einige Hundert aufhängen".

- "Unter Nikolaj Pavlovič begannen in der Rus' Literatur und Kunst zu erblijpen. Nachdem er diese Unordnung bemerkt hatte, befahl der Zar" 3 .

Komische Synonymie-Relation: "begannen in der Rus' Literatur und Kunst zu erblühen" = "Unordnung".

ad 2) E $t$ y $m$ l o g i s i e r u g: - "Ivan Kalita (stojal celyj den' u kalitki i obdiral prochozich)" ${ }^{4)}$.

(osvobodil múzikov ot zemli i chleba)" 5 ).

- "Aleksandr Osvoboditel"

ad 3) P a r o d $i$ e $r$ u g: "Boris entließ Sujskij und ließ die Bojaren zusammenrufen. Die Bojaren kamen. Boris ging hinaus zu ihnen und wandte sich mit den Blankversen an sie:

"Erlangte ich die höchste Macht..."

Die Bojaren wechselten verstohlene Blicke. Geflüster war zu hören: - Das hat er bei Py̧Kin gestohlen! ... Das ist Raub. Seinen Dichter zu bestehlen!" $"$ "

(D.h.: der Zar als personifiziertes Plagiat seines Mythos. Dieses Zitat verdeutlicht zugleich die mit diesem Decouvrierungsverfahren verbundene Gefahr: das Resultat ist, wie in diesem Fall, häufig nur dekorativwitzig - jedoch nicht decouvrierend!).

Die $p \circ s i t i v e G$ e $g$ e $p \circ s i t i \circ n$ ist in der 'Russischen Geschichte...' wie in fast allen Satiren des 'AußenBereichs' vom Volk besetzt; während das Volk in den vollentwickelten Paradigmen aber geschichtsgestaltendes Proletariat ist, tritt es hier als handelnde Kraft kaum in Erscheinung, ist es nicht Gestalter - sondern prioritär Interpret von Geschichte: das Volk fungiert als Interpretationshilfe für den Rezipienten, indem es die aus der Darstellung des Zarismus abzuleitende Neubewertung der Geschichte Rußlands direkt vorformuliert. Die positive Gegenposition ist hier wesentlich also nicht figural, sondern a $r-$ g $u$ m e $t$ a $t i v$ repräsentiert:

"Nachdem er Japan bestraft hatte (auch hier eine ironische Synonymie: die objektive vernichtende militärische Niederlage als subjektiver Sieg des Zaren j.e.), begann der Zar erneut zu herrschen. Aber da begannen irgendwelche Schwierigkeiten. 
Das Volk begann irgendwie sich zu versammeln. Sie schütelten den Kopf und begannen untereinander zu sprechen:

- Gerade als sei er...

- Wer er?

- Nun der Zar doch.

- Als sei er was?

- Als sei er irgendwie dumm ..."7).

Nachdem so der Mythos vom weisen Zaren aufgelöst wurde, werden auch die Mythen vom Zaren als Wohltäter, Moralexempel etc. seines Volkes in direkter Ausformulierung zerschlagen:

"- Ja was ist er denn tatsächlich? ...

- Kein Zar, sondern ein Räuber...

- Einfach ein Rowdy ...

- Mit einem Wort ein Van'ka Kain"8).

Aus dieser Einsicht zieht das Volk die e $i \mathrm{n} i \mathrm{~g} r i \mathrm{c} t \boldsymbol{t}-$ $g e$ politische Konsequenz: es fegt den Zaren mitsamt seiner Suite auf den Schuttabladeplatz der Zeit und übernimmt selbst $f \circ l g l i c h$ und $l$ e $g i t i m e r m a$ a $n$ (der Richter steht über dem von ihm Verurteilten) die Macht:

"Es lebte die Rus' dreihundert Jahre mit einem Zaren im Land und ohne einen Zaren im Kopf.

Jetzt, geb's Gott, wird es umgekehrt sein.

Die Rus' wird von nun an feben ohne einen Zaren im Land und mit einem Zaren im Kopf ..." 19 .

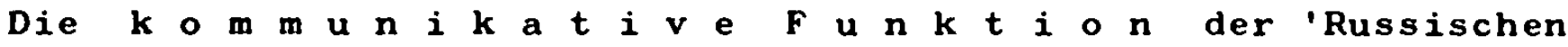
Geschichte ...' entspricht in allen wesentlichen Aspekten der ersten typologischen Möglichkeit des obigen Beschreibungsmodells. Durch kontinuierliche Opposition von im Interesse des Zarismus konstruierten Mythen, von zaristischer Ideologie einerseits und 'historischer Wahrheit' andererseits soll dem Rezipienten - der Autor geht davon aus, daß der Leser (1919!) häufig noch der Hjlfestellung bei der Destruierung der zaristischen Ideologie bedarf - in einem ersten Schritt die Negativität des monarchischen Systems bewußt gemacht werden: Die Geschichte Rußlands unter dem Zarismus ist die Geschichte allseitiger Dummeit, Unbildung, Unterdrückung etc.

Diese Negativmerkmale der autokratischen Ausbeutergesellschaft (der Aspekt kapitalistischer Ausbeutung bleibt unberückichtigt!) 
steigern sich gegen das Ende dieser Epoche zu einer wahren Apokalypse der Dummeit, Brutalität etc., diemit $N$ o $t$ e $n$ d $g$ $k$ e $i$ zur Ablösung dieses Systems durch die Herrschaft des Volkes führen muß: die 'Russische Geschichte ...' demonstriert

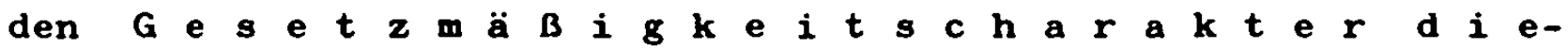

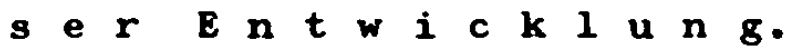

Die (hier implizite) These von der Unausbleiblichkeit der sozialistischen Revolution wird somit bestätigt. Bestätigt und legitimiert wird damit zugleich aber auch der sozio-ökonomische status quo: eine - noch so schwierige - gesellschaftiche und wirtschaftliche Situation, die sich mit absoluter Notwendigkeit aus geschichtsimmanenten Entwicklungsgesetzen ergab, trägt ihre Rechtfertigung in sich selbst. Und ebenso wie die Geschichte sich auf diesen Punkt zubewegte, wird sie sich auch uber ihn hinwegbewegen: der status quo als notwendige übergangsphase, aus der kein Weg zurück führt in die Monarchie (über die Konterrevolution), die vielmehr eine übergangsphase zur konsolidierten Herrschaft des Proletariats ist. Die Vermittlung dieser Einsicht in die Aussichtslosigkeit und Sinnlosigkeit der Konterrevolution ist eine der zentralen kommikativep Funktionen der 'Russischen Geschichte', die ja in der kritischten Phase des Bürgerkriegs erschien: Die Interpolation der kommunikativen Funktion von Satiren muß sich an der kommunikativen Situation des Erstrezipienten orientieren!

Die 'Russische Geschichte' ist konstruiert als pure, unvermittelte Reihung von Einzelporträts, die als einziges Ordnungsprinzip die Chronologie der Geschichte des Zarismus einsetzt. Eine darüber hinausführende $s u j e t k \circ n s t r u k t i \circ n$ fehlt vollkommen. 


\subsection{Die 'Satire der Kapitalistischen Endzeit'}

Nachdem nach 1919 die Produktion satirischer Romane in der Sowjetunion vorubergehend ganz ausgesetzt hatte, bringen schon die ersten Jahre der Nöp eine wahre Flut satirischer Romane hervor. Nacheinander - nicht nebeneinander! - werden die beiden Paradigmen der 'Satire der kapitalistischen Endzeit' (1922-1925. 'Erstes Paradigma') und der 'Satire der bourgeois-faschistischen Fratze' (1925-1927. 'Zweites Paradigma') entwickelt.

Bei aller Verschiedenheit weisen diese beiden Paradigmen umfangreiche Gemeinsamkeiten auf, vor allem im Bereich des Figurenbestandes und der Figurenkonstitution. Folglich - da Ziel dieser Arbeit nicht nur die Beschreibung typologischer Möglichkeiten des sowjetischen satirischen Romans ist, sondern auch die Herausarbeitung seiner Entwicklungstendenzen - wird in diesem Kapitel das Paradigma der 'Satire der bourgeois-faschistischen Fratze' v $\quad r \quad l$ a $u$ f $i g$ unter das Paradigma der 'Satire der kapitalistischen Endzeit' subsumiert. Erst $n$ a $c h$ dieser Betonung der starken Parallelen wird es möglich und auch sinnvoll sein, die Merkmale der Differenzierung zu unterstreichen, die so gravierend sind, daß trotz vieler gemeinsamer versatzstücke ein gemeinsames umfassendes Paradigma nicht konstruierbar ist, daß von zwei verschiedenen Paradigmen entsprochen werden muß. Bereits 1922 hatte sich ein sehr stabiles, bis zu seiner Ablösung (1925) völlig unverändert beibehaltenes Paradigma ausgeprägt, das in einigen Aspekten (Figurenbestand; kommunikative Funktion) eine konsequente $w$ e $i t$ e $n t w i c k l$ u $g$ der 'Satire der aristokratischen Agonie' darstellt - in anderen Aspekten (Figurenkonstitution; Decouvrierungsstrategien, Sujetkonstruktion) aber entweder Verfahren ubernimmt, die in der Zwischenzeit in anderen Genres (vor allem im Plakat-Genre) entwickelt wurden, oder auf traditionelle Muster (vor allem der Sujetkonstruktion) zurückgreift. Es handelt sich um das enorm produktive Paradigma derjenigen satirischen Romane, deren Angriffs- und Darstellungobjekte im Bereich der bürgerlichen Gesellschaft der 'letzten Tage' liegen. 


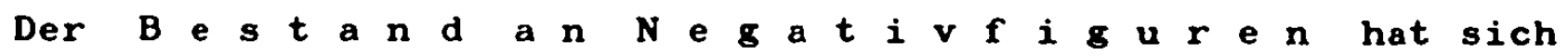
qualitativ wie quantitativ stark verändert. Während die Negativfiguren der 'Satire der aristokratischen Agonie' ausgewiesen waren als Repräsentanten der politischen und ökonomischen Macht des monarchischen Rußlands - auf das Fehlen des Bourgeois, ein echtes Manko der 'Russischen Geschichte ...', wurde bereits hingewiesen -, repräsentieren die Negativfiguren der 'Satire der kapitalistischen Endzeit' die ökonomischen und politischen Exponenten der spätkapitalistischen Gesellschaft - Fabrikbesitzer, Bankier, Aufsichtsrat - sowie ein Riesenheer von 'Prostituierten' im dollarweichen Bett des Kapitals: Regierungschef, Parlamentarier, Journalist, Polizist.

Diese Modifikation des Figurenbestandes ergibt sich mit zwingender Konsequenz aus der Verlagerung des Angriffsbereichs aus dem - ganz pauschal gefaßten - Feudalstaat in den spätkapitalistischen Staat. (D'Or konzentriert sich auf die Hocharistokratie als Repräsentanten einer ganzen Epoche, nicht auf eine spezifische politische und ökonomische situation).

Dieser kapitalistische Staat ist in der Regel (in der 'Satire der kapitalistischen Endzeit') ein geographisch nicht zu lokalisierender Inselstaat - das weitgehend von der politischen Umwelt isolierte Exemplar, das Modell des kapitalistischen Staates schlechthin. Nur ganz vereinzelt ist dieser staat direkt mit den USA identifizierbar. Der Zeitraum der Handlung ist einige Jahre in die Zukunft verlegt. Die Zeitspanne zwischen dem Jetzt und dieser Zukunft ist aber so kurz - sie beträgt in der paradigmatischen 'Satire der kapitalistischen Endzeit' nie mehr als zehn Jahre -, daß es, bei völligem Fehlen utopischer Details, nicht gerechtfertigt ist, diese Romane als 'utopische Pamphlets' (Vulis) zu bezeichnen.

Zentrale Negativfigur ist nun der kapitalistische ' $O$ O $B$, der seinem soziohistorischen Exitus entgegenvegetiert: der Boß als feistes, glatzköpfiges, zigarrenrauchendes Raubtier (oder Schwein), das an galoppierender ökonomischer und politischer 
Schwindsucht dahinstirbt und in einem letzten - komischen - Auf bäumen seinem ihn mit gesetzmäßiger Sicherheit ereilenden Schicksal zu entkommen sucht.

Die $K \circ n$ s $i t u t i$ o dieser Negativfigur geht qualitativ wie quantitativ weit uber die 'Satire der aristokratischen

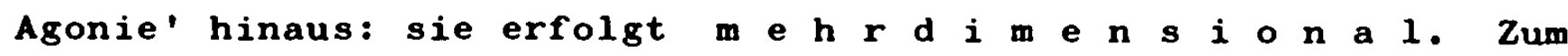
einen sind die negativen Figuren nicht mehr auf eine einzige Negativqualität festgelegt; vielmehr bündeln sie zumeist alle für ihre Klasse oder Gruppe 'typischen' Negativqualitäten: Habgier, Brutalität, Faulheit, Verlogenheit...

Zum andern tritt häufig eine zweite Dimension hinzu: der 'Boß' hat oft ein zumindest vages Bewußtsein, das Bewußtsein nämlich, daß seine Tage gezählt sind - er hat Angst; diese Angst konstituiert, da sie in Spannung zur (affektierten) Überlegenheitspose des Bourgeois tritt, das einzige in der Figurenkonstitution selbst angelegte komische Element:

"Uns ist bekannt, daß Sie und der anormale Phantast (= Kommunist j.e.) Smirnov davon träumen, die Arbeiter vom kapitalistischen Joch zu befreien ... Zunächst haben $i c h$ und meine Kollegen von der Weltkompanie "Kapital" nur gelacht uber die vagen Andeutungen, die in den truben Schmutz der Boulevard-Blätter hineinsikkerten, sowie über die beiden Holzköpfe (= Kommunisten j.e.), die sich mit der Entwicklung von 'Universellen Strahlen' befassen, deren Ziel ... deren Ziel ... ich weiß selbst nicht was ist ... (er weiß es sehr gut: die 'Universellen Strahlen' sind eine Waffe zur Zerstörung der Macht des Kapitals in der Hand des Proletariats j.e.). Aber wenn nur die Hälfte von dem, was die Zeitungen schreiben, wahr ist, dann ... ich weiß selbst nicht was! i10) (er weiß es sehr wohl: dann sind seine Tage gezählt

"Es ist nicht nötig, Ihnen das zu erklären. Die kleinen Firmen machen eine nach der andern Bankrott. Die Bankeq halten nicht Stand. Die Gefahr bewegt sich auf uns zu ..."1 .

Sozial relevante Negativqualitäten und sozio-historisch bedingte Angst konstituieren also zwei Dimensionen der 'Bosse'. Auffälligste Modifikation der Figurenkonstitution ist aber, daß die Negativfiguren nicht mehr nur zur $D$ e $o n s t r$ a $i$ o einer oder mehrerer Negativqualitäten eingesetzt werden: sie bekommen ein grob-typisierendes (nicht individualisierendes) Gesicht, ein häufig sehr breit angelegtes Porträt: 
"Annähernd drei Arschin beträgt der Zwischenraum zwischen den in lackierten Stiefeln steckenden Socken und der Krempe des Zylinders. Diesen Zwischenraum füllt Vil'jam Underlip. In diesem Zwischenraum finden wir: gut gebügelte makellos schwarze Hosen, die stramme Wölbung des Bauches mit den auseinanderstrebenden Flügeln des schwarzen einreihigen Jacketts, den runden und nackten, der Ferse gleichenden und ohne Hals auf die masiven Schultern aufgesetzten Kopf.

Sie entschuldigen, und die Augen? Ach so, die Augen? Da sind sie. Sie sind untergegangen in der Vertiefung zwischen den feisten Wangen, die an den rosigen Hintern eines neugeborenen Säuglings erinnem, und den wie feurjgg Besen herabhängenden Augenbrauen. Zwei kleine blaue Spalten"lz'.

"Die schnabelförmige Nase steht spitz und dïnn im runden Gesicht, ein dicker Hals, ein dunkler, sich langsam bewegender Pugpf, und das ist auch schon der ganze Mister Biks. Ein Porträt" $13{ }^{\text {. }}$.

"Mister Bebey ist auf allen Inseln bekannt (...). Und wenn wir uns eine kleine Unbescheidenheit erlauben wollen und einen Blick in sein Kabinett werfen (...), - so werden wir Mister Bebes dennoch nicht erblicken: Wir werden nur einen riesengroßen Haufen aus Hose, Gehrock, Krawatte und schneeweißem Kragen erblicken, und auf diesem ganzen Haufen eine rosarote Pyramide, die sich mit ihrer Basis auf dem schneeweißen Krägelchen abstuitzt.

Diese Pyramide entbehrt absolut jeglichen Haarwuchses und läBt keinerlei Vertiefungen oder Erhöhungen erkennen, die auf das Vorhandensein von Augen oder einer Nase bei Mister Bebes hindeuten könnten: (... und es ist nicht auszumachen), wo sich bei Mister Bebes die Vorderseite oder das Gesicht und wo sifh bei ihm die Rükseite oder der sogenannte Nacken befinden"

Diese beiden willkülich herausgegriffenen Textbeispiele sollen zweierlei demonstrieren: 1) Die Porträtierung beschränkt sich auf wenige Versatzstücke, die jahrelang unverändert beibehalten werden; 2) Die Porträtierung konstruiert eine totale Kongruenz von (sozialem) Wesen und (physischer) Erscheinung - während die Negativfiguren der 'Satire der aristokratischen Agonie' gerade aus der Inkongruenz von Wesen und Erscheinung etc. komisch waren: der 'Boß' ist bezüglich seines sozialen Wesens und seines physischen Erscheinungsbildes gleichermaßen - schlicht ein Schwe in.

Die Herkunft der Versatzstücke dieses Bourgeois-Porträts (Speckfalten, Fettwilste, Glatze, Stiernacken, Gesichtslosigkeit, Zigarre etc.) liegt auf der Hand: sie entstamen dem politischen Agit-Plakat der Revolutions- und Bürgerkriegsjahre, dew satirischen Feuilleton der frühen zwanziger Jahre. 
Während dem negativen Erscheinungsbild des Bosses breiter Raum gewidmet wird, wird seine soziale Negativität wesentlich als evident vorausgesetzt. Das bedeutet insbesondere, daß dieses erste Paradigma (im Unterschied zum nachfolgenden) auf eine Darstellung seines politischen Verhaltens weitgehend verzichtet; seine soziale Negativität manifestiert sich indirekt in der bereits erfolgten Reaktion des Proletariats und seiner politischen Führer, in der Tatsache, daß die unmittelbar vorrevolutionäre Situation schon eingetreten ist.

Lediglich die Aspekte bourgeoiser Faulheit und Dummheit - mithin der Aspekt bourgeoiser Autoliquidation - werden häufig noch unterstrichen.

Der bourgeoise 'Arbeits-Begriff:

(Der 'Boß' bereitet seine Flucht vor)

"Mister und Mistriss Bebes hatten ihre Koffer bereits gepackt. - Das Gold! Vor allem das Gold! - sagte Mister Bebes und wischte über seine Pyramide. Er war ganz ermattet! Er hätte sich niemals vorstellen können, daß er so viel arbeiten kanq'j) Mister Bebeł verpackte selbst das Gold und die Brillanten" ${ }^{\text {) }}$.

Bourgeoise Dummeit (Autoliquidation): Obwohl sie wissen, daB das Gespenst des Sozialismus umgeht und obwohl sie vor Angst vor ihm zittern, entfachen die Bosse nicht nur einen gnadenlosen Börsenkrieg - der viele der dollar- und fettschweren Kapitalisten ruiniert; nein, als automatenhaft-unkontrollierte Sklaven ihrer Bereicherungsgier vermarkten sie sogar ihr Angstobjekt Sozialismus: "Im Verkauf erschienen Zigarren, Hüte, Spazierstökke, Stiefel im 'Antichrist'-stil"16).

Die Konstitution der Negativfiguren erfolgt also wesentich durch Porträtierung ihres physischen Erscheinungsbildes und andeutend-ergänzende Skizzierung weniger Aspekte ihres sozialen Verhaltens - nicht unter kapitalistischen 'Normal-Bedingungen', sondern unter den Bedingungen der 'Endzeit', die den vom Proletariat in die Enge getriebenen Bourgeois ein letztes Mal in aller Schärfe sein soziales Wesen manifestieren lassen: Sie erfolgt d a $r$ s e 1 l e $n d$. Nur vereinzelt wird darüber hinaus ihre Negativität direkt benannt, etikettiert; und auch dann selbstironisch, selbst-etikettierend: 
'Nein ... ich, Robert Krejs, und meine Freunde in Sachen Scheck-

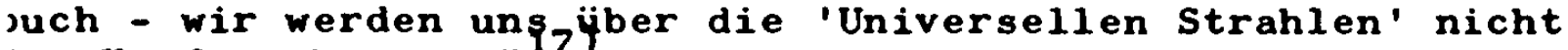
len Kopf zerbrechen" 17 .

"Die Zeit des erbitterten Kampfes mit dem Proletariat ist angejrochen ... Wir werden siegen ... Auf unseref) Seite steht eine inerschüterliche Macht - das Kapital! ..."18).

Als einziger Vertreter des sich um den 'Boß' gruppierenden Feldes von Nebenfiguren sei hier nur noch der Journalist präsentiert; ebenso wie konservative Politiker, Militärs und andere Lakaien der Bourgeoisie ist er schlicht - eine Prostituierte:

"Das heißt also, Thre Aufsätze, Telegramme sind lügnerische Erfindung, Lüge?

- Keineswegs. In einem zivilisierten Land ist die Presse ein patentiertes Verfahren zur Bearbeitung der öffentlichen Meinung. Minister, Bankiers, Präsidenten ...

- Jockeys, ganz gewöhnliche Gauner, jeder gibt sein eigenes organ heraus, beendete Tom den Satz ...

Der Redakteur runzelte die stirn:

- Möglicherweise haben Sie sogar recht, aber in meiner Eigenschaft als Herausgeber einer unabhängigen Zeitung ...

- Sind Sie verpflichtet, ich verstehe schon, jedem zu willen zu sein, unterbrach ihn Tom.

Der Redakteur lief rot an:

- Ach ... hm ... Genug! Wir haben telegraphische Informationen über den Antichristen erhalten! Wir haben sie gedruckt. Die Regierung will im Antipbjisten die Sozialisten sehen - so haben wir es gedruckt..."19).

Aus den oben zur Konstitution der Negativfiguren gemachten Angaben geht bereits eindeutig hervor, daß die Figurenkonstitution

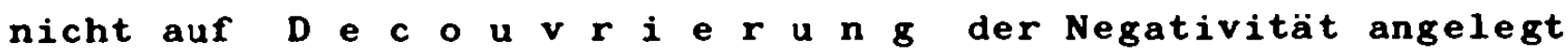
ist: alle Figuren der Negativposition sind von so uneingeschränkter und manifester Negativität und Widerlichkeit, daß ihre Decouvrierung Eulen nach Athen tragen bedeuten würde. Die Negativfiguren werden nicht als negativ d e c u $v i$ e $t$; vielmehr wird ihre bereits bekannte Negativität im Rahmen einer übergeordneten Intention (s.u.) mit oberflächlich-satirischplakativen Typisierungsklischees $d o k u m$ m $t i e r t . D e-$ couvriert werden nicht Negativität, Häßlichkeit etc. des Bosses; decouvriert wird nur seine Angst.

Die Tatsache, daß jede Inkongruenz von Wesen und Erscheinung 
fehlt, vielmehr kontinuierlich deren Übereinstimmung unterstrichen wird, bedeutet zugleich, daß die Komik dieser Figuren wesentlich nicht aus ihrer Konstitution resultieren kann; daran ändert auch die reiche Verwendung stereotyper Versatzstücke pseudo-komischer Typisierung - die den Rest der Physiognomie erdrückende Nase, der 'scharfe Hämorrhoiden-Anfall' etc. - nichts. Thre Komik ergibt sich vielmehr einerseits aus dem Kontrast zwischen negativen und positiven Figuren, andererseits und wesentlich aus der Inkongruenz von (eventuell nur noch affektiertem) intaktem Selbstverständnis und objektivem historischem Stellenwert $\left(s \cdot u_{0}\right)$.

Das weitgehende Fehlen einer Inkongruenz von Wesen und Erscheinung bedeutet darüber hinaus, daß kommunikative Funktion dieses Paradigmas nicht die Decouvrierung des kapitalistischen systems, auch nicht die Destruierung der von der gesellschaftlichen Alternative ausgestrahlten Faszination sein kann.

Das Volk besetzt bereits in der 'Russischen Geschichte' die

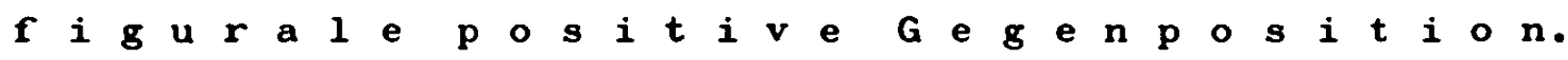
Ein Volk freilich, dessen Leben, politisches Denken und Handeln kaum dargestellt werden, das vielmehr als anonymes, gesichtsloses Sprachrohr zur Formulierung der a $r$ u m $\mathrm{m} t$ a $t \mathbf{i}$ e positiven Gegenposition - damit zur Vor-Formulierung der intendierten Interpretation des Textes fungiert.

Ganz anders in der 'Satire der kapitalistischen Endzeit' und in der 'Satire der bourgeois-faschistischen Fratze': hier nimmt die Darstellung des politischen Denkens und Handelns (im ersten Paradigma), des Privat-'Lebens' (tritt im zweiten Paradigma hinzu) des Volkes breiten Raum ein. 'Des Volkes' - genauer: des Proletariats, insbesondere aber seiner Exponenten - kommunistischer Arbeiterfuhrer. Proletarisches Denken und Handeln heißt darüber hinaus in beiden Paradigmen: Denken, Handeln, Sein des sowjetischen Proletariats. Damit ist der $B$ e $t$ a $n d a n$ $t \quad i \quad$ e $n$ F $i \quad g$ u $r$ e $n$ umrissen. 


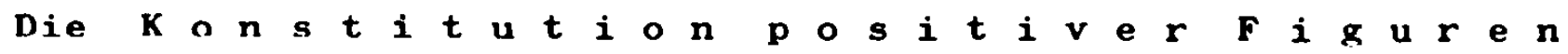
erfolgt streng kontrastiv zur Konstitution negativer Figuren auch hier drei korrespondierende Dimensionen: 1) die sozio-politische, 2) die 'menschliche', 3) die physische Dimension.

ad 1): "Der Bürger Djurevil" (ein Kommunist j.e.) ist eine äußerst popujäre Person in den Kreisen, in denen die Person des Mister Bebes (...) keine besondere Popularität genießt (...). Der Bürger Djurevil' ist schon seit füf Jahren Mitglied des Parlamentes und stejłf den besten Redner des linken Flügels der Arbeiterpartei dar"

Die damit signalisierte grundsätzlich richtige politische Orientierung wird weiter präzisiert. Der Kommunist hat erkannt:

"jedes Land hat seine Krejsy (Kapitalisten j.e.) und für sie quält sich eine Millionenarmee von Arbeitern in rauchigen und stickigen Fabriken (...) Aber nicht mehr lange sollen die Millionäre auf ihren Privatjachten schaukeln. Bald, bald wird alles uns gehören: die Autos, die Wolkenkratzer, der Komfort (...). So igt)
es in Rußland geschehen und so wird es auch bei uns sein! ..."

Aus dieser Erkenntnis, die - und das ist von ausschlaggebender Bedeutung für die Ermittlung der kommunikativen Funktion - das eigene gesellschaftliche Ideal mit dem in der Sowjetunion bereits etablierten Zustand identifiziert, werden die einzig richtigen Konsequenzen für das eigene - durch Entschlossenheit, Zielbewußtheit, Opferbereitschaft charakterisierte - politische Handeln gezogen: politische Agitation, Organisation von Streiks, Revolution. Und diese Revolution ist die sozialistische Weltrevolution; der Arbeiter denkt internationalistisch:

"Für sie gibt es keine Heimat (...). Die ganze Welt ersetzt ihnen ein Vaterland im Paß. Man soll ihnen nur die Möglichkeit geben und anstelle aller staaten und Imperien werden sie in fetter Schrift mit roter Tinte auf die Weftkarte ein SR (Sojuz Rabočch - Arbeiterunion j.e.) schreiben"

ad 2): Sein politisches Handeln weist den kommunistischen Arbeiter aus als Freund des Menschengeschlechts. Sein liebevolles Verhalten dem Mitmenschen gegenüber (kontrastiv zur Brutalität des Bosses) dokumentiert sich exemplarisch in dem nie fehlenden Rührelement der Kinderliebe: Djurevil' (Kozyrev) setzt sein Leben aufs spiel, um ein fünjähriges russisches Kind zu retten, auf das die Bourgeoisie - da sie in ihm einen verkappten bolschewistischen Agenten und Agitator vermutet - eine alle konser- 
vativen Kräfte vereinigende Treibjagd veranstaltet. "Nikel's (ein anderer Kommunist j.e.) streichelte zärtlich Džos (ein kleiner Junge j.e.) Kopf" - "Nikel's nahm Džo oft auf die Knie. und erzählte ihm mit leiser und zarter stimme (...) vom Leben"23).

ad 3): Auch das physische Erscheinungsbild des Kommunisten - der häßliche, ausgemergelte Arbeiter kommt erst in der 'Satire der bourgeois-faschistischen Fratze' hinzu - ist ganz auf Kontrast zum widerlichen Erscheinungsbild des Bosses angelegt:

"Da ist er (...): ein kräftiges Gesicht mit stark hervortretenden Backenknochen; schwere, stechend blickende Augen; gemessene, alles sehgyde Bewegungen; breite Schultern, die Hand zur Faust geballt" 24 .

"Und auch äußerlich stellt er nichts Auffälligeres dar: auf der Straße kann man ihn für einen einfachen Arbeiter halten (...), wenn man Djurevil's Gesicht aufmerksam betrachtet, bemerkt man das energische, gleichsam abgehackte Kinn, das dem Gesicht (...) den Ausdruck der Entschlossenheit und Zielstrebigkeit verleiht. Und außerdem bemerkt man die von Falten bedeckte Stirn: aber wenn er denkt, dann glätten sich die Falten und dieß̧5) Stirn nimmt das Aussehen einer gänzlich glatten Oberfläche an" $"$ ).

Fazit: auch die Konstitution der positiven Figuren zentriert die totale Korrespondenz von Wesen und Erscheinung.

Die positive Gegenposition des ersten und zweiten Paradigmas ist aber nicht nur figural stark repräsentiert, sie ist auch a r$g u m$ e $n$ a $t i v$ vertreten. Figurale und argumentative Komponente sind gekoppelt - die positiven Figuren formulieren die positiven Argumente.

Es sei hier darauf hingewiesen, daß diese Koppelung zwar naheliegend und häufig - aber nicht selbstverständlich ist: Spätere satirische Romane kennen durchaus die Möglichkeit, daß die positiven Argumente von negativen Figuren - sei es im Rahmen intendierter Ironisierung seitens dieser Sprecher; sei es, daß diese Sprecher bezüglich ihres sozialen status noch der Negativposition zuzuordnen bezüglich ihres Denkens aber bereits positiv 'infiziert' sind etc. - vorgetragen werden oder daß sich der Autor unmittelbar zu Wort meldet. Ganz zu schweigen von der Möglich- 
keit fehlender argumentativer Repräsentierung der positiven Gegenposition.

Die positive Argumentation ist in beiden Paradigmen $z w e ~ i$ $s t u f i g$ konstruiert: die erste stufe (1) beschreibt das anvisierte gesellschaftliche Ideal, die zweite Stufe (2) identifiziert dieses Ideal mit dem aktuellen (!) status quo der Sowjetunion, mit dem sowjetischen Arbeiter.

ad 1): "Irgendwer trägt eine rote Fahne heraus. Die Massen verlassen die Vororte.

Die eisernen Flügel der Internationale (...)

- Weg mit den Kapitalisten! Weg mit den Palästen!

Es schreiten die stählernen Kolonnen.

Wir waren! ...Wir sind! ...Wir werden sein!"26). "Die Arbejfer der Welt decken die blutigen Vorhaben der Bourgeoi-
sie auf"

Nach siegreicher Revolution "wird alles uns gehören: Autos, Wolkenkratzer, Komfort (...) je schneller die Gentlmens und Krejsy verschwinden - desto schneller wird er (der Arbeiter j.e.) mit allen Arbeitern $(: 28)$ ein Leben in hellen, geräumigen Wolkenkratzern beginnen" 28 .

Auf die auch nur andeutende Beschreibung der künftigen sozio-ökonomischen Organisationsformen wird verzichtet. Statt dessen werden zur Signalisierung des Lebens des Arbeiters in der sozialistischen Gesellschaft rein äußerliche Versatzstücke aus der spätromantischen Sozial-Utopie (à la Cernyłevskij) eingesetzt (Wolkenkratzer, helle Räume etc.).

ad 2): "So ist es in Rußland geschehen und so wird es auch bei uns sein!". Der Bolschewik ist dem Arbeiter der kapitalistischen Länder zum Leitbild, zum Mythos geworden. Er orientiert sich nicht nur an dessen bereits historischer Revoltuionstat; er ist auch davon uberzeugt, daß der sowjetische Arbeiter ihn aktiv bei der Durchfürung der Revolution unterstüzt: In einem überaus harmlosen Schneider vermutet man einen "Schneider, der vielleicht von Trockij geschickt wurde, und für wen er etwas näht, der wird gluicklich ..."30).

An dieser Überzeugung halten die Arbeiter der vormals kapitalistischen Länder auch noch nach der siegreichen Revolution fest - "Die Arbeiter waren überzeugt, daß ihnen unbedingt die russi- 
schen Bolschewiken geholfen hatten, den Umsturz so erfolgreich durchzuführen"31) - und schicken ein Dankschreiben nach Moskau: "Ich schlage vor ... eine Resolution ... Eine Grußbotschaft an das russische Proletariat ... Die Resolution wurde einstimmig angenommen"32).

Diese ihre Überzeugung geht in die Irre - kein einziger Sowjetbürger nahm an ihrer Revolution teil: der Bolschewik lebt nicht unerkannt $u n t e r$ ihnen, er lebt $i n$ ihnen. Die Revolution überzieht (im ersten Paradigma) ohne Zutun der Sowjetunion als Weltbrand alle kapitalistischen Staaten. Zur "Weltkommune"33) ist es nur noch ein Schritt.

Die noch ausstehenden Fragezugänge des vorgeschlagenen Modells zur Beschreibung satirischer Texte - historische Perspektive kommunikative Funktion; Sujetkonstruktion - müssen für das erste und das zweite Paradigma getrennt erfolgen: eine Subsumierung ist hier nicht mehr möglich. Alle unten noch gemachten Angaben beziehen sich also nur auf die 'Satire der kapitalistischen Endzeit'!

Die in den Text eingebaute $h i s t o r i s c h$ e $P r s$ e $t i v e$ ergibt sich wesentlich bereits aus obigen Ergebnissen. Die Schilderung der sozio-ökonomischen Ausgangsituation - ein Schulbuchkapitel über die vorrevolutionäre Situation: "Niedriger Verdienst, laufend Bankrotte der - wie es schien allersolidesten Firmen, Panik an der Börse, Erhöhung der Preise für Verbrauchsguter, Absinken des realen Geldwertes ... Und schließlich - Schließung der metallverarbeitenden Fqgrik (...) Streiks (...) spontaner Aufbruch des Proletariats" ${ }^{4}$ ?

Die Interpretation dieser Situation - eine $T h$ e $s$ : das kapitalistische system -

"ist zum Untergang verurteilt. Die Bourgeoisie spannt die letzten Kräfte an, um ihre faulen Knochen zu retten (...). Die Bourgeoisie in Panik, Unausbleiblichkeit der kommunistischen Revglytion (...) allen ist klar (...) - es gibt keine Rettung mehr"

Diese These wird verifiziert: auf allen kapitalistischen Inseln des Paradigmas wird modellhaft die Revolution durchgespielt, auf allen Inseln siegt die Revolution - sje siegt als Weltrevolution. 
Die verifizierte These mausert sich durch den Modell-Charakter der im geopolitischen ( $N$ ) Irgendwo stattfinden Inselrevolution zum objektiven historischen Entwicklungsgesetz. Erst vor dem Hintergrund dieses Entwicklungsgesetzes, vor dem Fond der allgemein anerkannten Wahrheit wird der Bourgeois von der nur widerlich-häßlichen zur auch komischen Figur: sein letztes Aufbäumen, das resultiert aus der - komischen (weil aus der Sicht des schon vor Beginn des Kampfes - eben aufgrund des objektiven historischen Entwicklungsgesetzes - siegreichen Klassengegners beobachteten) - Inkongruenz von subjektivem Selbstverständnis und objektivem historischem stellenwert, ist der grunzende Protest eines 'Schweines' gegen seinen 'Schlachter': die Geschichte selbst !

Die Interpolation der $k \circ m m u n i k$ a $i v e n f u k-$ $t i$ o $n$ der 'Satire der kapitalistischen Endzeit' ergibt eine konsequente Weiterentwicklung der kommunikativen Funktion der 'Satire der aristokratischen Agonie'; eine Weiterentwicklung, die der modifizierten kommunikativen Situation des Erstrezipienten - siegreicher Abschluß des Bürgerkriegs, Stabilisierung der innenpolitischen Machtverhältnisse und relative Konsolidierung der ökonomischen Situation; Vertrautheit des Lesers mit den Basisthesen der bolschewistischen Ideologie - (z.T. S.u.) Rechnung trägt.

Kommunikative Basisfunktion dieses Paradigmas ist nicht mehr satirische $B$ e $w$ u $m$ a $h$ u $g$ der Negativität des anderen gesellschaftlichen systems, vielmehr $B$ e $t \ddot{a} t i g u n g$ des Wissens um diese Negativität und Bewußtmachung der $S$ c $h$ w che des Kapitalismus: wie oben nachgewiesen, sind die 'Satiren der kapitalistischen Endzeit' nicht auf Decouvrierung des kapitalistischen sozio-ökonomischen systems, nicht auf Decouvrierung des Bourgeois angelegt! Auch - noch! - nicht auf Decouvrierung kapitalistischer Ideologie: diese kommunikative Aufgabe wird erst nach Ablösung der 'Satire der kapitalistischen Endzeit' durch exponierte Einzel-Texte angegangen, die sich der Einordnung in paradigmatische Konstruktion weitgehend entziehen (s:u.). 
Affirmation der Negativität des Kapitaliams u $n$ d Demonstration der Agoniesituation, in der sich die bürgerliche Gesellschaft befindet: Propagierung der These von der Unausbleiblichkeit, vom nahen Bevorstehen der Weltrevolution. Alle Satiren des ersten Paradigmas sind $T h e s e n-s$ a $i r e n$. Der Thesencharakter wird noch dadurch unterstrichen, daß die 'Satire der kapitalistischen Endzeit' - im Unterschied zur 'Satire der aristokratischen Agonie' - die zugrunde liegende These e x$p 1 i z i t$ in den Text einbezieht !

Unmittelbare Konsequenz der Verifikation der Ausgangsthese ist die $L$ e $g$ i $i m i$ e $r$ n $g$ der eigenen sozio-ökonomischen Situation durch Nachweis ihrer absoluten historischen Notwendigkeit, ist - darüber hinaus - die $G 1$ o $r f i z i$ e $\mathrm{r} g$ dieses status quo: der Rezipient findet sich im Text wieder als $M y t h \circ s$ des Arbeiters der kapitalistischen Länder!

Legitimierung des eigenen gesellschaftlichen status quo und Selbstbestätigung des Rezipienten - damit Stärkung seiner Bereitschaft zur Identifizierung mit der jungen Sowjetgesellschaft, die (noch) mit großen ökonomischen Schwierigkeiten zu kämpfen hat - sind die wesentlichen kommunikativen Funktionen der 'Satire der kapitalistischen Endzeit'.

Eine andere Funktion, die jedoch nur schwer nachweisbar und kontrollierbar ist, tritt möglicherweise hinzu - der Glaube an die 'magische' Kraft des Wortes: viele sowjetische Kommunisten 'der ersten Stunde' waren uberzeugt vom nahen Bevorstehen der Weltrevolution, lebten in ihrer Erwartung. Im Widerspruch zu den realen sozio-politischen Kräfteverhältnissen in den kapitalistischen Ländern - die nicht kommunistische, sondern faschistische Tendenzen favorisierten - 'beschwören' die 'Satiren der kapitalistischen Endzeit kontinuierlich das Ereignis der Weltrevolution. Sie a $g i t$ e $r$ e nicht für die Weltrevolution - sie b e s c h w ö $r$ sie: denn die Ziel-Rezipienten einer möglichen Agitation für die Weltrevolution - die 'Proletarier aller Länder' - waren weder faktische noch anvisierte Rezipienten dieser Satiren! Keine einzige dieser Satiren wurde aus dem Russischen uibersetzt ! 
Die 'Russische Geschichte ...' war konstruiert als unvermittelte Reihung von satirischen Porträts. Die 'Satiren der kapitalistischen Endzeit' hingegen - die nicht Einzel-Porträts reihen, vielmehr eine radikal zwischen Negativ und Positiv scheidende Opposition von zwei zentralen Figuren durchfüren - weisen ausnahmslos eine $s t$ o $y$ auf.

Genauer: d $i$ e story; denn das Paradigma kennt nur eine einzige story, die überall - mit geringfügigen Variationen - eingesetzt wird:

In einem kapitalistischen Inselstat haben sich die Klassengegensätze zur unmittelbar vorrevolutionären situation zugespitzt. Während die Exponenten des Kapitals einen Börsenkrieg entfachen, um ihre Schäfchen in letzter Minute ins Trockene (d.h. auf eine andere kapitalistische Insel) zu bringen: in Selbstzerfleischung verfallen, organisiert sich das Proletariat unter führung eines Kommunisten.

Die Fronten verlaufen eindeutig: hier die Masse des Proletariats unter ihrem kommunistischen Anfüher; hier eine kleine Gruppe von Bossen, in der der brutalste und skrupelloseste die Macht an sich gerissen hat. Die Polarisierung der Kräfte ist eindeutig: das Proletariat hat das Recht auf seiner Seite; die Bourgeoisie-Polizei und Militär u $n$ d eine zur Vernichtung des Proletariats bestimmte Geheimwaffe, meist eine Super-Strahlen-Kanone.

Vor Beginn der erwarteten bewaffneten Auseinandersetzung setzen die Bosse einen Detektiv auf den Kommunistenfürer an, einen glücklosen Detektiv: er ist immer und uberall verspätet. D.h. aber: er ist auf der Ebene der Kriminal-story das, was sein Dienstherr auf historischer Ebene ist - überfällig! Glucklos ist er auch insofern, als er nur einen einzigen Fang macht und dieser Fang, den er auch weidlich verprügelt, ist aus versehen der Falsche, d.h. der Richtige: sein Brötchengeber (Autoliquidation).

Die bewaffnete Auseinandersetzung findet nicht statt: das Militär läuft zum Proletariat uber; die Bosse ziehen sich - im Vertrauen auf ihre Geheimwaffe - auf eine letzte Bastion zurück. Und jetzt kehrt sich diese Waffe gegen ihre Besitzer, wird zum Werkzeug ihrer selbstvernichtung.

Satirische Typen, Thesen und story sind in diesem Paradigma also aufeinander zugearbeitet: die fast durchgehend mit der selbstrernichtung (der das Proletariat allenfalls noch nachhilft) der durch den Klassenfeind in die Enge getriebenen Kapitalisten endende story bestätigt die Ausgangsthese von der Unausbleiblichkeit der Weltrevolution, bestätigt das in der Konstitution der 
Bosse angelegte historische Verurteiltsein, bestätigt den in der Konstitution der Bosse angelegten Hang zur Autoliquidation.

Nur dieses Paradigma kennt eine 'organische'Integration von Figuren-Konstitution, These und story.

Die großen Schwächen des Paradigmas der 'Satire der kapitalistischen Endzeit' liegen auf der Hand: Das Paradigma übernimmt wesentlich Figurenbestand und Konstitutionsverfahren der in den Revolutions- und Bürgerkriegsjahren entwickelten unmittelbar agitatorischen Satire. Diese Verfahren, die auf eine politische Kampfsituation zugeschnitten und in ihr effektiv waren, werden nun einer völlig anderen kommunikativen Funktion untergeordnet, nicht-agitatorisch eingesetzt: sie decouvrieren nun nicht mehr, illustrieren nur noch - ihre satirische Potenz ist gleich Null.

Darüber hinaus erwies sich das Paradigma als so starr, daß die es einsetzenden Texte sich als detailgetreue gegenseitige Kopien lesen: Überall die gleichen und gleich konstituierten Figuren, überall die gleiche story, überall der gleiche Detektiv etc. Die Texte sind so stark klischiert, daß für den heutigen Leser die Lektüre schon des zweiten Textes zur Arbeit, die des dritten zur Qual wird. Das Paradigma wurde weder quantitativ (Erweiterung des Figurenbestandes) noch qualitativ (Modifikation der Konstitutionsklischees etc.) entwickelt. Der Hauptgrund dafür ist wohl darin zu sehen, daß Verfasser dieser Romane zumeist sehr junge, häufig schlicht untalentierte Autoren waren, deren literarische Fähigkeiten mit ihrem politischen Engagement nicht Schritt halten konnten: die Namen von D'Or, Kozyrev, Girłgorn-Keller, S. Beljajev, Okunev etc. sind die Namen literaturhistorischer Eintagsfiegen.

Die Tatsache, daß eine sehr schnelle Automatisierung - und als Konsequenz eine baldige Liquidierung des Paradigmas - trotzdem nicht stattfanden, ist darauf zurückzufüren, daß diese Romane in kleiner Auflage von verschiedenen Verlagen in verschiedenen Städten veröffentlicht wurden, die einzelnen Texte also kurzfristig nur einen relativ kleinen, auch geographisch begrenzten, 
Rezipientenkreis erreichen konnten. Erst nach einigen Jahren hoher Publikationsfrequenz ergab sich eine größere Streuung dieser Romane; ergab sich die Gefahr, daß ein- und derselbe Rezipient mehrfach Texte dieser Gruppe in die Hand bekam, ergab sich die Gefahr der Automatisierung. Und erst nach einigen Jahren bemächtigten sich versierte Autoren des Paradigmas - um es zu liquidieren!

Eine viel relevantere Schwäche des Paradigmas war aber, daß es von den außenpolitischen Realitäten und der erfolgenden MonoPolarisierung der innersowjetischen Ideologie-Diskussion zusehends diskreditiert wurde.

Zum einen war die (teilweise satirisch intendierte) Fehldiagnose des 'Gesundheitszustandes' des kapitalistischen systems zu offenkundig: die Weltrevolution fand nicht statt; im Gegenteil: die europäischen kapitalistischen staaten trifteten nach rechts ab und schufen damit für die Sowjetunion eine $n$ e $u$ Gefahrensituation - die Gefahr faschistisch-imperialistischer Aggressivität, die Gefahr militanten Antikommunismus. Diese neue Situation determiniert das nachfolgende Paradigma, das bei der Darstellung der kapitalistischen Welt neue Negativ-Figuren zur Erzielung einer neuen kommunikativen Funktion einsetzen muß.

Zum andern hatte die innersowjetische Ideologiediskussion zur eindeutigen Dominanz des stalinschen 'Sozialismus in einem Lande' gegenüber der Trockijschen internationalistischen Konzeption der Weltrevolution gefürt: die 'These' der 'Satire der kapitalistischen Endzeit' war also falsifiziert und diskreditiert zugleich. Das Paradigma somit literarisch automatisiert, politischhistorisch falsifiziert, ideologisch diskreditiert zugleich. 


\subsubsection{Modifikations - und überwindungsansätze}

Zentrale kommunikative Schwächen der 'Satire der kapitalistischen Endzeit' um 1925 also: 1) Diskreditierung durch die außenpolitischen Realitäten (Nämlich: a) Keinerlei Anzeichen für einen bevorstehenden Ausbruch der Weltrevolution und b) im Gegenteil: zunehmende Rechts-Entwicklung der europäischen kapitalistischen Staaten und Japans); 2) (In teilweiser Dependenz von 1a-b) Diskreditierung durch die Mono-Polarisierung der einschlägigen innersowjetischen Ideologie-Diskussion um den Stalinschen 'Sozialismus in einem Lande'. Diese beiden Schwächen waren es insbesondere, die 1925 zur ebenso abrupten wie endgültigen Ablösung der zuvor uberaus produktiven 'Satire der kapitalistischen Endzeit' durch die 'Satire der bourgeois-faschistischen Fratze' fühten.

Für die Jahre 1924 und 1925 - also zu dem (für produktionsästhetische überlegungen) Idealzeitpunkt - sind zwei satirische Romane zu registrieren, die relevante Modifikationen am Paradigma der 'Satire der kapitalistischen Endzeit' vornehmen; Modifikationen, die deren kommunikativen Schwächen Rechnung tragen und damit in wesentlichen Aspekten die 'Satire der bourgeois-faschistischen Fratze' vorbereiten. Es handelt sich um V. Kataevs 'Die Insel Erendorf, 36) (1924) und B. Lavrenevs 'Der Untergang der Republik Itl.,37) (1925).

v. Kataevs Roman trägt den Untertitel 'Humoristischer parodistischer Roman'. Der Roman weist drei strategische Ebenen auf:

1) Die parodistische Ebene, die expressis zitierte Klischees des zeitgenössischen Abenteuerromans a la Marietta Šaginjan 38) anvisiert und verlacht. (Diese Ebene kann hier nicht präsentiert werden).

2) Die literaturpolemische Ebene, die sich gegen I. Érenburg richtet. (Diese Ebene kann sinnvoll erst nach der Präsentierung der Erenburgschen satirischen Romane analysiert werden).

3) Die satirische Ebene. Sie soll hier kontrastiv zum Stereotyp der 'Satire der kapitalistischen Endzeit' verdeutlicht werden. 
Im Jahre 1975 errechnet der in den 'Vereinigten Staten von Amerika und Europa' lebende Geologieprofessor Grant, daß in wenigen Tagen eine geologische Katastrophe bevorsteht: mit Ausnahme einer winzigen Insel wird alles Land im Meer versinken. Grant setzt den 'König aller Handelskönige', den alle Macht in den 'Staaten' in Händen haltenden Ober-Boß Matapal' von seiner Entdeckung in Kenntnis, um die Rettung eines möglichst großen Teils der Menschheit in die Wege zu,leiten. Der Ober-Boß jedoch läßt sich von dem Schriftsteller Erendorf (literaturpolemische Ebene) das Modell einer 'idealen kapitalistischen Gesellschaft' entwerfen und etabliert diese Gesellschaft auf der Insel. Eine Gesellschaft ohne Proletariat. In den 'Staaten', bald auch weltweit, ubernimmt das Proletariat unter Führung des amerikanischen Kommunisten Pejč die Macht. Kapitalisten und Proletariat stehen sich zur letzten Schlacht gegenuberi die Proletarier umzingeln mit einer Riesenflotte die 'Insel Erendorf', um die Kapitalisten mit stumpf und stiel auszurotten. Was i h $n$ e n nicht gelingt; denn: die Kapitalisten verfügen uber eine Wunderwaffe - die 'Gegenstrom-StrahlMaschine' - mit der sie jeden Angriff abwehren können. Aber - die Kapitalisten werden von der Natur selbst vernichtet: während der Rest der Erde erhalten bleibt, versinkt ihre Insel in den Fluten. Professor Grant hatte sich verrechnet. (Satirische Ebene).

Der Grund für Grants Irrtum (parodistische Ebene): ein Fabrikationsfehler seiner Rechenmaschine. Ein Vertreter der Rechenmaschinenfabrik verfolgt Grant in waghalsigen Manövern über alle Kontinente hinweg, um ihn auf den Fabrikationsfehler aufmerksam zu machen. Was ihm erst post rem (nach dem Ausbleiben der errechneten Katastrophe) gelingt. Und ebenfalls erst post rem erfährt der Leser, daß dieser Verfolger kein Detektiv, sondern ein Vertreter ist. Ein weiterer von Kontinent zu Kontinent eilender Verfolger ist der Liebhaber von Grants Tochter: Abenteuer-, Detektiv- und Liebesgeschichte sind nach der zu parodierenden Schablone verquickt.

Es versteht sich von selbst, daß diese drei strategischen Ebenen im Text nicht völlig voneinander getrennt sind. Namentlich die satirische Aggression wirkt auf die Literaturpolemik ein: der Schriftsteller Érendorf steht in Diensten des Königs der Bosse Matapal' - die Literaturpolemik erfährt eine erhebliche Verschärfung durch die dargestellte Kollaboration des (Sowjet-)Autors Ėrendorf mit den Vernichtungsobjekten nicht nur d $i$ e $s$ satirischen Romans, sondern auch der satirischen Romane dieses Autors s e 1 b s $t$ !

Die parodistische Ebene einerseits (die zugleich diejenige Ebene ist, auf der humoristische Elemente dominieren: der zerstreute Professor, der außerhalb seines Fachgebietes ein kauziger Tölpel 
ist etc.), die literaturpolemische und die satirische Ebene andererseits weisen hingegen kaum Berührungspunkte auf: Die Abenteuerromanparodie hat ihre völlig separate story (die beiden Verfolger wissen uberhaupt nichts von den die story der satirischen Ebene darstellenden Vorgängen), hat ihre eigenen Figuren, die zu keiner Zeit in Kontakt zu den Figuren der satirischen Ebene treten (Lediglich Grant hat $e i n$ e $n$ Auftritt unter den Bossen; dieser Auftritt leistet die Initialzüdung für die Flucht der Bosse, damit für die story der satirischen Ebene).

Aber - auch diese im Text völlig voneinander getrennten Ebenen wirken $r$ e $z p t i v$ aufeinander ein: stereotyp pamphletistische Kapitel der antikapitalistischen Satire und humoristische Kapitel der Literaturparodie wechseln einander ab. Das von diesen ausgelöste Lachen greift auf jene ïber: das humorlosdüstere Gesamtpathos der stereotypen 'Satire der kapitalistischen Endzeit' stellt sich hier nicht ein!

'Die Insel Érendorf' weist auf der der 'Satire der kapitalistischen Endzeit' korrespondierenden Ebene fast alle Versatzstüke des im vorhergehenden Kapitel herausgearbeiteten Paradigma auf: Figurenbestand, Figurenkonstitution- und Konstellation, story und positive Gegenposition sind wesentlich unverändert. Einige relevante Modifikationen sind aber dennoch nicht zu ubersehen:

1) Figuren-Konstitution: Innovations-Element der Konstitution der Bosse ist deren $A g r e s s i v$ i $a$ $t$ nicht nur der Arbeiterschaft, sondern auch der UdSSR gegenüber. Während die Arbeiter "allgemeine Abrüstung fordern"39), investieren die Bosse Riesensummen in die Entwicklung neuer Waffensysteme; denn sie glauben "daß über ihnen das Damoklesschwert UdSSR hängt" $"$ " )

2) Historische Perspektive: die Handlung ist aus der allernächstej Zukunft 50 Jahre in die Zukunft verlegt (in das Jahr 1975). Eine Fülle geläufiger Details der technizistischen Utopie (Riesenflugzeuge, Hubschrauber, Farbfernsehen, Datenbank, 
Persönlichkeitsveränderung durch Hypnose) unterstreicht, daß der Zeitpunkt der weltrevolutionären Umbruchs in $f$ e $n$ e $z$ u $k$ n $t$ liegt.

Kataev verlacht indirekt die implizite Überzeugung der Autoren der 'Satire der kapitalistischen Endzeit', der Zeitpunkt der Weltrevolution könne gleichsam mit mathematischer Genauigkeit vorausberechnet werden:

Professor Grant berechnet den Zeitpunkt einer weltweiten geologischen Katastrophe - die dann nicht eintritt, weil das Berechnungs-Instrumentarium einen 'geringfügigen' Fehler aufweist (nämlich + und - verwechselt). Anstelle der vorausberechneten geologischen Katastrophe bricht die von niemandem erwartete soziale 'Katastrophe' der sozialistischen Weltrevolution herein; und zwar o b w o h l der Kommunistenführer Pejč sich vorübergehend von Lakaien des Kapitals ausmanövrieren läßt. Die Weltrevolution ereignet sich nicht $z u$ einem vorausberechneten (oder: erwiuschten!), sondern zu dem historisch einzig richtigen Zeitpunkt. Denn - so erfährt Pejč bei einem Besuch in der LdSSR: "Die Führer können Fehler machen, aber es gibt keine Fehler im Ablaur des historischen Prozesses" 41 ).

1925 publizierte B. Lavrenev seinen ersten Roman: 'Der Zusammenbruch der Republik It1,42). Auch dieser satirische Roman entspricht unter den Aspekten 'Figurenbestand', 'Figurenkonstitution- und Konstellation' sowie 'positive Gegenposition' wesentlich dem Stereotyp der 'Satire der kapitalistischen Endzeit'.

Aber: wie schon V. Kataevs 'Die Insel Érendorf' nimmt auch dieser satirische Roman zwei relevante Modifikationen der paradigmatischen Verhältnisse der 'Satire der Kapitalistischen Endzeit' vor. Beide Modifikationen betreffen den Aspekt 'historische Perspektive'.

Der Roman schildert das Scheitern eines Expeditionskorps in der in südlichen Breiten gelegenen und in unmittelbar vorrevolutionärem Zustand befindlichen Republik Itl', auf die von Norden her revolutionäre Truppen im Anmarsch sind: Zwar wird mit Hilfe der von der Seemacht Nautilien entsandten Interventionstruppen die 
von einer korrupten republikanischen Regierung kurz zuvor abgelöste Monarchie restauriert, und ein debiler Adelssprößling als Marionettenkönig eingesetzt; wenig später jedoch erhebt sich das Proletariat Itl's unter Führung einer kommunistischen Jeanne d'Arc, stürzt den Monarchen und verjagt gemeinsam mit den inzwischen eingetroffenen roten Einheiten die 'Schutz-Truppen', deren eigentlicher Auftrag nicht die Rettung der 'vom Sozialismus bedrohten Demokratie', vielmehr die Eingliederung des durch seine Erdölvorkommen attraktiven Itl' in das Kolionalreich Nautiliens war.

Die Charakterisierung der Interventen (sie tragen englische Namen, kommen aus dem über die stärksten Seestreitkräfte der Erde verfügenden Königreich Nautilien etc.), die Bestimmung der geographischen Lage, der machtgeographischen und innenpolitischen Situation Itl's drängen es auf, den Roman zu beziehen auf konkrete militärpolitische Vorkommnisse der (von 1925 aus gesehen) jüngsten Vergangenheit: die während des Bürgerkriegs für kurze Zeit erfolgte Etablierung der 'Demokratischen Republik Krim' mit Hilfe britischer Interventionstruppen und ihre Auflösung durch die Rote Armee: "Im wesentlichen entstammt das Material des Romans der Epoche des Bürgerkriegs. Reales Vorbild dessen, wovon im 'Zusammenbruch ...' erwählt wird, ist die Geschichte der 'Demokratischen Republik Krim'" 43).

Der zeitgenössische Leser hat - soweit festgestellte Rezensionen diesen Schluß erlauben - die Möglichkeit nicht gesehen, die militärische Intervention Nautiliens zu g e $n$ e $r i s$ e $r$ e $n$ zu einem generellen Merkmal $k$ a $i t a l i s t i s c h-i m-$ $p e r i a l i s t i s c h$ e $r$ Außenpolitik! GeneralisierungsAnsätze führen über die Herstellung des $r$ e $r$ e $s i v$ e Bezuges zu den imperialistischen Komponenten des zurückliegenden 'Bürgerkriegs überhaupt' nicht hinaus: "Die Pseudonyme des Lavrenevschen Romans lassen sich leicht dechiffrieren'. Die fröhliche Seemacht Nautilien' ist England, das Land der Revolution Assor ist Rußland, die Republik Itl' selbst, die am Südmeer gelegen ist und über reiche Erdölvorkommen verfügt, findet ihr reales Vorbild unschwer im Kaukasus" 44 ).

(Für den heutigen Leser wïrde sich aufgrund des veränderten historischen Erfahrungshorizonts eine wesentlich höhere Generali- 
sierbarkeit ergeben, wenn der Roman nicht längst - wie fast alle Roman-Satiren des 'Außen-Bereichs' - infolge seiner durftigen ästhetischen Qualitäten die Lesbarkeit verloren hätte!)

Verglichen mit der stereotypen 'Satire der kapitalistischen Endzeit' leistet 'Der Zusammenbruch ...' zwar eine $h$ i $t$ o $r$ $s$ c $h$ e $k$ o $k r$ e $i s i$ e $r$ n g (vom 'Kapitalisnus uberhaupt' zum 'imperialistischen Spät-Kapitalismus'), büßt aber zugleich Generalisierbarkeit und (da die konkretisierten historischen Verhältnisse eindeutig der Vergangenheit angehören) Aktualität ein. Aus der antikapitalistischen Thesen-Satire wird eine 'Satire' auf den bereits besiegten, keine Gefahr mehr darstellenden militärischen Gegner (wohlgemerkt: keine vom Text selbst thematisierte Gefahr!). Der 'Zusammenbruch ...' ist eine 'Satire' ohne Aggressivität: eine Pseudo-Satire!

Dennoch antizipieren auch die von Lavrenevs Roman vorgenommenen Modifikationen des Paradigmas der 'Satire der kapitalistischen Endzeit' konstitutive Merkmale des Nachfolge-Paradigmas der 'Satire der bourgeois-faschistischen Fratze': 1) Historische Konkretisierung der sozialen und politischen Situation; 2) Aufzeigen des imperialiatischen Charakters kapitalistischer Außenpolitik - Aufzeigen somit einer von der 'Satire der kapitalistischen Endzeit' nicht gesehenen Bedrohung (auch) des ersten 'Arbeiter- und Bauernstaates'. 


\subsection{Die 'Satire der bourgeois-faschistischen Fratze'}

1925 erschienen die letzten Texte der vier Jahre lang sehr produktiven 'Satire der kapitalistischen Endzeit', die Agonie und Tod des kapitalistischen systems darstellt. Die Gründe für das nahezu ubergangslose Verschwinden dieses Paradigmas rurden oben expliziert.

Ebenfalls 1925 werden die ersten Exemplare der 'Satire der bourgeois-faschistischen Fratze' publiziert, des wohl produktivsten 45 Paradigmas des sowjetischen satirischen Romans uberhaupt. Die Darstellungs- und Angriffsobjekte auch dieser Textgruppe liegen im 'Außen-Bereich': im Bereich der zeitgenössischen europäischen kapitalistischen Staaten, ganz vereinzelt der USA.

Diese Satiren stellen nicht mehr das - thesenadäquate - Sterben des Kapitalismus dar, vielmehr - in viel intensiverem und realistischerem Zugang - das 'Leben' des Kapitalismus und seiner Opfer ein 'Leben', das keine kurzfristigen überwindungsmöglichkeiten mehr eröffnet, das von weitgehend statischer Häßlichkeit - und Gefährlichkeit! - ist.

Figurenbestand, vor allem aber Figurenkonstitution, positive Gegenposition, historische Perspektive, kommunikative funktion müssen also z.T. erhebliche Veränderungen gegenüber dem Paradigma der 'Satire der kapitalistischen Endzeit' aufweisen.

Die Beschreibung des zweiten Paradigmas erfolgt in strenger Einhaltung des vorgeschlagenen Beschreibungsmodells, wird aber breiter dokumentiert. Zum einen soll auch in der Dokumentation der generell größere Umfang der Texte berücksichtigt werden. Zum andern scheint dies aus traditionell-philologischen Gründen geboten der Verfasser dieser Arbeit hatte an der Bibliothek der Akademie der Wissenschaften der Ukrainischen SSR Zugang zu vielen Texten dieser Textgruppe, die außerhalb der Sowjetunion unerreichbar, in der Sowjetunion äußerst defizit sind. Dem Raritätswert dieser Texte soll also durch relativ intensive Dokumentation Rechnung getragen werden. 
Die 'Satire der bourgeois-faschistischen Fratze' erweitert den $F$ i $g$ u $r$ b e $s$ a $n$ d des vorhergehenden Paradigmas erheblich; Zu den bereits vertrauten Negativ-Figuren - Fabrikbesitzer, Börsenhai, Politiker, Journalist, Militär, Detektiv - die durchgehend übernommen werden, treten neue Figurengruppen hinzu: Klerus, Adel; Künstler, Wissenschaftler, 'Lakaien'. Vor allem aber auch: Faschisten, russische Emigranten.

Schon der Figurenbestand macht deutlich: die satirische Perspektive erfaßt nicht mehr nur ganz pauschal die personalen ökonomischen und politischen Indikatoren des Kapitalismus uberhaupt, vielmehr darüber hinaus auch die die spezifische ökonomische, politische und ideologische Situation Mitteleuropas um 1925 markierenden Neu-Erscheinungen: 'Multis', Faschismus, Antikommunismus, Antibolschewismus.

Zentrale Negativfigur bleibt der 'Boß', der sich in den meisten Fällen aber vom Fabrikbesitzer zum Gebieter uber nationale und multinationale Konzerne gemausert hat: auch diese Modifikation dokumentiert den konkretisierten Zugang zu den spezifischen Merkmalen des Spätkapitalismus.

Die $K$ on $s t i t u t i o n$ der negativen Figuren wird deshalb auch fur das zweite Paradigma vorwiegend an dieser Figur herausgearbeitet. Der Boß der 'Satire der kapitalistischen Endzeit' hatte zwei zentrale Dimensionen: die nicht dargestellte, vielmehr als evident vorausgesetzte Dimension seines sozialen Wesens und die ihm total korrespondierende, breit angelegte Dimension seines physischen Erscheinungsbildes; häufig trat ergänzend die Dimension einer angedeuteten Bewußtheit - das Decouvrierungs-Element der Angst - hinzu.

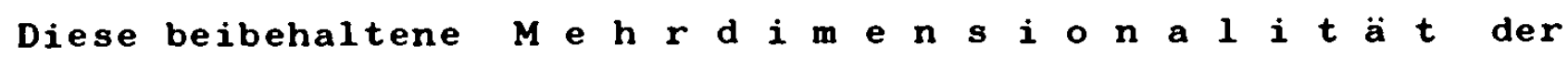
Figurenkonstitution wird quantitativ durch Aufstocken zusätzlicher Dimensionen ausgebaut, qualitativ durch die Intensivierung der Darstellung einzelner Dimensionen vertieft. 
Unverändert bleibt das physische Erscheinungsbild: der Boß als zigarrenrauchende, zeitungslesende, schwitzende, glatzköpfige Anhäufung von Fettwiilsten: "Karierte in Zeitungen vertiefte Amerikaner demonstrierten den Umfang ihrer Bäuche und pafften protzige Zigarren" 46 ).

Erhalten hat sich auch das Element der Angst; nur: diese Angst ist nicht mehr defensiv, sie ist innen- und außenpolitisch aggressiv geworden.

Neue Dimensionen treten hinzu: der BOß hat ein breit dargestelltes 'Privat'Leben; der Boß wird außenpolitisch relevant - er ist Ziehvater und sponsor aller faschistischen und antibolschewistischen Kräfte.

Wichtigste Modifikation der Figurenkonstitution ist aber, daß die Negativ-Merkmale von sozialem Sein und politischem verhalten nich mehr nur angedeutet oder wesentlich zu erschließen sind aus der bereits erfolgten Reaktion des Proletariats auf sie - daß soziales Sein (bourgeoises Leben) und politisches Verhalten vielmehr eingehend direkt dargestellt werden.

Die breite Darstellung sozialer und politischer Negativität hebt das im ersten Paradigma drückende übergewicht des Porträts 47 ) auf: obwohl die Versatzstücke des Porträts unverändert übernommen werden, obwohl sich allenfalls der Umfang der Porträts leicht reduziert, wird das Porträt hier vom zentralen Typisierungselement zum ein- und untergeordneten Element.

Bourgeoises Leben - Überfluß, Unsittlichkeit, Dekadenz:

"Märkte, uberquellend vor Fleisch, Früchten, toten Fischen; Geschäfte, vollgestopft mit Fetzen aller Farben (...). Fresserei, Protzerei, widerliche Sattheit bis zum Aufstoßen - sie keuchen in jeder Ecke. Zweibeiner fressen Fleischberge, trinken, umarmen halbnackte Straßenmädchen, die sich an jeder Kreuzung, in Hotels, auf einer Bank und, wenn es dem Monsieur nights ausmacht, auch gleich unter dem nächsten Baum feilbieten ..."

"Das sich erschöpfende Europa dürstete nach Ruhe. Noch waren die Leichen in der blutgetränkten Erde nicht verfault, da drehten sie sich in Paris schon zu einer tierischen Musik aus Geheul, Pfeifen, berauschten sie sich an Foxtrotts. Nur sich vergessen, sich nur nicht erinnern! ... Das cabaret 'Artistik' ist in vielfarbiges feuer getaucht (...). 
Auf der Estrade eine Frau in Lumpen.

Die zynischen Worte eines Liedes (...)

Zwischen den Stühlen, die Sitzenden anrempelnd, strömten Paare mit leidenschaftslosen, toten Gesichtern dahin (...).

Besonders entsetzlich und widerlich war einer von ihnen mit kleb-

rigen Haaren, die ihm ins Gesicht fielen.

"Peers, Lords, Bankiers; der Appetit dieser Mikroben ist ungeheuerlich"50).

Diese Dekadenz ist sowohl Produkt bourgeoisen Mußiggangs als auch Folge bourgeoiser A $\mathrm{n} s \mathrm{t}$; es ist die Dekadenz des Vergessenwollens: denn die Bosse wissen, daß "sie es nur den nackten, zitternden, von Peitschenhieben zerschlagenen Körpern zu verdanken haben, daß sie noch (...) geifernd schlummern können"51). Und sie wissen auch, daß das Proletariat die Revolution will: "Das Gift sammelt sich in jedem staatlichen Organismus an, wenn man der Revolut ... nicht beizeiten eine Spritze verpaßt ..."52).

Die Angst vor der Revolution würgt den Bourgeois:

"Wogen trüben, wiitenden Kummers, Wogen von Tränen umspülen die Stufen der Paläste der Geldsäcke. Bald werden sie bis an die Fenster heranbranden und werden ihre Betten mit scharlachrotem Feuer ubergießen, ihre Betten, in denen sie in siecher Schwäche versuchen, sich gleichsam in Mollusken zu verwandeln. Aber nogh) scherzen sie, noch verzerrt Lächeln ihr Gesicht zur Grimasse" 3 ).

Aber, wie gesagt - im Gegensatz zum ersten Paradigma ist diese Angst nicht mehr nur die den Boß decouvrierende, d.h. ihn als verletzbar, überwindbar - lächerlich - entlarvende Achillesferse; sie ist Folge seines Ausbeuterstatus $u$ d Impuls der Brutalität, mit der er seinen status zu erhalten und auszubauen sucht, ist Impuls seiner faschistischen, imperialistischen, antibolschewistischen Aggressivität.

Wie in der 'Satire der kapitalistischen Endzeit' fehlt auch hier eine Darstellung des Verhaltens der Bosse am 'Arbeits'-Platz, in den Betrieben: Zum einen wird es als im Erfahrungshorizont des Rezipienten verankert und somit evident vorausgesetzt. Zum andern - dies als Vorgriff - sind zentrale kommunikative Objekte der 'Satire der bourgeois-faschistischen Fratze' (nicht die 
Entlarvung der generellen $N$ e $g$ a $i v i t$ ä $t$ des Spätkapitalismus sondern): Destruierung des Mythos vom 'besseren Leben' unter dem Kapitalismus; Bewußtmachung der direkten politischen Bedrohung der Sowjetunion durch die kapitalistischen staaten (s.u.).

Die Grundtendenz seines $s$ o $i$ a $l$ e $r$ a $l$ t e n $s$ - brutale Ausbeutung - erhellt auch hier indirekt aus der bereits erfolgten Reaktion des Proletariats, aus der bereits eingetretenen Situation des verschärften Klassenkampfes. Sie erhellt außerdem - und diese Möglichkeit nutzt nur das zweite Paradigma - aus dem breit dargestellten Kontrast zwischen bourgeoiser überfülle, übersättigung einerseits, proletarischer Verelendung und Häßlichkeit andererseits.

Auch der Motor dieser Ausbeutungsbrutalität - hemmungsos-automatenhafte Bereicherungsgier - ist nur indirekt präsent: der Boß sieht die Welt als Markt und pfropft ihr sein Natursurrogat auf - die kapitalistische stadtlandschaft ist eine Reklamelandschaft. Alles, auch das den BOß intrigierende (sogar der Sozialismus) ist objekt der Vermarktung (Dummheit: automatenhafte Autoliquidation).

Dagegen werden die dieses Sozialverhalten allein ermöglichenden Merkmale des $p \circ 1$ i $i s c h$ e $v$ e $h$ a $l t$ e $n$ detailliert unter die satirische Lupe genommen; und zwar sowohl die generellen Merkmale als auch die für den aktuellen Zustand der kapitalistischen staten spezifischen, die insbesondere von außenpolitischer Relevanz sind (militanter Antikommunismus etc.). Oberste Maxime bourgeoiser Politik: alle politisch und ideologisch relevanten Faktoren haben eine dienende, stützende Funktion für Stabilisierung und Ausbau der Diktatur des Kapitals zu ubernehmen. Nur das Proletariat und seine politischen Exponenten - die Sozialisten - verweigern sich dieser mit dem Zuckerbrot erzielten Prostitution - und bekommen die Peitsche mit aller B $r u t$ a $l$ i $t \ddot{a} t$ zu spüren: 
"in den schmalen Straßen, wo Schmutz und Armut sich vermengen, dabei ihren besonderen scharfen Geruch bildend, entluden Menschen in blauen Uniformen ihre 'Winchesters' - eip\&) nach der andern - in die aufzuckenden Körper der Arbeiter" ${ }^{4}$ ).

"Die Arbeiter des Eclair-Werkes streikten. Das Streikkomitee wurde vollzählig verhaftet. Die Verschwörer wurden miț Familienangehörigen und Kindern in ein Gefängnis uberstellt" 55 .

"man 56 grsuchte Menschen dafür zu erschießen, daß sie essen wollten" 56 ).

Diese Brutalität wird mit dem fadenscheinigen Mäntelchen der Legalität bedeckt: die Bosse lassen in den Wohnungen der Sozialisten Bomben 'finden' etc....

Alle politischen und ideologischen Schlusselfunktionen sind besetzt mit gleichgeschlateten Marionetten, Handlangern - Prostituierten - der Bosse.

Der Premierminister: "Frankreich ist eine Republik (...). In einem der vergoldeten Kabinette der Tuilerien wird er (der Leser j.e.) einen runden Bourgeois im Frack vorfinden.

Treten Sie mutig näher. Das ist der Premier.
Der wievielte? Wie gelangte er hierher? Das ist ohne Bedeutung "57).

Der König: "er leistete einen Eid vor dem englischen Gott, daß er ein anständiges Leben führen, alle Zeit dem Wohle des Vaterlandes widmen werde - das heißt er versprach, in 5 ger Westminster Abbey zu stehen, Golf zu spielen und zu reiten"

Die Kirche: "Während er den Premier segnet, bittet der Prälat zärtlich um Geld. Um eine Subsidie zur Unterstützung der heiligen katholischen Kirche im Kampr mit dem Antichristen.

Man muß es ihm geben, beschließt der Premier, die Kirchg)unterstützt ihn. Kapital und Kirche sind Brüder in Christo" 59$)$.

Gegenleistung des Klerus: Pater eilen hinter der (vor der Polizei fliehenden j.e.) Menge her, sich in ihren langschössigen Röcken verheddernd, und versuchen, ohne stehen zu bleiben, zu segnen und zu retten. Bischöfe begeisterten digogemeinde mit den heiligen Gaben und anderen Produktionsmitteln"60).

Die Wissenschaft: "Sie (die Zuhörer j.e.) lockten die Namen von Gelehrten an, die für sie neue Theorien schufen, die sie verteidigten gegen die Entartungserscheipyggen und Krankheiten des Jahrhunderts (= Sozialismus j.e.)"

"Sie konstruierten gigantische Waffen. Tausende glatzköpfiger Chemiker krümmten ihr ${ }_{2}$ pücken über Gas-Formeln (zur Vernichtung der Sozialisten j.e.)" 62 ".

Die Kunst: der Künstler steht vor der Alternative, sich zu prostituieren oder zu verstummen. "Wie sollen Schriftsteller in der modernen Gesellschaft normal sein können, die von ihngq) moralische und politisch vertrauenswüdige Romane verlangt" $"$ ". 
Eine Weigerung der Kunst, sich dem Postulat der Subordination unter die herrschende Ideologie zu unterwerfen, hat zur folge, "daß es in unseren Tagen eine große Kugpt ist, sich mit der Kunst zu befassen und davon zu leben"

Die Presse: s.o. unter dem ersten Paradigma (unverändert übernommen).

Soweit die dargestellten generellen Merkmale bourgeoiser InnenPolitik. Darüber hinaus zentrieren alle Texte der 'Satire der bourgeois-faschistischen Fratze' ideologische und politische Faktoren, die das erste Paradigma nicht kannte. Es sind diejenigen Faktoren, die gemeinsam das spezifische politische Bild der europäischen kapitalistischen Staaten um 1925 bestimmen; insbesondere $s i$ sind außenpolitisch relevant - und relevant daher auch für die Ermittlung der kommunikativen Funktion des zweiten Paradigmas: Faschismus, Imperialismus, Antibolschewismus.

Faschisten und russische Emigranten sind die neuesten, ansteckend. sten - und gefährlichsten Prostituierten im Riesenbordell der Bosse: dem kapitalistischen staat. $S$ i e stellen die relevanteste Erweiterung des Figurenbestandes des ersten Paradigmas dar. Die $F$ a $s h i s t$ e $n$ als internationale Erscheinung: in Italien haben sie bereits die Macht ubernommen; in Polen, Deutschland, Belgien, Frankreich integrieren sie sich als Schlägerbanden in die innenpolitischen Auseinandersetzungen. "in der letzten Zeit hat man begonnen, schwarze Blusen zu nähen, und die Knöpfe auf ihnen sehen so aus ... und mit zwei Fingern zeigte der Warschauer Schneider:

\section{5}

Und was erstaunlich ist, Pan, ist die Tatsache, daß, kaum hat einer eine solche Bluse angezogen, dann 6 fängt er auch schon an, sich mit der Arbeiterklasse zu prügeln"65).

"In einer Ecke der rue Richeligy versammelt sich eine Menge
faschistischer Manifestanten"

Die sozialistische Demonstration wird zusammengeschossen; nicht so die faschistische. Denn:

"ein entsetzliches Ereignis. Sechs unserer Agenten waren außerstande, mit dem Komsomolzen Zan Petiło fertig zu werden (...) wir wären mit ihm zu Rande gekommen, wenn uns nicht etwas Wichtigeres beschäftigt hätte ... Befehlsgemäß versuchten wir, einen 
kommunistischen Aufstand zu provozieren. Ungeachtet der Hilfe der Faschisten, der prächtigen monarchistischen Kerls, $67 \rho^{t}$ es uns nicht gelungen, die Arbeiterkolonne zu zerstreuen"67).

Der Faschist als unmittelbarer Handlanger antikommunistischer - d.h. kapitalistischer - Interessen ist also nicht nur vage negativ; er gefährdet unmittelbar die nationale und internationale sozialistische Bewegung: gemeinsam mit den übrigen Parteigängern der Bosse unterdruickt er - erfolgreich! - die Sozialisten. Seine Konstitution verzichtet auf komische Elemente: er ist negativ und gefährlich und mächtig!

Dagegen ist der $r u s s i s c h e E m$ g $r$ a $n t$ durchaus komisch konstituiert: in einem Pariser Luxushotel wird ein "Menschewik im Exil"68) bei "seiner Hoheit dem russischen Imperator"69) vorstellig:

"Im Salon des 'Herrschers' war es stickig und ruhig. Generäle mit Orden und andere, die erlesene und altmodische Zivilkleider trugen, ja sogar verschiedene alte Bittstellerinnen 'vornehmelten' unglaublich.

Nach dem Verlust des Bodens unter den Füßen wurden sie jetzt (..) noch um ein Mehrfaches 'durchlauchter' und 'allergnädigster'. Im Salon war es - ungeachtet der Menge Anwesender - still. Kein Stimmengewirr; man vernahm irgendein ehrbares Geräusch, das dem Summen von Bienen und dem Geraschel von Küchenschaben an einer warmen Stelle hinter dem ofen ähnelte.

- Eure Ex..llenz..

- Seine Ex...x...nz...

"Meine Herren, schreit ein Greis: - aus Rußland reiste ein ehrbarer Mensch an, ein berümter russischer Schneider, der die ganze Zeit für die Gewalttäter im Kreml gearbeitet hat. Die militärisehen Absichten der Bolschewiken wurden ihm zuwider, zuwider der Spott über die rechtgläubige russische Kirche. Meine Herren, Repräsentanten aller Völker, zeigt und beweist, daß in Euch das Streben nicht schlummert, die Untiere, die sich in Moskau festgesetzt haben, zu zerdrücken (...). Ein Ende kommt für die Scheusale und Blutsauger, bald sollen sie alle an den Pfählen baumeln ... Bald wird sich das Kreuz über dem Kreml erheben, und den Hunden wird man die Knochen zum Abnageg, hinwerfen, die zu bestatten sich kein Mensch entschließen wird"71\%.

Komisch ist seine von Wunschdenken geborene völlige Fehlbeurteilung der innenpolitischen Situation der Sowjetunion, komisch sein klischeeklirrendes Vokabular.

Nicht komisch ist dagegen sein $H$ a $B$ auf die Bolschewiken, denn 
dieser HaB korrespondiert der antibolschewistischen Aggressivität der Bosse, stüzt deren antikommunistische Ideologie: Bosse, Faschisten, Emigranten formieren eine Phalanx der Aggressivität. Und diese Aggressivität manifestiert sich nicht nur im Klassenkampf, sie schlägt auch bereits außenpolitisch, militärisch-imperialistisch durch: Waffenhändler überschwemmen - als Vertreter der 'Schreibmaschinenfabrik' "Parabellum", der 'staubsaugerfabrik. "Mauser" etc. getarnt - die Balkanstaaten und inszenieren in dem leicht mit Rumänien zu identifizierenden 'Eritreja' einen Kleinkrieg (die Rechte an der Verfilmung der bevorstehenden Schlacht sind bereits an Amerikaner verkauft - ja, der Schlachtverlauf selbst ist vertraglich drehbuchgemäß festgelegt), dessen primäre politische Zielsetzung die Vernichtung überschüssigen Proletariats ist:

"Eine völlig vernüftige Anwendung des Artilleriefeuers. Beide Seiten beschießen das Arbeiterviertel. Wer auch immer siegen mag (...), in jedem Fall wird das Arbeiterviertel bis auf die Fundamente verschwunden sein. Das ist eine vernüftigg, völlig staatsmännische MaBnahme, mit Blick auf die Zukunft"72).

Sekundäre politische Zielsetzung: Vorbereitung des Vormarsches nach osten. Und dieser Vormarsch hat bereits eingesetzt: auf die Meldung hin, der 'Antichrist' habe sich in Deutschland festgesetzt, rücken französische Truppen in Deutschland ein ...73).

Die Konstruktion der Negativposition erfolgt prioritär d a rs $t$ e $l$ e n d. Obige Angaben zur Figurenkonstitution haben aber deutlich gemacht, daß b e $n$ e $n$ e $n$ d e Elemente hinzutreten - wenn auch, im Rahmen der Negativ-Position, in sehr bescheidenem Umfang (wie im ersten Paradigma): der Bourgeois wird direkt als "Geldsack" ("bogac") 74), der Bankier indirekt als 'Dieb' (Bankhaus: "Vorr i synov'ja") 75) etikettiert.

Die Merkmale der Negativität und Gefährlichkeit (Brutalität, Aggressivität, Verlogenheit etc.) indes werden wesentlich dargestellt, nicht benannt; eine der wichtigsten generellen satirischen Strukturen - die Indirektheit der Erstellung von Negativität - ist also auch hier zu beobachten: Satire sagt nicht 'der Boß ist brutal und dumm', Satire demonstriert ihn als brutal und dumm 
Wie für das erste gilt auch für das zweite Paradigma: die Figurenkonstitution ist nicht auf $D$ e $o u v r$ e $r$ u $g$ angelegt - die Negativfiguren sind offenkundig negativ, gefährlich und mächtig. Keine Inkongruenz von Wesen und Erscheinung, keine Inkongruenz von Machtanspruch und faktischer Macht; keine Inkongruenz aber auch von Selbstverständnis und (nahfristigem) dargestelltem (!) historischem Stellenwert - der Boß sitzt fest und mächtig im Sattel, die Möglichkeit einer (Auto-)liquidation in absehbarer Zeit wird in den meisten 'Satiren der bourgeois-faschistischen Fratze' noch nicht einmal angedeutet: und darin unterscheidet sich das zweite Paradigma radikal vom vorhergehenden! Zwei decouvrierende Elemente ubernimmt das zweite Paradigma zwar aus dem ersten: der Boß ist verängstigt, der Boß ist dumm. D.h.: der Boß wird als brutal, gierig, gefährlich etc. dargestellt, als verängstigt und dumm decouvriert. Aber: Im Gegensatz zum ersten Paradigma signalisieren Angst und Dummeit hier nicht das nahe Bevorstehen des Endes des Kapitalismus - sie haben seine Brutalisierung zur Folge.

In der $D$ a $r$ t $l l u n g$ des Textes ist die zentrale Negativfigur der 'Satire der bourgeois-faschistischen Fratze' also $k$ e $i$ e $k \circ m i s$ c $h \quad F$ i $g$ u. Eine Komik der Inkongruenz von Selbstrerständnis und 'objektivem' historischem Stellenwert - für Ja. El'sberg ${ }^{76}$ ) d a s Kriterium zur Begrüdung der 'Objektivität' des Komischen - ist nur dann ansetzbar, wenn der intratextuellen Figur ein extratextueller Geschichtsbegriff opponiert wird: der konkreten literarischen Figur also eine Geschichte opponiert wird, die in nicht präzisierbarer Zeit einmal zum Sozialismus führen wird. Diesem Komikverständnis zufolge - von dem sich auch Ju. Borev77) nicht eindeutig distanziert ist jede negative Figur cine komische Figur, da jede noch so negative Erscheinung mit Sicherheit von d e $r$ Geschichte überrollt wird, in der sie eventuell furchtbare Auswirkungen hatte (Konsequent ist folglich auch Hitler für $\dot{E}_{1}$ 'sberg eine 'objektiv komische Erscheinung'). 
Die Entscheidung 'komisch' - 'nicht komisch' muB sich orientieren an Kriterien der intentionalen Textkonstitution: das Komische muß als ästhetische Kategorie präzisiert werden.

Die übertragung schließlich des 'Ästhetischen' aus der Kunst in das 'Leben uberhaupt' - wie sie Borev unterläuft - schafft nur totale Begriffskonfusion und dokumentiert Borevs Unvermögen, sich eindeutig von mechanistischen und gänzlich undialektischen Widerspiegelungskonzeptionen zu lösen.

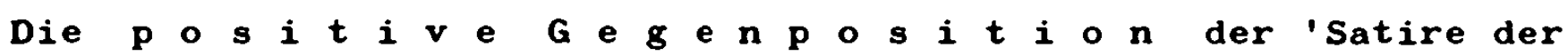
bourgeois-faschistischen Fratze' ibernimmt die figuralen und argumentativen versatzstucke des ersten Paradigmas: Proletariat, Sozialist; Sozialismus. Übernimmt sie - und formt sie in Ausrichtung auf eine stark modifizierte kommunikative Funktion, die der veränderten außen- und innenpolitischen Szene (respektive ihrer ideologischen Umbewertung) Rechnung trägt, um. Diese Umformung erfolgt sowohl durch eine Verlagerung des Schwerpunktes der positiven (s.u.) Gegenposition von der figuralen loder aktionalen: Revolution etc.) Darstellung zur Argumentation, als auch durch eine völlig a n d e r e Darstellung der 'gleichen' figuralen Versatzstücke. Diese Umformung erfolgt so radikal, daß ihr Resultat d e n zentralen Unterschied zwischen dem ersten und dem zweiten Paradigma konstituiert.

Versatzstücke der positiven Gegenposition der 'Satire der kapitalistischen Endzeit' waren: figural - das V o l k als impliziter Fond seiner Exponenten: $\operatorname{der} K \circ m m u n i s t e n$; $\operatorname{lorgu-}$ mentativ - die ausformulierte $T h e s$ e von der Unausbleiblichkeit und dem nahen Bevorstehen der siegreichen proletarischen Weltrevolution.

Die $f$ i u $r$ a $l$ e positive Gegenposition auch des zweiten Paradigmas ist streng kontrastiv zur Negativposition angelegt. Die zentralen tertia comparationis: 1) Lebensbedingungen, 2) Politisches Verhalten, 3) Politischer Erfolg.

ad 1): Das Leben des Individuums Bos: Überfüle, Pracht und Dekadenz. Das Leben der Masse Proletariat: Vegetieren auf dem als 
Almosen und nur zur Erhaltung der Arbeitskraft gewährten Existenzminimum, Häßlichkeit - und die Entschlossenheit zur Revolution:

"Hier sehen wir die Untertanen des Königs von GroBbritannien, die sich kaum von Leichnamen unterscheiden. Die Regierung ernährt sie mit Graupen (...). Hier kommen die Menschen zur Welt, leben und sterben, ohne etwas zu kennen außer den von Finsternis erfülten Straßen, durgh) die sie, Schatten gleich, auf der Suche nach Almosen huschen"78).

"Und in den Kellern? Schatten. Gesichter, (wie j.e.) herausgefallen aus den Rahmen von Bildern des schrecklichen Goya. Kranke, rauhe Gesichter mit finsterem Schmerz in den tiefen, ausgetrockneten Augenhöhlen.

Arbeiter.

Auf dem schmutzigen Tisch liegen drei Franken - um sie herum die ganze Familie. Die Versammelten stellen sich vor, was man für drei Franken essen könnte, wenn drei Franken für alle reichen würden. Der Antichrist!

Sie rühren sich nicht. Hier fürchtet man sich nicht. Man wartet. Wer flüsterte da? Der ältere Bruder dem jüngeren oder der Vater? - Wäre es nicht besser zu warten, diese drei Franken geben zehn Kugeln, Genossen, zehn saftige Schüsse auf die Beletagen. Und die unhörbare ab55) deutliche Antwort:

- Warten!!!"79).

Fazit: der Boß lebt dem Bauch, das Proletariat der Revolution. Der Boß lebt in aggressiver Angst vor dem 'Antichristen', das Volk lebt in Erwartung des 'Antichristen', des Sozialismus.

ad 2): Und diese Hoffnung ist nicht nur eine Hoffnung des Wortes, sie ist auch eine Hoffnung der politischen Tat - das Proletariat demonstriert, agitiert, streikt, greift zu den Waffen:

"In den Arbeitervierteln Londons flackerten Streiks auf. (...). Der Handel fiel, die Industrie erstarb, die Fabriken wurden geschlossen; Hygjerttausende von Arbeitern überschwemmten die Hauptstädte"

- ebenso in Paris, Berlin ...

Fazit: der Boß betreibt eine Politik der Unterdruckung, das Proletariat eine Politik der Selbst-Befreiung.

ad 3): Das eindeutige politische Ziel: "eine Revolut...machen"81) Nur: wie das Wort, so die Tat - es kommt allenfalls zur

'Revolut...', nicht aber zur 'Revolution'. Die Allgegenwart der Bosse ist so absolut, daß das Wort im Halse, ihre Allmacht und Überlegenheit so total, daß die Revolution in den Anfängen stek- 
ken bleibt. Alle in der 'Satire der bourgeois-faschistischen Fratze' dargestellten Aufstände sind zusamengeprügelte, zusammen geschossene Aufstände. Siegt in der 'Satire der kapitalistischen Endzeit' grundsätzlich die Revolution, so trägt im zweiten Paradigma immer das Kapital den Sieg davon - wenn es überhaupt zum offenen Ausbruch des Klassenkampfes kommt: zahlreiche Texte der 'Satire der bourgeois-faschistischen Fratze' beschränken sich auf die Darstellung der 'Fratze' des Kapitalismus und bauen die positive Gegenposition nur argumentativ ein!

Fazit: die Politik der Bosse ist jetzt (noch) erfolgreich, die Politik des Proletariats scheitert (noch) an der drückenden übermacht des Gegners!

Das Proletariat scheitert nicht nur an der drückenden machtpolitischen überlegenheit der Bosse; es ist zusätzlich gehandicapt durch die Faszinationskraft, die die Bosse auf Teile der Arbeiterschaft ausüben: nur das zweite Paradigma kennt vereinzel.t (z.B. Ivanov s.u.) den Typ des 'Lakaien', der seinen 'privaten' Boß - nicht die Bosse als Repräsentanten eines sozialen Systems liquidieren möchte - um selbst ein BOß zu werden!

Die Kollektivfigur Proletariat besetzt in diesem Paradigma also nur mit Einschränkungen eine figurale positive Gegenposition es lebt in derart absoluter Unterdrückung, Häßlichkeit und oft auch Verdummung (der 'Lakai'), daß es indirekt Teil der Negativposition wird: es dokumentiert die brutale übermacht der Bosse $u n$ die Verunstaltung des Menschen durch den Kapitalismus. Aber: $E$ m $p$ ö $n g$ über den Kapitalismus und $H$ of $f$ $n$ u $n$ auf den Sozialismus weisen das proletariat aus als eindeutige positive Gegenposition - der Zukunft.

Sprachrohr der a $r$ g m e $n$ a $t i v$ e positiven Gegenposition ist auch im zweiten Paradigma der zumeist nur noch episodisch in Erscheinung tretende Kommunist (das zweite Paradigma weist im Gegensatz zum ersten keine zentrale Kommunistenfigur auf, vielmehr in der Regel mehrere nur ein einziges Mal erscheinende Kommunisten als Randfiguren und Sprecher). Die Ar- 
gumente des Kommunisten bleiben dieselben: er vertritt die Überzeugung von der Notwendigkeit und die These von der Unausbleiblichkeit der Revolution.

Aber: der (scheinbare!) Widerspruch zwischen These und aktueller sozio-ökonomischer und politischer Situation falsifiziert diese These naturlich zwar nicht, läßt sie aber von einer auf die unmittelbare Situation direkt applizierbaren Erklärung geschichtlicher Entwicklungsvorgänge zu einer stark generalisierenden Aussage werden: Die These wird abstrakter; kein Zufall, daß sie in 'Antichrist' von einem Wissenschaftler formuliert wird: Die Geschichte bewegt sich zwar mit Gesetzmaßigkeitscharakter auf die proletarische Revolution zu; die kapitalistische Gesellschaft ist aber für die Revolution noch nicht reif - und folglich auch weiterhin eine Gefahr'

Nur die zweite Stufe der argumentativen positiven Gegenposition wird unverändert aus der 'Satire der kapitalistischen Endzeit' übernommen: die Sowjetunion als gesellschaftiches Ideal des vom Kapitalismus unterdruckten westlichen Proletariats ist die eigentliche positive Gegenposition des zweiten Paradigmas, die eigentliche Alternative zum kapitalistischen Bordell!

Schon aus den oben angestellten Überlegungen zur positiven Gegenposition in der 'Satire der bourgeois-Faschistischen Fratze' erhellt eindeutig, daß sich die in den Text eingehende $h i s t o-$ $r i s c h$ e $P$ e $s$ e $k t i v$ e gegenüber dem ersten Paradigma radikal gewandelt hat: Dort war der Puls der Zeit extrem beschleunigt, der der zugrunde gelegten These entsprechende Geschichtsverlauf extrem $d y n$ a $i s c h$ - die sozialistische Revolution 1 ag von Anfang an in Greifweite und wurde ausnahmslos noch innerhalb der Darstellung realisiert. Hier scheint die zeit nicht nur stillzustehen, sie scheint gar rückläufig zu sein: der bereits totgeglaubte, totgewünschte Kapitalismus hat sich erholt, ist vitaler und gefährlicher denn je zuvor; der Geschichtsverlauf ist generell $s t a t i s c h e$, die Morgenröte der ersehnten sozialistischen Revolution erst an fernen Horizonten 
zu sehen. Die Morgenröte des kommenden Tages ist nicht die der Revolution - sondern die des bevorstehenden imperialistischen Krieges, mit dem der inzwischen braun eingefärbte und hakenkreuzdekorierte Kapitalismus seinen Erzfeind - die Sowjetunion - bedroht. Die Zeichen der Zeit stehen auch hier auf sturm - aber (nahfristig) nicht mehr für den Kapitalismus, sondern für den von 'Außen' gefährdeten sozialistischen staat.

Damit ergibt sich auch für die Interpolation der $k$ m $m$ u $n$ $k$ a $t i v e$ Funktion des zweiten Paradigmas eine völlig veränderte Ausgangslage, in die zentral auch die veränderte $k \circ m-$ $m u n i k$ a $t$ i $v$ e $i t u$ a $t$ i $n$ des Erstrezipienten mit einbezogen werden muß: Einerseits liegt der Bürgerkrieg bereits Jahre zurück; das Bewußtsein um die unmittelbare Bedrohung der Sowjetunion durch den imperialistischen Kapitalismus ist durch den fur die Sowjetunion relativ friedlichen Verlauf dieser Jahre bei vielen Sowjetbürgern verschütet worden; damit sind sowohl die wache Bereitschaft zur gegebenenfalls aufgezwungenen militärischen Auseinandersetzung, als auch das Verständnis für die Politik der Sowjetregierung, die einer möglichen militärischen Bedrohung durch ausgabenintensive Wehrpolitik und Wehrpropaganda Rechnung trägt, abgebröckelt.

Andererseits bedeutet die Nöp ${ }^{82}$ ) ein Erstarken des privatwirtschaftichen Sektors in der Sowjetunion, das nicht nur zur Konsolidierung der ökonomischen Situation beiträgt, sondern auch eine Steigerung des Faszinationswertes des kapitalistischen Wirtschaftssystems und damit auch der kapitalistischen staten mit sich bringt; der während des 'Kriegskommunismus' liquidierte und verteufelte Kapitalismus hat im Rahmen einer 'ubergangspolitik' im eigenen Lande sektoriell wieder FuB gefaßt - eine Erscheinung, die auch von Zeitgenossen häufig als Bankrott-Erklärung des sozialistischen staatswirtschaftlichen systems und als Beweis für die Unverzichtbarkeit des an 'private Initiative' und egoistische 'interesovannost' ' appellierenden Kapitalismus interpretiert wird. 
Der 'Nöpmann' als sowjetische Variante des Bosses der kapitalistischen Länder ist nicht nur Neid- und Orientierungsobjekt vor allem kleinbürgerlicher Kreise, ist in den Augen vieler nicht nur alleiniger Garant wirtschaftlichen Aufschwungs, materiellen Wohlergehens überhaupt - viele sehen in ihm auch die erste Schwalbe eines nun auch die Sowjetunion wieder beglückenden kapitalistischen Frühlings. Dieser Aspekt ist eines der zentralen Angriffsobjekte der 'Binnen-Satire' (s.u.).

Schließlich, und darauf wurde bereits wiederholt hingewiesen, hat sich die außenpolitische und ideologische Landschaft gewandelt: die Weltrevolutionserwartung der frühen zwanziger Jahre hat sich nicht nur nicht bestätigt, die machtpolitischen Kräfteverhältnisse innerhalb der kapitalistischen staten haben das Pendel auf der Skala der Revolutionserwartung vielmehr eindeutig nach Rechts ausschlagen lassen. Und in partiellem kausalem Zusammenhang damit: die Weltrevolutionsthese selbst ist vorerst ad acta gelegt. Dementsprechend sind über den generellen Aspekt der Bewußtmachung bzw. Bewußthaltung der grundsätzlichen Negativität des kapitalistischen Systems hinaus, die kommunikative Basisfunktion aller Texte der 'Außen-Gruppe' ist, zwei zentrale kommunikative Funktionen für die 'Satire der borgeois-faschistischen Fratze' anzusetzen :

1) B e w $\mathrm{B}$ t m $\mathrm{m}$ $\mathrm{h} g$ der von den kapitalistischen Staaten ausgehenden Bedrohung der Sowjetunion, Stärkung der Bereitschaft zur potentiellen aufgezwungenen - nicht nur ökonomischen und ideologischen sondern auch - militärischen Verteidigung der Sowjetunion. Dies bedeutet zugleich: A $f$ i $r$ a $t i o n$ der Richtigkeit der Wehrpolitik der Regierung, die sehr aufwendig ist (nur ein Hinweis: 1924 beginnt der intensive Aufbau der sowjetischen Luftstreitkräfte) und in der immer noch angespannten ökonomischen Situation bis in das Budget jedes einzelnen Sowjetbürgers schmerzlich durchschlägt. Dies bedeutet weiterhin: Stützung der mit nicht-satirischen Mitteln vorgetragenen Wehrpropaganda. 
Unter diesem Gesichtspunkt hat die 'Satire der bourgeois-faschistischen Fratze' eine $m i t t e l$ b $r$ propagandistische Funktion.

2) Die 'Satire der bourgeois-faschistischen Fratze' signalisiert aber nicht nur die Gefährlichkeit des kapitalistischen systems - sie zentriert gerade auch seine 'Fratze': seine HäBlichkeit; insbesondere aber die Häßlichkeit und Menschenunwürdigkeit des 'privaten' und politischen lebens des Proletariats der kapitalistischen Länder. Sie ist eine $P$ a $m p l$ e $t-s$ a $i r e$ gegen den Kapitalismus, die - uber den Kontrast zwischen dargestellter Häßlichkeit und als uberlegen angesetztem eigenem status quo - nicht nur eine Legitimierung des Sowjetstaates, sondern auch eine Glorifizierung des Rezipienten und seiner Gesellschaft konstituiert; eine Glorifizierung per Faszinationszertrümmerung. Sowohl das erste als auch das zweite Paradigma stellen dem sowjetischen Leser ein direktes Identifikationsangebot zur Verfügung: der Sowjetbürger - also der Rezipient selbst hat für den Arbeiter der kapitalistischen Länder des Status d e s Ideals.

Auch in dieser Textgruppe ergehen keine Aktions-Appelle. Bewußtmachung der Gefährlichkeit des imperialistisch-faschistischen Kapitalismus und Stärkung des gesellschaftlichen überlegenheitsbewußtseins der Rezipienten sind also die wesentlichen kommunikativen Funktionen der 'Satire der bourgeois-faschistischen Fratze'.

Die Roman-'Satire der bourgeois-faschistischen Fratze' ist konstruiert nach dem Schema fast aller satirischen 'Romane': als Reihung einzelner Porträts, einzelner Episoden. Genauer: als ' $R$ e $i s e^{\prime}$ von Porträt zu Porträt, von Episode zu Episode. Diese 'Reise' ist einziges sujetfunktionales Verklamerungselement - weder bauen die einzelnen angelaufenen stationen aufeinander auf, noch nehmen sie (direkt per Autoren-Kommentar, durch wiederauftauchen fruherer Figuren, parodistisch) aufeinander 
Bezug: es ist eine lineare 'Informationsreise' durch die Welt eines Themas.

Die 'Reise' wird durch eine hauchdünne story motiviert: Ein kauziger Amerikaner hört, der 'Antichrist' sei in Europa aufgetaucht - er läßt alles liegen und stehen, weil er es sich in den Kopf gesetzt hat, dem 'Antichristen' die 'Pfote zu drucken'; auf der Suche nach ihm - mit dem er keinerlei gesellschaftspolitische Vorstellungen verbindet! - reist er kreuz und quer durch die kapitalistischen Länder ... Oder: Ein russischer Kleinbürger wird durch die Revolutions- und Bürgerkriegsereignisse aus der Sowjetunion gespuilt und durchwandert nun auf der suche nach der zertrümmerten Idylle kleinbürgerlichen Lebens oder auch nur auf der Suche nach der verlorenen Geliebten etc. die kapitalistische Bordell-Landschaft. Etc...83)

In beiden Fällen hat die story ausschließlich die Funktion, den Leser die Porträt-Reihe entlang zu fuhren; die story selbst ist ohne jedes Interesse; story und satirische Darstellungsobjekte sind so wenig verknüpt, daß die storys ohne weiteres gegeneinander ausgetauscht werden könnten, ohne daß dadurch Figurenkonstitution, historische Perspektive etc. auch nur im mindesten betroffen würden.

Die story-Variationsbreite ist äußerst gering.

Nur sehr vereinzelt finden sich Ansätze zur Überwindung des eintönigen Reise-Schemas durch die Entwicklung einer echten story und ihre organische Verknüpung mit den satirischen Porträts. Diese Versuche scheitern generell - sei es an der mangelnden literarischen Begabung, sei es an der Eile der Autoren. Sie scheitern ebenso im Bereich der gleichzeitig entstehenden 'Binnen'Romansatiren (s.u.)

Das Resultat dieser Versuche: Satirische Blöcke und völlig unsatirische Abenteuer-story-Blöcke stehen völlig unvermittelt nebeneinander. Als Beispiel seien L. Nikulins 'Die Geheimnisverkäufer' erwähnt: Nur der mittlere der drei Teile dieses satirischen Romans ist satirisch - er spielt im Satire-Land 'Eritreja' (s.o.). 
Die beiden anderen Teile haben auch hier nur die Funktion, die Reise nach 'Eritreja' durch eine uberaus verworrene Abenteuerstory zu motivieren; diese story ist so verworren, daB der Autor außerstande ist, sie am Ende mit erzählerischen Mitteln aufzulösen - statt dessen 'erklärt' er alles.

Der einzige Versuch im Bereich der 'Binnen-Satire', einen story und satirischen Porträts organisch verbindenden satirischen Roman zu produzieren ( Ju. Slezkin 'Der Ziegenbock im Gemüsegarten' s.u.), führt zu genau dem gleichen Schiffbruch. Erst Il'f und Petrov finden eine befriedigende Lösung (s.u.).

Das unvermittelte Nebeneinander von satirischen Blöcken und story-Blöcken ist nicht nur ästhetisch unbefriedigend, sondern auch rezeptiv problematisch, da es dem Leser die eindeutige 'Entscheidung' für das richtige - nämlich satirische - Rezeptionsverhalten erschwert, wenn nicht verunmöglicht. Die Folge: auch die zeitgenössische Kritik (d.h. nicht nur der 'naive Leser') ordnet viele dieser Produkte nicht unter 'satiriteskij roman' ('satirischer Roman'), sondern unter 'priključenčeskij roman' ('Abenteuer-Roman') ein und sieht häufig selbst dort, wo das Satirische - der Intention des Autors zufolge - dominierendes Konstitutionsprinzip sein sollte, nur noch 'satirische Elemente'. D.h. aber: der 'satirische Roman' wird als 'AbenteuerRoman' rezipiert - und verfehlt seine Intention! So charakterisiert sogar A. Lunalarskij eine der schärfsten antikapitalistischen Roman-Satiren - A. Siłkos 'Das Ende des gesunden Menschenverstandes" - als "sehr geistreiches Abenteuer, (...), das nicht eines satirischen stachels gegen die alte welt entbehrt" 84 ). 


\subsubsection{Modifikations- und überwindungsansätze}

Auch die der 'Satire der bourgeois-faschistischen Fratze' zuzuordnenden Texte sind auf allen relevanten Ebenen (Figurenbestandund Konstitution, positive Gegenposition, historische Perspektive) so stark klischiert, daß sich unschwer ein - von den Einzeltexten dieser Gruppe nur leicht abstrahierendes - Paradigma konstruieren ließ. Ein Paradigma, das zugleich das letzte geschlossene Paradigma des sowjetischen satirischen Romans ist: die weitere Entwicklung dieses Genres ist unübersichtlicher - und interessanter - und muß auf der Basis eines relativ breiten Fächers konkurrierender typologischer Möglichkeiten und solcher exponierter Einzeltexte dargestellt werden, die sich entweder um eine Synthese dieser typologischen Möglichkeiten bemühen oder aber isoliert stehen.

Die uberaus starke Klischierung auch der 'Satire der bourgeoisfaschistischen Fratze' macht es überflüssig, der 'abstrakten' paradigmatischen Darstellung die Analyse eines 'konkreten' Einzeltextes anzuschließen: diese Analyse wïde die paradigmatische Konstruktion in allen Aspekten bestätigen und wiederholen mussen - sie wäre allzu redundant.

Statt dessen soll hier ein Einzeltext vorgestellt werden, den die Literaturgeschichte (sofern sie ihn uberhaupt registriert) versehentlich als 'unter ferner liefen' der Massenproduktion der 'antikapitalistischen Pamphlet-Satire' zuordnet - und der dem Paradigma der 'Satire der bourgeois-faschistischen Fratze' bei oberflächlicher Betrachtung auch weitestgehend korrespondiert, faktisch aber weit über das Paradigma hinausgeht, sich um seine. 'Liquidierung' bemuiht.

Die Versuche der Überwindung der 'pensionsreifen' 'Satire der kapitalistischen Endzeit' durch Kataev und Lavrenev erfolgten genau zu dem zu erwartenden Zeitpunkt und setzten genau bei den zu erwartenden Elementen des Paradigmas an; sie ließen sich darstellen als ein Kapitel 'Produktionsästhetik für Anfänger': Modifikation derjenigen Elemente, die der veränderten kommunika- 
tiven Situation der Rezipienten nicht mehr gerecht wurden, Modifikation damit auch der kommunikativen Funktion. Anders gesagt: die in der 'Satire der kapitalistischen Endzeit' erfolgte Beantwortung der Frage 'Der Kapitalismus und wir?' wird ihrerseits in Frage gestellt, die alte Antwort ('der Kapitalismus wird bald überall liquidiert, stellt für uns folglich keine Gefahr dar') wird zur impliziten neuen Fragestellung der 'Satire der bourgeois-faschistischen Fratze' - 'der Kapitalismus und wir - heute?'.

Wesentlich komplizierter stellt sich - in produktions- wie rezeptions-asthetischer Hinsicht - der einzige registrierte Versuch zur 'Überwindung der 'Satire der bourgeois-faschistischen Fratze' dar; genauer der Versuch, dieses Paradigma $s$ erst gar nicht entstehen zu lassen.

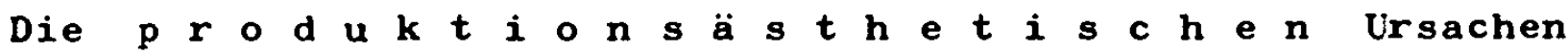
für das allmähliche Zurückgedrängtwerden und Verschwinden der 'Satire der bourgeois-faschistischen Fratze' sind komplexer und nicht auf einen Nenner zu bringen. Als wesentliche Faktoren können aber angesetzt werden:

- Der progressive übergang zur fast alle sektoren erfassenden sozialistischen Planwirtschaft und damit die progressive Liquidierung privatkapitalistischer Produktions- und Verteilungssektoren signalisieren die eindeutige, nicht mehr zu revidierende Abkehr vom 'Übergangs-Kapitalismus' im eigenen Lande; damit wird zugleich der durch die Nöp gleichsam bestätigte Reiz- und Faszinationswert des kapitalistischen Wirtschaftssystems - der Nimbus seiner grundsätzlichen Überlegenheit - reduziert. Gleichzeitig wird der Faszinationswert des eigenen sozialistischen wirtschafts. systems durch den Erfolg dieser Umstellung, insbesondere aber durch den Erfolg des ersten Füfjahrplans (1928-1932) gesteigert: mit zunehmender Konsolidierung der Sowjetökonomie sinkt das Bedürnis nach ihrer ideologischen Abstüzung a u c h (!) mit satirischen Mitteln - die Satire wird freigestellt für stärker satirische, weniger unmittelbar ideologisch-agitatorische Funktionen. 
- Die vor allem in der zweiten Hälfte der NöP verstärkte ökonomische und sogar militärische Kooperation mit kapitalistischen Staaten (z.B. Erprobung deutscher Waffensysteme, Ausbildung deutscher Militärpiloten in der UdSSR) favorisiert KoexistenzVorstellungen und läßt die Global-Verteufelung des 'kapitalistischen Lagers' unglaubwïrdig werden.

- Vor allem aber: noch während der Phase des absoluten Dominierens von satirischen Romanen, deren Angriffs- und Darstellungsobjekte im 'Außen-Bereich' liegen, sondieren kleine satirische Formen eingehend den Bereich des 'eigenen Sozialhaushaltes' ('Binuen-Bereich'), entwickeln für diesen satirisch ungleich ergiebigeren (größere Typenvielfalt etc.) und relevanteren (Bewußtmachung kann direkt in politisches und gesellschaftiches Verhalten umgesetzt werden) Bereich die wichtigsten Darstellungsmuster, die dann von den ersten größeren Texten der 'Binnen-Bereichs'-Satire - die vorübergehend mit Romanen der 'AußenBereichs'-Satire konkurrieren, um sie schließlich ganz zu verdrängen - aufgegriffen werden.

Die höhere Relevanz der sich dem eigenen Sozialhaushalt zuwendenden Satire wird auch in der satiretheoretischen Diskussion, die den Begriff des 'gesellschaftlichen Überbleibsels' zentral stellt, betont!

Der hier darzustellende 'überwindungsversuch' stellt aber auch insofern ein komplexeres Problem dar, als er produktionsästhetische Schulbuch-Vorstellungen sprengt - er findet nicht in der Spätphase der 'Satire der bourgeois-faschistischen Fratze' statt, ist vielmehr einer der ersten Texte dieser Gruppe!

Dieses produktionsästhetische Problem ist zugleich ein $r e z e p t i \circ n s \ddot{a} s t h e t i s c h$ e $s$ Problem: In Aniehnung an Konzeptionen des russischen Formalismus wird der Rezeptionsvorgang häufig folgendermaßen umrissen: der 'Leser' verfüge über einen durch vorgängige Lektüre anderer Primärtexte, kritischer und theoretischer Texte etc., durch seine soziale, politische und ideologische Situation determinierten Erwartungshori- 
zont. Die Rezeption eines gegebenen Textes erfolge vor diesem Erwartungshorizont (der in der momentanen literaturwissenschaftlichen Praxis meist freilich ein rein literarisch determinierter Erwartungshorizont ist!) - als seine Bestätigung oder Durchbrechung nach Maßgabe der Konstitution des zu rezipierenden Textes. Diese Auffassung des Rezeptionsvorganges vereinfacht unzuläsig - sie beschreibt bestenfalls (eine der) zentrale( $n$ ) RezeptionsMöglichkeiten; als generelles rezeptionsästhetisches Konzept ist sie schlicht falsch. Sie vernachlässigt insbesondere den qualitativen Faktor der Vitalität des Erwartungshorizontes: die Literaturgeschichte kennt unzählige fälle von Interpretationen, die diesem rezeptionsästhetischen Modell zufolge 'Fehl-Interpretationen' sind. Viele dieser 'Fehl-Interpretationen' sind darauf zurückzuführen, daß der Erwartungshorizont häufig so vital, so durchsetzungsfähig ist, daß ein gegebener Text selbst dann als Affirmation des Erwartungshorizontes rezipiert wird, wenn er 'objektiv' den Erwartungshorizont einer bestimmten historischen Leserschaft durchbricht, sogar wenn er intentional auf Durchbrechung dieses Erwartungshorizontes angelegt ist: der objektivdurchbrechende Text als subjektive Konkretisation des Erwartungshorizontes!

Genau dieser Vorgang ist aber zu beobachten bei dem auf Durchbrechung des generellen Erwartungshorizontes 'Außen-Bereichs'-Satire, insbesondere aber des durch die 'Satire der bourgeois-faschistischen Fratze' konstituierten Erwartungshorizontes angelegten Text zu beobachten, der unten darzustellen ist: dieser Text enthält zwar alle Elemente des sich gerade erst formierenden Paradigmas - überwindet dieses Paradigma aber zugleich durch ein nur diesen Text kennzeichnendes zentrales Element. Aber - ungeachtet des Ausnahmecharakters dieses zentralen Elementes wird dieser satirische Roman als 'normaler' Vertreter der 'Satire der bourgeoisfaschistischen Fratze' rezipiert (und von Kritik wie Forschung entsprechend eingeordnet): aufgrund der vitalen übermacht des Erwartungshorizontes - der sowohl durch das vorhergehende Paradigma und eigene oder fremde Kritik an ihm als auch durch die 
aus dieser Kritik resultierende Erwartung des neuen Paradigmas (!) determiniert ist - wird das zentrale den Erwartungshorizont durchbrechende Element zum dekorativen Element degradiert, rezeptiv unterdrückt !

Nur so ist es zu erklären, daß dieser Text - obwohl potentieller Totengräber der eben erst geborenen 'Satire der bourgeois-faschistischen Fratze' - zum viel kopierten Ahnherrn einer ganzen Epoche des sowjetischen satirischen Romans werden konnte: und damit ist aus dem rezeptionsästhetischen Problem wieder ein produktionsästhetisches geworden.

Dieses hermeneutische Ärgernis bereiten Vs. Ivanovs 1925 erschienene 'Wundersame Abenteuer des Schneiders Fokin' ${ }^{55}$ ).

Vs. Ivanov gibt seinen 'Wundersamen Abenteuern ...' den Untertitel 'povest' '; diese Genre-Bezeichnung hat aber kein Gewicht: Fokins 'Abenteuer' sind ebensowenig eine 'povest' im 'ublichen' (ibrigens höchst diffusen) Wortgebrauch, wie die vielen satirischen 'Romane' der zwanziger Jahre tatsächlich als Romane klassifizierbar sind (nebenbei: viele dieser 'Romane' umfassen kaum 50 Druckseiten). Der in sowjetischen Darstellungen breiten Raum einnehmende Streit um eine Abgrenzung zwischen satirischem Roman und satirischer 'povest'' ist eine Haarspalterei um Kaisers Bart: fast alle diese Texte sind Reihungen von stark am satirischen Feuilleton orientierten Porträts und Episoden, die nur durch eine aufgesetzte story verbunden sind. Nur sehr vereinzelte Texte sind so intensiv auf Integration von Figuren, Episoden und story durchkomponiert, daß sie sich genremäßig tatsächlich als Romane bzw. povesti bestimmen lassen: es sind dies die die Spitzenlëistungen der sowjetischen satirischen 'Großerzählung'.

Story und Sujet dieser satirischen 'povest' sind schnell referiert - sie korrespondieren in wesentlichen Aspekten den oben dargestellten paradigmatischen Verhältnissen: ein sowjetischer Kleinburger entdeckt sein gestörtes Verhältnis zur Sowjetgesellschaft (so wie er sie versteht), verläßt die Sowjetunion, sucht 
in den kapitalistischen staaten nach einew Realisationsfeld fü seine in der Sowjetgesellschaft nicht (mehr, noch nicht) aktuellen Vorstellungen und kehrt im Schlepptau einer Prau wieder an seinen existentiellen wie ideologischen Ausgangspunkt zurick. Diese seine Suche ist eine Reise durch den zeitgenössischen Kapitaliswus und führt den Leser zu allen wesentlichen vertrauten figuralen Versatzstücken - sowohl der Negativposition als auch der positiven Gegenposition - der 'Satire der bourgeois-faschistischen Fratze': BOB und Co., Faschist, russischer Emigrant; Proletarier, Sozialist. Auch die argumentative positive Gegenposition ist die ubliche: 1. Stufe - Sozialismus generell, 2. Stufe - Sowjetgesellschaft. Desgleichen die historische Perspektive: nahfristig trübe Aussichten für die (Welt) Revolution. Der Figurenbestand bringt eine wesentliche Erweiterung: den Typ des Lakaien.

Die Konstitution der Negativfiguren nimmt unter dem Gesichtspunkt der 'Decouvrierung' eine Modifikation und Akzentverlagerung vor: der BoB hat hier keine Angst, ist nur noch dumm und dumm auch nur in seinem 'Privat'-Leben. Als sozio-politische Institution ist er von - gigantisch - häßlicher überlegenheit, als 'Mensch' von gigantischer Erbärmlichkeit, Die Konstitution verzichtet außerdem auf eine proträtierung seines physischen Erscheinungsbildes, zitiert vielmehr nur lapidar dessen Versatzstücke ("Fette Bourgeois werden per Foxtrott... ihr Fett los")" 86 ). Völlig neu hingegen ist die Konstitution des 'Reisenden' selbst, neu ist auch sein funktionaler Einsatz - er ist nicht mehr nur gesichtslose 'Lokomotive' des Sujets, Dekor-'Held' der Feigenblatt-story: während der paradigmatisch 'Held' $n i$ e eine satirische Figur, vielmehr ganz auf die Erfüllung seiner SujetFunktion (Ermöglichung bzw. Verschleierung der puren Reihung) festgelegt ist, ist Fokin eine zumindest gleichberechtigte, vor dem Erwartungshorizont der gesamten 'AuBen-Bereichs'-Satire sogar d i e zentrale satirische Figur der 'Wundersamen Abenteuer...'. 
Fokin ist eine Figur mit einer präzisierten 'intellektuellen Physiognomie': er sieht die Welt der Erscheinungen (und nur sie) durch eine ganz spezifische Perspektive; er kommentiert, kritisiert, wertet die von ihm angetroffenen Erscheinungen reagiert auf sie und läßt in der Totalität der Reaktionen auf die Erscheinungen der satirischen Reduktionsstufe und der ihr opponierten positiven Gegenstufe seine 'intellektuelle Physiognomie', die eines sowjetischen Kleinbürgers, evident werden.

Die Erzählung nimmt ihren Anfang - und ihr Ende - in einem mittelsibirischen Etappenstädtchen, einem im wörtlichen wie übertragenen Sinne total verstaubten Kleinbürger-Nest: "Die Hauptsache ist dort Sand, und es ist nicht auszumachen: sind die Wolken am Himmel oder auf der Erde" 87 ). Diese 'Staubwolken' verwehren Fokin, dem Schneider zu Pavlodar, den Blick aus der 'kleinen Welt' des Kleinbürgers in die 'große Welt' der sozio-politischen und historischen Vorgänge - und so macht sich Fokin ein Bild von der Welt, das ausschließlich durch das Erscheinungs-Feld innerhalb der kleinbürgerlichen Enklave und die wenigen von außen in sie eindringenden 'Informationen' - sprich: Gerüchte - konstituiert wird.

"Der Schneider Fokin saß die ganze Zeit ruhig. Er war krumm wie die Pavlodarschen Zäune, hatte krumme Arme, schielte auf einem Auge, ja und überhaupt hing alles bei ihm nach einer Seite, so daß sich die Pavlodarschen Kommissare wunderten: 88 yoher hat er bloß eine derartige Sicherheit mit der Nadel?! "

Dieses Porträt erstellt allegorisch Grundstrukturen Fokins 'intellektueller Physiognomie': Unbeweglichkeit ('saß die ganze Zeit ruhig'), Un-Einsichtigkeit ('schielte auf einem Auge'),.. Unausgewogenheit ('hing alles bei ihm nach einer seite'), Beschränktheit ('Sicherheit mit der Nadel' - $n$ u 'mit der Nadel').

Diese Grundstrukturen determinieren Fokins Perspektive im Zugang zur engen Welt der ihn umgebenden Erscheinungen; eine Perspektive, die sein zentrales Problem in ihr kreiert und seinen Lösungsversuch bestiment. 
"Da sitzt nun Fokin am Tag vor Palmsonntag, Fokin Ivan Petrovič, zu Hause auf dem Nähtisch, die Wirtin brachte ih Palmedel, es roch nach Feiertagsfisch, und auf dem Nähtisch und auf den Stiuhlen liegen Uniformröcke, eine unglaubliche Anzahl von Uniforwröcken. Aus dem ganzen Bezirk, ja vielleicht sogar aus dem ganzen Semipalatinsker Okrug, hatte Fokin Bestellungen auf Uniformröcke erhalten.

Fokin schaut auf diese Uniformröcke und sagt zur Wirtin: - Ja was meinen Sie denn, Glikerija Egorovna, ob ich wohl noch lange Uniformröcke nähen muß?

- Ja, Ivan Petrovič, Uniformröcke, nehme ich an, werden Sie noch lange nähen muissen, da der Krieg noch nicht zu Ende ist.

- Wie denn, Glikerija Egorovna, der Krieg ist noch nicht zu Ende? Da ist doch, sozusagen, morgen Palmsonntag des Jahres dreiundzwanzig, und wer hat denn zuletzt mit uns gekämpft? Die Polen, - das war in welchem Jahr? Da hat doch, erzählt man, dem Popen irgendein Neffe aus der Hauptstadt eine Papyros-Schachtel geschickt, und auf ihr sind Zivilmoden abgebildet ...

- Aber das sind doch Bildchen, Ivan Petrovit, bei Thnen aber bestellen alle Uniformröcke. Wenn der Krieg zu Ende wäre, weshalb sollten sie dann Uniformröcke bestellen?

Fokin blickte um sich, und genau: Das ganze Zimmer wargfit Uniformröcken zugewachsen, es fiel sogar schwer zu atmen"89).

Das Grundgerüst kleinbürgerlichen Innenlebens, kleinbürgerlicher 'Welt'-Anschauung hat sich konkretisiert: Fokin nimmt die Welt der Erscheinungen wahr vor einem Erwartungshorizont, der konstituiert ist durch die Vertrautheit des altgewohnten Trotts und vor dem jedes 'neue.90) Element - die Uniformröcke - unangenehm (!) auffällt; vor dem Erwartungshorizont der Ignoranz: die Fokins wissen nicht, daB der krieg längst zu Ende ist; vor dem Erwartungshorizont totaler Beschränktheit - die Welt der Fokins ist eine Welt, in der kleider Leute machen, in der alles nur nach seiner Erscheinungsform beurteilt wird. Eine Welt, in der eine syllogistische Krüppel-Logik von den unmittelbar wahrnehmbarer Erscheinungen mechanisch auf das ignorierte Wesen schliebt:

'Wenn Krieg ist, werden Uniformen gebraucht; jetzt werden Uniformer gebraucht, folglich ist Krieg'. Bzw.: ...

"Und wenn ich, sagt Fokin, wenn ich, Glikerija Egorovna, wich wei gern werde, Uniformröcke zu schneidern?

- Weswegen denn sollten sie sich weigern, Ivan Pgfjovič?

- Nun deswegen, weil ich nicht mehr kämpfen will, Glikerija

Egorovna, deswegen, weil ich Zivil-Schnitte schneidern will. 
(...). Dort durch das Gefängnis sind alle Bürger passiert, und vielleicht auch Lenin, die die ReSeFeSeR schufen und den volkern Frieden schenkten. Ihr aber, meine Herren, Thr laßt auch weiterhin Uniformröcke schneidern, Thr geht nicht auf die Friedenslage über, da ihr insgeheim auf den Krieg hofft! Ich aber will keinen Krieg und werde Euch, friedlichen Menschen, keine Uniformröcke nähen, jqg bin Zivilschneider und erwarte von Euch Zivilaufträge ..."

Bzw.: 'Wer Uniform trägt, will auch den Krieg. Wer Zivil trägt, ist friedfertig'.

Fokin bekommt auch weiterhin keine Zivilaufträge; deshalb "aß er auf den Weg noch ein $E_{i}$ und steckte seine scheckigen Haare fest unter die Müze"93) und macht sich auf den Weg "ins Ausland, in unbekannte Dickichte" 94), in "ein solches Land, wo man Zivilkleidung trägt und Zivilschneidern Achtung entgegenbringt" ${ }^{25}$ ).

Fokins Problem also: der 'Militarismus' seiner eigenen Gesellschaft. Auf die Diskrepanz zwischen Eigeninteresse und von der Gesellschaft geltend gemachten Interessen reagiert der Kleinbürger nicht mit der Fragestellung 'ob $i c h$ das vielleicht nicht richtig sehe, ob i c h vielleicht falsch liege?' - sondern mit der Frage (die auch schon die Antwort ist) 'Was wollen die eigentlich von mir? Ob $d i$ e verrückt geworden sind?'. Sein Lösungsversuch: der 'bunt ličnosti', der 'Aufstand der (kleinbürgerlichen) Persönlichkeit' gegen die Sowjetgesellschaft. Ein vor dem Gesamthorizont der sowjetischen Satire der zwanziger Jahre eminent komischer ${ }^{96}$ ) 'bunt licnosti': dieser ist durchgehend Domäne des sich hoch über dem 'kleinbürgerlichen Mief' der 'sowjetischen Wurstkocher' Gesellschaft wähnenden - und sich ihr zugleich neidvoll unterlegen wissenden - 'Intelligent' (Siehe z.B. Ju. Oleša 'Neid' und unten).

Diese seine Perspektive der 'kleinen Welt' und seine ihr entstammende noch unverifizierte implizite These ('Wer Uniform trägt, will den Krieg. Wer Zivil trägt, ist friedfertig') promeniert Fokin durch Polen, Deutschland und Belgien nach Paris - und zurück ins auch weiterhin verstaubte Pavlodar. 
Hier interessieren also weniger die wie üblich aufgereihten angelaufenen Stationen - sie werden nur zur Herstellung des nötigen Kontextes und zur Verdeutlichung der Ivanovschen Diktion (die weniger holzhammerhaft, stärker ironisch ist; oder: weniger pamphletistisch, stärker satirisch. Auch dies ein wichtiger Schritt zur überwindung der zentralen Konstitutionsmuster der ersten Hälfte der zwanziger Jahre!) skizziert - als vielmehr die Konfrontation dieser Erscheinungen mit Fokins 'These', als seine Reaktionen.

Es kann hier auch darauf verzichtet werden, die gesamte Kette dieser Reaktionen aufzufädeln, da sich ihr gemeinsamer Nenner an wenigen Beispielen evident machen läßt.

Leitfragen: 1) Wie bewertet Fokin die Negativ-Erscheinungen?

2) Wie formuliert er sein Urteil?

3) Welche Konsequenz zieht er aus der Inkongruenz von Erwartung und Er-Fahrung?

4) Wie reagiert er auf das Sowjetunion-Bild des westlichen Proletariats?

Bevor Fokin in seiner Eigenschaft als Transporteur nicht nur des Sujets, sondern auch der kleinbuirgerlichen Perspektive, die es mit ihrem offenen oder heimlichen Ideal - der bürgerlichen Gesellschaft - zu konfrontieren gilt, den Boden des Gelobten Landes der 'friedfertigen Zivilisten' betritt, distanziert sich der Autor von ihm - und weist damit zugleich den Leser in das erwinschte Rezeptionsverhalten ein:

"Denn vieles verstehst du (=Fokin j.e.) nicht, und für vieles schäme ich mich, - entschuldige mich, aufgeklärter Leser Bucharin: und der 'Pravda', - nur einer von ufg, beiden ist der Schneider, der andere ist nur der Weggefährte" 17 ).

D.h. aber: der Leser wird aufgefordert, Fokins Urteile kontinuierlich zu uberprüen, sie gegebenenfalls zu falsifizieren, zu ergänzen.

Deutschland 1923, Deutschland des Versailler Vertrags: "Nicht Tataren und nicht skythen treiben die Herden von den saftigsten Weiden, pferchen sie in Waggons, und die Waggons sausen 
mit Geheul nach Frankreich; Tag und Nacht rieseln Weizen und Gerste in Säcke (...): die Reparationen beschleunigen, - und vor Hunger sterben die Kinder, $989^{r}$. Hunger legt sich das Mädchen in die Erde, um zu verfaulen"

Auch die Bosse treiben Vieh - sie veranstalten automobilisierte Treibjagden auf Haustiere:

"Onkelchen, die züchten, sagen wir mal, tausend Schweine und lassen sie dann aufs Feld und fahren sie mit ihren Autos tot - wer am wenigstgy) uberfahren hat, der hat verloren und ist ein schlechter Jäger""9).

Der Boß betreibt also das als Hobby, was das Volk unter Zwang und auf die Gefahr des Verhungerns betreiben muß.

Diese Jagd - die eine Jagd von Schweinen auf Schweine ist - findet statt auf den Ländereien des 'Adelsmarschalls der Faschisten', des Milliardärs Tinnich; und die Faschisten selbst nehmen an ihr teil, indem sie nahtlos und mit gleichem Vergnügen von der Jagd auf Arbeiter auf die Schweinejagd übergehen.

Fokin beobachtet das Milliardärs-Spiel und schreit seinen Kommentar (im Original in deutscher Sprache) in die Nacht: "Es lebe der, sukiny deti ('Hundekinder'), es lebe der Lenin, der! ..."100). Der Wunsch, nach dieser ersten, wenig Friedfertigkeit dokumentierenden Inaugenscheinnahme des zivilgekleideten Bosses diesen persönlich kennenzulernen, geht zwar nicht in Erfüllung. Dafür tritt Fokin in Gestalt von Tinnichs Chauffeur ein wahres MöchtegernAbbild seines Herrn - ein 'Lakai' - entgegen, ein weiterer Zivilist, der Fokins Erwartungen ebenfalls keineswegs entspricht: "mein Herr. Er ist unglücklicher als alle Menschen auf der Erde, (...), unglücklicher als jeder Türke, - die Franzosen nehmeqołłm das Geld weg, die Kommunisten - die Fabriken und das Leben"

Von der Verteidigung seines Herrn geht er zum 'Angriff' über: "Ich besitze Aktien in anderen Gesellschaften, mit denen mein Chef konkurriert. Tinnich, wissen Sie, begreift nichts, er hat einfach Glück. Ich aber will Gerechtigkeit, ich will, daß die Aktien meiner Gesellschaften steigen, ich verkaufe sie, ich verlege mich auf vorteilhaftere Unternehmungen, ich gründe einen Trust, - ich habe den Plan einer Aktien-Gesellschaft für Konzessionen in Rußland ausgearbeitet und geme insam mit inrem Vaterland, Herr okoff (unter diesem Namen kursiert Fokin als écran unter Kapitalisten wie Arbejtefn j.e.), werden wir den Ausbeuter und Unhold vernichten" 102$)$. 
Wohlgemerkt, mit der alleinigen Intention, selbst ein 'Ausbeuter' und 'Unhold' zu werden!

Auch auf diesen 'Zivilisten' reagiert Fokin 'richtig':

"Er spuckte aus und ging leise vom Palast weg. (...). Ich glaubte das Glück zu finden, Brüderchen, Genossen, in Zivilschnitten. Das Resultat ist ein Riesenmist oder, auf Sibirisch, eine Feige. Ich beobachte, beobachte und mir wird schlecht von den Zivilkleidern, die bis zur Jagd auf Sghyeine gehen, um nicht von schlimmeren Kleinigkeiten zu reden" 103 ).

Diese 'schlimmeren Kleinigkeiten' sind die 'Lakaien':

"Wozu, sagen wir, haben sie dieses Jünelchen da gebracht4)- man
schämt sich, wenn man sieht, was für ein Glück er will" Fokin reagiert spontan-verbal richtig, zieht aber nur eine einzige - sich stets wiederholende - Konsequenz: er zieht weiter auf der Suche nach seinem pazifistischen Zivilschneiderglück - und bleibt selbst immer derselbe Fokin mit derselben Perspektive und derselben un-falsifizierten These, "auf der Suche nach friedfertiger Zivilkleidung, oder anders gesagt, nach Ruhe" ${ }^{105}$ ).

Seine Suche, die eine Flucht vor der Einsicht in die Unhaltbarkeit der Koppelung 'Uniform=Militarismus, Zivilkleidung=Friedfertigkeit' ist, treibt ihn in die Fänge eines in Paris antibolschewistische wühlarbeit betreibenden internationalen 'Friedenskomitees'. Dessen durchgehend zivilgekleidete Mitglieder: Exilrussen, faschistische Zeitungsverleger -und Geistliche, "die Mitglieder faschistischer Orden sind und die nach der Messe losziehen, um Arbeiter mit Bleikugelpeitschen zu verprügeln" 106): der paradigmatische kapitalistisch-faschistisch-antibolschewistische Sumpf.

Der Präsident dieser antisowjetischen Fronde - "ein dicknasiger Spekulant, seiner Herkunft nach ein Rjazaner Kaufmann"107) kennt 'Okoffs' pazifistischen Impuls:

"das Zivilkomitee aller Länder hat mich beauftragt, Sie auf eine Sitzung und zugleich auf einen Ball zu bringen und Thnen das Stre. ben der völker 1885 Erde nach Ruhe, Frieden und Zivilkleidung zu demonstrieren" 108$\}$.

Fokin reagiert 'richtig': er 'weiß', daß Frieden nicht eine Sache 
der Bosse, sondern des Volkes ist - und diesen Einwand formuliert er sogar 'richtig':

"So, - sagte Fokin, jedes Wort in die Länge dehnend: - hat das Komitee Innen (...) nicht erklärt, wann es die Macht in unsere Hände übergeben wird?

- Sie gestatten, Ivan Petrovic..

- Nein, gestatten Sie schon mir, Genadij Semeny'̌, gemäß der Tagesordnung und da wir ja Vertreter der Sowjetunion sind (das nun gerade nicht! j.e.) und da hinter uns - ja ... Wir sind an diese Dinge betreffs Organisation gewöhnt und stellen alle Ordnungswidrigkeiten fest, da wir Vertreter der Arbeiter und Bauern sind. Sagen wir ein erstes Wort, eine Versammlung ist gut. Aber wozu dieser Ballibf9 die sinnlosen Ausgaben von Eigentum des Volkes?

Fokins Einwände sind 'sozusagen richtig' formuliert: sie dokumentieren, daß sein Wortschatz vom Vokabular der 'Kommissare' bereits infiziert ist - aber eben nur sein Wortschatz; denn: Fokins Einwände sind zwar 'richtig' formuliert - aber situationsunangemessen: es sind Einwände eines 'Kommissars' einem unwirtschaftlich arbeitenden Sowjet-Kollektiv gegenüber - beileibe aber nicht Einwände eines politisch denkenden Sowjetbürgers an die Adresse des Antibolschewismus. D.h. aber: auf einen Negativ-Reiz reagiert Fokin blind-automatisch mit einer einem völlig anderen NegativReiz korrellierten Entgegnung - eben: automatenhaft, nicht-denkend.

Konsequenterweise findet er sich ungeachtet seiner grundsätzlich ablehnenden Einstellung dennoch auf dem Friedens-Ball ein, der ein höchst militanter Aufmarsch ist:

"Fokin steht hinter einer Säule. Die verschiedensten Leute in den allerverschiedensten Schnitten gehen an ihm voruber. Es ist schwer, sich an alle Schnitte der Erde zu erinnern, aber eines ist klar - es gibt zwar (hier j.e.) keine militärischen Unifgregn, aber auch davon ist dem Schneider nicht leichter zumute" 10 . Auch hier die 'richtige' Reaktion, auch hier die 'richtige' Verbalisierung:

"Völlig verwirrt flustert Fokin (...): - Junge, das da ist ja die reinste Konterrevolution und eine Schande... Da kann man in etwas übles reinrutschen... Nein, Bruder, gehen wir (...) lieber ein Stück von der Sünde weg: das hier ist eine solche Verschwörung, ein solches Spiel, daß bei mir kein Kommissar noch eipeq) Uniformrock, ja noch nicht einmal Unterhosen bestellen wird" "II). 
Fokins Einwände sind auch hier 'sozusagen richtig' formuliert: er konstatiert, daß sich hier kapitalistischer Imperialismus, militanter Antibolschewismus artikulieren. Aber auch hier zieht er ein inadäquates Register: das Register 'Konterrevolution', das bei ihm automatisch das Bedürnis auslöst, sich abzusichern, seine Schäfchen ins Trockene zu bringen! Als befände er sich nicht an der heißen Front zwischen Kapitalismus und Sozialismus, vielmehr an der Gerüchte- und Ängste-Front seines sibirischen Krähwinkels.

Ebenso 'konsequent' ist seine Konsequenz: anstatt seinen impliziten Syllogismus 'Wer Uniform trägt, will den Krieg. Die Kapitalisten tragen Zivil, folglich sind sie friedfertig' zu falsifizieren und zu korrigieren - Wenn der Sozialismus sich und den Frieden erhalten will, muß er Uniform tragen - d.h. für den Krieg gerüstet sein' - und diese Korrektur würde sein Verhältnis zur Sowjetgesellschaft normalisieren, läuft er auch hier vor dieser vom Leser längst vollzogenen Konsequenz davon und zieht weiter, weiter...

Die Reise durch den Kapitalismus konfrontiert Fokin aber nicht nur mit den Negativ-Exponenten dieser Gesellschaftsordnung, sie konfrontiert ihn auch mit dem Arbeiter, dem Sozialisten in.der bürgerlichen Gesellschaft.

Diese Konfrontation verfolgt zwei Intentionen: Zum einen macht sie (in genauer Entsprechung zu den paradigmatischen Verhältnissen) die Leitbildfunktion der Sowjetunion für die sozialistische Arbeiterbewegung - und zugleich das stark romantisch verzerrte SU-Bild der westlichen Arbeiterschaft - evident: Fokin als écran, auf den der Arbeiter der kapitalistischen staaten Vorstellungen projiziert, die weder durch Fokin selbst noch durch den status quo der sU affirmiert werden.

Andererseits provoziert auch diese Konfrontation Fokin zu Stellungnahmen, die seine rein verbale, terminologische Infizierung durch den Sozialismus, sein totales faktisches Unverständnis für das wesen des Sozialismus und den politischen wie gesellschaftichen status quo der SU dokumentieren. 
Der Arbeiter "liebt es sehr, vom Dorf zu träumen, und zwar nicht von seinem eigenen, sondern vom russischen. Dort, glaubt er, gibt es längst den Kommunismus und alle Menschen sind Brüder. In der Stadt gibt es noch viele spitzbuben und Popen, 1 im) Dorf aber hat man allen Popen längst den Hals abgeschnitten" 112 .

Dieses SU-Bild ist so naiv, daß es auf den konkreten gesellschaftlichen Zustand der SU um 1925 überhaupt nicht referierbar ist: keine Spur von 'Kommunismus', vielmehr früheste Phase des Sozialismus; keine Spur von vollzogenem Abbau sozialer Antagonismen im dörflichen Bereich, vielmehr Situation verschärften Klassenkampfes ('Kulaken-Frage'); keine Spur auch von einer Liquidierung der Kirche im Dorf ...

Ebenso naiv - und die faktische sowjetische Außenpolitik wie die tatsächlichen militärischen Möglichkeiten der SU total ignorierend - sind die Erwartungen, die der westliche Arbeiter an die SU heranträgt: "Und sag mir zu meiner Freude, werden die Russen bald gen Warschau marschieren?"113). D.h. in einer Zeit, in der der westliche Sozialist von der braunen Allianz von Kirche, Kapital und Faschismus so total unterdrückt wird, daß er vogelfrei, ein "Toter"114) ist, sieht er die einzige Möglichkeit zur Liquidierung des Kapitalismus in einer militärischen Intervention seitens der SU...

Und diesen Erwartungen, die ein so stark verzerrtes Bild von der SU zeichnen, daß der sie artikulierende westliche Sozialist auf eine sehr rürende Weise komisch, als figurale positive Gegenposition zu den Bossen aber äußerst reduziert wird, kommt Fokin voll entgegen:

"Kinderchen, Genossen, hofft auf mich, ich, Kinderchen, werde euch nicht verraten; ich werde dort allen von euch berichten, - das, sozusagen, und das, sozusagen, hat der Schneider Fokin alles gesehen und beschlossen, - man kann nicht mehr warten (..). Ich werde das vielleicht sogar VIadimir Il'ic̈ selbst sagen, ich werde der ganzen Roten Armee und vielleicht sogar der $C_{K}$ von den Schweinejagden erzählen. (...). Und da begann Fokin zu lügen und $\log$ so, daß ihn selbst vor Angst schauderte und daß er sich sehr oft umschaute (..), daß fünzig Millionen Proletarier in Kleidung, die er, Fokin, ausgedacht hat, und mit Panzern bewaffnet bald gen Europa marschieren werden, daß sie alle Bourgeois nackt ausziehen und in den Kirgisischen steppen ansiedeln werden, daß Trockij in einer von Fokin genähten Uniform wartet, bis man eine genügende Menge eines chemischen Gases hergestellt hat, das 
über die Fähigkeit verfügt, alle nicht sowjetischen Russen, diff)
im Ausland leben und Verschwörungen ausdenken, zu vergiften" "Ich selbst aber, ich werde, Brüder und Genossen, trotzdem weiterziehen, und ich werde wohl doch noch, vielleicht zufällig, irgendso ein,tö̈qchen finden, wo man in Ruhe Zivilkleider schneidern kann"

Dieses 'ich selbst aber' ist der Schlüssel zur Psyche des Kleinbürgers: ein 'ich selbst', definiert durch hoffnungslose Ignoranz und kleinkarierten Egoismus.

In Fokins Reaktion auf die figuralen Vertreter auch der 'positiven' Gegenposition zeigt sich also: er sieht alles - seine eigene wie die fremde Gesellschaft - durch die kleinbürgerliche Perspektive des 'Kleider machen Leute' bzw. 'Erscheinungen machen Wesen'; seine Informationen über die eigene Gesellschaft beschränken sich auf das Wissen um verbale Etiketten, auf das 'Wissen' um einen Lenin, einen Trockij, die auf das Format von vergrößerten (weil mit Machtbefugnissen ausgestatteten) Fokins geschrumpft sind.

Als uneinsichtiger, blinder Sklave seiner geistigen Unbeweglichkeit, seiner Lernunfähigkeit - als sozialer Krüppel, den die neue zeit nur verbal infiziert, wie einen Lemschen Computer mit verbalen Versatzstücken, die contraindiziert abgerufen werden, gespeist hat - stolpert er zurück in sein Pavlodar, allenfalls zu einem Kompromiß mit seiner Gesellschaft fähig:

"es nimmt Bestellungen entgegeq) der Zivil- und Militärschneider aus dem Ausland, Ivan Fokin" 17 ).

Zu einem höchst faulen Kompromiß: das 'Ausland' bleibt aufwertender Bezugshorizont.

Fokins Fähigkeit zur Integration in die Sowjetgesellschaft ist nicht gewachsen. Er ist ein statisches Element in einer dynamisierten Gesellschaft, ein Fremdkörper. Ein Fremdkörper, dessen Gefährlichkeit - und satirische Relevanz - resultiert aus dem hohen prozentualen Anteil des Kleinbügertums an der Sowjetgesellschaft vor allem der Nöp-Jahre.

In Vs. Ivanovs 'Wundersamen Abenteuern ...' wird also durch die Intensiv-Konstituierung des kleinbürgerlichen Wanderers, durch 
seinen Ausbau vom sujetfunktionalen zum zentral problematisierten Element signalisiert, daß die eigentliche Gefährdung der Sowjetgesellschaft nicht vom kápitalistischen Lager ausgeht, daß sie vielmehr in nicht integrierten, kaum integrierbaren Gruppen der eigenen Gesellschaft zu suchen ist. In Gruppen, die gefährlich-belastend sind u.a. auch weil sie die von den kapitalistischen Staaten ausstrahlende Gefahr nicht erkennen, nicht einsehen wollen (und somit für bourgeoise Ideologien anfällig sind), weil sie der eigenen Gesellschaft verständnislos gegenuberstehen, weil sie der von ihnen letztlich mitzutragenden Politik der Bolschewiki - 'Wer den Frieden will, muß für den Krieg gerüstet sein' - kein Verständnis entgegenbringen können.

Damit ist auch die kommunikative Funktion dieses Textes, der präzise den typologischen wie historischen Grenzbereich zwischen 'Außen-Satire' und 'Binnen-Satire' markiert, bereits angesprochen: 'Die Wundersamen Abenteuer ...' dokumentieren die Häßlichkeit und Gefährlichkeit des kapitalistischen systems, bescheinigen somit die Notwendigkeit, gerüstet zu sein zur militärischen Auseinandersetzung mit ihm - der Aspekt der Wehrpolitik, der in den meisten Texten der 'Satire der bourgeois-faschistischen Fratze' interpoliert werden muß, wird hier direkt angesprochen der 'Uniformrock' als Allegorie militärischer Wehrhaftigkeit - und signalisieren darüber hinaus, daß die Hauptgefährdung der sozialistischen Gesellschaft nicht von eindeutig identifizicrbaren und längst identifizierten außenpolitischen Kontrahenten ausgeht, vielmehr in Elementen der eigenen Gesellschaft zu suchen ist, die schwer identifizierbar sind, weil ihr Unverständnis für die eigene Gesellschaft verborgen liegt hinter der Fassade der Loyalität.

Im Falle Fokins ist diese Fassade - im Gegensatz zu den meisten Texten der entwickelten 'Binnen-Satire' - aber noch keine Maske: Fokin tarnt sich nicht, paßt sich nicht an - er sieht noch nicht einmal die Notwendigkeit einer Tarnung seiner kleinbürgerlichen Weltanschauung. Er ist in aller offenheit der Kleinbürger, der er ist - sein Nachfolger ist 'in aller Offenheit' der Sowjetburger, der faktisch ein kleinbürgerlicher Konterrevolutionär ist. 
Dritter Teil: Sonderfall Érenburg - Desorientierte satirische Revue

Il'ja Érenburgs während der 20-er Jahre entstandene große satirische Romane - 'Julio Jurenito' (1922), 'Trust D.E.' (1923) und 'Lazik Rojtschwanz' (1929) ${ }^{1}$ ) - weisen zwar partielle Gemeinsamkeiten mit den oben herausgearbeiteten, die Roman-Satiren des 'Außen-Bereichs' charakterisierenden paradigmatischen Verhältnissen auf. 'Lazik Rojtschwanz' übernimmt darüber hinaus einige der Angriffsobjekte und Darstellungsmuster der unten zu präsentierenden Roman-Satiren des 'Binnen-Bereichs' (des 'eigenen Sozlalhaushaltes'). Trotz dieser (ohnehin nur vordergruidigen) übereinstimmungen in Einzelaspekten (dies betrifft insbesondere den FigurenBestand) entziehen sich alle drei Romane dennoch einer Einordnung in paradigmatische Zusammenhänge, da diese Einzelaspekte in einem sehr spezifischen Kontext von Figuren-Konstitution und Figuren-Konstellation, insbesondere aber der Negativ-PositivPolarisierung stehen.

Die Spezifik dieser Romane erhellt vielmehr gerade aus einer sie paradigmatischen Verhältnissen kontrastierenden Perspektive. Dies gilt zumal für 'Julio Jurenito', der nicht nur der wichtigste (weil bis heute wirkungsreichste) dieser drei satirischen Romane, sondern auch das insgesamt bedeutendste und erfolgreichste küntlerische Werk - im Gegensatz zu publizistischen Arbeiten und den Memoiren 'Menschen, Jahre, Leben' (1961-1965) - Il'ja Érenburgs ist. Die Präsentierung der satirischen Romane Il'ja Erenburgs konzentriert sich folglich auf 'Julio Jurenito' und beschränkt sich darauf, die beiden anderen Romane lapidar zu charakterisieren. 
3.1. I. Erenburg: 'Julio Jurenito'

Il'ja Érenburg ist eine der 'schillerndsten', 'widerspruchsvollsten', "viel bewunderten und viel geschmähten"2) Erscheinungen der sowjetischen Literatur. Und dieselben Epitheta kennzeichnen auch seinen 'Julio Jurenito'.

Es kann an dieser Stelle keinesfalls der Versuch einer 'GesamtAnalyse' des 'Julio Jurenito' unternommen werden. Diese wäre aufgrund der Komplexität dieses Textes - der kontinuierlich nicht aufzulösende Paradoxa konstruiert, eine Über-Fülle von Anspielungen vornimmt, Un-Mengen parodistischer und karikaturistischer Bezüge herstellt - einigermaßen befriedigend nur in einer umfänglichen Monographie zu leisten; darüber hinaus ist eine solche 'Gesamt-Analyse' im Rahmen einer Untersuchung, die sich an der Herausarbeitung von paradigmatischen Zusammenhängen und Entwicklungstendenzen orientiert, auch durchaus verzichtbar.

Wie oben bereits angedeutet, ist Intention dieser überlegungen $z u$ 'Julio Jurenito' vielmehr die Verdeutlichung der Außerordentlichkeit dieses Romans im Gesamtfeld des sowjetischen satirischen Romans (nicht nur der 20-er Jahre!); diese Außerordentlichkeit ist evident zu machen durch die Herausarbeitung sowohl der - wenigen - Merkmale, die 'Julio Jurenito' mit paradigmatischen Verhältnissen $g$ e $m$ e $n$ hat, als auch der - insgesant stark überwiegenden - $a b s$ e $t$ e $n$ d $n$ Merkmale, die den extraordinären Charakter dieses Textes, zugleich aber auch seine extraordinäre kommunikative Problematik ausmachen.

Dabei wird auch in diesem Kapitel weitgehend nach Maßgabe des allen Analysen zugrundeliegenden 'Frage-Horizontes' verfahren; nicht zuletzt, um so auf eine kontinuierliche explizite Gegenuberstellung des 'Julio Jurenito' einerseits, der beiden großen Paradignen des 'Außen-Bereichs' andererseits verzichten zu können. Eine explizite Gegenüberstellung würde nicht nur sehr breiten Raum beanspruchen, wäre in Anbetracht der oben sehr eingehend erfolgten Darstellung der 'Satire des Außen-Bereichs' vielmehr auch allzu redundant. Es mag also genügen, die paradigmatischen Verhältnisse, wo erforderlich, stichwortartig zu signalisieren. 
Problematisch ist die Textlage: Jederzeit zugänglich sind die sowjetische Ausgabe von $1962^{3)}$ sowie die von A. Eliasberg hergestellte deutsche Übersetzung ${ }^{4)}$. Letztere muß ungeachtet ihrer generellen Unzuverlässigkeit dort herangezogen werden, wo der russische Text - und dies betrifft insbesondere das letzte Drittel des Romans, das in der 'Sowjetrepublik' spielt - ein ganzes Kapitel und umfangreiche Passagen eliminiert hat. Ansonsten wird der russische Text zugrunde gelegt.

'Julio Jurenito' ist konstruiert als Ich-Erzählung einer der Roman-Figuren, des erfolglosen Dichterlings und 'Rotonde'-habitué Il'ja Érenburg. Il'ja Érenburg beschreibt im Auftrag des 'Großen Lehrers' Julio Jurenito dessen "Gespräche, Arbeiten und Anekdoten, besonders die Anekdoten"5). 'Gespräche, Arbeiten und Anekdoten', die anfallen während vieler $R$ e $i s n$, die Julio Jurenito mit seinen 'Jüngern' in den Jahren 1913-1921 absolviert und die sie - meist gemeinsam - in viele Länder Westeuropas, nach Afrika und schließlich auch in das revolutionäre Rußland und die junge 'Sowjetrepublik' füren.

Wie in den übrigen Roman-Satiren (vor allem des 'Außen-Bereichs') sind diese 'Reisen' auch hier Reisen durch die Satire-Welt als negativ und lächerlich ausgewiesener Erscheinungen, haben diese Reisen auch hier die Funktion, die storylose pure Aneinanderreihung einzelner Figuren, Episoden (und vor allem: zahlloser Kommentare aus Julio Jurenitos Munde zu ihnen!) zu ermöglichen und zu vertuschen; diese 'Reisen' haben also auch hier die Funktion, auch separat durchaus existenzfähige satirische feuilletons zu einem 'satirischen Roman' zu verklammern (nicht: zu integrieren!).

Der Figuren-Bestand des 'Julio Jurenito' gliedert sich in drei große Gruppen. Nämlich erstens in die Gruppe der $z$ e $t r$ a 1$f i g$ l $r$ e der 'Jünger' Julio Jurenitos. $s$ e sind ganz auf Demonstrativität angelegt, auf das Vorzeigen nämlich von negativen und/oder lächerlichen Qualitäten, die hier aber - im Gegensatz zu allen Roman-Satiren des 'Außen-Bereichs' - nicht 
als 'typisch' für bestimmte gesellschaftliche Organisationsformen oder gesellschaftiche Entwicklungsstadien (bürgerliche Gesellschaft; sozialistische Gesellschaft; Spätkapitalismus faschistischer Orientierung etc.) ausgewiesen werden, sondern als 'typisch' für einen bestimmten 'Weltzustand'; als 'typisch' nämlich, für den aktuellen Zustand des Abendlandes, der abendländischen 'Kultur'.

Die Merkmale dieses Zustandes der 'Kultur' vor dem 'Untergang des Abendlandes, ${ }^{6}$ ) werden herausgearbeitet an den Repräsentanten verschiedener Nationalitäten. Es ist aber keinesfalls gerechtfertigt, diese Merkmale - weil sie an Repräsentanten verschiedener Nationalitäten herausgearbeitet werden und weil die Koppelung von jeweils dominierender Qualität und nationaler Zugehörigkeit ihres Trägers gängigen Klischees der Nationalitäten-Charakterisierung (der Franzose: oberflächlich-verbalisierender Genußmensch; der Deutsche: stur-tatkräftiger Organisationsfanatiker etc.) durchaus entspricht - als typische Eigenarten bestimmter Nationalitäten aufzufassen!

Nejn: diese Qualitäten werden zwar - zumeist eindimensional-plakativ - an statischen Repräsentanten (diese Grundtendenz der Figuren-Konstitution korrespondiert weitgehend allen Satiren des 'Außen-Bereichs') verschiedener Nationalitäten $p r i$ o $i t a ̈ r$ herausgearbeitet. Aber - eben prioritär: der Franzose ist a $u f$ a $n$ d $r$ e $w$ e $i$ e kategorisierungsfanatisch als der Deutsche, auf andere Weise frömmelnd-geschäftstüchtig als der Amerikaner; diese 'andere Weise' - und nur sie! - ist das als für bestimmte Nationalitäten 'typisch' Ausgewiesene, ist gegenüber der $w$ e $s$ e $l i c h$ e $n$ Qualität sekundäres (partiell parodistisches) $K \circ 1$ or $i$-Element. Und: a 11 an diesen Nationalitäten-Repräsentanten vorfindlichen Merkmale rinden ihre Entsprechung in $e \mathrm{i} n \mathrm{e}$ anderen 'Nation'; bei den 'Russen' der 'Sowjetrepublik' nämlich, die alle diese Merkmale auf zugespitzte Weise manifestieren.

Also: die Zentralfiguren demonstrieren überlappend verschiedene E $i \mathrm{n}$ e l-Merkmale der aktuellen Zustandsform der abendländi- 
schen 'Kultur', die $g$ e m $i n g$ m deren gesellschaftliche Systeme ebenso wie Nationalitäten übergreifende essentielle Physiognomie ergeben!

Nach Maßgabe der prioritären (Merkmal-)Demonstrationsfunktionen listet sich die Gruppe der Zentralfiguren folgendermaßen auf (Julio Jurenito selbst kann nicht als eindimensionale Demonstrationsfigur gefaßt werden und bedarf einer gesonderten Analyse):

- der Hierarchisierungsfanatiker und Franzose M. Dele (Delhaie) ${ }^{7}$ )

- der Ordnungsfanatiker und Deutsche Karl Smidt (Schmidt)

- der fromme Kapitalist und Amerikaner Mister Kul' (Cool)

- der Intellektuelle und Russe Aleksey Tǐ̌in (Tischin)

- der Anarchist und Italiener Erkole Bambuti (Bambucci)

- der Kulturschaffende und Jude Il'ja Érenburg

- der außerhalb der 'jüdisch-europäischen Kultur' stehende Afrikaner Ajßa (Ayscha).

Während die Figuren der 'Jünger'-Gruppe Abstraktionen, Reduktionen auf jeweils ein prioritär zu demonstrierendes (und vor allem: von Julio Jurenito zu kommentierendes) Merkmal des abendländischen Weltzustandes sind, sind die der zweiten Gruppe bereits stärker konkretisiert: es sind dies Repräsentanten internationaler politischer Organisationen wie der Haager Friedenskonferenz wie der Genfer Zentrale der Sozialistischen Internationale. Aber auch sie sind durchgehend verkappte Schmidts und Cools, nationalistisch, heuchlerisch, militaristisch wie jene: auch sie keine Alternative. Auch sie somit Belegexemplare für Julio Jurenitos Geschichts-d.h. Endzeitkonzeption.

Die dritte Figurengruppe schließlich konstituieren nur zwei Figuren, zwei konkrete historische Personen: der Papst und der ('Großinquisitor') Lenin. Auch sie fügen sich nahtlos in Julio Jurenitos Geschichtskonzeption ein, auch sie stellen keine positive Alternative zu den Schmidts und Cools dar. D.h. aber insbesondere: auch Lenin ist 'beschränktes' (s.u.) Kind seiner End-Zeit, nicht Exponent der (in den Satiren des 'Außen-Bereichs' einzig möglichen $q u a l i t a t i v e n$ Alternative!

Und schließlich gibt es eine Vielzahl episodischer Figuren, die die Atmosphäre in den bereisten Ländern, aktuelle Situationen 
(wie den Ersten Weltkrieg undie russischen Revolutionen) charakterisieren: Bürokraten, Künstler, Soldaten, Arbeiter, Revolutionäre, Huren ... Sie alle Variationen der an den Zentralfiguren herausgearbeiteten Grund-Merkmale, sie alle Belegexemplare und Kommentar-Objekte; sie alle damit aber auch keine (positiven oder negativen) Alternativen zueinander, zu den Figuren der anderen Gruppen: denn die von Julio Jurenito vermittelte Weltsicht kennt keine Positiv-Negativ-Polarisierung, kennt keine im sozio-historischen Raum vorfindlichen oder durch gezielte politische Aktivität hervorzubringenden Alternativen, kennt nur ein negativ-lächerlich-paradoxes Jetzt (und ebenso paradoxe Kommentare zu ihm) und ein nirgendwo konkretisiertes paradoxes Utopia, kennt nur Desorientiertsein und Desorientierung!

Die oben passim erfolgten Angaben zur Figuren-Konstitution in 'Julio Jurenito' bedurfen der Konkretisierung; sie betrafen wesentlich nur die Basis der Figuren-Konstitution. Das 'wie?' der Konstitution ist zu ergänzen um das 'was?': welches sind die oben angesprochenen 'Merkmale'; welchen Stellenwert haben sie in Julio Jurenitos 'Belehrungen' etc.? Diese Konkretisierung wird sich beiläufig ergeben aus der Analyse der Figur Julio Jurenito; denn alle Figuren sind als Beleg- und Demonstrationsexemplare eingebettet in Julio Jurenitos Weltsicht; denn alle Figuren gewinnen ihre - von allen Satiren des 'Außen-Bereichs' radikal abweichende - Physiognomie erst aus den Kommentaren Julio Jurenitos zu ihnen.

Der Erzähler Il'ja Érenburg (die Figur) hingegen beschränkt sich zumeist darauf, Julio Jurenitos Äußerungen zu seinen 'Jüngern' zu referieren; wo er sich selbst porträtierend und kommentierend zu Wort meldet, geschieht dies im Rahmen der Konstitution seiner selbst als eines weltfremden, naiven - und intellektuell recht unbedarften - Ästheten, der seine Umwelt durch eine nach literarischen, philosophischen Versatzstücken polarisierte Brille wahrnimmt (und unter diesem Aspekt ein Doppelgänger des 'russischen Intellektuellen Tischin ist). Schon "Das erste Kapitel. Meine Begegnung mit Julio Jurenito. - Der Teufel und die 
holländische Pfeife" ${ }^{8)}$, in dem II'ja Érenburg einen "überaus gewöhnlichen Herrn in steifem Hut und grauem Gumimantel"9) die 'Rotonde' betreten sieht (dieser 'gewöhnliche Herr' ist Julio Jurenito selbst!) und in ihm sofort den Teufel 'erkennt', der unter dem Hut seine Hörner, unter dem Mantel "den spitzen, kriegerisch erhobenen Scheif zu verbergen suchte"10), signalisiert, daß II'ja Érenburgs Beobachtungen, Berichterstattungen, Generalisierungen nur bedingt zu trauen ist, daß sie kritischer Hinterfragung bedurfen. Ein Signal, das bei der Beurteilung der kommunikativen Funktion des 'Julio Jurenito' zu berücksichtigen ist:

Julio Jurenito zu Il'ja Érenburg über 'Julio Jurenito': "Über dieses Buch werden die Klugen lachen, die Dummen sich entrüten. übrigens werden die einen wie die anderen höchst wenig verstehen. Sei dann nicht betrübt über deine Talentlosigkeit. Mich zu verstehen ist überhaupt eine schwierige Sache"11). Was macht es zu einer so 'schwierigen Sache' Julio Jurenito zu verstehen?

Ja: K a $n \mathrm{n}$ Julio Jurenito überhaupt verstanden werden, $s \quad 0$ er überhaupt verstanden werden?

Viele Fragen ließen sich anschließen: Fragen, verlachendes Infragestellen - ohne die mindeste Aussicht, fertige Antworten 'serviert' oder auch nur nahegelegt zu bekommen - ist es, was Julio Jurenito als eindeutig rezeptionssteuernde Mittelpunktfigur bei den Rezipienten des 'Julio Jurenito' provozieren soll. Infragestellen, Verlachen, Provozieren sind auch die $s t r$ a $t$ $g$ i e $n$, die Julio Jurenito $s$ e $n$ e $r$ g $g$ e $n$ w $r t$ gegenüber einsetzt; einsetzt mit der $I n t e n t i o n$, den Fäulnisprozeß dieser Gegenwart zu katalysieren - denn "Der Provokateur ist die mächtige Hebamme der Geschichte"12) - um den von Julio Jurenito visionär evozierten idealen Weltzustand beschleunigt herbeizuführen: "Schände Heiligtümer, übertrete Gebote, lache; lache noch lauter, wenn man nicht lachen darf, säubere durch Lachen, durch Qual und Feuer den Platz für das Kommende, damit es für das Leere eine Leere gebe" ${ }^{13)}$. 
'Verlachendes Infragestellen' 'seiner Gegenwart' : diese Gegenwart faßt Julio Jurenito - wie schon angedeutet - nun freilich nicht als wesentlich durch bestimmte sozio-ökonomische und politische Strukturen definierte Gegenwart, er faßt sie vielmehr als 'kulturelle' Gegenwart. Kapitalisten, Sozialisten, Kleriker, Philosophen, Künstler etc. sind für Julio Jurenito letztlich gleich (un)wertige Belegexemplare der im Machtbereich der abendländischen 'Kultur' alt, dekadent erbärmlich gewordenen Gattung Mensch: "nach langen Überlegungen kam er (das war am 17. September 1912) zu dem Schluß, daß die Kultur ein übel sei und daß es gelte, sie auf jede Weise zu bekämpfen, aber nicht mit den erbärmlichen Messern der Hirten Sapatas, sondern mit der von ihr selbst gefertigten Waffe. Man brauche sie nicht zu überfallen, sondern müse auf jede Weise ihre Schwären pflegen, die sich immer mehr ausbreiteten und bereit seien, ihren halbverfaulten Leib zu zerfressen. Dergestalt ist dieser Tag das Datum, an dem Julio Jyfenito seine Mission erkannte - ein großer Provokateur zu sein"

Aus seiner Erkenntnis leitet Julio Jurenito seine Strategie der Bekämpfung der Kultur (mit ihren 'Schwären' 'Staatsleviathan', Religion, Ehe und insbesondere Kunst) ab; eine Strategie, deren 'theoretische' Begründung Julio Jurenitos Geschichtskonzeption liefert, der sein ganz spezifisches Verständnis historischer Dialektik korrespondiert: Zur Beschleunigung des historischen Prozesses bedarf es der Eliminierung aller Erscheinungsformen des 'Übels Kultur'. Diese Eliminierung ist nun aber nicht etwa durch $B$ e $k$ äm $p$ u $g$ von Staat, Religion, Kunst etc. zu erzielen, sondern durch das genaue Gegenteil: es gilt, Staat, Religion, Kunst etc. 'auf jede Weise zu pflegen', weil so zwangsläufig der Punkt erreicht wird, an dem Staat, Religion, Kunst - Kultur - in ihr Gegenteil umschlagen müssen, in die staats-, religions-, kunstlose 'Harmonie' der totalen Anarchie.

Dieses eigenartige Verständnis historischer Dialektik führt im Zusammenhang mit Julio Jurenito wildwuchernd verbalisierter Einstellung allen Erscheinungen der 'Kultur' gegenüber zu einem p a $r$ a $o x$ e $v$ e $r$ a $l t e n$, dessen grundlegende widersprüchlichkeit dadurch, daß Julio Jurenitos 'Belehrungen' jeder Konsistenz entbehren, sich zu keinem Zeitpunkt auflöst (nicht auflösen darf!): Julio Jurenito verhöhnt die unheilige 
Allianz von Kapital und Kirche, von Scheckbuch und Bibel - und tritt in die Dienste des Mister Cool, der sich mit "Dollar und Wort Gottes"15) die Erde untertan macht. Julio Jurenito bekundet "große Verachtung (...) für die Rolle der Kunst in der modernen Gesellschaft"16) ("Welch ein geistloser Scherz, welch ein erbärmliches Harakiri ist der hochmütige Bruch der Kunst mit dem Leben ... Die Kunst wird zu einem Geschicklichkeitsspiel, zu einem Sport für wenige Eingeweihte"17). Julio Jurenitos 'Alternative': "Ich aber ziehe diese Schweinekoteletts mit Erbsen vor" ${ }^{18)}$ ) - und verbringt seine Zeit "gern in Gesellschaft von Dichtern, Malern und Schauspielern"19). Julio Jurenito haßt Ordnung und Organisation - und grüdet mit M. Delhaie eine 'Universale Nekropolis', die jedem Verstorbenen ein seiner 'Klasse' (es gibt deren 17!) entsprechendes Begräbnis organisiert; ... - und 'schätzt' den deutschen Schmidt, der alles normieren, organisieren, alle Widersprüche ausmerzen und dessen "Leidenschaft für Ordnung und system"20) vor "künstlicher Befruchtung"21) und "künstlicher Ernährung"22) nicht Halt machen will. Julio Jurenito - um ein letztes Beispiel zu geben - verabscheut den Krieg - und "suchte mit außergewöhnlicher Geduld und Hartnäckigkeit nach verschiedenen noch ungenutzten Verfahren der Tötung von Menschen"23), entwickelt "Erstickungsgase und Pumpen zum Verspritzen brennender Flüssigkeit" ${ }^{24)}$, Todesstrahlen ...

Die Julio Jurenito kennzeichnende Struktur des Paradoxen wird oft noch zusätzlich dadurch gesteigert, daß seine 'Belehrungen' - die durchgehend $e i n$ ohne weiteres akzeptables Element enthalten - häufig in purem Geschwätz gipfeln: ... Ich aber ziehe Schweinekoteletts mit Erbsen vor!.

Julio Jurenitos Strategie der infragestellenden und verlachenden paradoxen Provokation zur Katalysierung des historischen Prozesses wird auch nicht unterbrochen oder gar ad acta gelegt, nachdem er sein und seiner 'Jünger' Aktionsfeld in das revolutionäre und unmittelbar nachrevolutionäre Rußland verlegt hat. Dieses nachrevolutionäre Rußland - die 'Sowjetrepublik' - ist ihm keine Alternative zu den zuvor bereisten kapitalistischen staaten. 
Auch in der Sowjetrepublik hat der dialektische Sprung, der Umschlag in neue Qualitäten noch nicht stattgefunden. Sie ist keine Alternative, vielmehr "die von mir vorausgesehene zweite Phase"25) der "Krankheit"26); die 'zweite Phase' nicht auf dem Wege der Gesundung, sondern der endgültigen überwindung von 'Kultur' und 'Staatsleviathan': die Sowjetrepublik "unterschied sich naturlich nur quantitativ"27) von dem in den kapitalistischen Staaten Beobachteten. Sie ist ein "nichtfliegendes Flugzeug" 28 ), die fast schon an die Umschlagssituation heranfürende äußerste und groteskeste Steigerung aller 'Schwären' der 'Kultur'. Sie ist ihr Negativ-Apogäum. Und diese 'Steigerung' ist das, was die Sowjetrepublik - Julio Jurenitos Begriff der historischen Dialektik zufolge - allen anderen staten voraus hat. Nicht mehr - aber auch nicht weniger!

"Das Schlimste ist, wenn man anstelle von Abbruch und Neubau eine Reparatur durchfuhrt. Was kann widerlicher sein, als wenn man, nachdem die Galerie ings) Parkett versetzt wurde, ein Stück desselben Inhalts spielt?" - "Die Menschheit geht jetzt durchaus nicht in das Paradies, sondern in das grimmigste, schwärzeste, schweißtriefendste Fegefeuer. Es bricht gleichsam eine Totalfinsternis der Freiheit an. Assyrien und Ägypten werden von dieser neuen, unerhörten Sklaverei ubertroffen werden. Aber diese strafgaleeren werden Vorstufe, Pfand der Freihoit scin (..) Ihr werdet fragen: 'Wozu dann diescr Schritt zurück oder zur Seite, wozu diese zwecklosen, hirnrissigen Monate?!. . Es ist ein guter Anschauungsunterricht! Heute ist es Lige $(0)$ ) Aber es wird der Tag kommen, wo es Wahrheit sein wird" 30 . - "Ihr vernichtet die 'Freiheit' - und darum begruße ich euch. Ihr seid die größten Befreier der Menschheit, denn ihr auferlegt ihr ein herrliches Joch, kein vergoldetes, sondern ein eisernes, solides und organisiertes"

Also setzt Julio Jurenito auch in der Sowjetrepublik seine Provokationen, setzt er sein paradoxes Verhalten fort: als organisator von Meetings ("Ich begrüße euren Wahnsinn, eure närrtschen Schreie, eure sinnlosen Resolutionen und diese Zirkusarena, in der ihr fromm und vollkommen ernst vor dem völlig verdutzten Europa Purzelbäume schlagt!"32), als Verfasser von Dekreten, als Kommissar und 'Oberkommissar' verschreibt er sich gesellschaftlicher Aktivität; nicht etwa jedoch, um an der Entwicklung dieser Gesellschaft mitzuwirken, vielmehr um durch deren Organisierung ("Der Meister glaubte an die große organisa- 
torische und folglich zerstörende Macht"33), die überwindung nicht nur dieser Gesellschaft, sondern von Gesellschaft, Staat, Kultur uberhaupt voranzutreiben.

In einem in der sowjetischen Ausgabe fehlenden Kapitel ('Der Großinquisitor außerhalb der Legende.34), besucht der 'Meister' "die Kapitänsbrücke" 35); er will dort "mit einem Mann sprechen, der dort immer steht" ${ }^{36)}$ : Lenin. Der Kapitel-Titel nimmt den Verlauf des Gesprächs vorweg: Lenin - "ein erhabenes Beispiel gesunder Einseitigkeit (... dessen...) Augenbinde ein großartiger Panzer (ist) gegen den Teufel der Weisheit, der Toleranz und ähnlichen Unsinns. Heute las ich in der' Iswestija' die Liste der Erschossenen ..."37) - ein (ignoranter, inkompetenter) sowjetischer Großinquisitor: "Wir treiben sie vorwärts, wir treiben sie mit eisernen Ruten ins Paradies (...) Den andern ist es leicht zu gehorchen! Aber hier ist die schwere last, hier ist die Pein! (...) wir nabmen ihnen die Verantwortung ab" ${ }^{38)}$. Und Julio Jurenito (der nicht nur in diesem Kapitel Jesus Christus parallelisiert wird): "Ich sah (Sprecher: II'ja Érenburg) hinter meinem Postament, wie der Meister auf ihn (Lenin j.e.) zuging und ihn auf seine hohe, steile stirn küßte (...) 'Ich respektiere immer die Traditionen des Landes. Auch die Kommunisten halten sich, wie ich bemerkt habe, in ihren Sitten an die Tradition'"39).

Wenig später erklärt Julio Jurenito, er müsse nun sterben, da er sein 'Werk abgeschlossen' und 'alles endgülig satt' habe. Einer 'Idee' wegen könne er nicht sterben - "Ich (...) habe, wie du weißt, keinerlei überzeugungen"40). "Bleibt nur die eine Hoffnung - die Stiefel"41). "Und ihretwegen läßt er sich schließlich ermorden - nicht ohne zuvor in seinen "letzten Worten" 4 ) s e i n e positive Alternative (die natürich - Julio Jurenito ist konsequent paradox - keine Alternative ist!) zu den (kapitalistischen oder sozialistischen) 'Staatsleviathanen' dargelegt zu haben:

"Zu Anbeginn eines finsteren, majestätischen Tages sprach ich vom kommenden Tage, wie ein Köter seinem Herrn vorauseilt, 
schnuiffelt, lauscht. (...) Ich sehe den Mittag dieses aufgehenden Tages. Das Parthenon wird in den Kantinen der gigantischen Staaten wie ein armseliges Kinderspielzeug erscheinen. Vor den Muskeln einer beliebigen Wasserpumpe werden sich die welken Arme der gotischen Dome schämen. Ein gewöhnliches Straßenpissoir wird in der Majestät des Betons, in der jungfräulichen Reinheit des Glases die Cheops-Pyramide übertreffen. So wird es sein! Hier, im armen, verwiisteten Rußland sage ich euch dies. Denn bauen werden nicht die, die überfluß an Steinen haben, sondern jene, die sich entschließen, die schweren steinquader mit ihrem klebrigen Blut Zu, vereinen. Ich sehe es voraus, freue mich dessen aber nicht" $"$ ).

Den Endzustand des 'Bauwerkes' beschreibt Julio Jurenito als

'Harmonie' :

"Außerhalb der Harmonie gibt es keine Freiheit, keine Liebe, keinen Sieg über den Tod. Entweder vertilgt Mister Cool mit wissenschaftlichen Methoden Ayscha wie Küchenschaben, oder Ayscha ißt Mister Cool Rippe für Rippe im Familienkreis zum Frühtück (...). Außerhalb der Harmonie gibt es kein Leben, sondern nur ein Existieren von Menschen und Rassen. (...) Ich spreche (...) von dem verlorengegangenen menschlichen Gefuhl, das für das herrliche Leben in Einklang mit dem Weltall unabdingbar ist.

Ich weiß nicht, wie es erworben werden wird: in Laboratorien, auf den Brandstäten einer Elementarkatastrophe oder durch letzte Anspannung des vernünftigen Willens. Ich weiß nicht, wann diese Stunde der Freiheit, des Entzuickens, der Gedankenlosigkeit kommen wird. Ich weiß, daß sie kommen wird. Ich weiß auch, daß man dazu den unausweichlichen Uhrzeiger der Ereignisse, der Kriege unf Revolutionen unseres mir widerwärtigen Tages antreiben muß"

Eine Vorahnung dieser küntigen 'Harmonie' vermittelt der 'kulturlose' Afrikaner Ayscha (denn: "Bei seinen Belehrungen zeigte Julio Jurenito uns gerne verschiedene Exemplare der einen oder anderen Menschensorte" 45 ) ):

"Lieber Ayscha, glaube mir: Du bist der herrlichste aller Menschen, die mir je begegneten. Aber die Welt wird nicht durch deine Kindheit gerettet werden. (...) Damit die Spirale der Welt dem neuen Glück entgegenschnellt, muß der Kreis der Jahr.hunderte, der Kreis des Błufes, des Schweißes, ein eiserner Kreis beschrieben werden" 46 ).

Die Beurteilung der kommunikativen Funktion des 'Julio Jurenito' kommt um eine kurze Beleuchtung der Relation Erenburg (Figur): Erenburg (Autor) nicht herum. Kommt also nicht herum um die Frage: ist (die Figur) Érenburg (der Autor) Érenburg; m.a.W.: teilt (der Autor) Érenburg die begeisterte Aneignung der 'Lehren' Julio Jurenitos durch (die Figur) Érenburg? 
Der Text setzt Signale zur Beurteilung der Relation Érenburg (Figur): Érenburg (Autor): Zwar ist die Figur Érenburg bis ins Detail sehr stark autobiographisch konstituiert ('Rotonde'-habitué, erfolgloser Lyriker, während der Revolutionsjahre Aufenthalt in Rußland und - enttäuschte - Abreise nach Frankreich, Ausweisung nach Holland etc.). Aber - gerade in Anbetracht der stark ausgeprägten autobiographischen Dimension der Figur Érenburg ist es als Signal zu bewerten, wenn diese Figur auf der letzten Seite des Romans von sich sagt: "Mein stark ergrautes Haar, mein unregelmäßiger Herzschlag und meine Schwäche trösten mich. Ich habe den schwierigen Gebirgspaß uberschritten (...) Ich habe schlecht gelebt, eine glückliche Neige meines Lebens wäre eine sinnlose und kränkende Dissonanz"47). (Die Figur) Erenburg: ein Greis; (der Autor) Erenburg: ein junger Mann von (1921) gerade dreißig Jahren!

Ein zweites Signal: (die Figur) Erenburg ist - uber die im ersten Kapitel signalisierte generelle intellektuelle inbedarfheit hinaus - politisch so naiv, wie es (der Autor) Érenburg, der im zaristischen Rußland immerhin schon aus politischen Grüden (RSDAP-Mitgliedschaft) im Gefängnis gesessen hatte und der aus denselben Grüden vor der Revolution in die Emigration gegangen war, mit sicherheit nicht war (auch nicht 1921). So sagt Il'ja Érenburg: "Viele Amerikaner, Engländer und sogar Franzosen beiderlei Geschlechts, die vor wenigen Jahren die Nähe der Front sorglich gemieden hatten, sind jetzt zur Vernunft (!j.e.) gekommen und zeigen die lebhafteste Neugier für die Schlachtfelder" 48 ).

Fazit: auch Erenburg ist (aus der Spannung Figur:Autor) - wie Julio Jurenito - als Paradoxon konstituiert: Érenburg ist Érenburg - und ist es auch wieder nicht. Auch Erenburg eröffnet dem Leser also keine nach Negativ und Positiv scharf polarisierende Perspektive auf den 'Weltzustand' - schon gar nicht die vertraute Perspektive nach Maßgabe gesellschaftlicher Systeme. 
(Der Autor) Érenburg ist ${ }^{49}$ ) g e $g$ e $n$ den Zustand der 'westlichen Demokratien', ohne $f$ i $r$ den Zustand (und die sich aus ihm eröfnenden Perspektiven) der 'Sowjetrepublik' zu sein. Érenburg provoziert durch seinen 'Julio Jurenito' multilaterale Reflexivität - ohne Lösungsmöglichkeiten zu offerieren. Der 'Weltzustand' ist hier nicht objekt einer im gesellschaftlichen Raum liegende Lösungsmöglichkeiten nachweisenden satirischen A $g$ g e s $s$ o $n$; er ist Objekt desorientierter $u n d$ desorientierender 'satirischer' $L$ a $m e t$ a $t i o n e n$.

3.2. V. Kataev: 'Die Insel Érendorf' (Polemik gegen I. Érenburg)

In anderem Zusammenhang (Ansätze zur Weiterentwicklung der 'Satire der kapitalistischen Endzeit') wurde bereits darauf hingewiesen, daß V. Kataevs 'Insel Érendorf' eine gegen Il'ja Érenburg gerichtete literaturpolemische Dimension aufweist. Eine Dimension, die insbesondere zwei Aspekte der Érenburgschen literarischen Aktivität (nicht nur) der ersten Hälfte der 20-er Jahre problematisiert, nämlich: 1) die (fast durchgehend die Qualität erheblich beeinträchtigende) enorme Produktivität dieses Autors und 2) das irritierende Faktum, daß sowohl 'Julio Jurenito' als auch 'Trust D.E.' (und - später - 'Lazik Rojtschwanz') eine eindeutige politische und ideologische Entscheidung ihres Autors - die Entscheidung nämlich g e $g$ e $n$ den Kapitalismus und $f \ddot{u} r$ den (sowjetischen) Sozialismus - nicht erkennen lassen. Der erste Aspekt ist hier ohne Interesse; der zweite hingegen soll kurz angerissen werden, da er die kommunikative Problematik der Érenburgschen satirischen Romane - die Möglichkeit ihrer Einbeziehung in antisowjetische/prokapitalistische Argumentationsstrategien - verdeutlicht.

Erendorf (-Erenburg) entwirft in der 'Insel Erendorf' im Auftrag des 'Königs aller Bosse' Matapal' das Modell der 'idealen kapitalistischen Gesellschaft'. Matapal': "Sie sind folglich einverstanden, eine Insel im Atlantischen Ozean nach allen Prinzipien der idealen kapitalistischen Gesellschaft zu organisieren, für deren großen Kenner und Kritiker man sie bei uns aus irgendeinem 
Grunde hält"50). 'Man' irrt: Érendorf mag zwar ein 'Kenner' der kapitalistischen Gesellschaft sein - ihr 'Kritiker' ist er bestimmt nicht. Érendorf hat sich fest an der sonnigsten stelle der Sonnenseite dieser Gesellschaft etabliert: in Nizza füht er - Inhaber eines Hotels für Milliardäre, der Spielbank in Monte Carlo etc. - die Existenz eines hochverdienenden, hochvermögenden Super-Erfolgsschriftstellers mit sozialkritischem Touch.

Seine literarische Produktion ist ganz am Profit ausgerichtet; die seine nach e $i n$ e Erfolgs-Schablone in ununterbrochener Folge auf den Markt geworfenen Romane charakterisierenden Paradoxa - "profitable Paradoxa"51). Ein (außerkommerzielles) 'Anliegen' kennt er nicht: soziale Probleme und Katastrophen sind ihm nur "toller stoff"52), "sensationelles Material"53) für "einen netten kleinen sozialen Roman"54). Seine Einstellung zur 'Menschheit', deren Schicksal ihm scheinbar am Herzen liegt: "Was aber die Menschheit betrifft - spucken Sie drauf. Ehrlich"55) Auf seine Leserschaft hingegen 'spuckt' der Kapitalist und Kapitalisten-Diener Érendorf nicht; und da er befüchten muß, eines Tages keine freiwilligen Leser - sprich Kunden - für seine Fliebbandromane mehr zu finden, hat er in seinem Modell der 'idealen kapitalistischen Gesellschaft' auch "eine Farm zur Aufzucht meiner künftigen Leser, die aus den allerwiderstandsfähigsten Sorten von Arbeitslosen rekrutiert werden" ${ }^{56)}$ vorgesehen....

'Desorientierend u n d desorientiert! In späteren Äußerungen zu seinem erfolgreichsten Werk - sie enthalten durchgehend ein peccavi-Element - bestätigt Érenburg direkt oder indirekt, daß er mit 'Julio Jurenito' nicht nur desorientieren - m.a.w. Vorurteile, Denkschablonen etc. zertrümern - wollte ("Im 'Jurenito' geißelte ich jedweden Rassismus und Nationalismus, den Krieg, die Grausamkeit, die Habgier"57), daß er vielmehr auch selbst desorientiert war. Direkt: "Unstreitig enthält das Buch eine ganze Reihe hanebüchener Werturteile und naiver Paradoxa; mein Versuch, die Zukunft zu erspähen, gelang eben nur zur Hälfte" 58 ? 
Direkt und indirekt: In seinem Vorwort zur sowjetischen Ausgabe von 1962 erklärt Ërenburg zwar "Es versteht sich, daß es in diesem Buch nicht fehlt an unsinnigen Urteilen und naiven Paradoxa; die ganze Zeit versuchte ich, in die Zukunft zu sehen; das eine sah ich, in anderem täuschte ich mich. Aber $i n s g$ e $s \mathrm{~m} t$ (meine Sperrung j.e.) ist dies ein Buch, von dem ich mich nicht distanziere"59). Dieses 'insgesamt' wird aber dadurch stark relativiert, daß die Rußland-Kapitel des Romans in dieser Ausgabe erhebliche Kürzungen aufweisen, daß insbesondere das Lenin (Großinquisitor-) Kapitel ganz fehlt. Kommentarlos.

'Julio Jurenito' ist zutiefst geprägt durch die Persönlichkeit seines überaus intelligenten, überaus intellektuellen, überaus gebildeten (der Roman ist mit Bildungsgut total uberfrachtet), uberaus produktiven 60) - und uberaus geschwätzigen! - Autors. 'Julio Jurenito' ist die Satire eines Intellektuellen für Intellektuelle ("die gedachten Leser dieses Buches, die ehrlichen Intellektuellen"61), - und entzieht sich somit schon unter dem Gesichtspunkt des (einzigmöglichen) Adressaten-Kreises einer Einordnung in die ubrige sowjetische satirische Roman-Produktion der 20-er Jahre.

3.3. I. Erenburg: Trust D.E.'

V. Kataevs in 'Die Insel Érendorf' vorgetragene Literaturpolemik gegen I. Érenburg betrifft erklärter- und gleichermaßen 'Julio Jurenito' $u \mathrm{n}$ 'Trust D.E.'. Und in der Tat ist der schon ein Jahr später (1923) vorgelegte zweite satirische Roman I. Erenburgs in jeder Beziehung ein 'Nachläufer', der sich an den Erfolg von 'Julio Jurenito' anhängt; dies gilt insbesondere auch für die Zentralfigur und die - für die Beurteilung der kommunikativen Funktion äußerst relevanten - ideologischen Implikationen.

'Die Geschichte ('Istorija') des Untergangs ('gibeli') Europas' (so der Untertitel) erzählt - nicht als Ich-Erzählung, sondern 
als viele Jahre später angefertigter, personal erzählter 'wissenschafticher Bericht' - die sich auf die Jahre 1927-1940 erstrekkende "Agonie Europas"62). Der "Untergang der alten Welt"63) des "sterbenden Europas"64) wird $k$ a $t$ a 1 y $i$ e $t$ durch den "zähen Proselyten"65) (Julio Jurenitos s.u.) und Provokateur Ens Boot, der mit dem Kapital kauziger (! - Vgl. dagegen die 'Satiren des Außen-Bereichs') amerikanischer Milliardäre einen 'Trust zur Zerstörung Europas' gründet und der als "letzter Mensch Europas"66) in der "mitteleuropäischen Wuiste"67) - die nach der von Éns Boot nur beförderten Selbstzerstörung aller Europäer zurickbleibt und die sich bis zum Ural erstreckt - den Tod sucht und findet.

'Trust D.E.' verzichtet auf eine Präzisierung der 'KrankheitsSymptome" der "europäischen Zivilisation"68). Vielmehr hatte Ens Boot - in dessen Blut Europas geographische und soziale Höhen und Tiefen verschmelzen - eines Tages 'einfach so' angefangen, "die europäische Zivilisation zu hassen. (.. Aber - j.e.) selbst wenn es keinen Ens Boot gegeben hätte, Europa wäre dennoch untergegangen (..). Aber selbstverständlich hat die Tätigkeit des Ens Boot die Ereignisse um einige Jahrhunderte beschleunigt"69).

Der ' $r$ und ' seines 'Hasses' (der eine Haß-Liebe ist): "Wir nehmen an, daß Éns Boot den 'Trust D.E.' organisiert und sich am Projekt der Vernichtung Europas nur aus dem Grunde beteiligt hat, daß er ein typischer Europäer seiner Zeit gewesen ist (..) Europa war von der Manie des Selbstmords ergriffen. Es ist keine Übertreibung, wenn wir sagen, daß es, sich selbst tötete. Und Europas treuer Sohn (..), der geniale Ens Boot, verwirklichte das, woran Millionen Europäer der 20-er und 390̄r Jahre dieses Jahrhunderts dachten - den Massen-Selbstmord"70".

"Weshalb haben Sie Europa vernichtet und vier ebenso widerliche Kontinente in Ruhe gelassen? (Ens Boot-Antwort) Weil ich Europa is ebe" 71).

Die 'M $\quad t i v$ a $t$ o $n$ ' seiner 'Provokationen' - "die Idee"liefert die Lektüre des 'Julio Jurenito', die Éns Boot zu einem Zeitpunkt unternimmt, da die selbstzerstörung des "altersschwachen und geilen Europas"73) schon in vollem Gange ist: "Éns Boot war vom heiligen Glauben an die Lehre des großen Provoka- 
teurs ergriffen worden. Mehr als dies: er erkannte, daß sein ganzes Leben nur die Verwirklichung der herrlichen Idee Julio Jurenitos war"74).

In seinem Kommentar zu 'Trust D.E.' vertritt A. Ušakov die Auffassung, dies sei "die phantastische Erzählung von der durch amerikanische Milliardäre bewerkstelligten Vernichtung Europas. In ihr bemüht Érenburg sich, die Gefahr, die der Kapitalismus für die Menschheit mit sich bringt, zu veranschaulichen und zu verdeutlichen. (..) So symbolisiert der Untergang Europas in Erenburgs Buch den Untergang nicht Europas insgesamt, sondern den Zusammenbruch gerade des kapitalistischen Europas"75). Diese kommunikative Beurteilung von 'Trust D.E.' steht in offenkundigem widerspruch sowohl zu obigen Schlussel-zitaten insgesamt als auch zu der expliziten Anknüpfung an die Argumentationsstrategie von 'Julio Jurenito' insbesondere! Diese Beurteilung ist eine Fehlinterpretation, die resultiert aus dem krampfhaften Bemühen, den frühen Érenburg, der $z w i s c h n$ den ideologischen stühlen sitzt, für die $s \circ w j e t i s c h e$ literatur zu 'retten'.

I. Erenburgs Kassandrarufe betreffen weder den westlichen Privat-Kapitalismus noch die sowjetische "NÖp"76) (die sich von ersterem nur dadurch unterscheide, daß der Staats-Boß im Gegensatz zum amerikanischen Privat-Boß "noch keinen Drehschemel"77) habe: sich also we sen $t l i c h$ n $i$ c $t$ unterscheide!); sie betreffen nicht das $k$ a $i t a l i s t i s c h e$, sondern das d e $k$ a $d e n t e$ 'Europa'; Europa bis zum Ural, bis an die Scheide zwischen Europa und Asien:

"In den Bergen des Urals, da, wo die Ferse des Faultiers ruht, stand noch immer ein Pfahl mit der Aufschrift:

Europa Asien

Zu diesem Pfahl flohen die übriggebliebenen Europäer und umarmten ihn abergläubisch wie einen gewissen Talisman. Hinter ihm war die unubersehbare bijgte, vor ihm das gesegnete Reich: Rußland, Asien, die Welt"lol.

Erenburgs impliziter Appell lautet in 'Trust D.E.' also nicht 'Sozialisten erwacht; verhindert, daß der Kapitalismus Europa zugrunde richtet!' (wie in 'Julio Jurenito' fehlt es auch hier 
keineswegs an $e i n g$ e $r$ d $n$ e $t$ e $r$ Sozialisten-Schelte), sondern 'Europa erwache!' ('Europa' auch hier als staten wie Gesellschaftssysteme übergreifendes zivilisatorisches Gebilde). Eine positive Gegenposition - gar eine soziopolitisch konkretisierbare - ist hier noch schwieriger als in 'Julio Jurenito' auszumachen.

\subsection{I. Érenburg: 'Lazik Rojtschwanz'}

Mit seinem 1926 entstandenen, 1929 (wie schon 'Julio Jurenito' und 'Trust D.E.') im Berliner 'Petropolis'-Verlag veröffentlichten satirischen schelmenroman 'Das bewegte Leben des Lazik Rojtschwanz' hat I. Érenburg die Grenzen der Publizierbarkeit in der Sowjetunion evidentermaßen uberschritten. Dieser Roman ist in der Tat in der Sowjetunion nie erschienen und wird bis heute in sowjetischen literaturgeschichten und historischen wie theoretischen Arbeiten zur sowjetischen Satire noch nicht einmal erwähnt 79): 'Lazik Rojtschwanz' ist eindeutig nicht der sowjetischen, sondern der exil $e \mathrm{~s} i s c h e n$ Literatur zuzurechnen 80 ), liegt also außerhalb des Untersuchungsfeldes dieser Arbeit.

Der Roman soll an dieser stelle dennoch kurz charakterisiert werden, da er insbesondere unter den Aspekten 'ursächliche Bestimmung negativer Erscheinungen in der Sowjetgesellschaft' und 'historische Perspektive' in einem signifikanten Kontrastverhältnis zu allen unten zu präsentierenden 'Satiren des Binnenbereichs' steht und damit zugleich (negativ) den normativ abgesteckten Bereich für $s \circ w j e t i s$ c $j$ Satire mö $g$ l i$c h$ e $r$ Angriffsobjekte und Konstitutionsmuster verdeutlicht.

Der - an Wuchs wie sozialer Stellung - kleine Gomeler Jude Lazik Rojtschwanz zieht ('reist') als vielgeprugelter 'Diener vieler Herren' durch die Sowjetunion (der NöP-Zeit), Polen, Deutschland, Paris, England und stirbt schließlich an Hunger und gebrochenem Herzen im Gelobten Land Israel. Als 'Diener vieler Herren' assimiliert er sich (unvollkommen bzw. outrierend) vielen verschiedenen Milieus, karikiert diese dadurch, decouvriert die 'Schwä- 
ren' der jeweiligen 'Herren'. Er ist aber nicht nur Kristallisationskern dieser 'Schwären', er fungiert auch als écran, auf den viele seiner 'Herren' ihre (antibolschewistischen, revanchistischen) Vorstellungen von den Christus und 'Mitterchen Rußland' 'verkauft' habenden 'Bolschewiken' projizieren. Schließlich ist er auch Kommentator der (ausschließlich negativen) von ihm angetroffenen und karikierten Erscheinungen; seine Kommentare entstammen fast ausnahmslos der Legendenliteratur des chassidischen Ostjudentums.

Die wichtigsten dem 'Außen-Bereich' zuzuordnenden Angriffsobjekte seien nur katalogisiert: Nationalismus, Korruption (Polen); ordnungs- und Disziplinsucht; Soldatentum; 'Geschäftstüchtigkeit', gefülsverarmte Kopflastigkeit, Antisemitismus und heuchlerisches Judentum (Deutschland); exilrussischer Antibolschewismus und Revanchismus, Bohémien-Dekadenz, Kunst-Degeneration (Frankreich); Israel: "Ein Land wie alle anderen auch" 81).

Während 'Julio Jurenito' und 'Trust D.E.' die kapitalistischen Staten und die Sowjetunion als gleich(un)wertige Erscheinungsformen von 'abendländischer Kultur', 'Europa' über einen Kamm scheren - die Sowjetunion also durch die $w$ e $i$ e $r$ u $g$, ihr eine überlegenheit zuzuerkennen, diskreditieren, eingeordnet kritisieren - weist 'Lazik Rojtschwanz' der "schwielhändigen Republik"82) spezifische Negativa zu; Negativa, die nicht pauschal als (end)zeitspezifisch, auch nicht als Importe aus der Vergangenheit ('Überbleibsel'), sondern als $s$ y $t$ e $m s$ e$z$ i $f \mathrm{~s} c h$, als von den durch die Revolution herbeigefürten sozialen, ökonomischen, politischen Verhältnissen a $\mu t o p r o-$ d $u z i$ e $r$ e Negativa charakterisiert werden: Die SowjetPhraseologie, die korrupten Genossen - nicht Kleinbuirgernetc.! als Loyalitätstarnkappe dient; die der Bestimmung der 'KlassenProvenienz' dienende 'Anketa'-Flut; Denunziantentum und Justizwillkür, die eine Atmosphäre allgemeiner Angst erzeugen; Korruption; Protektionismus; Spekulantentum; verlogene, alles legitimierende Pseudo-Dialektik; verlogenes Pathos der 'Produktionsliteratur' bei gleichzeitiger Volksarmut, wohnungslosigkeit, Ar- 
beitslosigkeit; Intoleranz gegenüber jeder Form von Normverletzung ...

Kein Wunder, daß der von allen geschlagene, gebeutelte, ausgebeutete Lazik Rojtschwanz nach seiner Odyssee durch den seinen 'Totentanz absolvierenden', 'in Verwesung übergehenden' 'verfaulten Westen' sich zwar nach seinem Gomel' zurücksehnt; zurücksehnt aber nur, weil er in seiner 'Heimat' ("was mich betrifft, so bin ich, nebenbei bemerkt, in Gomel' geboren, und es wird Zeit, daß ich mich auf den Heimweg mache") 83 ) und nicht in der 'Fremde' sterben will. Lazik opponiert 'Heimat' und 'Fremde', nicht 'Sowjetunion' und 'kapitalistische staaten'!

Und optimistisch ist die historische Perspektive kaum zu nennen, die sich (der rezeptionssteuernden Mittelpunktfigur) Lazik für die Zukunft des "blutbefleckten Paradieses"84) Sowjetunion eröffnet - wo man auch ihn, sollte er je zurückkehren, "eins, zwei, drei (als 'Republikflüchtigen' j.e.) erschießen wird" ${ }^{85}$ ). "Gewiß, dort ist es schlecht, dort ist es schwierig. Dort gibt es keine ausgeglichene Temperatur, sondern eine tödliche Zugluft. Aber dort suchen die Menschen nach etwas. Sie irren sich höchstwahrscheinlich. Vielleicht fliegen sie sogar nicht hinauf, sondern hinab, aber sie fliggen doch irgendwohin und gähnen nicht nur auf fertigen Kissen"

Verlogene, heuchlerische etc. - aber doch relativ behagliche (das 'Kissen')- $s t a t ~ i k$ einerseits; verlogene, heuchlerische etc. - zu nicht zu bestimmendem 'Ziel' führende - äußerst unbehagliche $D$ y $n$ a $i k$ andererseits: eine für den potentiellen zeitgenössischen sowjetischen Leser wenig erfreuliche, mit der sowjetischen Ideologie unvereinbare, für die sowjetische Literatur- und Editionspolitik völlig inakzeptable Alternative! 
Vierter Teil:

Satire des 'Binnen-Bereichs' (Eigener Sozial-Haushalt)

Im Jahre 1925 erschloß sich der sowjetische satirische Roman, der bis zu diesem Zeitpunkt jahrelang ausschließlich (mit nur einer registrierten Ausnahme 1) !) die 'zagranićnaja tematika' ('Auslands-Thematik') der Agonie, Häßlichkeit und Gefährlichkeit des kapitalistischen systems uberhaupt, seiner antisowjetisch-faschistischen Konkretisation insbesondere kultiviert hatte, einen objekt-Bereich, für den kleine satirische furmen (so u.a. vor allem Majakovskijs und Bednyj kurze Vers-Satiren sowie Zoščenkos Kurz-Erzählungen etc.) bereits umfangreiche 'Vorarbeiten' geleistet hatten: der in diesem Jahr erscheinende erste sowjetische satirische Roman, dessen Darstellungsobjekte Angriffsobjekten aus dem 'Bereich des eigenen Sozialhaushaltes' korreliert sind - es handelt sich um I. Lukašins 'Die stadt Rüberspuck.2) - kann bereits auf einen festen Bestand an Figuren, Typisierungs- und Decouvrierungsverfahren zurückgreifen, die zuvor in anderen literarischen (und nicht vorwiegend publizistischen ${ }^{3)}$ ) Genres entwickelt worden waren. Ein Faktum, das sich nicht zuletzt auch positiv auf die generell höhere literarische Qualität dieser Satiren des 'Binnen-Bereichs' auswirkt. Der Kreis der Autoren hat sich gewandelt: keiner ${ }^{4}$ ) der Autoren von Roman-Satiren des 'Außen-Bereichs' tritt als Verfasser auch von Satiren des 'Binnen-Bereichs' in Erscheinung - ihre Autoren sind bereits Autoren der 'zweiten Stunde', deren Arbeiten nicht mehr durch das fast alle Satiren des 'Außen-Bereichs' kennzeichnende radikale Mißverhältnis von politischem Engagement und fehlender literarischer Potenz charakterisiert sind.

\subsection{Grobcharakterisierung/Grobgliederung}

Die $A \mathrm{~g} r$ i $f \mathrm{f}$ o $\mathrm{j}$ e $\mathrm{t}$ e dieser Textgruppe, die zunächst noch (bis 1928) mit 'Satiren der bourgeois-faschistischen Fratze' konkurriert, dann bis zum vorläufigen Erlöschen des 
sowjetischen satirischen Romans um 1932 das Genre beherrscht, werden generell dargestellt als ' $S$ o $i o-R e l i k t e$ '. 'Sozio - $R$ e $l i k t e '$ heißt einerseits: die aktuelle gesellschaftliche Negativität dieser Angriffsobjekte - Kleinbürger, Spießer, Klerus, Ex-Bourgeoisie, Ex-Aristokratie, Bürokrat, Apparatschik, Intellektueller, Nöpmann - wird generell kausal zurückgefürt auf den gesellschaftlichen status, den diese sozialen Gruppen und Typen in der vorrevolutionären Gesellschaft innehatten. M.a.W.: sie werden generell dargestellt als Importe aus der bürgerlichen Vergangenheit - eben: als 'perez̈itki', als 'Überbleibsel'.

Die Möglichkeit der Eigen-Produktion gesellschaftlich negativer Gruppen (z.B. der Gruppe der Bürokraten), negativen Sozialverhaltens durch die neue gesellschaftliche widersprüche institutionalisierende junge sozialistische Gesellschaft selbst wird grundsätzlich nicht gesehen, bzw. - vom Typ des Nöpmanns abgesehen - nicht thematisiert.

's o z $i$ - Relikte' heißt aber andererseits: die Darstellung dieser Angriffsobjekte $z$ e $t r i$ e $r$ vorwiegend negative soziale Verhaltensweisen, zentriert nicht diese Verhaltensweisen determinierende, aus der Vergangenheit - oder dem koexistierenden Kapitalismus - importierte Denkmuster (Ideologien, Idealkonzeptionen etc.): Diese werden Angriffsobjekte der 'InnenBereichs'-Satire des 'eigenen Bewußtseinshaushaltes' sein.

Es versteht sich von selbst (und die Arbeit am Textmaterial wird das wiederholt unterstreichen muissen), daß eine Scheidung zwischen 'Binnen-Bereich' und 'Innen-Bereich' nicht mit derselben Eindeutigkeit möglich ist wie die Trennung zwischen 'Außen-Bereich' und 'Binnen-Bereich': hier sind die übergänge bisweilen fließend.

Zwei Kriterien müssen ausschlaggebend sein für die Zuordnung eines konkreten Textes zur 'Binnen-Bereichs', bzw. 'Innen-Bereichs-' Satire: 
1. Zentriert dieser Text negative soziale Verhaltensweisen oder zentriert er diesen zugrunde liegende sozio-politische Denkmuster? Im ersten Fall: Erfullung eines Basis-Kriteriums für die Zuordnung des Textes zur 'Binnen-Bereichs-' Satire. Und vice versa.

2. Sind diese Denkmuster $s t$ a $r$ gekoppelt an sozial

p $r \ddot{a} z i s$ definierte Träger? Wenn ja: Ein weiteres Kriterium für die Zuordnung zur 'Binnen-Bereichs-' Satire.

Anders gefragt: sind diese Denkmuster ausgewiesen als typisch für konkretisierte soziale Gruppen oder Typen - oder signalisiert die Darstellung, daß diese Denkmuster bei einer (nicht mehr einer sozialen Gruppe zuzuordnenden) Vielzahl, bei einer Mehrheit der Sowjetbürger - beim Rezipienten selbst! - ansetzbar sind?

D.h.: signalisiert die Darstellung die sehr starke Generalisierbarkeit, die sehr weite Verbreitung solcher Denkmuster? Wenn ja: Ausschlaggebendes Kriterium für die Zuordnung des Textes zur 'Innen-Bereichs-' Satire.

Stark verändert gegenüber der 'Satire des 'Außen-Bereichs' hat sich die 'paradigmatische Szene'. Einer starken Ausweitung des Figurenbestandes, der Entwicklung mehrerer typologischer Möglichkeiten steht eine geringere Produktion gegenüber: die meisten der im Bereich der 'Binnen-Satire' entwickelten typologischen Möglichkeiten (Nöp-Satire,Intellektuellensatire etc.) sind nur durch einige wenige Texte vertreten.

Die Darstellung der 'Satire der kapitalistischen Endzeit' und der 'Satire der bourgeois-faschistischen Fratze' erfolgte wesentlich unter paradigmatischen Gesichtspunkten. Dieser Darstellungsmodus drängte sich auf durch das Vorhandensein einer Vielzahl sehr stark klischierter Texte - der hohe Klischierungsgrad ließ sich durch die paradigmatische Behandlung direkt vorfuhren, brauchte nicht (für den Leser dieser Arbeit aufgrund der Textlage völlig unkontrollierbar) behauptet zu werden! - und durch 
das Vorhandensein exponierter Einzeltexte, die sich um Auflösung, überwindung, Modifikation des als nicht (mehr) praktikabel erachteten Paradigmas bemihten.

Dieser Darstellungs-Modus muß für die Satiren des 'Binnen-Bereichs' des 'eigenen Sozialhaushaltes' modifiziert werden: um nicht in letztlich nichtssagendes Pauschalieren zu verfallen, muß sich die Darstellung hier orientieren an einer relativ grossen Zahl relativ stark differierender typologischer Möglichkeiten.

Der e $r$ s e Zugang aber auch zu dieser Textgruppe wird für die Aspekte Figurenbestand- und Konstitution, positive Gegenposition, kommunikative Funktion paradigmatisch sein; d.h. er wird zentral das für alle typologischen Möglichkeiten gemeinsame Reservoir an Darstellungs-Verfahren herausarbeiten.

Dem ersten paradigmatischen Zugang wird sich die oft nur auf Einzeltexte zurückgreifen könnende Vorstellung der (anderen s.u.) typologischen Möglichkeiten anzuschließen haben. Diese Vorstellung wird zwar 'repräsentativ' für eine bestimmte Etappe der Entwicklung des sowjetischen satirischen Romans sein, nicht jedoch 'exemplarisch': die vorgestellten Texte sind die einzigen mit Sicherheit identifizierbaren (und verfügbaren!) Texte; 'exemplarische' Konstruktionen, wie sie Vulis vornimmt, sind entweder unkontrollierbar (da die Texte nicht zugänglich sind) oder aber (soweit die Texte zur Verifikation dieser Konstruktionen herangezogen werden konnten) - durchgehend falsch: offensichtlich im Vertrauen auf die Gutgläubigkeit seiner Leser weist Vulis häufig Texte seinen 'exemplarischen Interpretationen' (meist: schlechte 'Inhaltsangaben') zu, die entweder keinesfalls als $s$ a $t r$ e oder keinesfalls als satirische $R \circ m a n$ a (da nur sehr wenige Seiten umfassend) klassifizierbar sind (s.u.). 
4.2. Erste typologische Mölichkeit: 'Satire des Sumpfes'

Die 'Satire des Sumpfes' ist die erste typologische Möglichkeit, die der sowjetische satirische Roman für den Objekt-Bereich des 'eigenen Sozialhaushaltes' entwickelt hat; sie ist zugleich auch die quantitativ am stärksten vertretene Möglichkeit. Was ist dieser 'Sumpf', wo ist er situiert? Der 'Sumpf' ist die in tiefster Provinz - im gesellschaftlichen und geistigen Krähwinkel schlechthin - angesiedelte soziale Reduktionsstufe in die Sowjetgesellschaft nicht integrierter, nicht integrationswilliger, (nicht integrationsfähiger) gesellschaftlicher Gruppen und Typen. Er ist das satirische Reservat der 'kleinen welt' von Kleinbürger und Spießer, der Halb-Welt der Restbestände der vorrevolutionär herrschenden Klassen (Aristokratie, Bourgeoisie, klerus).

Ein 'Sumpf', der nur scheinbar eine rein harmlos-lächerliche, von gesellschaftichen 'Überbleibseln' bewohnte Enklave innerhalb der Sowjetgesellschaft darstellt. Nur scheinbar - denn: dieser 'Sumpr' vegetiert nicht nur in reiner Passivität gleichsam als Menagerie gesellschaftlicher Kuriositäten: dies ist nur ein Aspekt des 'Sumpres' - seinem sozio-historischen Exitus entgegen. Nein: er befindet sich in kontunierlicher. Interaktion mit der 'eigentlichen' Sowjetgesellschaft, reagiert - negativ, vereinzelt auch positiv - auf von ihr an ihn herangetragene Forderungen, agiert im Verborgenen gegen den ihm unverständlichen, ihm widerstrebenden Staat der 'Roten'.

Die 'Satire des Sumpres' erfaßt also nicht nur das 'Sein', das 'Denken' dieser gesellschaftlichen 'Überbleibsel'; vielmehr zentriert sie gerade auch deren $s$ o $i$ a $l$ e $h$ a $l e n$. Dieser 'Sumpf' ist ein echter Sumpf: einerseits treibt er giftige Blasen, die - rosarot behaucht - den 'Marsch durch die Institutionen' antreten, in den sowjetischen Apparat, in die Partei eindringen, diese lähmen, pervertieren; andererseits ist er ein gefährliches Terrain für viele grundsätzlich positive Glieder der Sowjetgesellschaft - er saugt sie ein, korrumpiert, vergiftet sie. 
Der 'Sumpf' enthält, die 'Satire des Sumpfes' thematisiert alle von den Satiren des 'Binnen-Bereichs' uberhaupt erfaßten gesellschaftlichen Negativ-Erscheinungen innerhalb der jungen Sowjetgesellschaft; diese Satire enthält also bereits den gesamten Figurenbestand auch der anderen typologischen Möglichkeiten der 'Binnen-Satire' - also auch Bürokrat, Nöpmann, Intellektueller ('intelligent'): auch diese Typen werden generell dargestellt als mißgeborene Kinder des 'Sumpfes', auch ihre soziale Negativität wird kausal generell zurückgefürt auf ihr tiefes Verwurzeltsein in den nichtproletarischen Klassen der vorrevolutionären Gesellschaft. Die 'Satire des Sumpfes' einerseits, 'Nöp-',('Bürokraten-') und 'Intellektuellen-Satire' andererseits setzen auch wesentlich identische Typisierungs- und Decouvrierungsverfahren etc. ein.

Die 'Satire des Sumpfes' spricht aber auch bereits alle Angriffsobjekte der 'Satire des eigenen Bewußtseinshaushaltes' an, zentriert zumindest deren zentrale argumentative versatzstüke.

Anders gesagt: die 'Satire des Sumpfes' ist die satirische 'Totale', verglichen mit der die anderen typologischen Möglichkeiten der 'Binnen-Bereichs'-Satire - die einzelne Erscheinungen, einzelne Typen herausgreifen oder bestimmte Erscheinungen in stark zeitspezifischer Konkretisation (insbesondere den Nöpmann) zentrieren - 'Nah-', bzw. 'Moment-Aufnahmen' sind. Die 'Satire des Sumpfes' erstellt das Gesamt-Panorama der 'überbleibsel' - aus dem die 'Satire des eigenen Bewußseinshaushaltes' die Momente der 'intellektuellen Physiognomie' isoliert, vergrößert und generalisiert.

Die Tatsache dieses ubergreifenden Charakters der 'Satire des Sumpres. hat natürlich Konsequenzen für die hier vorzunehmende Darstellung der Satiren des 'eigenen Sozialhaushaltes' und des 'eigenen Bewußtseinshaushaltes': die 'Satire des Sumpfes' soll hier so eingehend dargestellt werden, daß die Vorstellung insbesondere der anderen typologischen Möglichkeiten des 'BinnenBereichs' sich auf die an Einzeltexten erfolgende Herausarbeitung 
der über die' Satire des Sumpes hinausfürenden spezifischen Merkmale der 'Nöp-', 'Bürokraten-' und 'Intelligenzler-Satire' konzentrieren kann.

Die Ausfürungen zur 'Satire des Sumpfes' sind also für den 'Binnen-Bereich' weitgehend als paradigmatische Konstruktion, für die 'Satiren des eigenen Bewußtseinshaushaltes' als Erstellung eines kontrastiven Erwartungshorizontes anzusehen.

Eine Gefahr war dabei zu vermeiden: die Tatsache der starken Parallelen zwischen diesen verschiedenen typologischen Möglichkeiten und Textgruppen durfte nicht dazu verleiten, zur Erstellung des 'Paradigmas' 'quer Beet' Belege aus allen Texten der 'Binnen-' und 'Innen-Gruppe' zu sammeln - auf diese Weise würde sich die Darstellung der Möglichkeit begeben, die Spezifik der anderen typologischen Möglichkeiten herauszuarbeiten. Deren $s$ p $z i f i k$ besteht ja gerade nicht in den Gemeinsamkeiten mit der 'Satire des Sumpfes', vielmehr in den Abweichungen bezüglich Figurenbestand, Typisierung, positiver Gegenposition etc.. Die Darstellung der 'Satire des Sumpfes' stützt sich also ausschließlich auf eindeutig dieser typologischen Möglichkeit zuzuordnende Texte!

Der $B$ e $s$ a $n d$ an negativen Figuren ist ungleich weiter gefächert als in den Satiren des 'Außen-Bereichs'. Aus dem Bestand der 'Satire der bourgeois-faschistischen Fratze' werden - bei völlig veränderter Typisierung, Decouvrierung, Figurenkonstellation etc.: das Resultat sind qualitativ neue Figuren! - Bourgeois, Aristokrat, Geistlicher (Pope, Ksendz) 'ubernommen', die im Verein mit Kleinbürger und Spießer den harten Kern des 'Sumpfes' konstituieren. Meist treten Apparatschik und Bürokrat (zur hier vorgenommenen Scheidung zwischen Apparatschik und Burokrat s.u.), Nöpmann und Intellektueller zumindest episodisch-eingeordnet in Erscheinung.

Häufig wird dieser Negativfiguren-Bestand erweitert um Figuren, die entweder als Variationen zu einem der zentralen figuralen Themen (Geistlicher: Mönch, Nonne, 'Heilige Väter'; Bürokrat: 
'bürgerlicher spezialist' etc.) aufzufassen sind oder nur scheinbar bezüglich ihres e $i g$ e $t$ l $i$ h $n$ sozialen Stellenwertes qualitativ andere Figuren darstellen (der Parteibonze, der ein verkappter konterrevolutionärer 'obyvate 1 , 5) ist etc.); es wird sich freilich erweisen, daß der a $k$ u e 11 e soziale Stellenwert des letztgenannten Figurenkreises ein qualitativ anderer ist: sind jene vorwiegend von erbärmlicher Lächerlichkeit, so sind diese vorwiegend gefährlich!

Die Herausarbeitung der $K$ on $t i t$ t $i$ on der Negativfiguren der 'Satire des Sumpfes' kann weitestgehend pauschal für deren gesamten Figurenbestand erfolgen, da sich die Einzelfiguren eigentlich nur durch ihre (meist) explizite oder implizite Etikettierung - 'Kleinbürger', 'Pope', 'Ex-Aristokrat' etc. - unterscheiden: sie alle sind von den nach der 'guten alten Zeit' miefenden Fermenten kleinbürgerlicher Gesinnung, kleinbürgerlichen Sozialverhaltens, kleinbürgerlichen Familienund Liebeslebens so durch- und zersetzt, daß sie wesentlich auf den gemeinsamen Nenner des 'me šcanstro', der 'obyvatel' '̈̌̈ina' reduziert sind.

Es ist dabei allerdings zu beachten, daB gerade diese Gleichsetzung der Mitglieder des 'Sumpfes' - der eine antisowjetische Interessengemeinschaft ist - eines der zentralen VerlachungsVerfahren, eine der zentralen Vernichtungs-Strategien der gesamten Satire des 'Binnen-Bereichs' ist: der Aristokrat, der Intellektuelle etc., die nicht nur den 'Roten', sondern auch ihrem aktuellen gesellschaftlichen Kontext - eben dem 'Sumpf', dessen Dominante der 'Kleinbürger' ist - mit einem gigantischen Überlegenheitsanspruch begegnen, werden über ihre Konstituierung als komische Einzelfiguren hinaus (s.u.) zusätzlich noch dadurch verhöhnt, daß sie dem 'Kleinbürger' - der ihrem Selbstverständnis zufolge unendich tief unter ihnen steht, und zu dem sie sich nur unter dem Zwang der 'vorubergehend' 'aus den Figuren geratenen' Gesellschaftsordnung 'herabgelassen' haben - zumindest 'ebenbürtig', wenn nicht gar unterlegen sind! ${ }^{6}$ ) 
Die Konstitution aller Negativfiguren der 'Binnen-Satire' erfolgt $m$ e h $r$ d $m$ e $n s i o n$ a l. Die Dimension des physischen Erscheinungsbildes - die insbesondere in der 'Satire der kapitalistischen Endzeit' oft Schwerpunkt der Figurenkonstitution war - tritt hier sehr stark zurück, fehlt häufig ganz. In seiner 'Geschichte von drei Heiligen und einigen zweitrangigen Personen 7 ) skizziert A. Buchov das Äußere des obligatorischen Aristokraten :

"Nach seiner Erscheinung war das (..) ein kümmerlicher Blondling mit sinnlichen Äuglein, langem Hals, weit abstghenden Ohren und lustig über beide Wangen verstreuten Pickeln" $"$.

Diese bescheidene Skizze ist das am breitesten angelegte Porträt (einer Negativfigur) aller 'Satiren des eigenen Sozialhaushaltes', die hier berücksichtigt werden können! 9 )

Zumindest angedeutet wird in allen 'Satiren des Sumpfes' die Dimension der vorrevolutionären Biographie der Negativfiguren, die dem Nachweis ihrer festen Verwurzelung in einer anderen, grundsätzlich negativen Gesellschaftsordnung dient, zugleich aber auch dem Nachweis ihrer lächerlichen Statik: der obyvatel' bleibt sich auch unter den Bedingungen einer qualitativ neuen, grundsätzlich positiven Gesellschaftsordnung treu. Sein Selbstverständnis hat weitgehend unbeschadet - oft sogar aufgewertet: er versteht sich nun als Bewahrer der 'wahren Werte' - den qualitativen Sprung in der gesellschaftlichen Entwicklung uberstanden.

Die Herstellung dieser Diskrepanz zwischen antiquiert-statischem Selbstverständnis und qualitativ neuer-dynamischer Gesellschaft ist eine der wichtigsten Verlachungs-Strategien der gesamten 'Binnen-Satire'.

In denjenigen typologischen Möglichkeiten der 'Satire des eigenen Sozialhaushaltes', die Einzelerscheinungen des 'Sumpres' ('Intellektuellen-Satire') oder soziale Gruppen in stark zeitspezifischer Konkretisation ('Nöpmann-Satire') zentrieren, ist die biographische Dimension stark ausgebaut.

Wichtigste Dimensionen der Konstitution der Negativfiguren sind 
aber: 1) Privatleben, 2) sozio-politisches Denken, 3) soziopolitisches Verhalten.

Die Basis-Konstitution der Negativfiguren erfolgt dabei fast durchgehend in eben dieser Reihenfolge (1-3): oft mit traditionellen Verfahren der Ehestands-, Schwiegermutter-, Impotenzetc.-Humoreske wird zunächst die 'private' Lächerlichkeit der 'Helden' vorgefuhrt, bevor das eigentliche satirische Anliegen - die Demonstration ihrer sozialen Negativität und ihrer soziohistorischen Komik - in Angriff genommen wird. Diese Aufeinanderfolge der Objekte des Lachens ist sicher nicht Zufallsprodukt (dazu erfolgt diese Anordnung zu 'gesetzmäßig'), vielmehr rezeptionspsychologisch sehr wohl motiviert - der Leser wird von Anfang an in die erwinschte Rezeptionshaltung eingestimmt: er verlacht von Anfang an die satirischen Helden. 'Verlachen' heißt aber nicht nur irgendeine Überlegenheitshaltung ihnen gegenüber einnehmen, heißt auch: (Zunächst unbewußte) übernahme der überlegenheits-Perspektive des Satirikers, übernahme seiner (meist implizit bleibenden) positiven gesellschaftlichen und politischen Werte! In dieser Opposition, in dieser Spannung zwischen emotionaler Verlachung einerseits und implizit-zu interpolierendem positivem werthorizont andererseits liegt die intellektuelle Aktivierungspotenz vieler Satiren!

Zur Herausarbeitung der Spezifik satirischer Figurenkonstitution - im Unterschied vor allem zu 'humoristischer' und 'realistischer' Figurenkonstitution - empfiehlt sich bei der Analyse satirischer Figuren die gesonderte Betrachtung zweier Ebenen: der Ebene der sozio-politischen Negativität einerseits (denn nur $s \circ z i o-p o l i t i s c h$ negative objekte sind als satirische Angriffsobjekte relevant!), der Ebene der Lächerlichkeit andererseits (denn $v$ e $l$ a $c h$ $n g$ ist unabdingbares Ingredienz der Konstitution satirischer Darstellungsobjekte). $B$ e $i d e$ Ebenen müssen in einer satirischen Figur (eventuell auf dem Umweg der Karikierung dieser Figur durch eine andere(s.u. 'Das Goldene Kälbchen') angelegt sein: die 'böse Schwiegermutter' favorisiertes objekt vieler Humoresken, wird erst dann zu einem 
$s$ a $t$ i $r$ s $h$ relevanten Objekt, wenn sie gesellschaftich negativ ist, wenn sie nur noch 'nebenbei' Schwiegermutter ist (die Mutter in 'Die Herren Golovlev' von Saltykov-ščedrin); andererseits wird etwa Hitler erst dann von einer rein negativen zu einer satirischen Figur, wenn er als lächerlich dargestellt, wenn ihm eine Achillesferse der Verletzlichkeit, Erbärmlichkeit etc. verpaßt wird, die dem Rezipienten ein von Lachen begleitetes überlegenheitsbewußsein vermitteln soll (d.h.: Aggressivität + Überlegenheitsbewußtsein).

Die Dimension des 'Privatlebens' ist primär Ebene der Verlachung: es ist die Sphäre, in der sich in der 'Satire des Sumpes' Er-

bärmlichkeit und Lächerlichkeit in aller Deutlichkeit artikulieren, während sie im unmittelbar gesellschaftlichen Raum getarnt, unter der Chamäleonsfärbung absoluten Angepaßtseins an die 'Roten' verborgen werden. 'Primär' heißt: es versteht sich von selbst, daß auch die Dimension des Privatlebens satirisch relevante Angriffsobjekte umfaßt (der seine Familie tyrannisierende Patriarch ist gesellschaftlich relevant, wenn sein 'Patriarchentum' als aus der bügerlichen Gesellschaft importierte Geisteshaltung dargestellt wird, wenn sein 'Patriarchentum' eine Entwicklung seiner Kinder und seiner Frau zu vollwertigen Gliedern der sozialistischen Gesellschaft verhindert etc.). Die potentielle unmittelbar $s$ a $t r i s c h$ e Relevanz der Dimension 'Privatleben' wird von den 'Satiren des Sumpres', die zentral ganz offenkundig gesellschaftich und politisch relevante Negativität anvisieren, jedoch meist nicht genutzt - die Darstellung des Privatlebens ist ganz auf Verlachung angelegt: der 'Patriarch' wird von seinen eigenen Kindern - die wesentlich 'Kinder' der neuen sozialistischen Gesellschaft sind - verlacht etc... Die Dimension des 'Privatlebens' wird hier folglich in die Verlachungstrategien mit einbezogen.

"Inmitten der Stadt befinden sich der Fluß Pererytica mit der Roten Brücke und die Uferstraße. Auf dem Stadtplatz ein Dom mit füf $Z$ wiebeltürmen, der übertrieben groß ist, nach bourgeoiser Art ... Auf dem Platz berindet sich die gesamte neue Kultur: unlängst hat man dem Marx ein Denkmal errichtet, das 
einem gigantischen Kürbis gleicht. Die Stadt Rüberspuck ist still wie ein schlärriges Kind. Selten erwacht sie: zu Kirchweihfesten, zum Jahrestag der ReY8fution, wenn irgendjemand aus dem Zentrum angereist kommt" "Absolutester Stillstand (...). Weder der Krieg, noch die Revolution, noch der Machtwechsel, weder eigene noch fremde Banditen - nichts und niemand, schien es, konnten die durch nichts zu trübende Ruhe unserer stadt stören, die sich gleichsam mit einer Tarnkappe bedeckt und sich vor allen Winden hinter ihren Kirschg̈̈ptchen und den schiefhängenden Flechtzäunen verborgen hatte" ${ }^{1}$ ).

So porträtieren Lukä̈in resp. Slezkin ihre geographisch in tiefer Provinz angesiedelten, historisch fest in der Vergangenheit verwurzelten obyvatel'-Reservate der gesellschaftlichen überbleibsel: die sowjetischen Krähwinkel sind höchst vergangenheitslastige Kontaminate der 'guten alten Zeit' und des roten Jetzt - $s$ i $n$ die bügerliche Vergangenheit hinter roter Fassade.

Diese Porträts skizzieren zugleich auch allegorisch die Grundstrukturen der 'intellektuellen Physiognomie' der Krähwinkler, die noch fest im heimeligen Würgegriff (der Sowjet-obyvatel' ist ein personifiziertes oxymoron!) der 'guten alten Zeit' sitzen: Alles ist 'scheinbar' beim Alten geblieben; die Neuzeit manifestiert sich nur als hauchdunner roter Firnis, ohne selbst Konturen anzunehmen - Marx gleicht einem 'Kürbis' (das MarxBild der 'Rüberspucker' ist also iberaus bodenständig!). Ja selbst die verbale Etikette für den 'Geist' der Neuzeit hat den Transfer aus der 'großen Welt' in den 'Sumpf' nicht unbeschadet überstanden: in Krähwinkel $l$ a $u$ e $t$ 'marxistisch' "marxisch"i2) in Krähwinkel b e d e u t e t 'marxistisch' schlicht nichts:

"Um ihm einen Gefallen zu tun, hatte Marusja ihn eines Tages gebeten, er möge ihr etwas von Engels zum Lesen bringen - nur nichts yijtorisches, sondern etwas mit Liebe und nichts Neuzeitliches" 13 .

In Krähwinkel hat die Neuzeit der 'roten Wirrköpfe' noch keine eigene Bedeutung: sie ist präsent nur als etwas rein Negatives, auf das es zur Wahrung der eigenen Haut zu reagieren gilt, dem nur mit Haß, Mitleid, Ironie zu begegnen ist.

Überaus einfach aufgebaut ist das Koordinatensystem der 'intellektuellen Physiognomie' des obyvatel, 14), uberaus bescheiden 
- dafür übersichtlich - deren kategoriales Repertoire. Der Kleinbürger - mit ihm seine aristokratischen, boúrgeoisen klerikalen und intellektuellen Gefährten im antisowjetischen Gesinnungs- und (Untergrund-)Kampfverband der gesellschaftlichen 'Überbleibsel' - begegnet der 'historischen', 'gesellschaftlichen', 'politischen' Welt'mit einem Raster, der nur glasklare Oppositionen kennt: Vergangenheit und Gegenwart, herrlich und schrecklich, Gold und Rot, weiß und schwarz - wobei herrlich, Gold, weiß Epitheta der Vergangenheit sind, während schrecklich, Rot, schwarz die der Gegenwart zugeordnete Negativ-Kontrastreihe bilden.

Dieser Raster konstituiert die Weltsicht des obyvatel', konstituiert seine 'Brille', die zwar 'glasklar' - aber polarisiert ist: Sie ergibt ein blendfreies, übersichtliches - den obyvatel' beruhigendes, bestätigendes - Bild der Welt; ein Bild, das nur in das kleinbügerliche Koordinaten- und Wertesystem integrierbare Informationen enthält: alles Vergangene ist herrlich, alles Gegenwärtige ist schrecklich, die Zukunft wird wie die Vergangenheit herrlich sein.

Damit sind das Geschichtsbild der 'Überbleibsel' - ihre Auffassung der historischen Vorgänge, die die oktoberrevolution und den gesellschaftlichen und politischen status quo (um 1925) herbeifuhrten - und ihre Bewertung der Perspektiven der jungen (NöP-) Sowjetgesellschaft bereits angesprochen: die 'sozialistische' Gegenwart ist Produkt einer historischen Entgleisung, die von einer Handvoll unzurechnungsähiger 'bolschewistischer Wirrköpfe', 'Blutsauger', 'Juden' inszeniert wurde. Wie die 'Roten' bewerten auch die Krähwinkler die Gegenwart als 'übergangsphase'. Nur: setzen jene die Nöp als 'Übergangsperiode', "die mit Gesetzmäßigkeitscharakter beim übergang von Kapitalismus zum Sozialismus eintritt" ${ }^{15}$ ) - versteht der obyvatel' sie als unerfreuliche übergangstufe aus dem 'Goldenen Zeitalter' der Vergangenheit - der schlechthin 'guten alten Zeit', an deren Mythos die 'überbleibsel' kontinuierlich weben und wirken - in das ihr wesensgleiche 'Goldene Zeitalter' der Zukunft. Anders 
gesagt: die Gegenwart als Entwicklungsstufe - zurück in die vorrevolutionäre Antike der Gutsbesitzer, Bourgeois, Popen..

Dürftig sind die Argumente, die der obyvatel' für die Allüberlegenheit der Pracht, Herrlichkeit und Gottgefälligkeit dieser $s$ e $i$ e $r$ ureigensten Vergangenheit ins Felde füht: alle 'Satiren des 'Sumpfes' verzichten auf eine inhaltliche Konkretisierung und Präzisierung der Vorstellungen von der 'guten alten Zeit' - die Allüberlegenheit des für die gesellschaftlichen 'Überbleibsel' im wahrsten Sinne des Wortes 'Goldenen Zeitalters' wird als im 'Bewißtsein' des obyvatel' verankert gesetzt und nur mit wenigen Versatzstücken und Assoziationsangeboten signalisiert.

In diese Lücke der Konkretisierung und Präzisierung der 'Ideologie' des obyvatel' stößt die 'Satire des Bewußtseinshaushaltes' vor. Die 'Satire des eigenen Sozialhaushaltes' hingegen verlacht (s.u.) zwar den obyvatel' als $T r$ ä $g$ e $r$ vergangenheitslastiger Ideologien - nicht jedoch diese Ideologien selbst - zentriert vielmehr sein Sozialverhalten, das Resultat seiner nur angedeuteten ideologischen 'Schweinehunde' ist.

Die 'gute alte Zeit' des obyvatel': "Das Leben - es war ein echtes Leben"16). 'Damals' gab es eine "echte Macht"17), die "eine legitime Macht"18) war und das Leben verlief "im normalen Gleis"19 - was nichts anderes besagt, als daß sich 'damals' in "unserem teuren Vaterland"20) "Kommerz"21), "Handel"22), "Besitz"23) der ihnen gebührenden Achtung erfreuten, daß die "Eigeninitiative" 24) des "Gutsbesitzers"25), des "allerreichsten Menschen"26) noch nicht abgeblockt war, daß es 'damals' folglich auch noch "anständige Kunden"27) gab. Ke in Wunder: denn 'damals' waren ja auch 'Kirche' und 'Glaube' - und zwar nicht ein lauer Glaube, vielmehr "feuereifernder Glaube" 28 ) noch unerschütterliche säulen von 'Recht' und 'Ordnung'.

Man sieht - alle wesentlichen Versatzstücke religiös eingefärbter konservativ-bürgerlicher Ideologie gehen in die 'intellek- 
tuelle Physiognomie' des obyvatel' ein. Diese Versatzstücke werden insbesondere in der 'Satire des Sumpfes' nicht - direkt! konkretisiert; sie werden eingesetzt als den ideologischen Status der 'überbleibsel' grob charakterisierende Signale.

Indirekt freilich erfahren diese Versatzstücke eine gewisse Konkretisierung auf einer 'anderen' Ebene 'kleinbürgerlichen' Wunschdenkens; denn die Krähwinkler-Ideale sind (zumindest scheinbar) nicht ausschließlich vergangenheitslastig, finden vielmehr durchaus auch in der Gegenwart einen Nährboden. In einer 'anachronistischen' Gegenwart freilich: die Sehnsucht nach der eigenen Vergangenheit treibt den obyvatel' in die kapitalistischen Länder, in denen diese Vergangenheit noch Gegenwart ist. Diese Koppelung, diese wesentliche Identifizierung von russischer vorrevolutionärer Vergangenheit und kapitalistischer Gegenwart versetzt beiden Gliedern einen satirischen Tiefschlag - sowohl der kapitalistische status quo als auch der russische status quo ante sind um 1925 so eindeutige Negativ-Positionen, daß sie sich hier gegenseitig diskreditieren.

Der Idealcharakter, den 'Paris', 'Konstantinopel', 'Berlin' im sozio-politischen 'Bewußtsein' des obyvatel' annehmen, manifestiert sich auf verschiedene Weise: In seiner harmlosesten Form (die bis heute eines der zentralen Versatzstuicke sowjetischer Satire darstellt) ist 'Rio de Janeiro' 29) - um die seit Il'f und Petrov klassische Kurzformel für den aus obyvatel'Perspektive idealisierten Kapitalismus einzusetzen - 'Gütezeichen': eine Ware ist erst dann spitzenqualität, wenn sich ihr das Epitheton "aus dem Ausland" 30) anflüstern läßt; ein Mensch erst dann "ein echter und kultivierter Mensch"31), wenn seine Provenienz "aus Paris" 32) nachgewiesen ist etc. Kurz: 'vse otlično, simpatično potomu c̈to zagranično.33).

Die zweite Variante der Kapitalismus-Idealisierung ist der Wunsch, sich nach 'Rio de Janeiro' abzusetzen: "Ich will endgültig wegfahren. Nach Paris, nach Konstantinopel, meinetwegen auch aur eine Hundeinsel, nur nicht mit den Bolschewiken" ${ }^{34}$ ). 
Zentrales Motiv ist naturlich die Hoffnung, sich dort eine Existenz aufzubauen, wie sie vor der Machtergreifung der Bolschewiken auch in Rußland möglich war. Aber auch bescheidenere Motive gibt es: "Was es dort nicht alles gibt, in diesem Berlin (..). Man zeigt den Luna-Park, man fährt unter der Erde herum. Und welche Jacken! (..). Neger putzen einem bei jedem Schritt die Schuhe" 35) - der Kapitalismus als Einkaufs- und Dienstleistungsparadies.

Nur ganz vereinzelt artikuliert sich eine Hoffnung, die Motiven aus der gleichzeitigen 'Satire der bourgeois-faschistischen Fratze' korrespondiert; die vage Hoffnung, die kapitalistischen staaten schickten sich an, der "Hölle des Bolschewismus"36) ein Ende zu bereiten:

"Man sagt ein Erdbeben voraus.

- Was hat das zu bedeuten? - fragten die Gäste 37 ).

- Nun, das bedeutet, daß es mit Moskau auf das Ende zugeht. Die Hauptstadt wird in Kostroma (also in allertiefster Provinz! j.e.) errichtet werden. Und an Lenins Stelle wird ein aus Italigy angereister faschistischer Präsident die Macht ubernehmen"

Die - asozialen, weil ausschließlich die Restauration der eigenen materiell und politisch privilegierten vorrevolutionären Situation anvisierenden - gesellschaftlichen Ideale der 'überbleibsel.' werden also wesentlich nur signalisiert. Ihre "Gänsehautgedanken"39) bedürfen auch keiner eingehenden positiven Darstellung - ihre Verdeutlichung erfolgt negativ, bleibt wesentlich dem Leser überlassen: das gesellschaftliche Ideal des obyvatel' ist das genaue Gegenstück zur gegenwärtig - d.h. 'vorübergehend' existierenden - d.h. 'ihrem Ende entgegenvegetierenden' - Sowjetgesellschaft - Nicht-Rot, Nicht-'marxisch'. Kurz: nicht "Bolschewistisch" 40) sondern "russisch" 41 ).

Kernstück der 'intellektuellen Physiognomie' der gesellschaftichen und politischen obyvateli ist folglich auch deren Haß auf die 'Roten', ist ihre zwischen Schadenfreude und Verzweiflung pendelnde Einschätzung der Überlebenschancen der 'bolschewistischen Hölle'. 
Die Perspektive der 'Überbleibsel' ist polarisiert: der ideologisch Polarisationsfilter ihrer politischen Brille läBt fast nur solche Eindrücke passieren, die ihrem Erwartungshorizont gemäß sind: während aus ihren Erinnerungen an die eigene paradiesische Vergangenheit und aus ihren Vorstellungen uiber das kapitalistische 'Rio de Janeiro' alle negativen 'Einschüse' (d.h. aber: das Wesentliche) herausgefiltert sind, ist ihr Bild der sozialistischen Gegenwart ein apokalyptischer - in Rot und Schwarz gehaltener - Totentanz. Alles ist negativ - und an allem, aber auch an allem Negativem sind nur die Roten schuld: Ivan Pavlovic̈ okolesin - "ist Besitzer eines privaten Häuschens und einer kleinen Dienststellung: er arbeitet als Buchhalter der Finanzabteilung" ${ }^{42}$ ) (paradigmatische Personalunion von obyvatel' und Apparatschik s.u.) - bekannte sich zeitlebens als "groBer Liebhaber von Seiten weiblicher Fulle"43) und war feuriger Verehrer und eifersüchtiger Bewacher der wildwuchernden Reize (und nur ihrer!) seiner Ehefrau. In ihre klebrige - zwischen Bett und Eifersuchtsgezänk pendelnde - Eheidylle 'bricht die Revolution ein': aus der fülligen 'Beischläferin und Dienstmagd' (Kleinbürger-Synonym für 'Ehefrau') wird für Okolesin schlagartig - obwohl sie sich selbst nicht verändert - schlicht "eine fette Sau" ${ }^{44)}$. Schuld daran sind angeblich die Roten; tatsächlich 'verliebt sich' - s.u. unter 'Verlachung' - Okolesin in eine ranke 'überbleibsel'-Gattin und rechtfertigt seine seitensprünge 'sozio-historisch', ja 'dialektisch'. Nach dem Muster:

"Heutzutage gibt es eine Unmenge $g$ e m a c h $t$ e $r$ Schurken. (..). Ein Schurke, sozusagen, aufgrund der Bedingungen des Milieus. Sie selbst wissen ja zweifelsohne als politjsch gebildete Menschen, daß das Sein das Bewustsein definiert" 4 .

In einem anderen Krähwinkel erkrankt. eine Kleinbürgerstochter (aufgrund eines schlechten Scherzes) an chronischem Schluckauf: "Krankheiten haben sich da eingenistet, - brummelte der $\operatorname{Graf}(\ldots)$, eben das, was man sowjetische Krankheit nennt. Sie uberlesen sich da an ihrer Polit-Fibel - und das k86 tabei heraus ... Zu unserer Zeit gab es so etwas nicht..."46).

Unter den Bolschewiken hat das Leben seinen Wert verloren: "Das sowjetische Leben - ist kein Leben"47), vielmehr eine 'Hölle des 
Bolschewismus', in der "eine Verfolgung der Kirche vor den letzten Zeiten" 48 ) stattindet - so daß einem 'normalen Menschen' nur der Seufzer bleibt:

"Weh ist mir zumute, ich will keinen Platz mehr im Leben (..) Nichts zu machen, weh ist mir - sagte Anton Antonovic, nachdem er zur seite gespuckt hatte, - im heutigen Leben gibt es für mich keinen Platz mehr (..). Gekränkt hat man mich .. man hat mich gequetscht, requiriert 49 fequiriert (...") heutzutage ist unserem Element weh zumute" 49 ).

Aber, nicht nur die öde der Existenz der obyvateli, die - ihres goldhaltigen angestammten Nährbodens beraubt - sich der "Rückgabe ihres Besitztums"50) und der "Restauration des Throns"51) entgegenlangweilen, ist den Roten zu verdanken. Alleinige Schuld tragen die "wirrköpfigen"52) bolschewistischen "Henker"53) - "die Bolschewiken werden uns vertilgen"54) - auch an allen wirtschaftlichen Schwierigkeiten. (Die obyvateli bekommen die Roten nur mit einer der Psychopathologie und Boulevard-Kriminalistik entlehnten Terminologie in den Griff, deren Funktion die Diskreditierung der Roten ist: ein 'wirrköpfiger Krimineller' ist zur Ausubung der politischen Macht nicht legitimiert!). Denn: "Sie verstehen keinerlei Kommerz. Sie sind reine Tölpel aber kein Staat" 55).

Entsprechend vernichtend beurteilen denn auch die Krähwinkler die Perspektiven der Sowjetmacht: "Sie werden bankrott machen"56); "Teure Freunde (..), nur noch kurze Zeit, nur noch einige Prüfungen .. Und unser teures Vaterland .."57). Mit Schadenfreude werden Versorgungsschwierigkeiten, Engpässe etc. registriert und als 'Vorzeichen' - denn, da der obyvatel' außerstande ist, in sozio-politischen Kategorien zu denken (s.u. unter 'Decouvrierung-Verlachung'), ist er auch hier auf Zeichen und Wunder angewiesen - des baldigen Endes des 'Lebens - das kein Leben ist' interpretiert:

"Die Hoffnungen von Kapiton Petrovič auf die NöP erfüllten sich nur zum Teil (..). Seine weiteren Hoffnungen richteten sich auf jene Zeit, da alles wieder zur Vernunft kommen wird, da Gott der Herr dem Land eine echte Macht geben wird, da das Leben wieder im normalen Gleis verlaufen wird und da anständige Kunden wieder Möbel für nette gemütliche Wohnungen kaufen werden. Jedes Frühjahr - wenn er erfahren hatte, daß das Kooperativ nicht genügend 
Sonnenblumenöl und Nägel hatte - lief Kapiton Petrovid erheitert herum, lïchelte listig uber irgend etwas, scherzte mit seinem Adoptivkind, das mit gestohlener Manufakturware Handel trieb, und klebte auf alle Waren neue Preisschildchen.

- Nun denn, bald, bald, - flüsterte er gerijgt und streichelte väterlich die Diwane, Schränke und Regale"58).

An dieser Stelle sei darauf higgewiesen, daß zwar alle 'Satiren des Sumpfes' im e $n$ e $r$ e $n$ Zeitraum der Nöp - also vor Einleitung des ersten Fünfjahrplanes 1928 - spielen, daß auf eine intensive Herausarbeitung Nöp-spezifischer Elemente aber generell verzichtet wird. Diese Elemente werden vielmehr nur angedeutet - der Nöpmann ist ein obyvatel unter anderen: nier gibt es eine private Konditorei, dort ein privates Nachtlokal etc.. An ihnen werden aber nicht etwa die kommerziellen Machinationen des 'Castnyj sektor' ('Privatwirtschaftlicher Sektor') herausgearbeitet; vielmehr fungieren sie als aus der eigentlichen Sowjetgesellschaft ausgeklammerte 'Vereinslokale' zur Herstellung von Gesprächsrunden der 'Überbleibsel', in denen sich deren Denken, Empfinden (s.u.) - in Ermangelung einer geeigneten story - einigermaßen glaubwirdig artikuliert, in denen antisowjetische Intrigen eingefädelt werden (Also: sujetfunktionale Herstellung einer satirischen Reduktionsstufe der obyvateli). Der Grund für diesen generellen Verzicht auf detaillierte Herausarbeitung dex NöpSpezifik in den 'Satiren des Sumpfes' (im Gegensatz zur eigentlichen 'Nöp-Satire') liegt auf der Hand: die meisten derjenigen satirischen Romane des 'Binnen-Bereichs', die sich um die 'Totale' der gesellschaftlichen 'Überbleibsel' bemühen, erscheinen erst nach 1927, also in der Spätphase der e $\mathbf{g}$ e $\mathbf{r}$ Nöp (1921-1928). Eine starke Betonung der Nöp-spezifik wäre in diesen Romanen zu diesem Zeitpunkt kommunikativ also bedenklich gewesen: der Rezipient wäre in Versuchung geraten, die satirischen Angriffsobjekte als wesentlich erledigt, historisch uberwunden, ihn nicht mehr betreffend anzusehen - die Satire wäre als Humoreske rezipiert worden, hätte sich als kommunikativer Blindgänger erwiesen (s.u. 'Kommunikative Funktion)! 
Dominante der 'intellektuellen Physiognomie' des obyvatel', die - s.u. unter 'Decouvrierung, 60) - eine Physiognomie ohne soziopolitische Intelligenz ist, ist also der $H a B$ auf alles Rote, Kind der Sehnsucht nach Restauration des verlorengegangenen Privilegie-Paradieses.

Dieser $H a ß$ äußerst sich zumeist in ganz direkter Negativ-Epithetisierung der Bolschewiken ('Wirrköpfe', 'Henker' etc.). Oft aber artikuliert er sich auch ironisch; die 'überbleibsel' fühlen sich den Roten so überlegen - bzw. affektieren zur Selbst-Beruhigung dieses Überlegenheitsbewußtsein - daß sie Mitleid mit ihnen empfinden (und dadurch nur noch lächerlicher werden: Mitleid als Steigerungsform des überlegenheitsanspruchs im Kontrast zu totaler Einlösungs-Impotenz): "der bis ins Mark von den Striemen der Sklaverei und der Vorurteile durchgepeitschte obyvatel' luchste ironisch hinter den Ecken hervor"61).

In Slezkins 'Ziegenbock im Gemüsegarten' ist die figurale positive Gegenposition mit der Bilderbuch-Komsomolzin Var'ka besetzt, deren Entwicklung von der allseits 'geachteten' - weil total an ihr obyvatel'-Milieu angepaßten, brutal ausgebeuteten - Dienstmagd zur forsch-emanzipierten Kommunistin den obyvateli ein Dorn des Neides im Auge ist. Dieser Neid artikuliert'sich als hämisches Mitleid: "Und das will eine Frau sein! Eine unglückselige Komsomolzin - Na, ja.. Trotzdem ist sie so etwas wie eine Frau ..."62) - Der politisch links-engagierten Frau wird nach altbewährter konservativer Diffamierungsstrategie die 'Weiblichkeit' abgesprochen - was versehentlich ein Kompliment ist; denn - der obyvatel' versteht unter 'Weiblichkeit': Tauglichkeit für Bett und Herd!

"Nach fester Überzeugung der obyvateli hatten sie (die Komsomolzer j.e.) im Kern nichts aufzuweisen außer wirrköpfiger Jugend und 63 ) Neid als indirektes Eingeständnis - wenn nicht eingesehener, so doch zumindest empfundener - Minderwertigkeit und das 'No..' ('Aber..') des Diffamierungsbedürnisses sind im Bereich der gesamten 'Binnen-Satire' gekoppelt. Die 'Überbleibsel' können zwar nicht umhin die faktische sozio-politische, intellektuelle und 
moralische Überlegenheit der (von ihnen nicht infizierten!) Roten zu registrieren - versuchen aber, diese Überlegenheit durch ein großes 'NO' zu reduzieren. Es bleibt zumeist beim Versuch, denn die Krähwinkler sind außerstande, dieses No inhaltlich zu füllen, zu konkretisieren:

"Die Sowjetmacht ist gut - aber ..."64)

"Die Komsomolzin in Ehren - aber ..."65)

Schon der Neid signalisiert, daß Teile der 'Überbleibsel' - insbesondere im engeren Bereich des 'më̌̈̌́anstvo' - 'auf der Kippe stehen'; d.h.: daß sie bei entsprechender politischer Beeinflussung (Agitation, Schulung) zur Integrationsfähigkeit gefihrt werden können - eines der zentralen intratextuellen Elemente zur Ermittlung der kommunikativen Funktion(en) der 'Satire des Sumpfes'.

Vereinzelt erahnt der obyvatel' aber nicht nur die Hoffnungslosigkeit seiner Restaurationshoffnungen und die standfestigkeit der Roten; vereinzelt erkennt er deren Überlegenheit auch und artikuliert diese Einsicht auch: "die Herzen schluchzten dumpf (im Gedanken an) die unwiederbringlichen Tage"66) - 'unwiederbringlich', denn: "die Bolschewiken, sagt man, werden nicht mehr weggehen"67). Diese Einsicht in die Lächerlichkeit des eigenen konterrevolutionären 'Schweinehundes' und die Vergeblichkeit des eigenen sozio-politischen Verhaltens beraubt diese ihrer 'Legitimation', läßt sie peinlich werden und eben dieser "mëš́anskij styd"68) ('Kleinbürger-Scham') ist Hauptansatzpunkt für alle Versuche, potentiell integrationsfähige 'überbleibsel' in die junge Sowjetgesellschaft einzugliedern, geht folglich auch in die - teils zu interpolierenden, teils direkt apostrophierten s.u. - kommunikativen Funktionen der Satiren des 'Binnen-Bereichs' des 'eigenen Sozialhaushaltes' ein.

Nur in einem der hier berücksichtigten Texte ${ }^{69}$ wird die Entwicklung eines obyvatel' vom 'früheren Kaufmann' zum aktiven 'Atheisten' - d.h. zum 'Maurer'70) der Sowjetgesellschaft direkt vorgefürt. Allerdings wenig überzeugend - diese 'Entwicklung' ist hier ein Sprung, ausgelöst durch ein Eifersuchts- 
Drama: der 'frühere Kaufmann' beschimpft einen 'fröhlichen Maler', der ihn daraufhin auf einem Altarbild als in der Hölle schmachtend darstellt und so einen höchst privat motivierten antiklerikalen 'Klassenkampf' auslöst ...

Haß auf die Roten und ihren alle überkommenen Werte außer Kraft setzenden oder pervertierenden Stat ist Dominante der intellektuellen Physiognomie der Bewohner des 'Sumpfes', der 'Überbleibsel'. Dieser Haß ist darüber hinaus Ursprung und Nährquelle ihres Wunschdenkens: der obyvatel' lebt in bald siegesgewiß-ironischer, bald hoffnungslos-verzweifelter Erwartung des Tages $X$ der Restauration des für ihn Goldenen Zeitalters.

Haß auf die Roten sowie Restaurations-Hoffnung bzw. Restaurations-Gewißheit steuern denn auch das $s$ o $i$ a $l$ e $r$ a l$t e n$ der sowjetischen Krähwinkler - ein asoziales, antisowjetisches Sozialverhalten - dessen Devise lautet: 'Abwarten und Tee trinken'. Was bedeutet: sich dem Aufbau der sozialistischen Gesellschaft verweigern, ihn passiv oder aktiv hemmen, sabotieren; was bedeutet: sein ideologisch gewürtes Süpchen kochen im Verborgenen und auf Kosten der Roten, d.h. aber der Gesamtgesellschaft.

Die Bloßlegung der Negativität dieses schmarotzenden (wie eh und je) und sabotierenden (unter veränderten sozio-politischen Bedingungen hinzutretend) Sozialverhaltens des obyvatel' bedarf zuweilen des 'Skalpells des Satirikers', der ihm sein rotes etc. (s.u.) Fell abzieht. Das Verhalten der gesellschaftlichen 'Überbleibsel' in der jungen Sowjetgesellschaft ist das Verhalten von Chamäleons gegenüber Feind wie Opfer: $T$ a $r$ u $n g$, Anpassung der Fassade an den feindlichen gesellschaftichen Kontext ist denn auch oberste Maxime des Sozialverhaltens der 'Überbleibsel':

"Damals (während des Bürgerkriegs j.e.) gab es offene Feinde, heute unsichtbare, fast nicht zu fangende! viele Feinde gibt es - und zwar sowohl unter den obyvateli als auch unter seinen eigenen Parteigenossen. N4p verbergen sie sich, wie Küchenschaben, in Spalten und Ritzen" 
Die $M \circ t i v a t i \circ n$ e dieses Tarnverhaltens ergeben sich zwingend aus der oben skizzierten 'intellektuellen Physiognomie' der 'Überbleibsel':

- Um die übergangsphase zurück in die Vergangenheit unbeschadet zu überstehen, um auch weiterhin den Trott altväterlichen Lebens traben zu können - während die Roten den Jahrestag der Oktoberrevolution feiern (und dabei von den obyvateli ironisch beobachtet werden), feiern die obyvateli auch weiterhin Kirchweih, Thronbesteigungstag etc.: "wir haben unsere eigenen Feiertage"72) - gilt es um keinen Preis aufufallen. Denn: "In unserer Zeit ist jeder kluge Mensch vorsichtig"73).

- Aber: der obyvatel' will nicht nur irgendwie passiv über die roten Runden kommen - er will gleichzeitig auch seine Schäfchen ins Trockene bringen, sich - wie gehabt - auf Kosten der Arbeit anderer bereichern: stehlen, verschieben, spekulieren. Will Rache üben für ihm von den Roten angetanes 'Unrecht' - und will sich die Rache durch ergaunerten Reichtum versüßen. Will die Agonie der Roten beschleunigen - durch Sabotage, politische Brunnenvergiftung und Korrumpierung bolschewistischer Aktivisten: will die Grenzlinie zwischen dex 'großen Welt' der Roten und der 'kleinen Welt' der aktiven oder passiven Konterrevolution verwischen - will die Exponenten der 'großen Welt' einsaugen in den 'Sumpf' der obyvateli.

Intentionen, die realisierbar sind nur unter dem - vorzugsweise purpurroten - Deckmäntelchen gesellschaftspolitischer Unbedenklichkeit. Aktivitäten, die sorgfältiger Tarnung bedürfen - und die 'Überbleibsel' verfügen über ein festes Repertoire an $r$ a $r$ - $s t r a t e g i e n:$ - Aufbau einer 'harmlosen' 'schaffe-schaffe-Häusle-baue'-Existenz: die obyvateli

"wechselten ihr Fell mehrmals. Sie flogen jeweils wie Zugvögel dahin, wo es warm und vorteilhaft war... Und die im Rahmen einer Ċistka ('Säuberung' j.e.) gefeuerten (..) legten sich bescheidene Häuschen, eine unschuldige Wirtschaft zu. Die 'Pibel des Kommunismus' (..) tauschten sie ein gegen Grammophone (..), gegen Kärige mił 4 fanarienvögeln und kamen peu à peu in bequemen Posten unter" 14 . 
Schon 1920-1921 thematisiert v. Majakovskij in 'o drjani' ('Vom Plunder') die vom 'obyvatel'skij byt' ('obyvatel'-Lebeweise')

- der sich unter einem fadenscheinigen sowjetischen Deckmäntelchen (der obyvatel' apostrophiert seine Ehefrau per 'Genossin Nadja') verbirgt - ausstrahlende Gefahr, die größer sei als die von den Wrangels ausgehende. Schon er setzt den 'Kanarienvogel' als Symbol des 'obyvatel'skij byt' ein. 'o drjani' endet mit dem Appell:

"Schneller

dreht den Kanarienvögeln die Köpfe um -

damit der Kommunismus

nicht duxch die Kanaxienvögel besiegt werde!"75)

Auch Luka'sin ('Rüberspuck') führt die geläufigen Versatzstücke des Kleinbürger 'Gerümpels' an: Bescheidenheit, Harmlosigkeit, Gemütlichkeit, .. Kanarienvogel. Nur: bei ihm (ebenso bei Buchov etc.) signalisieren diese Versatzstüke nicht mehr direkt die - passive - soziale Negativität des vom Ballast der Spießeridylle b e s c $h$ we $r$ e $n$ obyvatel'. Bei ihm sind diese Versatzstücke Elemente der Tarnung, der Harmlosigkeitsdekoration der obyvateli, unter denen sich häufig eine qualitativ andere - aktive - soziale Negativität bewußt-intentional $v$ e $r$ i $r g t$ : der obyvatel' der 'Satire des Sumpfes' ist nicht mehr nur der von der 'drjan'' für die sozialistische Gesellschaft gehandicapte - er ist daruber hinaus aktiver Saboteur, Konterrevolutionär. Folglich ist auch Majakovskijs Appell hier zu modifizieren:

'ReiBt den obyvateli ihre 'Kanarienvögel' vom Leibe - ihre 'Harmlosigkeit' ist nur eine scheinbare! Entfernt die obyvateli aus Apparat und Partei!

Harmlosigkeits- und Neutralitätstarnung auch innerhalb des bürokratischen Apparats: Der obyvatel' will es weder jetzt mit den Roten noch mit den zukiinftigen bürgerlichen Machthabern verderben - folglich bietet er beiden eine aalglatte Oberfläche:

"Wie stellen Sie sich zur Sowjetmacht, fragt man ... Mich,meine Herren-Genossen (auch diese Anrede eine unverbindliche KompromiBFloskel j.e.), mich wird man schwerlich fangen. Zum Beispiel, obwohl das nur eine Lappalie ist, ob ich in dienstlichen Schriftstiucken 'gospodin' ('Herr' - bürgerlich j.e.) und nicht 'graždanin' ('Bürger' - sowjetisch j.e.) schreibe, aber für mich ist das keineswegs eine Lappalie. Die Frage ist nämlich - wie ict fühle. (Ich schreibe 36$)^{\prime}$ ', tiret und ' $n$ '.. Finde da was zu bemängeln, bitteschön"76). 
- Verbal-Tarnung, Aneignung der 'roten' Phraseologie, Affichierung hyper-revolutionärer, hyper-bolschewistischer Gesinnung, verbale und existentielle Anpassung an die rote Neuzeit - auch sie durchgehende Versatzstücke aller Satiren des 'Binnen-Bereichs' des 'eigenen Sozialhaushaltes'.

Hauptfunktion der Biedermann-Tarn-Strategie der 'Kanarienvogel'obyvateli: nicht auffallen, so leben können, als habe es nie eine Revolution gegeben; sekundär treten Motive aktiven konterrevolutionär-sabotierenden Sozialverhaltens hinzu.

Anders der sich a $n p a s$ e $n d e$ obyvatel': er hängt sein Fähnchen in den sozio-politischen wind, um positiv aufzufallen, um sich in Apparat und Partei einzunisten - um sich dort bereichern, um dort sabotieren zu können!

In seiner 'Geschichte von drei Heiligen ...' arbeitet A. Buchov an der Figur des 'bürgerlichen Spezialisten' Zapachin (eines Juristen) die virtuose Anpassungs- und Prostitutionsfähigkeit der obyvateli, zumal ihrer intelligenzlerischen Elemente heraus. Zapachins Biographie ist die eines Chamäleons, ist die Aneinanderreihung völlig verschiedener - aber jeweila total kontextadäquater - Gesichter.

Die Handlung des Romans - mit Sicherheit eine Spitzenleistung des sowjetischen satirischen Romans 77 ) - setzt 1924 ein. Zapachin wird eingefürt als typischer Liberaler, Tolstojaner und Kapital-

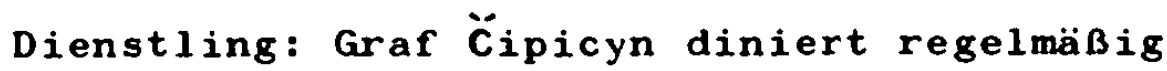

"mit dem Schwurgerichtsbeisitzenden Zapachin, einem hundertprozentigen Liberalen, Mitglied der beiden ersten Staats-Dumen (..). Dienstags und Freitags hielt Zapachin in der Staats-Duma Reden mit Zitaten von Tolstoj und Abreiß-Kalendern, die in den Bezirkshauptstädten Tränen der Rührung hervorriefen; Montags und Donnerstags hingegen verteidigte er vor Gericht potente Klienten, vorzugsygjse Indendanten und Aktionäre, die bankrott gemacht hatten" 18 .

Spontan paßt sich Zapachin nach der Februarrevolution an die veränderte innenpolitische situation an und wird "Vorsitzender der Gesellschaft zur Förderung der Revolution"79) - obwohl er von der baldigen 'Wiederherstellung' der 'Ordnung' überzeugt ist: 
"Alles, alles, wird in Ordnung kommen .. Fünf-sechs Wochen .. Angriffe an der Front .. Ordnung im Lande .. Seien Sie beruhigt, Thre Durchlaucht ... Sind wirgofie echten Revolutionäre etwa
blind? Seien Sie beruhigt .."

Seine kontextadäquate gesellschaftliche Aktivität verfolgt höchst private Ziele:

"Prozesse gab es nicht, aber Zapachin kochte (vor Aktivität j.e.) den ganzen Tag von früh bis spät, trat auf allen Meetings für den Krieg bis zum siegreichen Ende ein (s.o. 'wir, die echten Revolutionäre ..' j.e.) (..) und erwarb wertvolle Verbindungen in Kreisen der Provisorischen Regierung. Diese Verbindungen trugen einen derart praktischen Charakter, daß (..) es ihm gelang (..) zwei Waggons mit Konserven und Brennholz zu bekompen, das ihm auf einem Militärlastwagen ins Haus geliefert wurde"

Nach der Revolution schlägt Zapachin die Laufbahn eines 'bürgerli chen Spezialisten' ein, geht - mit einer selbstgezimnerten exemplarischen Revolutionärs-, Frontkämpfer und Bolschewik-Biographie getarnt - in den Apparat, der - Schaltstelle des sozialistischen Staates! - in allen Satiren des 'eigenen Sozialhaushaltes' Sammel becken 'sozial-fremder' Elemente ist. Die Obrigkeit vermutet in Zapachin zwar einen weißen Wolf im roten Schafspelz - läßt ihn aber vorerst ungeschoren: die junge sozialistische Gesellschaft verfügt noch nicht über genügend 'eigene' Kader, ist folglich zum Aufbau der sozialistischen Gesellschaft auf deren intentionale Totengräber - eben die 'sozial-fremden' 'bürgerlichen spezialisten' - angewiesen:

"Gesockse ..82)

Es gab sogar Versuche, ihn ganz rauszuwerfen - aber da raufte sic der Vorsitzende des Gorsovet noch wittender die Haare und brummelte grimmig vor sich hin:

- Soll er noch eine Zeit arbeiten .. Durch wen soll ich ihn ersetzen? .. Er ist ein hervorragender spezialist. Ich kann nicht mit leuten um mich werfen .. Ein alter Jurist ...

Sein Fragebogen war äußerst nebulös ausgefült. Am hellsten waren in ihm der eine politische Verfolgung wegen Teilnahme an ZemstroTagungen im Jahre 1906 betreffende Punkt und die Frage nach seiner langen juristischen Praxis beleuchtet. Subalterne Mitarbeiter schließlich gaben sich respektvoll mit einigen beiläufig hingeworfenen Phrasen zufrieden:

- Ich habe da irgendwie das Reißen im Kreuz .. Das Rheuma, Väterchen .. Ich habe es mir noch anläßlich der Einnahme des Winterpalais geggft ... Ja und auch die Fronten machen sich bemerkbar ...." 
"Zloslovie"84) ('üble Nachrede'), "spletni"85) ('Gerüchte'), Diebstahl-Hauptebenen der 'gesellschaftlichen Aktivität' der als Biedermänner getarnten, der im Apparat untergetauchten gesellschaftlichen 'überbleibsel'. (In den erfaßten Satiren des 'eigenen Sozialhaushaltes' wird generell der unmittelbar kriminelle Charakter der zu 'Apparatschiki ' mutierten 'Überbleibsel' herausgestellt; Elemente der eigentlichen Bürokraten-Satire - Bürokratismus als Arbeitseinstellung, generell als Geisteshaltung - fehlen hingegen durchgehend! Erst Il'f und Petrov bauen den Bürokratismus in ihre satirischen Totalisierungen ein s.u.).

'Zloslovie', 'spletni' - Verbreitung antibolschewistischer Latrinen-Parolen :

"Die Zamojsker (Zamojsk ist ein sowjetisches Krähwinkel j....) ließen sich gern kurieren, waren aber wählerisch. Zu den Ärzten gingen sie nur ungern. (..) - Parteilose behandeln die Doktoren jetzt schlechter, - sagten sie in der Vorstadt iberzeugt - dem Parteimitglied geben sie eine bessere Mixtur und geben sie Chipin der besten Sorte. Es wurde ein solches Dekret erlassen ...." $86 T^{\text {. }}$

Ideologisch 'gerechtfertigter' Diebstahl:

"Evmenij brachte Fläschchen und Gläschen mit (..), die er für eine geringe Entschädigung beim früheren Kurier einer der (örtlichen j.e.) Organisationen ergattert hatte, der sie eigeninitiativ auf die Seite gebracht hatte, um sie (wie er erklärte) eines Tages der rechtmäßiggf Macht als vor den Bolschewiken gerettete Habe zu übergeben"' (das 'ideologisch gewürzte Süppchen').

I. Lukä̌ins 'Stadt Rüberspuck' ist der mit Abstand aggressivste satirische Roman der Sowjetliteratur. Er zentriert das Problem des obyvatel', der nicht nur den Weg in den bürokratischen Apparat - in die Schaltstellen des sozialistischen staates - gefunden hat, der sich vielmehr im Hirn selbst der neuen Gesellschaft festgesetzt hat, es vergiftet und zersetzt: der obyvatel'-Bolschewik, der in allen Parteiinstanzen - bis hinauf ins Moskauer Zentral-Komitee! - sitzt, wiihlt, sabotiert.

In der Stadt Rüberspuck sind die Grenzen zwischen 'Sumpf' und Partei - sowie den politischen Vollzugsorganen - verwischt, sind - mit einer einzigen figuralen Ausnahme - uberhaupt nicht mehr feststellbar. 'überbleibsel' wie Parteimitglieder sind als noch 
nicht reif gekennzeichnet, als noch nicht reif für die sozialistische Gesellschaft, als schon gar nicht reif für eine würdige KPdSU-Mitgliedschaft.

Diese soziale und politische Unreife wird auf der 'Decouvrierungs'-Ebene (s.u.) signalisiert als ewige Pubertät (diese strategie wird von durchgehend allen 'Satiren des eigenen Sozialhaushaltes' eingesetzt!): ganz Rüberspuck ist eine schwüler Sumpf klebriger Erotik, pubertärer Sexualnöte 'gestandener' obyvateli. Hier ist ein Pope hinter jeder prall gefülten Schürze her, dort versuchen altjüngferlich-unkontrolliert mannstolle Gutsbesitzerstöchter einen zwölfjärigen Jungen inrer Geilheit gefügig zu machen ...

Und diese Atmosphäre brüstiger Unreife hat auch die Partei infiziert: obyvateli und Bolschewikin finden sich regelmäßig zu wïsten gemeinsamen Orgien bei den Nonnen des Rüberspucker Klosters ein, das Partei-Fußvolk angefüht von Mitgliedern des städtischen Ispolkom ('Vollzugskomitee'). Kein wunder folglich, daß sich auch Miliz, Konterrevolutionäre und Nöpmänner zu wilden Saufgelagen zusammentun ...

Kein Wunder auch, daß die politischen Maßnahmen dieser 'Kommunisten' unreif, in ihren Konsequenzen schlicht konterrevolutionär sind. Im 'Klassenkampf' greifen sie zu irrwitzigen Terror-Maßnahmen: Sie verhaften einen durchaus im Rahmen der Nöp-Gesetze seine Geschäfte treibenden Nöpmann, inszenieren seine fingierte Erschießung. Der 'Delinquient' wird vor Angst wahnsinnig und verübt im Irrenhaus als "japanischer Kaiser" 88 ) selbstmord. Die unmittelbare Konsequenz: das Negativbild, das sich die obyvatel'-Bevölkerung zur Abstützung ihrer reaktionären Ideologie von den Bolschewiken gezeichnet hat - ihr antibolschewistisches Feindbild - bestätigt sich. Die 'spletni' "die Bolschewiken werden uns vertilgen" 89 ) bewahrheiten sich im politischen Verhalten dieser 'Bolschewiki': "Die Bolschewiki haben (ihn j.e.) vertilgt"90) Vergiftung der politischen Atmosphäre. 
Der obyvatel Marsch durch die Institutionen' führt bis ins "CKKPSS (b)"91): In Ruiberspuck findet sich der politische Inspekteur, das (faktische, nicht vorgebliche!) ZentralkomiteeMitglied Goloskov ein und "rief zum Kampf gegen Bürokratismus, Parteiarroganz, liederliche Arbeit einzelner Genossen und MiBwirtschaft auf"93). Unter dieser vorzüglichen existentiellen (politischen Position) und verbalen Tarnung - Goloskov zitiert alle Schlagworte der gefürchteten aktuellen čıstka-Kampagne verbirgt sich das Motiv der politischen Rache: Goloskov, "ein ehemaliger Gutsbesitzer" ${ }^{94)}$ und Bruder der mannstollen Gutsbesitzertöchter s.o., war Jahre zuvor als 'sozial-fremdes Element' aus dem Apparat entfernt worden und will sich nun am Regisseur jener c̈istka - dem Ispolkom-Vorsitzenden Anton, einzige positive Einzelfigur des Romans - rächen. Nur zum Zweck dieser Rache an den Roten hatte er - erfolgreich - eine Karriere in der KP betrieben. Die Rache gelingt: Goloskov betrügt das Ispolkom um einen großen Geldbetrag. Zwar wird er bald darauf verhaftet; aber Anton wird von allen 'Kommunisten' Rüberspucks im Stich gelassen, als für Rüberspuck Verantwortlicher nun selbst Opfer einer čistka (die somit, da sie den einzigen echten Bolschewiken aus Rüberspuck entfernt, gar zum Werkzeug der Konterrevolution wird!):

"Aus Moskau reiste eine Spezial-Kommission zur Überprüfung aller Organisationen an (..). Ein kräftiger Zugwind blies in alle Spalten der örtlichen Organisationen. Die per Zufall in die Partei geratenen Parteibonzen intrigierten gegen Anton. Sie einte ein Gedanke: den unbeugsamen Anton loswerden. Und sie wurden ihn $199^{3}$. Sie erreichten, daß Anton nach Sibirien strafversetzt wurde" $95{ }^{\circ}$.

Die Konsequenz des politischen Verhaltens der 'partpidžaki'

('Partei-Bonzen') für die politische Atmosphäre:

"bitteres Mißtrauen nistete sich ein... Genossen gruben einander Gruben, und es ging bis zu Lächerlichem: wie kleine Jungen kletterten sie zu Fenstern hoch, beobachtefop und belauschten heimlich (...) und denunzierten einander" 96 .

Selbst der Kommunist Anton beginnt an der Möglichkeit des Aufbaus der sozialistischen Gesellschaft - in Rußland - zu zweifeln:

"Soll ein anderer in Zukunft in diesem Sumpf arbeiten .. Hundert Antons sind nötig. Die Erziehung eines Kindes erfordert Zeit, dieses Rüberspuck aber ist uns mit allen alten Knochen, mit einem alten Magen zuteil geworden ... (..). Man sollte auf dieses Rüber- 
spuck spucken, - eine derartige Verantwortung (lastet einem j.e.) auf den Schultern. Niemand ist da, mit dem man die Arbeit organisieren könnte, - 999 hte Anton und wurde böse, grimmig wie der Herbst im Norden" 97 .

Kleinbürger, Ex-Adlige und Ex-Bourgeois - die Grundstrukturen ihrer 'intellektuellen Physiognomie' sowie ihr negatives Sozialverhalten: die zentralen Negativfiguren, die zentralen Angriffsobjekte der 'Satire des Sumpfes'. S i e bilden auch den gemeinsamen Nenner des Figurenbestandes aller Satiren des 'Binnen-Bereichs'.

Andere Figuren, damit andere Angriffsobjekte, treten generell - in der 'Satire des Sumpfes' jedoch nur episodisch! - hinzu: Überall zumindest spuren der antiklerikalen Satire (zumeist: Verhöhnung kleinbürgerlichen Wunderglaubens) - aber nur im in sich geschlossenen dritten Teil von A. Buchovs 'Geschichte...' stehen diese Elemente zentral.

Fast durchgehend finden sich eingeordnete 'intelligent'-Figuren - aber erst in S. Zajaickijs 'Lebensbeschreibung ... 98) wird aus dem harmlos-kauzig-lächerlich vor sich hin schwafelnden Intellektuellen ${ }^{99)}$ der satirisch konstituierte, der sozio-politisch direkt negative Intellektuelle, der sein IntellektuellenSein als Alibi einsetzt, sich der Sowjetgesellschaft zu verweigern.

Überall auch Elemente der Spießer-Satire im engeren Sinne des Wortes 100), besser: Elemente der Spießer-Humoreske (fehlende Aggressivität, fehlende kausale Festmachung der dargestellten Lächerlichkeiten und Kauzigkeiten an gesellschaftlichen Zuständen): hier die ihre Tochter um jeden Preis an den Mann bringen wollende Mutter, da die Tochter selbst, die von ihrer bevorstehenden Karriere als Filmstar so uberzeugt ist, daß sie dem erstbesten 'Regisseur' (natürlich: einem 'prochodimec'-'Hochstapler') gemeinsam mit ihrer Mutter auf den Leim kriecht und schließlich 'sitzen bleibt.101) ..... Letztlich harmlose 102) SpieBer-Lächerlichkeit, Spießer-Kauzigkeiten, deren Hauptfunktion in der 'Satire des Sumpfes' Erheiterung des Rezipienten ist, Herstellung 
seiner Bereitschaft zu lachen, zu lachen auch über gesellschaftlich unmittelbar relevante Negativität (anstatt sie zu verdrängen, anstatt sie zu fürchten, anstatt sich ihr unterlegen, ausgeliefert etc. zu fülen): Herstellung damit des satirisch intendierten Überlegenheits-Bewußtseins und damit letztlich auch der Bereitschaft und Fähigkeit, sich mit dieser Negativität politisch auseinanderzusetzen.

Nicht immer wissen die Autoren sich der Gefahr der übergewichtung der humoristischen Elemente zu erwehren: In Slezkins 'ziegenbock ..' etwa erdrückt die Humoreske die Satire; aus dem obyvatel'-'Sumpf' wird eine Kuriositäten-Schaubude, die den Leser mit dem sehr traditionellen Repertoire des Schwiegermutter-Ehestands-Spießer-Klamauks erheitert - und nur erheitert: ein satirischer Blindgänger, Resultat der Verwechslung von Komik und Blödelei.

Alle 'Satiren des Sumpfes' situieren die 'Überbleibsel'-Reservate räumlich in der 'Provinz schlechthin', zeitlich in den Jahren der Hochphase der 'engeren' Nöp: nirgendwo fehlen Merkmale der Nöp wie der 'c̈astnyj sektor' auch im städtischen Bereich, wie vor allem aber auch der Nöpmann selbst. Sie sind wichtig als atmosphärische Elemente, als Fond, vor dem den zentralen von der 'Satire des Sumpres' anvisierten sozio-politischen Problemfällen besondere Brisanz eignet:

"Die Nöp bleckte ihre Zähne, verspritzte ihren giftigen Speichel nach allen Seiten. Für eiserne Leute wie für Anton wafogje keineswegs schrecklich - die Schwachen aber infizierte sie" 103 .

Der Nöpmann signalisiert zwar die sozio-politische Atmosphäre der Jahre um 1925; in keiner einzigen 'Satire des Sumpfes' tritt er aber als Zentralfigur oder auch nur als gleichberechtigte Figur in Erscheinung. Er bleibt hier namenlose Episode. Alle (zumindest für das Genre des satirischen Romans) typischen Elemente der eigentlichen NöP-Satire ${ }^{104}$ ) fehlen: der mit einer präzisierten Biographie ausgestattete und in der Hauptstadt (und nicht mehr in der 'Provinz schlechthin') agierende Nöpmann als zentrale Negativfigur; die enge personelle Verflechtung von NöP-Milieu und bürokratischem Apparat; die kriminelle Kooperation schließlich von Nöpmann und Apparatschik (s.u.). 
In der 'Satire der kapitalistischen Endzeit' wie in der 'Satire der bourgeois-faschistischen Fratze' war die Negativ-Etikettierung der Negativfiguren - in bescheidenem Umfang eingesetzter Bestandteil des Paradigmas: der Kapitalist wurde nicht nur als 'BoB', als 'Unterdrücker', als 'Faschist' etc. dargestellt, er wurde auch - sei es in der Autorenrede, sei es durch eine exponierte Positivfigur, sei es durch die Negativfiguren selbst direkt als solcher benannt, etikettiert.

Auch in der 'Satire des Sumpfes' wird die Negativität der Negativfiguren über die Darstellung hinaus häufig benannt. Die NegativEtikettierung ist aber nicht mehr 'paradigmatisch'; sie ist ungleichmäßig verteilt: während Lukašin ('Rüberspuck ..') kontinuierlich, Slezkin ('Ziegenbock ...') vereinzelt etikettiert verzichtet Buchov ('Geschichte..') völlig darauf, seine Figuren direkt abzuqualifizieren.

Die Verteilung der Elemente der Negativ-Etikettierung steht in einem interessanten Zusammenhang mit der Verteilung der Elemente der Verlachung - im Zusammenhang der umgekehrten Proportionalität: starke Etikettierung und starke Verlachung schließen einander in den 'Satiren des Sumpfes' aus, in keinem der erfaßten Texte befinden sie sich im Gleichgewicht.

Da Lukä̈ıns 'Rüberspuck ..' der früheste, Buchovs 'Geschichte .... 105) der späteste derjenigen satirischen Romane ist, die sich um die 'Totale' der 'Überbleibsel' bemühen, läßt sich diese Beobachtung auch literaturhistorisch formulieren und für den gesamten hier untersuchten Zeitraum generalisieren: unter dem Gesichtspunkt 'Darstellung und/oder Benennung' der Negativität führt die Entwicklung des sowjetischen satirischen Romans von sehr stark 'benennender' Pamphlethaftigkeit zu einem völligen Verzicht auf Etikettierung, vom politisch-agitierenden satirischen Roman-Feuilleton zum mit indirekten Strategien Bewußtmachung intendierenden satirischen Roman (Das 'Goldene Kälbchen' von Il'f und Petrov markiert Höhepunkt und AbschluB dieser Entwicklung). 
'Satire des Sumpfes' - der Titel für diese Gruppe satirischer Romane ist kein Zufall; sowohl slezkin als auch Lukä́in etikettieren ihre Krähwinkel wiederholt als 'Sümpfe': "ein regelrechter Sumpf ist unsere stadt"106) - "Soll ein anderer in Zukunft in diesem Sumpf arbeiten .."107) ... In der "Rüberspucker Grube" 108) "werden wir noch mit Rüberspucker Schlamm zuwachsen"109).

Der Reservat-Etikette korrespondieren die Etiketten für ihre Bewohner: "obyvateli"110), "Kleinbürgertum"111); korrespondieren die direkten Benennungen der zur Lösung anstehenden Probleme: "entschlossener Kampf gegen lifgerliche Arbeit, Kleinbürgertum und die Perepljuevsker Sitten ${ }^{2}$. Er rief alle dazu auf, darauf zu verzichten, sich in ihrem engen Rahmen einzuschljłeßen und einen seriöseren revolutionären Weg einzuschlagen" 13 .

Auch die ganz aktuelle Problemstellung im "hartnäckigen byt"144) und der "durch nichts zu trübenden Ruhe" 115) Krähwinkels wird direkt benannt: "Jetzt haben wir die NöP (..). Der eine braucht eine Karriere, der andere eine gemütliche Wohnung, der dritte wer weiß was - nur nicht den Kommunismus ..."116). Und konsequent erfolgt auch eine ganz direkte politische Zielansprache: "Die Arbeit (..) (zielt j.e.) in drei Richtungen: Kommunisten, NöP und obyvatel'"117).

Der Terminus D e o $\mathrm{c}^{\mathrm{r}} \mathrm{i}$ e $\mathrm{r}$ n ('obličenie') geistert als weitgehend unreflektierte Kategorie durch die gesante sowjetische Satire- und Komikdiskussion. Dabei wird unter 'Decouvrierung' durchgehend die 'Bloßlegung' verborgener, kaschierter - maskierter - gesellschaftlicher Negativität verstanden ${ }^{18}$ ). Dieser 'Decouvrierungs'-Begriff ist so allgemein, daß er nichtssagend ist: insbesondere legt er nicht fest, ob unter 'Decouvrierung' Merkmale der Textkonstitution (die 'Bloßlegung' wird intratextuell an einer Figur etc. mit dem vielbemüten 'Skalpell des Satirikers' durchexerziert) oder aber eine mehr oder weniger zufällig (durch undefinierte Konstitutionsprinzipien) erzielte Rezeptions-Wirkung (dem Leser 'fallen Schuppen von den Augen') zu verstehen ist! 
Dieses an der 'Bloßlegung' von 'maskierter' Negativität orientierte 'Decouvrierungs'-Verständnis verweist auf den normativen Horizont der sowjetischen Satire-Theorie, verweist auf die 'klassischen' russischen Satiriker des 19. Jh.: Gogol' und Saltykovšcedrin. Genauer: verweist auf die sowjetische Gogol'- und

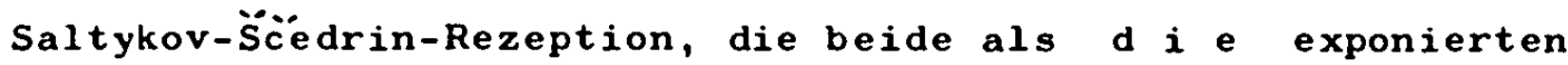
satirischen Kritiker der russischen Gesellschaft des 19. Jh. kanonisiert hat.

(Es sei an dieser Stelle nur beiläufig erwähnt, daß Gogol - im Gegensatz zu dem 'sozialdemokratisch-konstitutionell' orientier-

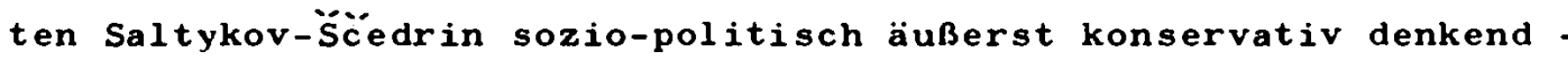
erst bei ideologiekritischer Betrachtung gesellschaftskritisch - im Sinne progressiver Gesellschaftskritik! - verstehbar ist und daß sich diese Erkenntnis in der juingeren sowjetischen Gogol'-Literatur auch artikuliert ${ }^{19)}$ ).

Während aber Saltykov-S̈̈edrin, der vorrevolutionäre D. Bednyj u.a. i n (nicht nur 'm i t'! ) ihren Satiren tatsächlich Repräsentanten der herrschenden Klassen sowie ihrer politischen und ideologischen Sattrapen - also: Aristokratie, Bourgeoisie, Klerus, Beamtentum, konservative politische Parteien - aufs Korn nehmen und ihre (vielen ihrer Leser noch nicht evidente) gesellschaftliche Negativität bloßlegen: sie als negativ decouvrieren, steht der sowjetische Satiriker der 20-er Jahre in einer völlig veränderten sozio-politischen Landschaft, steht damit auch vor völlig veränderten kommunikativen Aufgaben.

Diesen Veränderungen muß die Konstitution satirischer Texte Rechnung tragen: Der Figurenbestand der vorrevolutionären russischen Satire und der Figurenbestand der sowjetischen Satire der 20-er Jahre ('Binnen-Bereich') weisen weitgehende Parallelen auf: Aristokraten, Bourgeois, Beamten, Popen etc.. Aber: die Figuren der 20-er Jahre - und ihre gesellschaftlichen Korrelate! präfigiert ein großes EX: sie sind Ex-Aristokraten, Ex-Bourgeois, Ex-Beamten etc.. Anders gesagt: es sind dies Figuren, deren Korre late im sozio-ökonomischen und politischen Raum weistestgehend 
entmachtet (also: nicht mehr - wie in der vorrevolutionären Satire - Repräsentanten der sozio-politischen Macht), ideologisch weitgehend dethroniert sind, hinter deren $f \quad r$ i $h$ e $r$ gesellschaftliche Negativität die Oktoberrevolution einen Schlußpunkt gesetzt hat. Die Negativität ihres vorrevolutionären Sozialverhaltens (nicht so ihrer Ideologien s.u. 'InnenBereich') bedarf nach der Revolution - zumal gegen Ende des Jahrzehnts - keiner Decouvrierung mehr; sie ist - für die Rezipienten dieser satirischen Literatur, die in gesellschaftichen Gruppen zu suchen sind, die die Sowjetmacht bejahen (während die gesellschaftichen Korrelate der satirischen Figuren der Satiren des 'Binnen-Bereichs' diese Literatur mit Sicherheit a priori ablehnen!) - evident. Und Satire darf nie 'Eulen nach Athen tragen', darf nie Fuhrunternehmen für Gemeinplätze werden: Automatisierung ist der Tod satirischer Rezeption! ${ }^{120}$ )

Bleibt die n e u e unter veränderten sozio-politischen Bedingungen qualitativ andere - gesellschaftliche Negativität des aktuellen Sozialverhaltens der nun zu 'Überbleibseln' degenerierten; auch sie ist für den primär in Frage kommenden Rezipientenkreis weitestgehend evident: dieser weiß 121) längst um das brennende Problem der in die Sowjetgesellschaft Nicht-Integrierten, Nicht-Integrierbaren, kennt das - tagtäglich in den sowjetischen Zeitungen behandelte - brennende Problem der in Apparat und Partei untergetauchten (potentiellen) Konterrevolutionäre etc..

Dieses aktuelle Sozialverhalten, dessen wichtigste Merkmale Tarnung und Schädigung sind, wird folglich in den 'Satiren des Binnen-Bereichs' zwar direkt dargestellt und auch direkt benannt, aber nicht 'decouvriert'; das Problem der 'überbleibsel' wird thematisiert, zur Unterstüzung vorhandener Aggressivität erinnert und demonstriert - aber nicht als eine per intratextueller Decouvrierung erst zu erkennende Aufgabe problematisiert! Konsequent koppeln die 'Binnen-Bereichs'-Satiren entweder die Darstellung von Tarnverhalten und sich hinter einer Loyalitätsmaske etc. verbergendem Schädlingsverhalten ${ }^{122}$ ) oder stellen 
$z u e r s t$ die (potentielle) gesellschaftliche Negativität ihrer Figuren heraus (z.B. anhand ihrer vorrevolutionären Biographie) und weisen erst dann darauf hin, daß sich dieses Schädlingsverhalten unter den Bedingungen der sowjetischen Gesellschaftsordnung oft verbirgt, weil verbergen muB ${ }^{123}$ ). Von einer intratextuellen ${ }^{124}$ ) Decouvrierung gesellschaftlicher Negativität - sie läge dann vor, wenn Ausgangspunkt die Darstellung (vorgeblich) loyalen sozio-politischen Verhaltens wäre und den Figuren erst dann die 'Maske heruntergerissen' würde kann also in aller Regel nicht die Rede sein. Die Übertragung des an Texten vorrevolutionärer progressiver Satire gewonnenen Decouvrierungs-Begriffes auf den sowjetischen satirischen Roman der 20-er Jahre ist also unzulässig!

Es versteht sich von selbst, daß auch eine Satire ohne intratextuelle 'Decouvrierung' extratextuell - nach Maßgabe des Erwartungshorizontes der Rezipienten - decouvrierende, ihm bislang nicht bekannte, nicht bewußte Problemstellungen aufdeckende Wirkung haben kann. $D i$ e wirkung ist aber keine satire-spezifische, kann vielmehr auch von anderen 'Textsorten' erzielt werden. Hier interessieren aber gerade satire-spezifische - und satire-spezifisch gesteuerte! - Rezeptions-Wirkungen, d.h. solche Wirkungen, die vom Text (über die objekt-Konzentrierung auf Negatives hinaus) mit spezifischen Mitteln $s$ a $i r i s c h e r$ Textkonstitution erzielt werden!

Was nicht bedeutet, daß die Kategorie 'Decouvrierung' überhaupt auf den sowjetischen satirischen Roman der 20-er Jahre nicht mehr applizierbar sei. Denn: auch diese Satire 'decouvriert' ihre Negativfiguren; sie decouvriert aber nicht mehr prioritär deren gesellschaftliche $N$ e $g t i v i t a ̈ t$ (die sie direkt darstellt und benennt), vielmehr deren $L$ ä $c h$ e 1 i c h$k$ e $i$ (Nichtigkeit, Verurteiltsein)! sie $v$ e $l$ a $c h t$ s i e !

Somit unterscheiden sich die sowjetischen Satiren des 'BinnenBereichs' nicht nur wesentlich von der russischen vorrevolutionären Satire (andere prioritäre Decouvrierungs-Ebene), sondern 
auch fundamental von den Satiren des 'Außen-Bereichs': In den bis 1925 dominierenden satirischen Romanen (der 'kapitalistischen Endzeit' und 'der bourgeois-faschistischen Fratze') gab es wenig zu lachen; wo man lachte, lachte man vorwiegend über die Unfähigkeit der Autoren. Die Satiriker der Romane des 'Binnen-Bereichs' (und des 'Innen-Bereichs') hingegen haben auf ihr Panier geschrieben: Es darf gelacht werden! Genauer: Es muß gelacht werden!

Alle Negativfiguren der Satiren des 'Binnen-Bereichs' sind konstituiert als zu verlachende komische Figuren. Thre Komik resultiert durchgehend aus dem Spannungs-Verhältnis zwischen soziohistorischem und politischem Anspruch einerseits, objektiver und subjektiver Einlösungs-Impotenz andererseits: dies ist die Grundstruktur aller Decouvrierungs-d.h. Verlachungs-strategien der Satiren des Binnen-Bereichs'.

- $0 b j e k t i v$ Einlösungs-Impotenz: Der sozio-historische und politische Anspruch der 'Überbleibsel' ist Vater und Kind zugleich ihrer Restaurationshoffnung, ihrer wunschgeborenen Gewißheit, die Tage der Roten seien gezählt. Diese Hoffnung, diese GewiBheit stehen im Widerspruch zur objektiven (in den Erwartungshorizont der Rezipienten eingehenden!) Tatsache der eindeutigen Verfestigung der Macht der Bolschewiki, der endgültigen Etablierung des sozialistischen States; der sozio-historische und politische $A \mathrm{n} p \mathrm{r}$ c also im Widerspruch zu den objektiven sozio-historischen und politischen $F$ a $k$ e $n$ (Was etwas völlig anderes ist als das von Ja. El'sberg (s.o.) zur Begrünung seines Begriffes des 'objektiv Komischen' eingeführten $p$ o $t$ u $l$ a eines 'objektiven historischen Entwicklungsgesetzes'. 'Objektives historisches Entwicklungsgesetz' und 'Erwartungshorizont' des zeitgenösischen Rezipienten sind nicht identisch: diesen sozio-politischen 'Erwartungshorizont', mit dem der Leser den Texten der 'Binnen-Satire' begegnet, konstituieren primär seine sozio-politischen Erfahrungen nicht geschichtshypothetische 'objektive' Entwicklungsgesetze!). 
D $i$ e $s$ e Spannungs-Verhältnis nimmt in der Konstitution der Texte der 'Binnen-Satire' aber nur geringen Raum ein, seine Herstellung bleibt wesentlich dem Rezipienten überlassen: während die Satiren des 'Außen-Bereichs' die Überlegenheit, den endgültigen Sieg der sozialistischen Gesellschaftsordnung (und damit des Sowjetstaates) eingehend thematisieren, werden überlegenheit und SiegesgewiBheit in den Satiren des 'Binnen-Bereichs' nur signalisiert. Signalisiert einerseits anhand der allseitigen (d.h. nicht nur sozio-politischen, vielmehr auch intellektuellen, moralischen etc.) Überlegenheit ${ }^{125)}$ der figuralen Vertreter der positiven Gegenposition (s.u.). Vor allem aber wird die irreversible Überlegenheit der Roten indirekt signalisiert: die 'überbleibsel' reagieren kontinuierlich auf die verhaßte, neidvoll als überlegen empfundene Sowjetmacht, fürchten sich, passen sich ihr an etc. - sind also ungeachtet ihres Anspruchs auf politische, intellektuelle, moralische Überlegenheit längst in die Defensive des letzten Widerstandes, an die Wand gedrängt. Eine weitere Möglichkeit (die rezeptionspsychologisch problematischste. s.u. unter 'Kommunikative Funktion') der Darstellung der endgültigen Überlegenheit der Sowjetmacht nutzt Buchov: er zeichnet den sozio-politischen Geschichtsverlauf 1914-1925 in scincm (1930126) veröffentlichten) Roman nach und läßt seine Negativfiguren in diesem historisch präzisierten Raum agieren, zunächst florieren und schlieblich auch - die Sowjetmacht hat sich endgültig konsolidiert - im sozio-politischen Raum scheitern (sie werden verhaftet).

- Hauptebene der intratextuell direkt gesteuerten Verlachung ist aber die Ebene der $s u b j e k t i v e n$ Einlösungs-Impotenz: nach altbewährter satirischer Taktik werden die Repräsentanten gesellschaftlicher und politischer Negativität als 'Menschen' verlacht, der Nachweis ihres sozio-politischen Verurteiltseins etc. gefüht über die Decouvrierung $n i c h t$ der Unhaltbarkeit ihrer politischen Konzeptionen etc., sondern ihrer 'persönlichen' Lächerlichkeit, Erbärmlichkeit, Dummheit etc. - der satirische Knüppel schlägt den Sack, trifft den Esel ... Nur ganz 
vereinzelt wird direkt der Nachweis gesellschaftlicher, politischer Lächerlichkeit geführt (die Unfähigkeit politisch zu denken als thematisierte Variante genereller Dummeit s.u.).

Das Repertoire an Verlachungs-Strategien ist umfangreich; da die meisten dieser Strategien aus der satirischen Literatur anderer Epochen vertraut sind, kann sich ihre Vorstellung hier wesentlich darauf beschränken, sie zusammenfassend 127 ) zu nennen und kommentarlos zu dokumentieren.

1 a) Bedeutungsnamengebung: Okolesin 128) ('okolesica' 'Unsinn, Quatsch' - 'der Quatscher'; zugleich assoziiert der russische Leser Gogol's Podkolesin' 'der unter die Räder Geratene'); Chorochorkin 129) ('chorochorit'sja' 'sich brusten' - 'der wichtigtuer'); Goloskov'130) ('golosok' 'Stimmchen' - selbst der in das CK vorgedrungene Konterrevolutionär wird damit als soziohistorischer 'Piepser' verlacht) .......

1 b) Lächerliche Vor- und Vatersnamen: Timofej Finogenyc̈ ${ }^{131}$ ); Epofen Danilyc̈; Vater Emel'jan 132) ....

2) Satirische Demokratisierung: Die Satire des Sumpfes' schert Graf, Duma-Politiker etc. mit Kleinbürger, Spießer etc. über einen Kamm, reduziert sie so auf das Wesentliche - ihre gemeinsame gesellschaftliche Negativität. Diese - ihrem Selbstverständnis zufolge skandalöse - Gleichbehandlung verlacht Graf, Politiker etc....

3) Pubertierung: Bereits oben wurde darauf hingewiesen, daß fast ausnahmslos alle Negativfiguren der 'Binnen-Bereichs'-Satire - 'gestandene' Manner und Frauen - geil, mannstoll, ewig unreife Nie-Erwachsene sind.

4) Dummheit, Blödheit etc.: In Slezkins 'Ziegenbock ..' lassen sich die Filmstarkarriere-Süchtigen Krähwinklerinnen im Evas-Kostüm von einem 'prochodimec'-Regisseur 'filmen' - der 'Filmapparat': eine Kaffeemühle ...

Buchovs 'drei Heilige' (natürlich Scharlatane s.u.) befinden sich in Geldnot und beschließen, bei einer bigotten Kleinburgerin zu 
'geistern' - um anschließend eine für diese 'Alte' kostspielige

'Geisteraustreibung' inszenieren zu können:

"Es würde gar nichts schaden, bei dir die Teufel auszutreiben ... Wofern man nämlich die unreine Kraft nicht austreiben wird, so wird das ihretwegen kein Leben mehr sein, - Heilig, heilig, heilig, - bekreuzigte sich die Alte, die in Panik verfiel (..). Nachdem sie weggegangen war, seufzte der Graf verträumt auf. Irgendwann einmal hat man solche Alte erschlagen, und in ihren Truhen fanden sich Geld und allerlei Dingelchen... Irgendjemand hat sogar darügej geschrieben.. Ich habe das selbst gelesen sehr komisch"

Der Graf (auf ihn konzentriert Buchov seine Vernichtungs-strategien) hat Dostoevskijs 'Schuld und Sühne' gelesen - und 'sehr komisch' gefunden: er hat folglich rein nichts begriffen!

5) Unfähigkeit in politischen Kategorien zu denken: die 'überbleibsel' lösen das Problem, ob es zu einer Restauration des Kapitalismus kommen wird oder nicht - nach dem Blümchenzupf-Spiel 'Sie liebt mich, sie liebt mich nicht'.

"Nach dem Würelspiel bestätigten sich Chorochorkin und der Doktor im Schachspiel. Sie spielten um folgende Wette: wenn Chorochorkin die Partie gewinnt - wird es um die Bolschewiken geschehen sein, wenn der Doktor gewinnt - wird die Sowjetmacht bleibjq) Der Doktor gewann. Chorochorkin spuckte vor Verdruß aus"134).

6) Automatenhaftigkeit, Statik, Lernunfähigkeit: Buchovs Graf C̈ipicyn besucht jeden Tag dasselbe Restaurant, frißt sich jeden Tag voll - jeden Tag bis zum qualvollen Erbrechen. Nach der Revolution schmarotzt er sich bei Kleinbirgern durch:

"Alltäglich, jeden Abend, wenn sich alle zu Tisch gesetzt hatten, arbeitete der Graf seine Existenz in der Familie Gorbul's mit ein- und denselben Erzählungen uber das fruhere Leben ab" 135 .

Alle Negativ-Figuren sind lernunfähige Marionetten ihres Wunschdenkens: obwohl sie die Wirklichkeit der stabilisierung der Sowjetmacht eines Besseren belehren müßte, halten sie unbeirrt an ihrer Restaurationsgewißheit fest ...

7) Sprachverhalten (Archaismen, Kirchenslavismen, Fremdwortverstümelungen, Floskelhaftigkeit etc.): "naslyäany my"136), 'marxisch', "revmazim"137) ....

8) Autodecouvrierung: Buchovs 'Überbleibsel' fristen ihr Dasein als 'Heilige Väter'. Dennoch: Vater Ignatij "füchtete sich 
selbst (..) etwas vor den Höllenqualen und war selbst keineswegs weit davon entfernt, selbst in die Kirche zu laufen"138): sie fürchten sich - wie Kinder vor der selbstgefertigten Maske.

9) Tierhaftigkeit: Lukašin beschränkt sich darauf, seine Figuren mit 'Küchenschaben' ("wie Küchenschaben in den Spalten"139), zu vergleichen. Buchov hingegen betreibt durch seinen ganzen Roman hindurch systematisch die Annäherung des Hauptobjektes der Verlachungstrategien - des Grafen - und uber ihn ('satirische Demokratisierung') seines gesamten 'Überbleibsel'-Kontextes an

'lächerliche' Tiere.

Der Graf "quietscht wie ein Ferkel"140). (..) der Graf "ging auf Zehenspitzen zur Tür und trat ein, nachdem er die Krawatte zurechtgerückt und den Hut keck aufs Ohr geschoben hatte. Im Korridor war es dunkel, die Tür ins Zimmer war geöffnet. Der Graf zündete ein Streichholz an und taumelte zurück: aus dem $Z$ immer schaute eine weiße Kuh mit dem teilnahmslosen Blick ihrer ruhigen Augen auf ihn. Sie neigte leicht die Hörner und muhte zärtlich los (Liebe auf den ersten Blick j.e.). - Entschuldigung, sagte der Graf verlegen - und um die Peinlichkeit, die sich eingestelftiqatte, zu beenden, murmelte er: - Und wo sind meine leute? (Er akzeptiert die Kuh als gleichwertigen Gesprächspartner = Autodecouvrierung).

Der Graf stiehlt eine Sau: "Der Graf (..) grunzte still und fried-

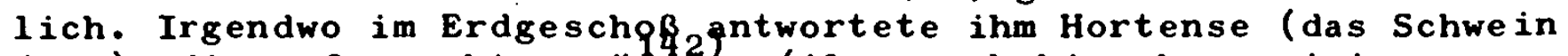
j.e.), die aufgewacht war" ${ }^{2}$. (Also auch hier kommunizieren Graf und Haustier).

Schließlich kommt der Graf ganz 'auf die Sau' - sie wird sein einziger Gesprächspartner:

"Der Graf, der Árgumente der menschlichen Logik schlecht aufgenommen hatte, erriet den geringsten Wunsch seines Lieblings (= Hortense) schon am Ausdruck ihrer schmalen wässrigen Äuglein. (Oft-im Text unlesbar j.e.) -mals besuchte er sie abends und trug ihr voller Gefül - begleitet von ihrem gleichförmigen Grunzen - 143 ) ' alle Beschwerden vor, die sich in seiner primitiven Seele 143 angestaut hatten 1449 rtense verstand ihn gleichsam.

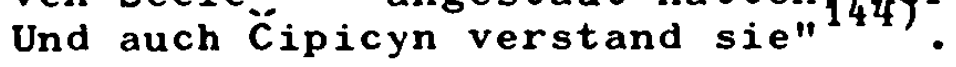

10) Verlachung per story: bei Nikitin, insbesondere aber in slezkins 'Ziegenbock ...' scheitern die Krähwinkler zwar nicht in der Geschichte (an ihrer stellung in der Sowjetgesellschaft ändert sich nichts), aber in der story - sie alle sind am Ende die Genarrten eines 'Hochstaplers', respektive die Genarrten von ihrer Dummheit zuzuschreibenden Mißverständnissen (s.u. unter 'Sujet-Fügung'). 
Soweit die Vorstellung der zentralen Verlachungs-Strategien. Durch nahezu vollständiges Vorhandensein der gebräuchlichen satirischen Verlachungs-Strategien lassen sich die' Satiren des Sumpes' lesen als ein Kapitel 'angewandte satirische Poetik'.

Wie alle satirischen Romane des 'Binnen-Bereichs' arbeiten auch die 'Satiren des Sumpfes' die $p o s$ i $i v e$ G $g$ e $n$ o$s i t i o n$ generell direkt in den Text ein - und sie tun dies generell nach ein- und derselben Schablone: sie besetzen die positive Gegenposition durchgehend schwergewichtig $f$ i $g$ u$r$ a 1 - während die positive Gegenposition in allen satirischen Romanen des 'Außen-Bereichs' gleichgewichtig figural und argumentativ repräsentiert war, also sowohl den als negativ ausgewiesenen sozialen Gruppen und Typen als auch ihrer (impliziten) 'Ideologie' ausfuhrliche positive Alternativen opponierte; sie besetzen sie durchgehend mit den gleichen Figuren und konstituieren diese Figuren durchgehend mit den gleichen versatzstuicken. Die positive Gegenposition ist in den satirischen Romanen des 'Binnen-Bereichs' wesentlich stärker als die NegativPosition schabloniert, weist eine wesentlich geringere Variationsbreite als jene auf. Sie tritt - verglichen mit den Satiren des 'Außen-Bereichs' - aber auch quantitativ stark zurük, sie wird nur skizziert.

Die figuralen Repräsentanten der Negativ-Position: die am Alten klebenden (und auch an Jahren alten!) integrationsunwilligen etc. ' $\ddot{U} b$ e $r \quad l e i b s$ e ' der vorrevolutionären Gesellschaft, genauer - ihrer nichtproletarischen Schichten. Konsequent-schematisch opponiert die positive Gegenposition ihnen die exponierten Repräsentanten des Neuen, die integrationsfähigsten- und willigsten Glieder der jungen Sowjetgesellschaft, die 'Maurer' (nur vereinzelt: die 'Poliere'! s.u.) dieser Gesellschaft: die $j u n g e$ e $n$ e $r$ a $i$ o $n$ der Komsomolzen. $S i$ wachsen mit (fast) absoluter selbstverständlichkeit in die neue Gesellschaft hinein; $s$ i nehmen mit (fast) absoluter Selbstverständichkeit aktiven Anteil am Aufbau der neuen 
Gesellschaft. Für $s$ e gibt es (zumeist) uberhaupt kein Abwägen von pro und contra für die sozialistische Gesellschaftsordnung (auf eine 'Argumentation' auf dieser Ebene wird in den Satiren des 'Binnen-Bereichs' im Gegensatz zu jenen des 'AußenBereichs' generell verzichtet!) - s i e kennen (zumeist)nur e $i$ contra: das gegen die gesellschaftlichen 'überbleibsel'. Und dieses ihr contra setzen sie um in politische Aktion: in die Aktion der Selbstbefreiung aus der Umklammerung des 'Sumpfes' . (d.h. der Emanzipation von ihren heillos 'versumpften'Eltern), in die Aktion der Selbsterziehung und Selbstbildung auf das sozialistische Menschenbild hin - und in Agitation, in direkten politischen Kampf gegen die 'überbleibsel'-Generation: der Konflikt zwischen Progression und Reaktion ist in allen satirischen Romanen des 'Binnen-Bereichs' zugleich ein $G$ e $n$ e $r t i$ $n$ e $n k$ o $f(1 k t$ ! 145)

Dies ist der generelle Fond der positiven Gegenposition. Von ihm - von der das Positive global figural repräsentierenden jungen Generation also - hebt sich stereotyp ein exponierter Repräsentant ab: ein Ideal-Komsomolze, eine Ideal-Komsomolzin, die exemplarisch und leitbildhaft (sie sind $d$ a $s$ figurale Identifikationsangebot der Satiren des 'Binnen-Bereichs' und verweisen damit direkt auf den primär anvisierten Rezipientenkreis, verweisen auf die zentralen kommunikativen Funktionen dieser satirischen Romane!) den bewußt eingeschlagenen, zielstrebigselbstbewußt verfolgten Weg aus dem 'Sumpf', in den hinein sie geboren wurden, in die Sturmspitzen der jungen Sowjetgesellschaft vorführen. Womit bereits gesagt ist, daß sie der komischen $s t a t i k$ der (nach Wesen und Erscheinung) Alten $d y$ a$m i k$ - dem toten Bodensatz der bürgerlichen Vor-Zeit also Leben - opponieren.

Die negativen Figuren waren entweder häßlich (vor allem: fett) oder gesichtslos; die exponierte Positivfigur hingegen hat ein schönes, sympathisches, sportgestähltes etc. physisches Erscheinungsbild, das sie für den Leser, der sich mit ihr identifizieren soll, mit einem Sympathievorschuß ausstattet: 
"ein junges von der Sonne gegerbtes Gesicht mit feuereifrigen, lachenden Augen (..). Muskulöse Arme, die sich in die strammen Hüften einstemmen, (..) entblößte saftige Schultern, die leicht angehoben und gleichsam bereit sind, die ganze Last eines langen hartnäckigen Kampfes und der Verantwofthyqg für seine überzeugungen und Taten auf sich zu nehmen ..." 1467.

Die sympathisch-schöne Komsomolzin steht freilich erst am Ende eines (wegweisenden!) aus dem 'Sumpf' hinausfuhrenden Emanzipationsprozesses: Aus dem Dorf kommend, wird sie in Krähwinkel von einem NöP-Konditor brutal ausgebeutet - und genießt dafür 'allgemeine Achtung'. Der Grund: die junge Var'ka ist ein außer Arbeit nichts kennendes Arbeitstier, läßt sich brav um ihren Lohn betrügen und geht regelmäßig in die Kirche (und beileibe nicht in die Versammlungen der 'wirrköpfigen' Komsomolzen). Fazit (aus obyvatel'-Perspektive): "Wir brauchen mehr von der Sorte, keine Revolution"147). In diese Ausbeutungs-Idylle hinein bricht die 'Katastrophe' los: 'Plötzlich' (ohne von außen gedrängt gesteuert etc. zu sein: in ihr manifestieren sich unvermittelt Geist und Tendenz der Zeit!) lernt Var'ka lesen und schreiben, tritt in die Gewerkschaft ein, treibt Sport, arbeitet die 'Fibel des Kommunismus' (Gegen-Bibel und rotes Tuch aller obyvateli) durch, geht - statt in die Kirche - in den Komsomolzen-Klub; sie kündigt ihrem NöP-Konditor und verlangt in der Vergangenheit vorenthaltenen Lohn. M.a.W.: sie erfühlt und erkennt zunächst vage die Unhaltbarkeit der ihr aufgenötigten Lebensumstände, bildet und informiert sich dann, zieht die existentiellen Konsequenzen, integriert sich in $i h r$ Kollektiv in das Kollektiv ihrer dem 'Sumpf' entronnenen Altersgenossen, der 'Maurer' der Sowjetgesellschaft.

Dieser in keiner 'Satire des Sumpfes' fehlende EmanzipationsProzeß der jungen Generation wird häufig mit einer leicht ironischen Rür- oder Schmunzelkomponente ausgestattet: Buchovs Muster-Komsomolze Carev schämt sich seines negative Assoziationen beschwörenden (Carev - Zar) Familiennamens, fühlt sich von ihm für die Revolution gehandicapt. Lukä̌ins exponierte Komsomolzen-Figur zieht aus dem gleichen Anlaß die Konsequenzen: er legt den (negativen Bedeutungs-) Familiennamen Okolesin 
('der Quatscher') ab und legt sich den neuen Familiennamen Oktjabrev zu, der gleichfalls ein Bedeutungsnamen ist, jedoch ein solcher, der Bekenntnischarakter hat - er bekennt sich zur 'Oktober'-Revolution und damit zugleich gegen die ihr wesensfremde 'Quatscherhaftigkeit' seines Vaters und dessen Gesinnungsgenossen, die konterrevolutionäre 'Fasler' sind..

Negativ-Position und positive Gegenposition sind als schematisches Kontrastsystem angelegt: den zentralen Negativmerkmalen des 'Denkens' und sozio-politischen Verhaltens der 'überbleibsel' werden die entsprechenden Positivmerkmale der jungen Generation gegenuibergestellt. Während aber die Negativmerkmale eingehend dargestellt werden, werden die Positivmerkmale nur signalisiert: in der Darstellung der Satiren des 'Binnen-Bereichs' dominiert das Negative, das Positive (das in den Satiren des 'Außen-Bereichs' breit angelegt war) setzt nur geringen Raum einnehmende, an Identifikationsfiguren (für den vorwiegend jugendlichen Leser) gekoppelte Leitlinien, Orientierungswerte des richtigen Denkens und Verhaltens - immer in direkter Opposition zu den zentralen Negativmerkmalen.

Mittels einer von außen als écran-Figur - auf die zentrale Merkmale des $D$ e $n$ e $n$ s bloßlegende Erwartungen projiziert werden - in Krähwinkel eingeführten Figur, an der sich die alten und neuen Geister scheiden, macht Slezkin ('Ziegenbock ...') die beiden konträren Wertesysteme evident: während sich der 'Sumpf' nur für Mode, Filmsternchen, Klatsch, Ausländisches und Foxtrott (als Inbegriff westlicher Dekadenz ${ }^{148}$ ), interessiert, demonstrieren die Komsomolzen eine qualitativ andere Interessenlage:

"Als einen aus Moskau angereisten Menschen bestuirmten sie ihn mit Fragen nach den Erfolgen des Städtebaus, nach den Bedingungen der Arbeit in den Hochschulen, nach den Proletschriftstellern und Tigern, die im ZjFłys auftreten, nach dem Aviachim und der internationalen Lage" 1494 .

Die Komsomolzen entsprechen also haarscharf dem comme-il-fautKomsomolzen-Klischee! Waren zentrale Werte der 'Alten': 'Geld', 'Glauben', 'Ordnung', 'alte Zeit' - sind die der 'Jungen': 'Arbeit', 'Mathematik', 'Kommandirovka', 'Arbeiterfakultät'. 
Auch Buchovs 'heilige Väter' wirken als Grundhaltungen zum Vorschein bringende Kondensationskerne: während ihr Agitator - der "ehemalige Diakon Evmenij"150) - im 'Sumpf' überall einen fruchtbaren Boden für seine religiöse Werbecampagne findet, erweist sich das Terrain der Kolchos-Jugend als unfruchtbar für seine 'Saat':

"Er ging sogar in einen Dorfsowjet, aber da geriet er an irgendeinen Burschen mit einer roten Mitze, (..); nachdem der seine Erzählung angehört hatte, spuckte er durch die Zähne nach links aus, wollte wissen, ob man dem Kooperativ (ihn interessiert also nicht das eigene Seelenheil, sondern das Wohlergehen seines Kollektivs j.e.) Teer und seife geliefert habe und (..) und warf ihn unvermittelt raus:

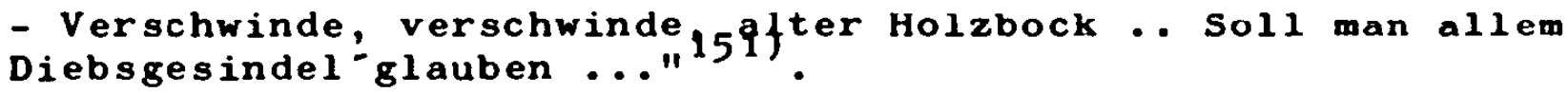

Ebenso klar ist die Opposition der Merkmale des $v$ e $h$ a $1-$ $t$ e $n$ im sozio-politischen Raum: dort - Bewahren des Alten, Verleumden und Behindern des Neuen; hier - das genaue Gegenteil und - darüber hinaus - A $g$ i a $t$ i $n$ und direkte $p$ o 1 $t i s c h e A k t$ i o $n$ gegen die Exponenten des 'Sumpfes' und ihre Ableger in Apparat und Partei, Agitation und Aktion direkt vorgefürt von den Figuren der positiven Gegenposition. Und eben diese Positivelemente der Verlachung (Agitation) und Bekämpfung (Aktion) der 'Überbleibsel' sind zentrale Merkmale der Darstellung des sozio-politischen Verhaltens der KomsomolzenGeneration: der Komsomolze leistet also in der satirischen Darstellung das, was die Satire in der Gesellschaft leisten will - Verlachen und Bekämpfen der 'Überbleibsel' - wobei der LeserKomsomolze anvisierte Umsetzungs- und Realisierungsinstanz ist ! slezkins Komsomolzen und Pioniere verlachen ihre 'Sumpf'-Mitbürger, die sich von allerhand 'rätselhaften' Ereignissen mystifizieren lassen, sie verlachen sie als Freizeit-Satiriker, gehen den 'rätselhaften Ereignissen' auf die Spur, entlarven alle Beteiligten, benennen direkt ihre Negativität und setzen die strafrechtlich Schuldigen gefangen. Ähnlich bei Buchov, wo der Krähwinkler Komsomol die 'heiligen Väter' zunächst observiert und dann - und damit schließt der Roman - ihre Schlupfwinkel aushebt und die 'sozial-schädlichen Elemente' hinter Schloß und Riegel bringt. 
In allen erfaßten 'Satiren des Sumpfes' weist auch die generell positive junge Generation vereinzelt 'schwarze Schafe' auf hoffnungslos im 'Sumpf'ihrer Eltern versackende Jungen und Mädchen im Komsomolzen-Alter. Thre exponierte Erbärmlichkeit und Lächerlichkeit resultiert daraus, daß sie sich nicht unmittelbar in das auch nach Generationszugehörigkeit polarisierte NegativPositiv-Kontrastsystem dieser Texte eingliedern lassen: $s$ e gehören weder der Gruppe der nach Erscheinung $u n d$ Wesen negativen - und Alten! -, noch der nach Erscheinung u $n d$ Wesen positiven - und Jungen! - an; sie sind komisch aus eben dieser Spannung zwischen Erscheinung (jung - also vermeintlich positiv) und Wesen (alt - also erbärmlich negativ) sie sind blutjunge uralte Greise - personifizierte Oxymora!

Nur in Lukašins 'Stadt Rüberspuck' findet sich eine der älteren Generation angehörende exponierte Positivfigur, eine Positivfigur freilich, die zwar selbstverständlich frei ist von den Negativmerkmalen der obyvatel'-Generation, die aber - im Gegensatz zu schablonierten Komsomol-Positivfiguren - durchaus problematische Züge aufweist: der bereits verschiedentlich erwähnte Anton. Anton - altes Parteimitglied, Oktober-Revolutionär, aktiver Bürgerkriegsteilnehmer und jetziger Vollzugskomitee-Präside zu Rüberspuck - ist bisweilen geplagt von Zweifeln an der Möglichkeit, zum jetzigen Zeitpunkt in Rußland die sozialistische Gesellschaft zu 'mauern': er war und ist 'Kämpfer' für die sozialistische Gesellschaft, nicht ihr geduldiger unbeirrt-selbstsicherer 'Maurer'; er fühlt sich phasenweise vom 'méšcanstvo' nicht nur Krähwinkels, sondern Rußlands überhaupt überrollt und erdrückt und gibt sich dann der Erwartung der "folgenden Revolution"152) - in Deutschland hin, schweift "in Gedanken in die ferne Zukunft"153). Aber eben nur 'phasenweise' - denn (trotz weltrevolutionärer und sozialutopischer Schwärmereien, trotz eines 'Maurers' der sozialistischen Gesellschaft unwirdiger Anfälle von Verzagtheit) grundsätzlich ist der stark von momentanem Erfolg und expliziter Anerkennung ("ob das Zentrum von den von ihm absolvierten Arbeiten weiß, ob es von seinen revolutionä- 
ren Verdiensten weiß"154), abhängige (also etwas kurzatmige und kurzsichtige) Anton überzeugter Revolutionär und 'Polier' auf der Baustelle des Sozialismus. Und diese Grundüberzeugung können ihm auch seine kontinuierlichen Rüberspucker Mißerfolge nicht rauben :

"Anton findet überall dort eine Heimat, wo es Menschen, wo es Arbeit gibt ... Er verzagte nicht (als er nach sibirien strafversetzt wurde j.e.). (..). Wenn Anton imstande war, auch im Untergrund Sieger zu sein, so jetzt, da hinter seinem Rückepjoje mächtige Wahrheit der Arbeiterklasse steht, umso mehr" ${ }^{155}$. Dies umso mehr, als alle konterrevolutionären obyvatel'-'Ideen' und Aktionen nur den Rang von Zuckungen einer (bei Lukasin freilich sehr langwierigen) historischen Agonie haben:

"der Weggang Antons veränderte das Leben Rüberspucks nicht (..) aber der Kampf der pgyyateli mit den neuen sowjetischen Aufrürern war geschwächt ${ }^{156}$. Def 9 gyvatel' gab Ruhe .. das alte Leben stieg langsam im Preis"

Prioritär nur mittelbar ist in den meisten Satiren des 'BinnenBereichs' die positive Gegenposition nicht nur figural und aktional, sondern auch argumentativ repräsentiert: die a $r g u-$ $m e n t$ a $t$ i $v$ positive Gegenposition ist hier wesentich nur indirekt repräsentiert (d.h. ihre inhaltliche Konkretisierung bleibt dem Leser überlassen), und sie ist - auf dieselbe indirekte Art und Weise - wesentlich a p p 11 a $t i v$ repräsentiert.

'Indirekt' heiBt einerseits - das Negativ-Positiv-Oppositionssystem der Satiren des 'Binnen-Bereichs' weist eine vom Leser zu füllende Entsprechungs-Lücke auf: Die Negativfiguren 'verhalten sich' nicht nur (negativ) im sozio-ökonomischen und gesellschaftlichen Raum, sie 'rechtfertigen' dieses ihr Sozialverhalten auch durch eine mehr oder minder detaillierte Ausbreitung ihrer 'Ideologie'; m.a.W.: sie a $r$ u m e $n t i e-$ $r$ e $n$ auch für 'ihre' Gesellschaftsordnung, gegen die bestehende Gesellschaftsordnung. Die positiven Figuren hingegen $s$ i n d schlicht und einfach positiv, sie 'verhalten sich' schlicht und einfach positiv - o h $n$ e für die sozialistische Gesellschaftsordnung zu argumentieren: die vor ihrem positiven 
Sein, die vor ihrem positiven sozio-politischen Verhalten liegende - auf 'Argumenten' für die sozialistische, gegen die kapitalistische Gesellschaftsordnung basierende - Entscheidung für dieses positive Verhalten wird in den Satiren des 'Binnen-Bereichs' generell $n i c h t$ vorgeführt. Die Erschließung der Argumente für die sozialistische Gesellschaft ist Sache des Lesers, der sie als Gegen-Argumente zu den Argumenten der Negativfiguren gewinnen kann. Ja - gerade der Verzicht auf explizit vorgetragene Argumente für die sozialistische Gesellschaftsordnung weist diese Argumente als keiner Darlegung mehr bedüftig, als evident aus: das sozialistische gesellschaftliche Ideal wird als von den zentral anvisierten Rezipienten im KomsomolzenAlter bereits akzeptiert vorausgesetzt.

Anders als die Satiren des 'Außen-Bereichs' bemühen sich die Satiren des 'Binnen-Bereichs' also nicht mehr um Legitimation, Affirmation etc. der sozialistischen Gesellschaftsordnung. Vielmehr setzen sie sich die verlachende Verurteilung negativer u $n$ d die Propagierung positiver Verhaltensweisen in dieser Gesellschaft zum Ziel.

Denn 'indirekt' heißt andererseits - die die positive Gegenposition (also prioritär: positive im Gegensatz zu negativen soziale Verhaltensweisen) direkt in den Text einarbeitende Satire des 'Binnen-Bereichs' fordern den Leser nicht direkt appellativ zu einem positiven Sozialverhalten auf: sie füren dieses positive Sozialverhalten vielmehr am Beispiel exponierter Positivfiguren andeutungsweise (die Konkretisierung ergibt sich aus der vom Leser vorzunehmenden Extrapolation dieser Andeutungen in Opposition zu den breit dargestellten negativen sozialen Verhaltensweisen) vor: Bekämpfung und Verlachung der obyvateli; erzieherische Einwirkung auf die obyvateli, Werbung für den Komsomol.. 'Indirekt appellativ' sind alle Satiren des 'Binnen-Bereichs' darüber hinaus durch ein überall vorfindliches, dem zeitgenössischen Leser überaus vertrautes Signal: durch das Schluisselwort der 'c̈istka', vor der sich alle obyvateli fürchten, der 'Säuberung' (von 'sozial-fremden' etc. Elementen) also des büro- 
kratischen Apparates, der Partei. 'Säuberung' nämlich von den den Negativfiguren korrelierten 'sozialen Typen': alle Satiren des 'Binnen-Bereichs' werben um Verständnis für die das innenpolitische Klima außerordentlich belastende) c̈istka-Politik, propagieren die c̈istka als unumgängliche und effektive Klassenkampf-Maßnahme.

Die in die 'Satire des Sumpfes' eingehende $h i s t o r i s h e$ Perspektive ergibt sich bereits aus der oben dargestellten Koppelung der Negativ-Positiv-Opposition an eine Generationen-Opposition: zentraler Träger des Negativen ist der a 1 t e obyvatel'; zentraler Träger des Positiven der d e m $s$ b e $n$ Milieu entstammende, den obyvatel'-Balast der Vergangenheitslastigkeit aber abgeworfen habende $j$ u g e Komsomolze, genauer: das die Barrieren zwischen proletarischer und nichtproletarischer ${ }^{158}$ ) Herkunft aufhebende Kollektiv der jungen Generation.

Damit ist bereits gesagt, daß der 'Sumpf' schon aufgrund der verbleibenden Lebenserwartung seiner in Unehren ergrauten Bewohner zum Aussterben verurteilt ist, verurteilt durch biologische Auszehrung der personellen Substanz. Die endgülige Erledigung der Hemmklötze 'gesellschaftliche Überbleibsel' ist also zentral ein Generationsproblem, eine Frage der Zeit!

Diese generelle optimistische historische Perspektive konkretisiert sich in den hier vorgestellten Roman-'Satiren des Sumpfes' verschieden: Zwar besetzt auch in Lukašins 'Stadt Rüberspuck' die junge Generation die figurale Positiv-Position (gemeinsam mit Anton), der Autor beschränkt sich aber auf den lapidaren Hinweis. daß die endgültige Liquidierung des 'Sumpfes' durch die junge Generation erfolgen wird, verweist hingegen kontinuierlich auf die aktuell notwendige gesellschaftspolitische Kampfmaßnahme, die c̈istka. In der Darstellung dieses Textes befindet sich der 'Sumpf' zwar längst in der Defensive, seine Position ist aber am Ende der story nicht 'geschwächt', da die čistka - bedingt durch Verleumdungen seitens in Apparat und Partei eingedrungener obyvateli - den Falschen, nämlich Anton trifft. Eine 'Schwächung 
des 'Sumpfes' wird lediglich in einer Schlußbemerkung behauptet: Die generelle positive historische Perspektive bleibt hier also affirmativ-abstrakt! Lukałins 1925 erschienene Satire verlegt ihre dargestellten Ereignisse in die unmittelbare Gegenwart keine Distanz also zwischen Publikationszeitpunkt und dargestelltem Zeitraum!

Anders Slezkin, anders vor allem Buchov: der dargestellte Zeitraum beider satirischer Romane ${ }^{159)}$ fällt in die Nöp-Jahre bis 1925. Bei Slezkin (1927) liegen also zwei/drei, bei Buchov (1930) fün/sechs Jahre zwischen Publikationszeitpunkt und dargestelltem Zeitraum; in beiden satirischen Romanen kündigt sich die Liquidierung der figuralen 'Überbleibsel' entweder zumindest an (bei Slezkin, wo der Komsomol nach erfolgter Verlachung auch ihre Bestrafung fordert), oder wird sogar (bei Buchov, dessen Roman mit der Inhaftierung der zentralen 'Überbleibsel'-Gruppe endet) direkt dargestellt: die generelle positive historische Perspektive erfährt hier also in der Darstellung ihre direkte Bestätigung! Sie erfährt eine zusätzliche steigerung durch die zwischen Publikationszeitpunkt und dargestelltem Zeitraum liegende Distanz: insbesondere bei Buchov wird so suggeriert, die mit den in der story 'liquidierten' negativen Figuren verknupfen (extratextuellen) negativen Erscheinungen gehörten wesentlich bereits der Vergangenheit an!

Die Interpolation der $k \circ m m u n i k$ a $i$ e $n$ i $n k-$ $t i o n$ der verschiedenen typologischen Erscheinungsformen der Satiren des 'Außen-Bereichs' brachte gewisse Schwierigkeiten mit sich, da die Angriffs-Objekte dieser Großgruppe satirischer 'Romane' generell außerhalb der eigenen (Sowjet-) Gesellschaft lagen, eine an die satirische Verlachung anschließende Aktivierung des Rezipienten gegen diese Angriffs-Objekte also nicht als Intention angesetzt werden konnte. Als kommunikative Funktionen der Satiren des 'Außen-Bereichs' wurden schließlich die globale Legitimation und Affirmation des eigenen gesellschaftichen Systems, die sozio-politische selbstbestätigung des in ihm lebenden Rezipienten sowie die Propagierung - außerhalb der Gesellschaftspolitik liegender - politischer Maßnahmen und Strategien (Ausbau der Roten Armee etc.) Jöreamit tost 
kommunikative Funktionen also, die nicht einem Problem-Bewußtmachung, Verlachung (Herstellung eines Superioritätsbewußtseins) und Aggressivierung (die Satiren des 'Außen-Bereichs' leiten Aggressivität gegen die 'anderen' um in SelbstBestätigung) zentral stellenden $s$ a $t r$ - Begriff entsprechen, wohl aber dem Begriff $p r o p$ a $g n d i s t i s c h e r$ Literatur. Die Satiren des 'Außen-Bereichs' arbeiten zwar partiell mit satirischen Mitteln (Typisierungsverfahren), ihre kommunikative Funktion ist - da diese Texte nicht (oder nur sehr stark vermittelt) die überwindung eines gegebenen gesellschaftlichen Zustandes, vielmehr gerade seine stabilisierung intendieren - nicht - satirisch, 'ideologisch'160).

Anders die Satiren des 'Binnen-Bereichs' (deren kommunikative Funktionen hier nur noch zusammengefaßt werden, da sie sich zwingend bereits aus den überlegungen zur Negativ-Position, zur - positiven Gegen-Position und zur historischen Perspektive ergeben). Sie machen - besser: sie halten s.o. - das Problem der gesellschaftlichen 'Überbleibsel' bewußt und weisen diesem Problem - per Verlachung und Nachweis der geschichts-bzw. zeitimmanenten Überwindungsgewißheit - die 'richtigen' historischen Dimensionen $z u$; nur bei Lukä̌in bilden die 'Überbleibsel' (noch) eine echte Gefahr (und nicht nur eine Belastung) für die Sowjetgesellschaft, bei Slezkin und Buchov hingegen sind sie eindeutig lächerlich eine zum Aussterben verurteilte 'prähistorische' Spezies: Herstellung eines Superioritätsbewußtseins!

Alle Satiren des 'Binnen-Bereichs' verweisen zugleich aber auch agitatorisch auf Möglichkeiten zur Beschleunigung dieser historischen Agonie, auf Möglichkeiten der aktuellen politischen Ausschaltungen, der aktuellen ökonomischen steuerung hof fnungsloser 'überbleibsel'-Fälle, auf Möglichkeiten der aktuellen gesellschaftspolitischen Integration dynamisierbarer 'Sumpf'-Sprößlinge: C̈istka von Apparat und Partei, Abwürgen der Nöp-Bourgeoisie per Steuerpolitik, Agitation gegen den 'Sumpf' und für den Komsomol.. 
Und diese indirekten Appelle zu einem positiven sozio-politischen Verhalten haben als Adressaten insbesondere den Leser im Komsomol-Alter: $i \mathrm{~h} m$ werden figurale Identifikationsangebote und Leitbilder offeriert, $i \mathrm{~h} m$ werden Richtlinien für sein sozio-politisches Verhalten abgesteckt! E $r$ insbesondere soll damit aktiviert werden für Ausbau und Weiterentwicklung des gesellschaftlichen status quo (nicht - wie in den Satiren des 'Außen-Bereichs' - für dessen Stabilisierung), aktiviert werden auch zur Bekämpfung der negativsten - weil vergangenheitslastigsten - gesellschaftlichen Gruppen und deren gesellschaftlicher Verhaltensweisen. $E r$ insbesondere soll gewonnen werden als "Prokuror des Alten (..) und Verteidiger des Aufbaus"161). Die kommunikative Funktion der Satiren des 'Binnen-Bereichs' ist also viel unmittelbarer als die der Satiren des 'Außen-Bereichs' 'satirisch', im Mannheimschen Sinne 'utopisch' (auf 'Transzendierung' des gegebenen status quo ausgerichtet)!

Die 'Satiren des Sumpfes' sind - wie die Satiren des 'Binnen-Bereichs' generell - 'typische' satirische 'Romane': umfangreiche Reihungen einzelner satirischer Porträts, satirischer Einzelepisoden und - zur Belustigung, zum 'bei-Laune-halten' des Lesers - zwischengeschalteter rein humoristischer Szenen. Nur ansatzweise wird die Reihung motiviert durch eine Mini-story (das Reise-Sujet wird nicht mehr eingesetzt); die satirischen Einzel-Porträts und Episoden, die durchgehend Schablonen des zeitgenössischen satirischen Feuilletons einsetzen - unter diesem Gesichtspunkt ist Vulis 162) Genre-Klassifizierung der meisten satirischen Romane der zwanziger Jahre als 'Roman-Feuilletons' berechtigt - bleiben auch isoliert durchaus lesbar.

Nur slezkin erzählt eine echte story, eine äußerst verwirrende und verworrene story - eine story aber vor allem, die nicht konstitutives Element seines Romans ist, vielmehr völlig unorganisch auf den letzten Seiten des 'Ziegenbocks ..' zur Erklärung vieler bis dahin für den Leser völlig unklarer Ereignisse nachgeliefert wird. 
(In eine X-beliebige ukrainische Kleinstadt gerät per Zufall ein Perückenmacher - er muß vor einer früheren Geliebten, die von ihm Alimente für ein nicht von ihm gezeugtes kind fordert, aus dem Zug springend fliehen und landet so in X-Stadt - der in einen Wirbel fataler Zufälle und Mißverständnisse gerät: er wird von einer Posträuberbande - die ihn für einen Künstler hält - für ihre Zwecke vereinnahmt und am Ende hingerichtet; er wird von den X-Städter 'überbleibseln' für einen auslandserfahrenen Regisseur, von den X-Städter Komsomolzen für einen auf der Höhe der Zeit befindlichen Moskauer gehalten ...: er wird - und dies zu ermöglichen ist einzige Funktion dieser ihn von außen als écran-Figur in die stadt schleudernden story zum Spiegel kleinstädtischer Erwartungen).

Dieser erste Versuch (und einer der seltenen Versuche der 'Binnen-Bereichs'-Satire uberhaupt) das satirische Thema 'Sumpf' zu koppeln mit einer tragfähigen, an sich interessanten story ist eindeutig gescheitert. Erst Il'f und Petrov finden mit ihren ' 12 Stühlen' eine befriedigende Lösung, die weniger von der bescheidenen story als von der zentralen, die story in Bewegung haltenden Figur (Ostap Bender) getragen wird (s.u.).

Bei Lukåsin und Buchov schließlich finden sich nur bescheidene Ansätze zu einer story: ersterer schildert eine Kette von obyvatel'-Intrigen, obyvatel'-Gesprächen etc. - jedes Glied der Kette ist für sich lesbar und verständlich, denn es ist eben eine $K e t t e$ von Intrigen etc., kein $N$ e $z$ von Intrigen; letzterer schildert in drei scharf getrennten Teilen (1. Teil: Aristokraten- und Intellektuellen-Satire; 2. Teil: 'Sumpf'-Satire; 3. Teil: Antiklerikale Satire) die Reaktion von Vertretern der vorrevolutionär herrschenden Schichten auf die Zeitläufe, die Reaktion des nachrevolutionären 'Sumpfes' auf sie, die Reaktion der 'eigentlichen' Sowjetgesellschaft auf sie - nur spuren einer nacherzählbaren story.

Fazit: Sujet-Fügung heißt in der 'Satire des Sumpfes' - pure Porträt- und Episodenreihung (Für die gesamte satire des 'Binnen-Bereichs' werden nur für die eigentliche 'NöP'-Satire Präzisierungen vorzunehmen sein). 


\subsection{Exkurs: Antiklerikale Satire}

Der dritte Teil von Buchovs 'Geschichte von drei Heiligen und einigen zweitrangigen Personen' zentriert ein in den übrigen 'Satiren des Sumpfes' ein-bzw. untergeordnetes Angriffs-Objekt: die Anfälligkeit der sowjetischen 'Krähwinkler'für religiöse Indoktrinierung, Aber- und Wunderglauben, religiös verbrämte Quacksalberei, Sektierertum. Der präzisierten Ansprache der satirischen Angriffs-Objekte korrespondieren spezifizierte Aufdeckung der Ursachen dieser Anfälligkeit (über die Pauschale der 'Vergangenheitslastigkeit' hinaus) und konkretisierter Nachweis der Lösungsmöglichkeiten.

Buchovs 'Geschichte ...' ist der letzte eindeutig der 'BinnenSatire' zuzuordnende sowjetische satirische Roman - er erschien erst 1930 (Verlag: 'Bezboünik' - 'Der Atheist'). Die Teile 1 und 2 dieses Romans korrespondieren in allen Aspekten dem Paradigma der 'Satire des Sumpfes', zu dessen Erstellung sie ja auch eingehend herangezogen wurden.

Mit der im dritten Teil erfolgenden Herausstellung eines gesonderten Problemkreises (1), mit der generell überaus stark verlachenden Konstituierung aller Negativfiguren (2) sowie dem präzisierten (wenn auch indirekt vorgenommenen s.u.) Nachweis der Möglichkeiten zur Lösung (3) der aufgeworfenen Probleme verdeutlicht die 'Geschichte ...' zugleich wesentliche generelle Entwicklungstendenzen desjenigen sowjetischen satirischen Romans, dessen Darstellungs-Objekte dem Bereich des 'eigenen Sozialhaushaltes' korreliert sind:

1. Von der 'Totalen' zum Einzelaspekte (der Intellektuelle) oder stark zeitspezifische Erscheinungen (der Nöpmann, der korrumpierte Apparatschik) zentrierenden Zugang.

2. Vom grobklotzig pamphletistischen zum stark verlachenden Zugang.

3. Vom die positive Gegenposition $g 1$ o b a 1 ansprechenden Zugang ('die junge Generation') zum problemspezifisch appellierenden Nachweis politisch konkretisierter Lösungsmöglichkeiten. 
Die Situation: die aus den Teilen 1 und 2 vertrauten (eingehender Nachweis der Negativität, eingehende Verlachung s.o.) zentralen Negativfiguren

- der Ex-Polizist Gorbul'

- der Ex-Aristokrat $\ddot{C}$ ipicyn sowie

- die Ex-Bardame Annet

haben sich in der Provinzstadt Zamojsk (der zweite Teil der 'Geschichte ...' konstituiert Zamojsk als paradigmatisches sowjetisches Krähwinkel) als 'Heilige Väter' niedergelassen und verdienen ihren Lebensunterhalt als Geisteraustreiber, Quacksalber, Lohn-Trostspender. Eher schlccht als recht, denn als (intellektuell zudem unbedarfte) Hauptstädter verfügen sie nicht über das Know-how zur erforlgreichen Bearbeitung des Marktes provinzieller Primitiv-Religiösität, Quacksalberei, Ignoranz ....

Als Fachmann in Sachen kommerziell betriebener klerikaler Volksverdummung wird der 'gewesene Diakon' Evmenij Blagopapertov als zusätzliche zentrale Negativfigur eingefüht. Aus langer klerikaler Routine kennt er den religiösen 'Schweinehund' seiner Krähwinkler en détail und so dient er sich den 'Heiligen Vätern' als Public-Relations-Spezialist und Manager an. Er ist ebenso geldgierig und skrupellos wie die Trojka (um sich eine Erbschaft zu erschleichen, macht er einer widerlichen Greisin den Hof), ebenso diebisch ... Aber: er ist routinierter, raffinierter.

Sein Stellenwert in der jungen Sowjetgesellschaft:

"Zu einer Zeit versuchte Evmenij, in einer der Zamosker Organisa tionen zu arbeiten, aber die kurzen Tage seiner besonderen Dienstaktivität fielen unangenehm zusammen mit dem geheimnisvollen Verschwinden einer Schreibmaschine und endeten mit einer Unannehmlichkeit anlässlich der Ausfülung des Fragebogens zum Eintritt in die Gewerkschaft (....). Dies wie vieles andere verschaffte ihm eine äußerst negative Popularität bei der Zamojsker obrigkeit (..), dafür hatte Evmenij bei einem gewissen Teil der Zamojsker obyvateli unbedingten Erfolg.

- Bei jedem beliebigen System wäre dieser Mann von unschätzbarem Wert.. Aber die da - wissen die etwa zu schätzen ... Bei iłfej marxischen Einstellung ist der Mensch ja kein Mensch ...."

Das Zitat spricht für sich. 'Bei einem gewissen Teil der ..obyva- 
teli' betreibt Evmenij religiöse Agitation, die Gorbul' (der jetzt unter 'der Heilige Ignatij' firmiert) als messianische Erscheinung vermarktet:

"Aus dem Rjazaner Gouvernement kam er zu uns gereist (..) - mächtige Wunder hat er dort gewirkt.. Die Geheilten folgten ihm nach in Scharen.. Blinde heilte er, Lahme heilte er.. In den Wäldern wanderte er umher, Quellwasser trank er ... (...) ... Und so hat er von Wasser gelebt $(64)$. Bei ihm leben die an ihn Glaubenden

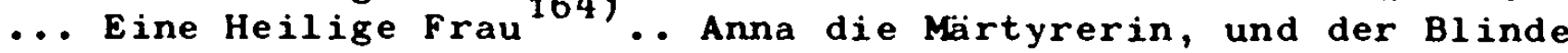
Vasilij ...

- Ein Blinder sagst du..

- Ein Blinder. Jetzt sieht er alles, aber früher war er ein Blinder.. Auch ihn hat der Heilige Ignatij geheilt.. Der Blinde Vasilij warf sich ihm zu Füßen und spricht 'Vater Ignatij, ich will sehen'. Und der spricht mit ruhiger stimme: 'werde sehend, Jüngling'..

- Ja, was sagst du.. Ein Jüngling also? ...

- Nun ja, ein Jüngling. Früher war ef $6 j^{j}$ n Jüngling, aber jetzt ist er schon kein Jüngling mehr ..." 165$).$

Schon diese Einführung Evmenijs decouvriert den 'gewesenen Diakon' - und mit ihm die ihm auf den Leim kriechenden Krähwinkler: Evmenij lïgt im wahrsten Sinne des Wortes 'wie gedruckt' - er ist außerstande, seine Bibel-Paraphrase unaufgefordert lückenlos den Gegebenheiten anzupassen; er ist ein raffinierter, klerikalroutinierter - Dummkopf !

Dank Evmenijs Aufbereitung des provinziellen Aber-, Wunderglaubensund Quacksalbermarktes, insbesondere aber dank der von diesem Markt selbst betriebenen Mund-zu-Mund-Propaganda finden die ' 3 Heiligen', die inzwischen eine Sekte ('Ignat'evcy') gegrüdet haben, überaus regen Zulauf: Das Geschäf mit teuer zu bezahlendem mit Dünger vermengtem Zahnpulver (als Allheilmittel), mit alle Krankheiten des Körpers und der Seele heilenden wundertätigen Sprüchen etc. floriert. Auch die Angestellten des Zamojsker Gorsovet finden sich bei dem 'Heiligen Ignatij' ein. Einzige Ausnahme: ein junger Mitarbeiter des Dorfsovet, der Evmenij die Tür weist $(s .0$.$) .$

Nachgewiesene Gründe für den durchschlagenden Erfolg der 'Heiligen Väter':

1) "In Zamojsk kränkelten fast alle: das $F$ e h 1 e $n$ a $n$ d $r$ e $r$ e $r$ s $r$ e $u n g$ e (meine Sperrung j.e.) zwang 
die eingeborne Bevölkerung, aufmerksam alle alteingewurzelten Krankheiten nicht nur bei sich selbst, 168 qdern auch bei allen Verwandten und Bekannten zu studieren" 166 ).

Im Klartext: Langeweile - Mangel an organisierter Zerstreuung.

2) "Erstens lag ihnen das (das Aufsuchen von Quacksalbern j.e.) irgendwie näher, erinnerte sie an den alten (..) byt, war billiger; 4 g9 zweitens war das auch politisch irgendwie angenehmer" 107 .

Im Klartext: Konservativ-antibolschewistische Grundhaltung.

3) "Tatsächlich gab es auch immer solche Patienten, die im Grunde keineswegs krank waren, die nur die Heiligen Menschen ausfragen wollten, weshalb denn man die Kirchen schließt und in den geschlossenepgirchen verschiedene Lieder singt und Spektakel auffürt" 168 .

Im Klartext: Mangel an atheistischer Aufklärung.

4) "Die Ignat'evcy, - erzählte man in der ganzen Gegend, - haben einen solchen, einen solchen Chor! Das sind dir keine näselnden Baptisten.. Wie die reinsten Engel singen die (..). Wie angenehm, ihnen zu lauschen. Heute gibt es keine solfhģ Chöre mehr.. Die Bolschewiken haben sie auseinandergejagt" "169).

Im Klartext: Kulturelles Defizit nach Unterdruckung des orthodoxe Kultes.

Die nachgewiesenen Grüne sind indirekte $A$ p e 11 e:

1) Intensivierung der allgemeinen und der politischen Bildung insbesondere in der Provinz.

2) Namentlich: Durchfürung antiklerikaler agitatorischer Maßnahmen.

3) Zurverfügungstellung wertvoller Zerstreuungsmöglichkeiten.

4) Namentlich: Beseitigung des kulturellen Defizites.

Auch die Instanz für die Umsetzung dieser Appelle in die politische Tat wird nachgewiesen: Generell der Komsomol (dem figurale Identifikationsangebote zur Verfügung gestellt werden, die eine in der Aushebung der 'Sekte' gipfelnde exemplarische gesellschaft liche Aktivität demonstrieren). Präziser wird diese Instanz aber in einem den Roman beschließenden Moskauer Zeitungsartikel angesprochen, der die laschen Zamojsker Agit-Organe kritisiert, die 
dem Kampf gegen "Heilige, Wundertäter, Sekten"170) nicht die erforderliche Bedeutung beimäßen:

"Die Zamojsker bezbožniki (organisierte Atheisten j.e.) schlafen und führen sich schändlich auf. Obwohl sie in einer derartigen Umgebung leben, betreiben sie keinerlei Agitation, (..) und der Genosse Vorsitzende dieser nur auf dem Papier existierenden bezbozniki-Zelle (..) hat sogar einmal erkfärt, die Ignat'evcy täten sozusagen niemandem etwas zuleide"lli .

Wie für viele Satiren gilt auch für diese: der satirische Knüppel schlägt den Sack, trifft (auch) den Esel. Im Klartext: Zwar verlacht die 'Geschichte ..'Provinz-Aktivitäten von Sekten, Wunderdoktores und Gottesnarren, schildert $n i c h t$ Aktivitäten der russisch-orthodoxen Kirche. Einerseits werden also kirchliche Empfindlichkeiten aus taktischen Gründen geschont. Andererseits aber wird indirekt die russisch-orthodoxe Kirche mit in die satirische Aggression einbezogen: Kirche und Sekten etc. werden als zwei verschiedene Erscheinungsformen $e$ i $e$ sroblems ausgewiesen. Denn: der Public-Relations-Manager Evmenij ist ein 'gewesener Diakon' - ein Mann der russisch-orthodoxen Kirche, der unter dem Zwang der nachrevolutionären Kirchenpolitik seine Aktivität auf eine Ersatz-Terrain $v$ e 1 a $g$ e $n$ mußte. Und: der Kunden-Kreis von Kirche, Sekten etc. ist derselbe - auch für ihn sind die 'Heiligen Väter' (auch) eine E $r$ a $t z$ - Lösung.

Ersatz-Lösungen wie Kirche werden nicht nur eingehend verlacht (uiber ihre figuralen Repräsentanten), sie werden darüber hinaus auch indirekt e $t i k$ e $t i$ e $t$ als organisationen zur gewerblichen Vermarktung provinzieller 'Dunkelheit': "das ist keine Verkaufsbude, das ist eine Fabrik"172), werden durchgehend mit privatwirtschaftichen Unternehmensformen parallelisiert: die Ignat'evcy betreiben regelrechte Industriespionage bei einer noch erfolgreicher arbeitenden benachbarten sekte etc.. Und Kirche wie degenerierte Erscheinungsformen derselben werden direkt a $r$ g m e $n$ a $t i v$ desavouiert, durch einen kompetenten Sprecher - den Kirchen-Spezialisten Evmenij selbst: 
"Das ist mir ein Pack, dieses Volk (...). Da war ich doch in (..) Lysovka.. Da haben sie im Dorfsovet zwei solcher Wirrköpfe.. Parteigenossen.. Die liefen hierhin und dahin, scheuten keine Muihe - und man hat ihnen die Ambulatorium gebaut, ein solches Krankenhaus, daß es sogar in der Stadt... Und zwei Doktoren, junge, vernünftige. Die heilen dir, wie man so sagt, aus dem Effeff. Und immer ist es voll, und da gibt es dir Leute, die zu unsereinem kriechen.. Eselsneffen.. und dabei sind das doch, Ignatij Enempodistovič, (..) erwachsene Menschen ... Laufen aus dem Krankenhaus zu den gräflichen Gläschen.. Kurieren sich qiţ) Zahnpulver und Pferdemist ....Ech, Menschen, Menschchen..." 


\subsection{Nöp- und Apparatschik-Satire}

Die 'Satire des Sumpfes' erfaßt das Gesamtpanorama der in die Sowjetgesellschaft (noch) nicht integrierten sozialen 'überbleibsel'-Gruppen- und Typen, situiert Figuren und Ereignisse geographisch in der 'Provinz schlechthin', zeitlich in den '20-er Jahren uberhaupt'. Verglichen mit dieser 'Totalen' stellt sich die 'NÖP- und Apparatschik-Satire' (unten meist kurz 'NöpSatire' genannt) dar als 'Nah'- und 'Momentaufnahme' zugleich: Sie zentriert einzelne Typen und Problemstränge - sie greift den im 'Sumpf' nur episodisch in Erscheinung tretenden 'Nöpmann' und seinen von ihm korrumpierten Handlanger im staatswirtschaftlichen Apparat heraus. Und sie präzisiert außerdem den Zeitpunkt - die kritisierten und verlachten satirischen Angriffsobjekte beziehen sich auf eine ganz spezifische sozio-ökonomische, wirtschafts- und gesellschaftpolitische Situation: auf das Jahr 1925, auf die in diesem Jahr eingeleitete Liquidierungsphase der 'engeren NöP' also. Auch der Ort der Handlung ist genau ausgewiesen: Moskau.

Der Begriff 'engere NöP' - ja der Begriff 'NÖP' generell - bedürfen der Abklärung, da der (hier relevantere) sowjetische Nöp-Begriff und das westliche Nöp-Verständnis (das partiell inadäquater Horizont für die Beurteilung der 'Nöp-Satire' ist) erheblich differieren, differieren nicht nur bezüglich der in sie eingehenden wertenden Implikationen (dort: die Nöp als gesetzmäßige Übergangsphase zur vollsozialisierten Wirtschaft; hier: die Nöp als 'Bankrotterklärung der Bolschewiken', als 'Rückfall in den Kapitalismus' u.ä.m.), differieren vielmehr auch hinsichtlich ihrer Periodisierungen.

Exkurs: Zum Begriff 'NÖP'

= = = = = = = = = = = = = = = = = = =

Der im Sommer 1918 eingeleitete 'Kriegskommunismus' - der erst post rem geprägte Begriff meint sowohl den Versuch, eine vollsozialisierte Wirtschaftsordnung unter den Bedingungen des Bürger-K $r$ e $g$ e $s$ zu etablieren, als auch eine wirtschaftspo- 
litikmit dem Ziel, "eine $k \circ m m u n i s t i s c h e$ Wirtschaftsform auf der Basis unterentwickelter ökonomischer (nämlich vorwiegend vorkapitalistischer j.e.) Verhältnisse zu errichten"174) - hatte bis zum Früjahr 1921 eine höchst problematische ökonomische und innenpolitische situation herbeigefuhrt: Absinken der industriellen Produktion auf $14 \%$ der Gesamtproduktion von 1913 sowie der Agrarproduktion auf unter 50\% der Vergleichszahlen von 1913 (d.h. aber: gewaltige Versorgungsschwierigkeiten, die 1921 in einer Hungerkatastrophe gipfelten); 40\% Arbeitslose; Bauernaufstände; Marzaufstand der Kronstadter Matrosen etc.. 175)

Der vom 8. bis 16. März 1921 tagende 10. Parteitag der KP trug dieser Situation und ihren Ursachen (insbesondere: ubersturzte Nationalisierung fast aller Wirtschaftszweige; Enteignungen und Lebensmittelrequisitionen im agrarischen Bereich; ersatzlose Zerschlagung gewachsener sozio-ökonomischer strukturen) Rechnung und leitete die 'Neue ökonomische Politik' ein.

Im April desselben Jahres wurde zunächst die Zwangseintreibung von Agrarprodukten eingestellt - an ihre stelle traten gesetzlich festgelegte, mit zunehmender Produktion prozentual abnehmende Naturalabgaben; eine Maßnahme, die die Erzielung von Produktionsüberschüssen durch die Gewährung materieller Anreize und die Wiederherstellung des freien Marktes zum Verkauf dieser überschüsse zum $\mathrm{Ziel}$ hatte.

Wenig später wurden

"der freie Binnenhandel fast uneingeschränkt, grundsätzlich auch das private Unternehmertum und in gewissem Umfange selbst ausländische Kapitalinvestitionen wieder zugelassen, die Vollsoziali sierung nur im Bereich der Grundstoff- und Schwerindustrie erhalten, (..) die Reprivatisierung kleiner Betriebe erlaubt und durch ein neues Grund- und Bodengesetz von 1922 für eine kurze Zeitspanne 59 gar bäuerliches Eigentum (an Grund und Boden) geschaffen" 17698 .

In Zahlen: Bereits 1923 betrug der Anteil der Privatindustrie im Bereich der GroBindustrie 4,4\%, in der K1einindustrie $87,3 \%$ der Gesamtproduktion, während in Groß-bzw. Einzelhandel 18, 1 
bzw. 66,5\% des Umsatzes von Privatunternehmen erzielt murde. In der Landwirtschaft schlieblich belief sich der privatwirtschaftliche Produktionsanteil auf nicht weniger als $98,6 \%{ }^{177}$ ). Als Ergebnis eine baldige ökonomische Konsolidierung: 1923 war die Talsohle verlassen, 1927 hatte die Produktion - von Getreideerzeugung und verstaatlicht gebliebener Schwerindustrie abgesehen - den Stand von 1913 wieder erreicht.

Die durch die NöP etablierten Produktionsverhältnisse stellen also keinen puren 'Rückfall in kapitalistische Produktionsverhältnisse' dar, vielmehr eine Kompromißlösung zwischen privatkapitalistischer und 'sozialistischer' (resp. 'staatskapitalistischer') Wirtschaftsordnung dar: weitgehende Rückkehr zur marktwirtschaftlichen Verhältnissen, grundlegende - die Wiedereinführung des unlängst als kapitalistisch verurteilten Leistungslohnes beinhaltende - Revision der Lohnpolitik etc. einerseits, gleichzeitiger Ausbau von zentraler Wirtschaftsplanung und Zentralverwaltungswirtschaft (1921: Gründung von GOSPLAN als Zentrale staatlicher Wirtschaftsplanung; der gesamte Außenhandel und die Schwerindustrie bleiben statich etc.) andererseits. Zwei Zahlenreihen signalisieren die Entwicklung nach 1924/1925:

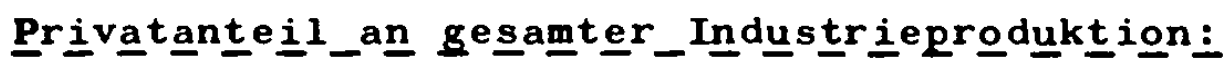

$1924: 18,7 \%$

$1927: 14,1 \%$

1929: $0,60 \%$

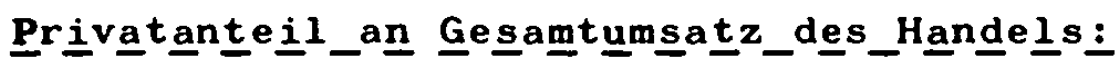

1924: $57,5 \%$

$1927: 36,9 \%$

$1930: 5,6 \%^{178)}$

Zu beachten ist in beiden Reihen der deutliche Rückgang von 1924 bis 1927: das Jahr 1925 markiert eine Wende, markiert den Beginn der forcierten Ausweitung des staatswirtschaftichen Sektors, der forcierten Zurückdrängung des privatwirtschaftlichen Sektors also! 
Westdeutscher und sowjetischer Nöp-Begriff differieren: Während der Begriff 'NÖP' in BRD-Darstellungen nicht nur ein bestimates wirtschaftspolitisches Konzept, sondern auch eine klar abgegrenzte Epoche (1921 - 1928, also bis zur Einleitung des 1. Füf jahrplans 1928 - 1932) signalisiert, meint der Terminus im sowjetischen Sprachgebrauch schwergewichtig ein bestimmtes wirtschaftspolitisches Programm, dessen Gültigkeitszeitraum lediglich hinsichtlich seines Anfangs (1921) eindeutig absteckbar ist. "Mit dem Sieg des Sozialismus in der UdSSR hatte sich die Nöp als besondere Politik des proletarischen staates im wesentlichen erschöpft. Als I.V. Stalin die Veränderungen im Leben der UdSSR von 1914 bis 1936 charakterisierte und 1924 mit 1936 verglich, sagte er: Wenn wir damals die erste Periode der Nöp hatten, den Anfang der NöP, die Periode eines gewissen Auflebens des Kapitalismus, so haben wir jetzt (1936 j.e.) die letzte Periode der NÖP, das Ende der NöP, ${ }^{\text {gaj }}$ Periode der vollständigen Liquidierung des Kapitalismus" 1799 .

Nicht zufällig wird 1936 gerade mit 1924 verglichen: 'Istorija SSSR, 179a) wie 'BSÉ' periodisieren folgendermaßen (und diese Periodisierung ist für die Beurteilung der 'Nöp-Satire' eminent wichtig):

1. 'Vosstanovitel'nyj period' (1921 - 1925)

2. 'Rekonstruktivnyj period' $(1925-1928)$ ' 'engere Nöp'

= Liquidierungsphase der 'engeren NöP'

= Rekonstruktionsphase der staatskapitalistischen Planwirtschaft.

3. Nöp im weitesten Sinne (bis etwa 1936 s.o.).

Westdeutscher und sowjetischer Nöp-Begriff w e $r$ e $n$ auch verschieden: während BRD-Darstellungen meist eine $r$ e $r$ e s$s i v e$ Kontinuität zwischen Nöp und vorrevolutionären Produktionsverhältnissen ansetzen und den übergang zur Planwirtschaft als 'Kurswechsel' etc. bewerten, betonen die sowjetischen Darstellungen das Moment der $p \quad r \quad g$ e s $i$ e $n$ Kontinuität. Das ausschlaggebende Element für die Kontinuität von 'razgar NÉPa' ( 1921 - 1925), Liquidierungsphase der 'engeren NÖP' ( 1925 - 1928) und Funfjahrplanwirtschaft (1928 ff.) sehen 'Istorija SSSR' wie 'BSE' in den sie verklammernden planwirtschaftlichen 
Strukturen, mithin im industriellen (d.h. aber im städtischen) Bereich, da diese strukturen $h i$ e $r$ schon seit 1921 (GOSPLAN, STO) ansatzweise zu finden sind und seit 1925 eindeutig dominieren.

Fazit der sowjetischen Bewertung der NÖP: "Schon und gerade die NöP schuf die Voraussetzung für den Angriff auf kapitalistische Elemente"180). Die eigentliche Legitimation der Nöp: die Nöp ist eine ausgesprochene Übergangspolitik - "Das Land ging den einzig richtigen Weg zur Lösung der sozio-ökonomischen Probleme der Epoche des Übergangs vom Kapitalismus zum Sozialimus"181) eine übergangspolitik, "die unvermeidlich ist für alle Länder im Verlauf einer jeden übergangsperiode vom Kapitalismus zum Sozialismus"182), eine Übergangspolitik also mit $G$ e $s t z$ m ä $\beta$ i $g$ k $i t s$ c h a $r$ a $t e r$.

Auch für die 'NÖP-Satire' gilt, was für die anderen typologischen Möglichkeiten satirischen Groß-Erzählens, die in den zwanziger Jahren in der Sowjetunion entwickelt wurden, oben festzuhalten war - sie ist auf allen Ebenen uberaus stark schabloniert: Die beiden erfaßten satirischen 'Nöp-Romane' - es handelt sich um L. Grabar's 'Die Lachudrin-Gasse 183) und Ju.Berzins 'Ford, 184), beide 1926 entstanden - sind auf den Analyse-Ebenen Figurenbestand- und Konstellation, Figurenkonstitution, positive Gegenposition (figural wie argumentativ), historische Perspektive, ausgewiesene Problem-Lösungsmöglichkeiten (s. kommunikative Funktion) bis ins Detail analog konstruiert; sogar die storys weisen weitgehende Parallelen auf.

(Um aber nicht à la Vulis in unkontrolliertes und unkontrollierbares Pauschalieren und Generalisieren zu verfallen, sei ausdrücklich darauf hingewiesen, daß die Beobachtungen zur 'Nöp-Satire' nur an den beiden explizit genannten Texten angestelit wurden, daß folglich die Möglichkeit, die aus ihrer Analyse gewonnenen Ergebnisse zu generalisieren für eine ganze Entwicklungsstufe des sowjetischen satirischen Romans nur vermutet, nur per Analogieschluß als sehr wahrscheinlich vorausgesetzt werden kann: 
weil die Textauswahl dem Zufall der Verfügbarkeit überlassen blieb, weil sich auch die anderen Möglichkeiten satirischen Groß-Erzählens sofort zu nur geringfügige Abweichungen erlaubenden, quasi nach festen Bauplänen angefertigten Modellen verfestigten.)

Beide Romane situieren ihre Handlung und Figuren im Moskau des für die Nöp eine Wende markierenden Jahres 1925: schon die geringe Spanne von nur einem Jahre zwischen dem Zeitpunkt der erzählten Ereignisse und dem Publikationszeitpunkt läßt einen hohen kommunikativen Aktualitätsgrad vermuten. Beide Romane schildern einerseits (kriminelle) wirtschaftliche Transaktionen von Nöpmännern und die Ermöglichung dieser Transaktionen durch schwar ze Schafe - 'sozial-fremde', 'sozial-gefährliche Elemente' - im statswirtschaftichen Apparat die für den 'razgar Nèpa' ('Hochsaison der NöP') charakteristische Verflechtung von privatwirtschaftlichem ("častnyj') und staatswirtschaftlichem 'gosularstvenny') 'Sektor'. Beide Romane sparen nicht mit milieu- und atmosphärecharakterisierenden zeitspezifischen Merkmalen: privater (Groß-) Handel; Zufluß ausländischen Kapitals; private Aktiengesellschaften; Börse; Luxus-Restaurants (stereotyp das Moskauer 'Praga'); Spielbanken; Spekulation mit westlicher Ware und Valuta; Riga als kapitalistisches Eldorado etc.. Beide Romane machen andererseits aber auch deutlich, daß sich der Nöpmann - auch in seinem Selbstverständnis - bereits in der Defensive gegenüber der 'Sowjetmacht' befindet, die ihn mit wirtschafts-, steuer- und gesellschaftspolitischen Maßnahmen aus den ihm noch verbliebenen privatkapitalistischen Reservaten verdrängt; machen deutlich, daß auch die Tage der 'sozial-fremden etc. Elemente' im Apparat gezählt sind - ihnen rückt eine kurz 'ëistka' genannte Gesellschaftspolitik zu Leibe. M.a.W.: Beide Romane signalisieren die sozio-ökonomische Umbruchssituation, signalisieren die Einleitung einer die forcierte Liquidation der Nöp sowie die Eliminierung 'bürgerlicher Spezialisten' aus dem Apparat beinhaltenden Politik.. Genauer: begründen, propagieren, popularisieren diese höchst aktuelle Politik - die Vermutung eines 
hohen kommunikativen Aktualitätsgrades bestätigt sich also.

'Nöpmänner' (nèpmany' - 'NöP-Bourgeois') und 'Kommissare' (1eitende Angestellte von Staatsbetrieben - 'Apparatschiki') sind die zentralen Figuren des satirischen 'NÖP-Romans'. Bei Grabar' - dessen 'Lachudrin-Gasse' der 'Satire des Sumpfes' noch wesentlich näher steht als Berzins 'Ford' und so den Übergang von der 'Satire des Sumpfes' zur 'NÖP-Satire' deutlich markiert - treten (genau wie die obyvateli der 'Satire des Sumpfes' konstituierte) obyvateli und Dörfler (letztere ein absoluter Ausnahmefall im ansonsten das Dorf nicht tangierenden satirischen Roman der zwanziger Jahre!) als milieucharakterisierende Figuren sekundär, Pioniere und Komsomolzen (auch sie in genauer konstitutioneller Entsprechung zur 'Satire des Sumpfes') als (natürlich positive) Exponenten der jungen Generation sehr episodisch hinzu.

Nöpmann und Kommissar als Zentralfiguren - dies bedeutet nun aber keineswegs, daß die Figuren - $\mathrm{k}$ n $\mathrm{s}$ e 1 a $t$ i $n$ der 'Nöp-Satire' - wie zu erwarten - auf der Opposition von Nöpmann (als Negativfigur) und Kommissar (als Positivfigur) basiert. Vielmehr verläuft die Front zwischen Negativfiguren und Positivfiguren innerhalb der Gruppe der Kommissare, innerhalb des staatswirtschaftichen Apparates also. Figurales Oppositionsschema: Die story (sie ist der um 1925 häufig kultivierten 'Defraudanten'-Erzählung s.u. entlehnt), die die Korrumpierung eines 'labilen' Kommissars durch Nöpmänner, seinen moralischen Verfall und seine Autoliquidation per Selbstmord erzählt, konfrontiert der Negativ-Allianz aus Nöpmännern und korrumpiertem Kommissar einen positiven Kommissar.

Im Falle der Kommissare ${ }^{185)}$ erhellt die Besetzung der figuralen Negativ-bzw. Positivposition also nicht aus dem sozialen status und dem Sozialverhalten dieser Figuren am Anfang des Romans. Dies bedeutet für die $K \circ n s t i t u t i$ $t$ der Kommissare, daß sie sich nicht auf wenige Versatzstücke beschränken kann, daß sie vielmehr wesentlich intensiver erfolgen muß: die Figuren-Konstitution muß insbesondere die Ursachen des Fehlverhaltens des strauchelnden Kommissars, die Ursachen des positiven 
Verhaltens des Kontrast-Kommissars aufdecken. Und sie weist diese Ursachen nach in der spezifischen Milieu-Verklammerung und in der Biographie der beiden Kommissare (Grabar'). In der Einarbeitung einer breitangelegten biographischen Dimension unterscheidet sich die Figurenkonstitution der 'Nöp-Satire' am auffäligsten von den Konstitutions-Merkmalen der bisher vorgestellten Möglichkeiten satirischen Erzählens: die Figur des negativen Kommissars ist keine statische Puppe mehr, vielmehr verläuft sie in der Erzählung eine zu einem 'tragischen' - in keiner Weise verlachten - Ende (Selbstmord) führende Entwicklung. Nicht er - der Nöpmann steht im Zentrum der Verlachung. Der Nöpmann und die obyvateli tragen auch die unmittelbare schuld am Scheitern des einen Kommissars, sie korrumpieren ihn.

"zu Beginn des Jahres 1920 (..) fand sich Michail Moiseevič S̈arfötejn, nachdem er die letzten überreste seiner früheren Kapitalien verzehrt hatte, auf dem Trödelmarkt von Nižnij Novgorod ein; auf den Armen trug er ein Paar seiner Feiertagshosen, die er wichtigtuerisch anspruchslosen Käufern feilbot. In dieser Situation verblieb er denn auch bis zum unvergeßlichen Jahre 1921, wobei er so nach und nach mit Fertigkleidung, Tabak, staatskleidung, Reizkern, Sacharin und patentierten Gummisohlen handelte.

Im Jahre 1921 gewann M.M. ̈̈arf s̈tejn die überzeugung, daß der freie Handel von den Bolschewiki endguitig legalisiert worden war, putzte seine Galliffethosen, die ihm von einer Partie verkaufter staatskleidung verblieben waren und verfügte sich mit einer überaus begrenzten Anzahl von Geldscheinen in der Tasche nach Moskau. (..). Eine Woche später eröffnete er in der Mjasniékaja ein Geschäft. Einen Monat später nahm er eine kleine Lederfabrik in Pacht. Nach einem halben Jahr bezogen er, seine Frau (..) und sein Sohn (..) eine frühere gräfliche villa in der Prečistenkaja.

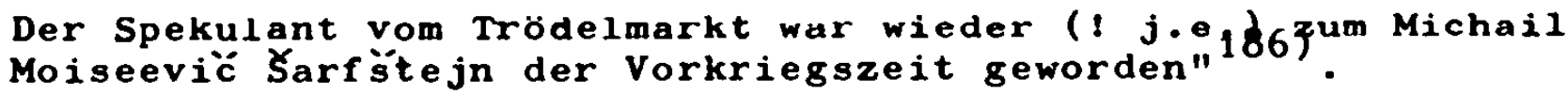

Šarfötejns Biographie wiederholt sich beim Gros der Nöpmänner mit minimalen Abweichungen: Jude ${ }^{187}$ ), vorrevolutionärer Bourgeois, durch den 'Kriegskommunismus' zum kleinbürgerlichen Spekulanten reduziert, mit Einleitung der Nöp Umzug nach Moskau, 
Nöpmann - der Nöpmann ist $w$ e d e $r$, was er schon imer war: ein 'buržuj'.

Es gibt aber einen zweiten Typ Nöpmann mit abweichender Biographie :

"Wissen Sie, wer diese sauberen Bürschchen 188) waren, in Gomel 189) nämlich? Genau genommen Rotznasen und weiter nichts. Liefen wie die allerletzten Spekulanten von Trödelmarkt rum, in erbärmlichen Uniformröcken und Galliffethosen. Und jetzt? Sehen Sie doch nur, wie sie sich kleiden! Die letzten Pariser Moden. Und haben eine Vierzimmer-Wohnung in der Mesčanskaja - sie verstehen: in Moskau vier Zimmer! Die Parkettböden, glauben Sie mir, glänzen wie Gold; ihr Schlafzimmer haben sie dem Grafen Zubov abgekgyft (..), ein luxuriöser Salon, ein englisches Arbeitszimmer"

Man sieht: das Resultat dieser Biographie ist das gleiche - ein Nöpmann. Aber: war jener Nöpmann unmittelbares - in die Sowjetgesellschaft nur verschlepptes - Produkt ('perez̈itok') der bürgerlichen Vergangenheit (er 'war wieder zum M.M.S. der Vorkriegszeit geworden'), so ist dieser Nöpmann unmittelbares Produkt der Nöp selbst: die Nöp gestattet nicht nur der alten Bourgeoisie den 'Rückfall'; sie bringt auch eine n e u e Bourgeoisie hervor! Sie korrumpiert das Kleinbürgertum! Diese von der Nöp ausstrahlende soziale Ansteckungsgefahr ist d a $s$ Anti-Nöp-Argument der 'NÖp-Satire'.

Die Biographien differieren; Sozialverhalten und es 'legitimierende' Ideologie aber sind dem Alt-Bourgeois und dem Neu-Bourgeois - dem Nöpmann generell also - gemein. Mit Adleraugen verfolgt der Nöpmann das Wechselspiel von Angebot und Nachfrage, und wie ein Raubvogel stößt er in jede sich auftuende Marktlücke: der 'deficit' (die Mangelware) ist seine ganz spezifische Ware, brutale Ausbeutung sein Geschäftsgebaren. Seine Spekulationsobjekte sind insbesondere: Wohnungen, westliche Ware und Valuta, Arbeitsplätze, Halbfabrikate für die staatsindustrie.

"Nun, sie wissen ja, die neue Politik, (..), Geschäfte werden eröffnet, Kinos, Cafés, Theater, die Börse - unglaubliche Umsätze. Nun, zuerst müssen Sie wissen, begannen sie wie alle anderen auch. (..) sie handelten mit Valuta - (..) Dann allerdings beschlossen sie, diese Sache sein zu lassen! Das ist zu riskant! (..) Wie aber wuBten sie diesen Augenblick zu nutzen? Damals herrschte zwar noch nicht eine derartige Wohnungsnot, trotzdem saßen sich 
die Leute schon wie bei einer Hochzeit auf der Pelle. Halbzerstörte Häuser, die nur einer kleinen Reparatur bedurften, gab es in Hülle und Fülle. Nun, die Burschen kapierten die Lage; nun, sie gingen in die entsprechende Abteilung, gingen hierhin und dahin, gaben dem einen was in die Hand, dem andern was zum Beißen - nun, erstick' dran, nur halt die Klappe! Leb' selbst und $l a ß$ andere leben! Und was glauben Sie? Sie ubernahmen ein Haus nach dem anderen zur Reparatur. In einer einzigen Saison machten sie ihr Geld. Jetzt leben sie wie Grafen. Der eine hat ein Geschäft ${ }_{1} \oint \dot{9} \nmid 5$ Manufakturwaren (..), der andere organisiert in Petrograd 191 eiqg 2 \$ache: 'Galanterie des Nordens' - eine Aktiengesellschaft" 192 ".

'Dem einen was in die Hand, dem andern was zum Beißen' - kurz: Bestechung, Korrumpierung leitender Angestellter des statswirtschaftlichen Apparates. Was umso leichter gelingt, als der Apparat durchsetzt ist mit 'sozial-fremden Elementen, nämlich 'bürgerlichen Spezialisten'; d.h. aber - durchsetzt ist mit im Apparat untergetauchten 'verflossenen Bourgeois': (Der ehemalige Millionär) "Lebt heutzutage nicht mehr, sondern vegetiert .. er steht im Brot bei einem Chemie-Trust, ist dort völlig unersetzlich"193) "der wirtschaftliche Direktor? Ivan Ivanovic̈? fragte der Juriskonsult. - Der ist parteilos. Ein ehemaliger Fabrikbesitzer. Ein fähiger Spez."194) : der für den Sowjetstaat noch 'unersetzliche' (weil 'eigene' Kader noch nicht existieren) bürgerliche Spezialist, der aus der 'Satire des Sumpfes' vertraute Klassenfeind an den Schaltstellen des Staates.

Offener Nöp-Bourgeois und verkappter Apparatschik-Bourgeois bilden gemeinsam eine Front gegen den zu Fall kommenden Kommissar. Thre gemeinsamen Motive: Bereicherung, konterrevolutionäre Sabotage. Ihre Strategie: Aufspuren der Achillesferse des sich bis dahin sowjetloyal verhaltenden Kommissars (seine - oder seiner Frau - aufgrund schlechter Bezahlung nicht zu befriedigenden gehobenen Konsumbedürfnisse s.u.), Gewährung eines 'Darlehens', das der Kommissar nicht zurückzahlen kann - 'dem einen was in die Hand, dem andern was zum Beißen': der Kommissar in Abhängigkeit von den Nöpmännern.

Die Abhängigkeit wird umgemünzt in Erpressung. Das Resultat: kriminelle (den staat teuer zu stehen kommende) Transaktionen 
zwischen privat- und staatswirtschaftlichem sektor:

"Die private Genossenschaft 'Zentrale Universale', deren Leitung ich innehabe, hat einen äußerst dringenden Bedarf an der Produktion ihres Trusts (...). Wir winschen über die Norm hinaus und zu den günstigsten Vorzugsbedingungen, die sie uns bieten können, beliefert zu werden .. Sie verstehen natürlich, daß ich ein Meqģ bin, der nicht gern einen Dienst umsonst an-

Der Kommissar will zwar nicht mitspielen, aber: "Ich muß Zweitausend für die Wohnung bezahlen. Von allen Seiten bedrängt man mich mit Forderungen, und ich habe in einem derartigen Maße über meine Verhältnisse gelebt..."196).

Die auf diese Weise zu Spottpreisen bei Staatsbetrieben erstandene Ware wird - als defizite Ware - zu Spekulationspreisen mit Riesengewinnen an andere Staatsbetriebe verkauft. Die sich aufdrängende Frage: "Kann man denn nicht ohne private Lieferanten auskommen?"197) muß - noch - verneint werden. Der Nöpmann "ist zweifelsohne eine charakteristische soziale Erscheinung. Die anwachsende neue Bourgeoisie, die durch die Schule des Krieges und der schwierigen Jahre der Revolution gegangen ist, ... gelangt uberall hin .. sie demoralisiert den staatlichen $1989^{a-}$
rat.. Massenprozesse.. Bestechungen.. Veruntreuungen"

Bei Grabar' wie bei Berzin b e $g r$ u $n d$ e $t$ der Nöpmann sein auf möglichst schnelle Bereicherung ausgerichtetes und insbesondere Spekulation mit 'Defiziten' beinhaltendes Sozialverhalten. Berzin führt mit seiner Titelfigur Ford - einem 'z̈ulik' (Gauner), der nicht nur den Sowjetstaat, sondern auch alle Nöpmänner schädigt (s.u. 'story') und zynisch kommentiert und so als eine 'Vorstudie.199) zu Ostap Bender (s.u.) aufgefaßt werden kann sogar eigens einen 'Ideologen', ein Sprachrohr zur Darlegung der I d e $\quad l \circ g$ e der Nöpmänner und ihrer 'Artgenossen' im Apparat ein.

Diese Ideologie umfaßt drei Blöcke: 1) Antibolschewismus (Haß auf die 'Roten' - siehe 'Satire des Sumpfes'); 2) Das Wissen, daß für den Nöpmann die Zeiger der Geschichte auf fünf vor zwölf stehen; 3) Der Mythos von der unverzichtbaren Privatinitiative des Privatunternehmers. 
ad 2) (Endzeitbewußtsein): "Ja, auch das Proletariat ist heutzutage ein Lumpenpack. Mit einem Wort - kein Proletkult, sondern ein Kultprolet (Kulturverflug j.e.). Typisch $20 b_{j}$ e sie die Steuern handhaben - die ersticken uns noch ganz" 200 " "Ob sie dort in ihrem Kreml wieder etwas Neues betreffs steuern aushecken? - Kann schon sein, seufzte Nikitaffgorovic, - nur mich und Sie wird man bestimmt nicht fragen" 1 ". "Sie brauchen nur die Zollgebühren noch etwas anzuheben, die zulässige Zahl der Auslandspakete etwas einzuschränken - und unser Liedchen ist aus"202) "Sind etwa wenig Paragraphen speziell für unsereinen fabriziert worden? Denn was sind wir eigentlich? Nöpmänner, Spekulanten, Parasiten am Hals der Werktätigen und sqowiter und so weiter, - wer wird mit uns schon lange fackeln"

ad 3) (Privatunternehmer-Ideologie): "Der Staat, was für eine Wirtschaft ist das schon? Die Partei - ist es etwa ihre Sache, sich mit der Wirtschaft zu befassen? Ich sehe das so! Amerika! Bei denen mussen wir in die Lehre gehen, Kommissar! (..) Jede Kopeke, jeder Groschen bringt dort einen Ertrag! Jeder Knopf ist an seinem Ort, nicht das kleinste Haar geht verloren! Das ist in meinen Augen eine Wirtschaft! Das igt ${ }^{j}$ in meinen Augen ein Mensch! Das ist in meinen Augen ein Genie! wir in die feghe gehen! Aber was machen wir? Wir bauen den Sozialismus" 205 . "Kühnheit erobert Städte (..): das ist mein liebstes Sprichwort. In unserer Zeit ist ein Mensch ohne Kühnheit und Frechheit verloren, ich vergdgpere Sie. In unserem Beruf kommt man ohne Risiko zu nichts" mer noch davon, ein vaterländischer Ford zu werden? ${ }^{207}$ He-hezwinkerte Ford prahlerisch (..), he he! Ford hin, ford her, aber ohne unsereinen werdet ihr nicht zu Rande kommen. Was heißt das: Ford, Kommissar? Das heißt Initiative und Fähigkeit. Ihr habt zwar Initiative - akg6) keine Fähigkeit. Ihr werdet schon noch
zu uns kommen ..."

Kurz: Eine Wirtschaft ohne den privatinitiativen Privatunternehmer ist eine Mißwirtschaft, der sowjetische Staat folglich auf Initiative und ökonomisches Know-How der Nöpmänner angewiesen..

Die ge ne $r$ e 1 l e soziale Negativität des Nöpmanns wird - wie aus obigen Belegstellen erhellt - in der'NöP-Satire' direkt dargestellt (der Nöpmann ist offen Nöpmann - er. braucht sich 1925 ja auch noch gar nicht zu tarnen!) und direkt etikettierend benannt ('spekulanten', 'Parasiten' etc.). 'Decouvriert'209 wird allenfalls der häufig $k r i m i n l l e$ Charakter seiner korruptiven Geschäftspraktiken. Wesentlich gilt aber für die zentrale Negativfigur auch der 'NöP-Satire' (wie für die Negativprotagonisten der 'Satire des Sumpfes'): intratextuell d e- 
c o $u r$ i e $r$ wird die sich hinter Überlegenheitsanspruch und weltmännischem Gebaren etc. verbergende Lächerlichkeit, Erbärmlichkeit etc. des Nöpmanns. Decouvrierung heißt also auch hier primär: $\quad v$ e $l$ a c $h$ n $g$. Die satirisch konstituierte Figur ist also auch hier sozial negativ u n d komisch (s. dagegen u. die Negativfigur 'Kommissar')!

Durchgehende Decouvrierungs-d.h. aber: Verlachungsstrategien:

1) Bedeutungsnamengebung ('Drakin' - 'der Schläger'; 'Volosov' - 'hängt an einem Haar' etc.) 210); 2) Nachweis der Automatenhaftigkeit: Die Nöpmänner bilden eine Kollektivfigur - sie haben alle die gleiche 'typische Vergangenheit' (zwei Varianten s.o.), das gleiche 'typische Sozialverhalten', die gleiche 'typische Ideologie'; eine 'Individualisierung' erfolgt nur ironisch: jeder Nöpmann hat seinen nur ihm eigenen 'Tick' - der eine stottert kontinuierlich an ein- und demselben Judenwitzchen herum, der andere beschnüfelt jeden Abend seine Socken und komentiert seinen Eindruck jeden Abend mit ein- und derselben Floskel; der dritte schläft ausnahmslos jede Nacht mit seiner Frau - obwohl sie ihn anekelt etc.; 3) Pubertierung: der Nöpmann favorisiert eine ganz bestimmte 'Sorte' von Ehefrauen - ehemalige Baronessen, Füstinnen etc. 210a) - und haßt die einmal erworbene 'Ware', die sich als äußerst fade erweist. Die Folge: Alle Nöpmänner sind mehr oder minder glücklose Schürzenjäger, sind wie die obyvateli der 'Satire des Sumpfes' nonstop-erotisiert; 4) Verlachung per story: bei Grabar' wie bei Berzin scheitern die Nöpmänner ausnahmslos in der story, wird ihnen in der Erzählung von den 'Roten' das Handwerk gelegt. Bei Berzin werden sie zusätzlich dadurch verlacht, daß sie alle über einen 'ל̌ulik', einen Thresgleichen also zu Fall kommen (Autoliquidation).

Wie erwähnt gehen in den Figurenbestand von Grabar's' 'LachudrinGasse' (diese 'Gasse' ist nichts anderes als eine "Pfütze-MeerOzean" 211) von 'gesellschaftlichen Überbleibseln", ein obyvatel' 'Sumpf') auch obyvateli ein. Auf eine Darstellung dieser Figurengruppe 212 ) kann hier verzichtet werden: diese Figuren sind 
aus der Analyse der 'Satire des Sumpfes' vertraut.

Von Interesse hingegen sind die Bauern-Figuren dieses Romans: Grabar' ist wohl der einzige sowjetische Satiriker, der vor weitgehend abgeschlossener Zwangs-Kollektivierung (d.h. aber: bevor die Möglichkeit bestand, eine nach Privat (-) - und Kolchos (+)-Bauern polarisierende Figurenopposition zu konstruieren 213), Bauern ${ }^{214}$ ) als sekundäre Negativfiguren in eine satirische Großerzählung eingebaut hat. Die Konstitution der Bauern - genauer: der nicht im Komsomol organisierten Bauern - weicht gravierend ab von der der obyvateli: Die obyvateli sind auch hier hirnlos-antisowjetisch vor sich hingeifernde, lernunfähigstatisch ihrem historischen Exitus entgegendämmernde Marionetten ihrer Vergangenheitslastigkeit und Ignoranz - sie werden verlacht. Die Bauern hingegen werden in zunächst tiefschwarzen, gegen Ende des Romans in tiefgrauen Farben gezeichnet: "Dunkelheit, Sittenlosigkeit, Samogon" lautet des positiven Kommissars Kurzformel für die Kernprobleme der größten Bevölkerungsgruppe 215) der jungen Sowjetgesellschaft - Ignoranz, religiöse Indoktrinierung, Analphabetismus, Geschlechtskrankheiten, Vergewaltigungen, Alkoholismus, Brutalität, Faulheit....

\section{Die Kommissare (Die Apparatschiki)}

Die Untersuchung von Figurenbestand- und Konstitution des satirischen 'NÖP- und Apparatschik-Romans' setzte ein mit der Analyse des Nöpmanns. Nicht von ungefähr! Denn: beide hier zu charakterisierende Romane sind zweiteilig. Und in beiden Romanen dominiert im jeweils ersten Teil - dessen story die Einfädelung der Korrumpierung eines Kommissars durch Nöpmänner, die Verstrikkung dieses Kommissars erzählt - der engere soziale Kontext, in dem die Kommissare stehen, dominieren also Nöpmann- und (bei Grabar') obyvatel'-Figuren.

Der jeweils erste Teil ist die eigentliche NöP-Satire. Was nicht nur bedeutet, daß hier die Negativität der $N$ ö $P$ an ihrem ex- 
ponierten figuralen Repräsentanten zentral thematisiert wird; vielmehr bedeutet das auch, daß der jeweils erste Teil der eigentliche $s$ a $t r i s c h e$ Teil ist!

Zentral im jeweils zweiten Teil - dessen story Versuche des zu Fall gekommenen Kommissars erzählt, sich aus der finanziellen Abhängigkeit von den Nöpmännern zu befreien; Versuche, die - mit dem irreversiblen Griff in die Staatskasse - zu immer tieferer Verstrickung, zum Tode des gestrauchelten Kommissars führen - steht der korrumpierte Kommissar, der korrumpierte Apparatschik. Ihm opponiert wird ein ihm seit dem 'Oktober' freundschaftlich verbundener pusitiver Kommissar, den die Nöp nicht aus der Sowjetgesellschaft (und aus dem Leben selbst!) hinauskatapultiert, den vielmehr die Einsicht in die Negativität vieler Begleiterscheinungen der Nöp und sein Widerstand gegen sie zu einer Vertiefung seiner aktiven Integration in die Sowjetgesellschaft führen.

Die zentralen Figuren des ersten Teils sind eindeutig satirisch, die zentralen Figuren des zweiten Teils eindeutig nicht-satirisch konstituiert. Ja - der scheiternde Kommissar selbst ist keine negative Figur im Sinne einer selbstverschuldeten, einer selbst-korrigierbaren (oder gar: verlachbaren) Negativität; er scheitert vielmehr 'tragisch' an sich seiner Einflußnahme entziehenden Faktoren, scheitert entweder zufällig oder an seiner Klassenprovenienz $u n d$ an seiner aktuellen Sozialverklammerung $(s . u$.$) .$

Da auch im zweiten Teil dieses Romans die Verlachung der Zentralfiguren des ersten Teils fortgefüht wird, stehen hier satirische und (in keiner Weise verlachte) nicht-satirische (aber auch nicht einfach - wie in oben dargestellten Möglichkeiten satirischen Erzählens - eine figurale positive Gegenposition besetzende) Figuren nebeneinander, agieren gemeinsam und gegeneinander gehen hier Satirisches, Tragisches, Rührendes durcheinander, wird hier der Rezipient zwischen Lachen, Gerühtsein und bloßem Betrachten im sozialen Raum nicht begrüdeter Abnormitäten hin und her gebeutelt: Er wird verunsichert - aber nicht in seiner 
'Weltsicht' (diese Verunsicherung intendiert Satire zur Zerschlagung eines alten und zur Durchsetzung eines neuen Wert-Horizontes ja sehr häufig!), vielmehr in seiner Rezeptionshaltung! Diese Uneinheitlichkeit der Textkonstitution scheint unter dem Gesichtspunkt der Rezeptivität, der Realisierbarkeit der intendierten kommunikativen Funktion (s.u.) problematisch.

Weist der jeweils erste Teil fast alle Versatzstücke der in kleinen Formen (wie insbesondere dem satirischen Feuilleton) um 1925 kultivierten NÖP-Satire auf, entspricht der jeweils zweite Teil sehr genau dem Paradigma der zwischen 1924 und 1926 überaus häufigen nicht-satirischen 'Defraudanten'-Erzählung (der ebenso generell wie fälschlicherweise $V$. Kataevs 'Defraudanten' zugeschlagen werden. s.u.).

Die Konstitution, insbesondere aber die Konstellation der Kommissare in den beiden Romanen weisen weitgehende Parallelen auf. In beiden Romanen sind es jeweils zwei Kommissar-Figuren, die - im Gegensatz zu den vielen Nöpmännern, die so weitgehend identisch konstituiert sind, daß sie sich letztlich nur durch ihren Namen und einen ihrer Verlachung dienenden Tick (wesentlich also gar nicht!) unterscheiden - nicht als Zwillinge nebeneinander stehen, die vielmehr oppositiv konstelliert sind: Zwei Figuren mit zwar identischem sozialen status, aber mit verschiedenem gesellschaftichem Verhalten und verschiedenem Schicksal.

Die Opposition der zwei Kommissare erfolgt in beiden Romanen nach $e i n$ e Schablone: zwei in Revolution und Bürgerkrieg verdiente 'Kriegs-Kommissare' werden während der Nöp zu leitende Positionen im staatswirtschaftichen Apparat besetzenden WirtpchaftsKommissaren (Apparatschiki 216)). Thre Ämter bedingen kontinuierlichen Kontakt mit der NÖP-Finanz- und Wirtschaftsaristokratie, setzen sie kontinuierlichen Korruptionsversuchen dieses Milieus aus: stellen sie in eine sozio-ökonomisch typische Konfliktsituation, vor eine Prüfung, in der sie sich als Kommunisten (und Menschen) zu bewähren haben. Ein Kommissar scheitert an dieser. Prüfung, der andere bewährt sich. In beiden Romanen sind die Kommissare seit Revolutionszeiten befreundet; in beiden Romanen 
sind (eigene oder fremde) nicht stillbare Konsumbedürnisse unmittelbare Ursache der Korruptivität des scheiternden Kommissars. Soweit die gemeinsame Schablone. Die Konkretisierung dieser Schablone erfolgt in den beiden Texten aber mit erheblichen Abweichungen.

Schon auf den ersten Seiten des Romans führt $B$ e $z$ i $n$ seinen positiven Kommissar (einen wahren Ideal-Kommissar) Andrej ein, der (1925) aus Usbekistan kommend, wo er bisher mit der Waffe in der Hand für die Sowjetmacht gekämpft hatte, in Moskau eintrifft. Dem Ideal-Kommissar opponiert er dessen früheren Freund und Mit-Kämpfer Pavel, der seit Jahren im hauptstädtischen statswirtschaftlichen Apparat arbeitet:

"Neben ihm fühlt sich Pavel regelrecht dreist in seinem grauen, gut auf Taille geschnittenen Anzug, den spitzen gelben Halbstiefeln und dem Filzhut. Pavel hat irgendein unbekanntes rundes Gesicht, und eine runde amerikanische Brille sitzt ihm solid auf der Nase. (...)

- Du, mein Freund, bist offensichtlich von der NöP infiziert ('obnèpilsja') Pavel bleibt abrupt stehen und schaut einen Augenblick unzufrieden auf den Kommissar. Betrachtet sein russisches Hemd, seine Mütze und seine Hose, die er in einem örtlichen Kooperativ erstanden hat (...). Andrej betrachtet die Aushängeschilder und Schaufenster. Zufriedene, herausgeputzte Menschen springen ihm von den plakaten geradezu ins Gesicht, schwimmen ihm kontinuierlich entgegen. Aufgedonnerte Frauen streifen ihn mit ihren Schultern und Hüften. Andrej betrachtet ihre geschminkten Gesichter und unvermittelt bemächtigt seiner eine Wut. Er bleibt stehen und sagt Pavel:

- Das Pack sitzt ganz schön im Speck, als sei nie etwas gewesen. Im Jahre zwanzig hätte ich solche erschossen ........).

Sie betreten ein Restaurant. Und Pavel, der frühere Kriegskommissar und Kampfgenosse Andrejs, mit dem er gemeinsam unzählige Wege an allen Fronten absolviert hatte, setzt sich an einen Tisch. Freundschaftlich begrüßt er eine ganze Gruppe wohlgenährter, gut gekleideter Menschen (vielleicht war jeder von ihnen seinerzeit ein unversöhnlicher Kämpfer und Kommandeur), nickt lässig dem Kellner zu und studiert mit demselben Ernst, mit dem er einst in der Politischģ $7 \hat{f} b t e i l u n g$ Agit-Flugblätter korrigiert hatte, die Speisekarte" 217 .

Damit ist das figurale Oppositionsschema konstituiert: der eine ist ein NÖP-modebewußter Hauptstädter, der andere spartanischer Kämpfer bis auf den heutigen Tag; der eine hat sich mit der Nöp arrangiert, der andere vergleicht die Nöp mit dem Kriegskommu- 
nismus - und kommt zu ihrer vernichtenden Verurteilung (diese Verurteilung wird im Roman nicht zurückgenommen, nicht relativiert etwa als übertreibung eines weltfremden Provinzlers: die Nöp wird aus autorisiertem Munde als eindeutig und absolut negativ deklariert und dabei bleibt es! ${ }^{218)}$ ) ....Kurz: der eine $i s t$ Nöp-infiziert, $i s t$ ein Todeskandidat; der andere i s $t$ absolut positiv.

Dieses starre Schema wird ohne Abweichungen bis zum Ende beibehalten: der eine verhält sich problematisch bis kriminell-negativ, der andere verhält sich absolut exemplarisch-richtig und kommentiert das Fehlverhalten des ersten:

Andrej stellt fest, daß Pavel in seine (ihm von Nöpmännern beschaffte) Geliebte Summen investiert, über die er legal gar nicht verfügen kann. Andrej kommentiert, warnt:

"Ich will keine Vermutungen bezüglich der Quelle dieses Geldes anstellen (..), aber du arbeitest in einer solchen Position. Durch deine Hände gehen Riesenbeträge, Staatsgelder, und du kommst, ob du willst, 8 ger nicht, in Kontakt mit den allerschmutzigsten Affäristen" 19 )

Andrej trifft Pavel in Gesellschaft von Nöpmännern: "Da riecht es schon schwer nach Nöp" 220).

Pavel tappt allen Warnungen zum Trotz (denn e $r$ i $t$ eben Nöp-infiziert!) in die Fallen der Nöpmänner, und er erkennt und artikuliert:

"Andrej hatte recht: ich bin ein Dreckskerl und ein Vieh, aber kein Kommunist. Was für ein Kommunist bin ich schon? Da habt ihr Pavel Michajlovič! Kriegskommissar, Mitglied der RKP, alter Untergrundkämpfer? Da habt ihr meine Verdienste, meine Ehre: ich habe dem Volk gehörendes Geld veruntreut. Da habt ihr dăg Praga' $^{\prime}$
und die Zigeuner und die hübsche Wohnung und die Möbel"

Pavel ist zum 'rastratčik' geworden, zum Defraudanten. Der Erscheinung nach noch ein Kommissar, ist er wesentlich mit den Nöpmännern identisch:

"Ich"22) und sie ... (...) sind Vögel einer Rasse.. Wie man sagt - aus einem Nest .... Jawohl. Sie nehmen, ich gebg ... Sie geben, ich nehme ... Ein völlig normales Geschäft.." 2239 .

Am Ende wird Pavel mit den Nöpmännern inhaftiert, am Ende steht sein Selbstmord im Gefängnis. 
Beide Kommissare sind in ein uberaus starres Schema eingepaßt: Andrej $i s t$ ebenso positiv, verhält sich ebenso positiv - wie Pavel negativ $i s t$, sich negativ verhält. Die Frage nach den U $r$ a $c h$ e der Positivität des einen, der Negativität des anderen wird nicht aufgeworfen: beide sind der potentiellen Korruption durch die Nöp ausgesetzt; der eine widersteht ihr, der andere nicht. Ja, diese Frage entzieht sich einer plausiblen textbezogenen Beantwortung! Einzige Erklärungsmöglichkeit: NöPspezifischer Zufall! Denn der Leser erfährt lediglich, daß beide früher gleichermaßen positive Bürgerkriegskämpfer waren, daß der eine um Jahre früher in das 'ungesunde' Moskauer NöP-Klima geriet als der andere. Daß jener diesem Klima nicht gewachsen war, während dieser in demselben Klima in seinen - den richtigen, den zu propagierenden! - Ansichten über die Nöp bestätigt wird. Welcher SchluB wird dem Leser nahegelegt: scheitert der eine, weil er $f r u h$ e $r$ in das NÖP-Klima geriet, scheitert er, weil es ' e b e ' labile und stabile Charaktere gibt?

Grabar' vermeidet Berzins Schematismus, und er macht die Ursachen des Verhaltens seiner Kommissar-Figuren evident. Er vermeidet Berzins Schematismus - und konstruiert ein anderes, ebenso starres Schema, das beide Kommissare zunächst zu Defraudanten werden, dann aber den einen endgültig scheitern, den anderen auf den Weg sozialistischer Tugenden zurückfinden läßt; und er findet die Ursachen für das (letztliche) Scheitern, für das (letztliche) Bewähren in zwei Bereichen: primär im biographischen Bereich (soziale Provenienz), sekundär im Bereich der aktuellen Sozialverklammerung. Werdegang und Verhalten werden streng oppositiv parallelisiert: 


\section{Volosov (+)}

Proletarische Provenienz Arbeiter
Ivanov (-)

Jüdisch-kleinbürgerliche Provenienz Student

Rote Armee

Parteimitgliedschaft

Bürgerkriegskommissar

Tätigkeit im staatswirtschaftlichen

Apparat

Fehl-Heirat mit

Kleinbürgerin

Wird von den kleinbürgerli-

chen Konsumgelüsten seiner

Frau auf die schiefe Bahn

gebracht wird wieder integriertes Glied seines kleinbürgerlichen Milieus

Wird von eigenen kleinbürgerlichen Konsumgelisten auf die schiefe Bahn gebracht

Defraudanten $=$

Kriminelles Fehlverhalten

Stellt sich Justiz und Partei

Geht (zur Läuterung)

in Haf $t$

Löst sich von seiner kleinbürgerlichen Frau

Knuipft an seine proletarische Vergangenheit an, wird wieder Arbeiter

Erstrahlt in geläuterter Kommunisten-Schönheit
Entzieht sich Justiz und Partei

Flieht, bleibt

Defraudant

Sucht Unterschlupf in der kleinbürgerlichen Subkultur

Knüpt an seine kleinbürgerliche Vergangenheit an, schmarotzt sich bei Verwandten durch

Verkommt endgültig und begeht Selbstmord

Verirrungen eines grundlegend Niedergang eines wesentlich positiven weil 'klassenhegemonischen Elementes'

'sozial-fremden Elementes'

Zusammenfassend ist also festzuhalten, daß die 'NöP- und Apparatschik-Satire' die $p$ o $i t i v e$ e g e $p$ o $s i t i o n$ f $i$ g $r$ a 1 mehrfach besetzt. Exponierte positive Einzelfigur ist der jeweilige positive Kommissar, der nicht nur positives gesellschaftliches Verhalten (selbstverständliche oder letztliche Bewältigung einer Konfliktsituation) und 'privates' Verhalten (Lösung kleinbürgerlich infizierter familiärer Bande) demonstriert; der vielmehr zugleich als autorisiertes sprachrohr zur Verurteilung der Nöp ${ }^{244}$ ) fungiert - zu einer verurteilung, die 
als zentrales 'A $r$ ume $n t$; die Etikette 'Nöp' selbst einsetzt: 'es riecht schwer nach Nöp', 'du bist von der Nöp infiziert' etc..

Der positive Kommissar ist exponierter Repräsentant der Sowjetmacht in seinem engeren sozialen Kontext, und er ist ihr einziger figuraler Repräsentant: die Sowjetmacht selbst (Partei, Regierung) ist im Text nur mittelbar repräsentiert, repräsentiert in Gestalt von ihr durchgefuhrter bzw. eingeleiteter wirtschaftsund gesellschaftspolitischer Maßnahmen, die dargestelltermaßen die Negativfiguren 'entschärfen', ihre Eliminierung aus dem Apparat intendieren. Die Sowjetmacht hat die Negativität der NöP erkannt - und die Konsequenzen in Steuerpolitik, Jurisdiktion etc. gezogen; die Sowjetmacht hat das Problem der 'sozialfremden etc. Elemente' im Apparat erkannt - und trägt dieser Erkenntnis durch eine kontinuierlich als 'Ćistka' signalisierte Gesellschaftspolitik Rechnung. 'Čistka' ist der von der 'NÖp- und Apparatschik-Satire' propagierte Schlissel zur Lösung der im staatswirtschaftlichen Apparat anstehenden Probleme! ' $\ddot{c}_{i s t k a}$ ' lautet in aller Kürze der von ihr formulierte $A$ p e 11 ! wie in der 'Satire des Sumpfes' geht schließlich die junge Generation in die figurale positive Gegenposition ein: sie verlacht den Nöpmann, zerschlägt die Samogon-Destillierapparate etc. - sie ist grundlegend positiv!

Auf 'Argumente' zum Nachweis der Negativität des Nöpmanns ('der Nöpmann ist negativ, weil ...') wird weitgehend verzichtet 225), diese Negativität wird am Sozialverhalten des Nöpmanns d a r$g$ e $t$ e $l 1 t$. Nicht am Sozialverhalten des Nöpmanns iberhaupt, vielmehr an dem des eindeutig kriminellen Nöpmanns. Aber: a 11 e dargestellten Nöpmänner sind kriminell; es wird also suggeriert, der Nöpmann, der - noch - legitimes Kind der aktuellen Wirtschaftspolitik ist, sei generell kriminell. M.a.W.: der Nöpmann wird verurteilt - ohne daß zugleich die ihn produziert habende Politik desavouiert wirde! 
Die 'NÖP- und Apparatschik-Satire' ist zwar 'Nah- und Momentaufnahme' - sie stellt ihre Figuren aber dennoch nicht absolut statisch in den sozio-ökonomischen und politischen Umbruchs-'Moment' 1925. Zwar durchlaufen auch hier die satirisch konstituierten Figuren (anders der negative Kommissar) wesentlich keine Entwicklung - eine entschiedene Entwicklung durchläuft aber innerhalb dieses 'Momentes'226) die gesamte sozio-ökonomische Situation; eine Entwicklung, die zur Folge hat, daß die Nöpmänner der Sowjetgesellschaft inadäquat $w$ e $d$ e $n$ (obwohl sie sich selbst nicht verändern); eine Entwicklung also, die eine positive, optimistische $h i s t o r i s c h e p e r s p k t i e$ eröfrnet!

Die Herstellung dieses unüberbrückbaren widerspruchs zwischen Nöpmann einerseits und sozio-ökonomischer Gesamtsituation und Entwicklungstendenz (hin zum staatswirtschaftlichen Monopol) andererseits wird zwar wiederholt angedeutet mit Hinweis darauf, daß sich der Nöpmann bereits in der Defensive weiß, weiß, daß er sich bereits in der Doppel-Schere zwischen Steuer-, Wirtschafts- und Gesellschaftspolitik befindet; wesentlich erfolgt die Herstellung dieses Widerspruchs jedoch abrupt gegen Ende der beiden Romane: aus zwar nicht heiterem, aber doch nur getrübtem Himmel schlägt die Sowjetmacht zu und eliminiert die Nöpmänner radikal aus der Sowjetgesellschaft, transferiert sie scharenweise nach Sibirien. Berzins 'Ford' schließt denn auch mit einem wahren Exodus der Nöpmänner aus dem gelobten Nöp'Land' Moskau:

"In Solovki (sibirischer Verbannungsort j.e.) gibt es jetzt eine sehr anständige Gesellschaft (..): - in der vergangenen Woche verreiste dorthin, d.h. man expedierte ihn dorthin, der Ingenieur Vokal'čik. Darüberhinaus befinden sich dort der Schwurgerichtsbeisitzende Vjalcev, Doktor Kruk und die Baronesse von Vancenknakker, bei ihr, wissen sie, hat man unvermutet eine spielhölle entdeckt. Eine sehr ordentliche Gesellschaft ...."227)

Das Problem der Nöpmänner wird also am Ende der beiden Romane 'abgehakt'. Nicht so das Problem der 'sozial-fremden und sozialgefährlichen Elemente' im staatswirtschaftlichen Apparat: zwar furchten diese bereits die als Damokles-Schwert über ihnen schwe- 
bende čistka; die čistka selbst hat aber noch nicht stattgefunden! Dieses in beiden Romanen als unerledigt ausgewiesene Problem verweist somit direkt auf eine der zentralen kommunikativen Funktionen der 'NÖP- und Apparatschik-Satire' (s.u.)!

Liquidation der Nöpmänner (und eines Teils der Dorf-Negativität bei Grabar') durch den Staat einerseits, Autoliquidation des negativen Kommissars andererseits. Beide Liquidationen erfolgen auf den letzten Seiten der Romane. Gerade dieser Schluß läßt die Nebeneinanderstellung satirischer und nichtsatirischer Negativfiguren noch einmal problematisch erscheinen: insbesondere bei Grabar', dessen Roman mit dem (auch nicht andeutungsweise bespöttelten!) Selbstmord des getrauchelten Kommissars endet (während Berzin dem Selbstmord den Zwangs-Exodus der Nöpmänner folgen läßt), kann sich der Leser des Gefühls nicht erwehren, sein vorangegangenes Lachen sei unangebracht gewesen, da diejenigen, deren Verlachung er mitvollzogen hatte, letztlich derart schreckliche Ergebnisse zeitigen konnten. Rezeptive Verunsicherung, ästhetisches Unbehagen sind die Folge!

Die spezifischen $k \circ m m u n i k$ a $i v e n f u n t i o-$ $n$ e $n$ der 'NÖP- und Apparatschik-Satire' sind evident - teils konnten sie pauschal bei der Darstellung der 'Satire des Sumpfes' angesprochen werden, teils erhellen sie bereits aus der in Bezug zur gleichzeitigen sozio-ökonomischen und innenpolitischen Situation gesetzten Analyse der beiden Romane: mehr als eine kurz zusammenfassende Registrierung der aufgrund unübersehbarer Signale eindeutig interpolierbaren zentralen kommunikativen Funktionen ist an dieser stelle also nicht mehr erforderlich.

- Begruindung, Propagierung, Popularisierung der Notwendigkeit der forcierten Ablösung der NöP, des forcierten Übergangs zur (im industriellen Bereich, im Handel mit nichtagrarischen Produkten) staatswirtschaftlich monopolisierten ökonomie.

Argumentiert wird nicht damit, die Nöp sei ökonomisch nicht mehr erforderlich - auf dieses Argument wird erstaunlicherweise gänzlich verzichtet - vielmehr mit dem Hinweis a) auf das den staats- 
wirtschaftlichen Apparat korrumpierende kriminelle Geschäftsgebaren des Nöp-Milieus, b) auf die von diesem Milieu insbesondere auf das Kleinbürgertum ausstrahlende Ansteckungegefahr. Interessant ist die undifferenzierte Verurteilung der Nöp in diesen Satiren, interessant die hieraus resultierende Diskrepanz zwischen der Bewertung der NöP in der 'NÖP-Satire' einerseits (totale Verteufelung einer offiziell noch nicht dethronisierten Politik) und ihrer Bewertung in der sowjetischen Geschichtsschreibung andererseits (die Nöp als völlig normale, gesetzmäßig eintretende Übergangspolitik)!

- Begrüdung, Propagierung, Popularisierung der nach 1925 forcier. ten 'čistka'-Politik, die die Entfernung 'sozial-fremder etc. Ele. mente' aus dem Apparat (aber z.B. auch - und diese Zielrichtung thematisiert Berzin - aus den Universitäten: "akademische čistka der Studentenschaft"228), beinhaltet. Zentraler Appell also: Fordert, organisiert, fördert Säuberungsaktionen in euren Apparaten, Behörden etc..

- Sympathiewerbung für Partei und Regierung: beide betreiben gemeinsam die richtige Erfolgspolitik (die vorgefuhrte 'Erledigung' des Nöpmann-Problems), beide begegnen auch Gestrauchelten mit Verständnisbereitschaft und räumen ihnen eine Chance ein: Grabar' 'positiver' Kommissar, dem zwar ein gravierendes Fehlverhalten - die Veruntreuung von staatsgeldern - unterlief, der hieraus aber die einzig richtigen Konsequenzen zog - sich nämlich der Ver antwortung gegenuber Partei und Justiz stellte - wird nicht liquidiert, vielmehr nach verbüßen einer gerechten strafe rehabilitiert, wieder in die Partei aufgenommen.

Die figurenbezogene Textanalyse hat en passant schon festgehalten, daß beide satirische NöP-Romane eine Zäsur aufweisen: wie er innerlich stellt sich der jeweils erste Teil dar als weitgehend auf eine nacherzählbare story verzichtende Reihung satirischer Nöpmann- und Kleinbürger-Porträts; hinzu kommen bereits hier die beiden nichtsatirisch konstituierten Kommissar-Figuren.

Im jeweils zweiten Teil hingegen treten die beiden Kommissar-Fi- 
guren in den Vordergrund und die story erzählt ihre Kollision mit den Nöpmännern, insbesondere aber den Niedergang des via Bestechung durch die Nöpmänner zum 'Defraudanten' gewordenen (und in beiden Romanen auch wiederholt direkt so apostrophierten!) und sich aus dieser Verstrickung nicht mehr befreienden negativen Kommissars.

In diese story gehen wesentliche Versatzstücke der um die Mitte der zwanziger Jahre häufig kultivierten, uberaus klischierten (nichtsatirischen) 'Defraudanten'-Erzählung um einen über eine 'rastrata' ('Veruntreuung') zu Fall gekommenen Angestellten eines staatsbetriebes - den 'rastratik' ein.

Chomutovs 229) Kassierer Kol'čugin etwa befindet sich mit Frau und Tochter in einer prekären wirtschaftlichen Situation: er steht ringsum in der Kreide, ist buchstäblich mittellos. Ausgerechnet jetzt muß er seiner lebensgefährlich erkrankten Tochter einen Kuraufenthalt finanzieren. Aus Kummer und Verzweiflung vertrinkt und verspielt er am Zahltag sein Gehalt. Die jetzt umso dringendere Notwendigkeit Geld zu beschaffen, sowie die Faszination durch die dem häuslichen Elend aufs blendendste kontrastierende Pracht der NöP-Spielsalons lassen Kol'čugin zum Spieler werden. Seine Spielleidenschaft finanziert er durch wiederholte Griffe in die Kasse seines Staatsbetriebes, die er durch Gewinne auszugleichen hofft. Nach langem Hin und Her zwischen Gewinn und Verlust, nach wilden Gelagen mit Nöpmännern, Dirnen und seinesgleichen stürzt sich Kol'čugin vor den Augen seiner Frau aus einem Fenster der Spielbank und stirbt.

Insbesondere Grabar' ibernimmt viele Elemente der nicht-satirischen 'rastrata'-Erzählung. Aber: weder bei ihm noch bei Berzin wird die 'rastrata' motiviert durch eine fatale ökonomische Situation der Defraudanten; motiviert wird sie vielmehr durch das fatale Verhaftetsein der Defraudanten in - ihrer ökonomischen und politischen Situation nicht angemessenen - Konsumbedüfnissen, in kleinbürgerlichen (Grabar') oder bourgeoisen (Berzin) Luxus-Bedürnissen. M.a.W.: die 'rastrata' wird motiviert durch aus der Vergangenheit importierte Denkmuster, Bewußtseinshaltungen!

Damit kontaminiert der satirische NöP-Roman Elemente der nichtsatirischen 'rastrata'-Erzählung mit einem Element der satirischen 'rastrata'-Erzählung $v$. Kataevs (s.u.): Wie in der nicht-satiri- 
schen 'rastrata'-Erzählung gehen die Defraudanten des satirischen NÖP-Romans nach vollzogener (aber - im Gegensatz zum Paradigma - nicht im Detail beschriebener!) Veruntreuung auf vorgezeichnetem Weg durch Spielkasinos etc. zugrunde; wie in Kataevs satirischer 'rastrata'-Erzählung werden 'Überbleibsel der Vergangenheit im Bewußtsein' als Ursache des Fehlverhaltens mit angesprochen.

Ein weiteres Element der satirischen 'rastrata'-Erzählung wird - sehr episodisch - übernommen: nur als Randfiguren auftauchende satirisch konstituierte Defraudanten-Figuren ziehen - in genauer Entsprechung zu Kataevs -Defraudanten' - auf der Suche nach dem verlorenen Paradies durch die (erhofften) verbliebenen Reservate der 'Crème' der vorrevolutionären Gesellschaft. Grochotov, Pavels Buchhalter:

"Ech, Pet'ka, wie liebe ich diese Situation. Wind, Eisenbahn, Lich. ter, Fernstraße.. Vor uns rätselhafte Weite, lockende Ferne, unbekannte Horizonte, Quellen des Glucks. Wenn wir, Pet'ka, in Leningrad ankommen, fahren wie als Barone ins Gasthaus 'Evropejskaja' (..) Hotel Europa, - Lakaien (..), ein paar Mädchę 3 ) Hm Abendessen (..) Freiheit der Person, Herr der Schöpfung"

Pavel, Ivanov sowie eine ganze Reihe sekundärer Figuren sind Funktionäre des statswirtschaftlichen Apparats - sie sind $k e i n$ e $\quad$ ü $r \circ k$ a $t$ e $n$, und die 'NöP- und ApparatschikSatire' ist $k$ e $i n e$ 'Bürokraten-Satire', $k$ e $i$ e 'Bürokratismus-Satire' !

Zwar finden sich Apparatschik und Bürokrat 'im Leben' in dem gleichen Personenkreis leitender oder subalterner Mitarbeiter von Staatsbetrieben, Behörden etc. - die Satire k o n $s$ i$t u i$ e $t$ 'Apparatschik' und 'Bürokrat' aber grundverschieden: im Unterschied zur 'NÖP- und Apparatschik-Satire' (die eindeutig $k r i m i n$ e 1 e s Fehlverhalten von Funktionären darstellt und ebenso eindeutige gesellschaftpolitische, administrative und juristische Lösungsmöglichkeiten - cistka, Anklageerhebung ... - vorschlägt) verlacht die 'Bürokraten'- bzw. 'Bürokratismus'-Satire $n$ e $g t i v e$ 'bürokratische' Verhaltensweisen am Arbeitsplatz, $n$ e $g t i v e$ 'bürokratische' Ein- 
stellung (Desinteresse, Formalismus, Stumpfsinn etc.) zur Arbeit im engeren Sinne, dann aber auch zur Kunst, zu Parteiaufgaben...

Erst die Spitzenleistung des sowjetischen satirischen Romans 'Das Goldene Kälbchen' von Il'f und Petrov - zentriert den Bürokraten als satirisches Darstellungsobjekt, den Bürokratismus als satirisches Angriffsobjekt. Aber: auch dieser satirische Roman ist (einem in der Forschung weitverbreiteten Fehlurteil zum Trotz) keine 'Bürokraten-Satire', keine 'Bürokratismus-Satire': diese 'Schubladen' sind für die breite Palette satirischer Darstellungsobjekte um Ostap Bender viel zu eng (s.u.).

Ja: der sowjetische satirische Roman hat - soweit dies in Anbetracht der schwierigen Materiallage behauptet werden kann - überhaupt keine 'Buirokraten-Satire' hervorgebracht! Dies - obwohl (und vermutlich zugleich: weil!) Bürokrat und Bürokratismus insgesamt wohl Hauptangriffsobjekte der sowjetischen Satire nicht nur der zwanziger Jahre sind: andere satirische Genres (vor allem satirisches Feuilleton, Fabel, Komödie) kultivieren diese Angriffsobjekte bis hin zur Ausschließlichkeit (siehe 'Krokodil')!

Diese Genres sind aber nicht Gegenstand dieser Untersuchung: im Gegensatz zu vorliegenden sowjetischen Arbeiten zum sowjetischen satirischen Roman, die - wohl zur 'Abrundung des Bildes'? - auch sehr kurze Texte 231 ) unter die Behandlung des satirischen $R$ o $m$ a $n$ subsumieren (ohne Hinweis auf den Subsumtionscharakter dieses Verfahrens!) und so letztlich kein 'abgerundetes Bild' sondern ein Zerrbild erstellen, weist die vorliegende Arbeit also kein Kapitel uber den sowjetischen 'Bürokraten'- bzw. 'Bürokratismus'-Roman auf ! 


\subsection{Intellektuellen-Satire}

Die 'Satire des Sumpfes' kennt als eingeordnete Figur den 'Intelligent', den'Intellektuellen'232). So weist etwa slezkins 'Ziegenbock...' einen intellektuellen Krähwinkler auf, der einerseits in hochtrabenden Phrasen volkstümelt -

"ich liebe das Volk", "da ist es, das ukrainische Dorf! Es wird nicht von Tag zu Tag, sondern von Stunde zu Stunde kräftiger, reicher, größer. Es wächst kulturell, 3 yqd da sagt man noch, es gäbe keine smyčka (Annäh̨̧łyłg j.e.) ? 233 "Wir brauchen die engste smyčka mit dem Dorf" 234 "

- andererseits aber eben dieses 'Volk' (die Bauern) abgrundtief verachtet: "Stinkschnauze"235).

Schon diese Figur deutet das zentrale Konstitutionsmerkmal der satirischen Intellektuellen-Figur an: den unvermittelbaren widerspruch zwischen wildwuchernd verbalisierter 'Idee an sich' und fehlender lebenspraktischer (wesentlicher) Konsequenz.

Erst S.S. Z a $j$ a $i c k i j s$ s 1928 erschienener satirischer Roman 'Die Beschreibung des Lebens des Stepan Aleksandrovic̈ Lososinov. Ein tragikomisches Werk.236) jedoch zentriert den Intellektuellen als satirisches Angriffs- und Verlachungsobjekt: die für Ende der zwanziger Jahre entstehende sowjetische satirische Romane des 'Binnen-Bereichs' kennzeichnende Herausarbeitung e $i \mathrm{n} r$ (in früheren satirischen Romanen eingeordneten) negativen Erscheinung.

Zajaickijs Satire ist dreiteilig. "Der Erste Teil. Vorvergangenheit (Plusquamperfectum)" arbeitet die zentralen IntellektuellenMerkmale Lososinovs heraus (Zeitpunkt: 1913). "Der Zweite Teil. Vollendete Vergangenheit (Perfectum) " konfrontiert den zuvor in der bürgerlichen Normal-Zeit vorgefühten satirischen Helden der (scheinbaren) Bewährungs-Situation des (bürgerlichen Ersten WeltKrieges, *Der Dritte Teil. Unvollendete Vergangenheit (Imperfectum)" schließlich versetzt Lososinov in eine qualitativ völig neue Situation: in die ersten Jahre der Sowjetgesellschaft. 237) Alle zentralen Figuren des Romans - einschließlich des Erzählers, der sich eingangs als 'intelligent' und enger Freund Lososinovs 
ausweist und sich im weiteren Verlauf wiederholt ausdrücklich mit inm identifiziert - sind 'Intellektuelle'. Keine dieser Figuren wird - über den Eigennamen hinaus, der ihr einziges individuelles Merkmal ist - durch 'Angaben zur Person' individualisiert: sie sind durchwegs noch relativ junge (Mitte 20) BourgeoisSöhne, verfügen - ohne selbst zu arbeiten! - über unbeschränkte finanzielle Mittel, verfügen über eine gewisse akademisch-humanistische Bildung, über ein hochentwickeltes Verbalisierungsvermögen. Sie bilden die in sich undifferenzierte soziale Gruppe der Intellektuellen; die Herausarbeitung ihrer gemeinsamen Intellektuellen-Merkmale, ihre Verlachung werden an Lososinov lediglich exemplarisch vorgenommen: Lososinov - das sind die Lososinovs, die Intellektuellen!

Die im ersten Teil erfolgende Basis-Konstituierung der Lososinovs konstruiert zwei fundamentale komische Widersprüche, zwei fundamentale komische Spannungsverhältnisse zwischen subjektivem Anspruch und objektivem Einlösungsvermögen: 1a) Verhaftetsein in der 'Idee an sich', ihre unkontrolliert schwafelnde Verbalisierung einerseits - b) völlige Unfähigkeit, diese 'Idee an sich' (die 'an sich' schon in komischer spannung zur Realität steht s.u.) in Aktivität, in Lebenspraxis umzusetzen andererseits. 2) Komische Spannung zwischen a) subjektivem Selbstverständnis und b) objektivem Sein.

ad 1)

a) Lososinov führt sich ein mit dem Bekenntnis zur 'Ewigkeit klassischer Schönheit' und mit der Feststellung, daß es um sie im russischen Volk schlecht bestellt sei - und mit einem Vorschlag zur Behebung dieses kulturellen Notstandes:

"eine Wiedergeburt ist unumgänglich, denn die Kunst ist in eine Sackgasse geraten.. Folglich besteht unsere Aufgabe darin, diese Wiedergeburt durchzuführen. Zu diesem Zweck müssen wir dem Publikum und der Masse nur das Bewußtsein vermitteln, daß das Studium der antiken Welt unumgänglich ist. Der Bauer ist geschmeidig und sprachbegabt. Man muß ihm die griechische und die lateinische Sprache beibringen (..) die Zeit zur Philologisierung Rußlands ist 389 gebrochen! Das wird etwas von Art einer Revolution sein" 238 . 
b) Zum Zwecke der 'Philologisierung' des russischen Volkes wird eine 'Akademie der klassischen Wissenschaften' gegrüdet. Aber schon die erste Vorlesung (die, da kein 'klassischer Referent' zur Verfügung steht, Alfred de Vigny behandeln soll) fällt ins Wasser: Lososinov verschläft sie (wie später Kriegsbeginn und Revolution) im Ehebett seines Freundes ...

Intellektuelle - terminologisch aufgeplusterte - 'pustoslovie' (Geschwätz):

"In unserer Gesellschaft ist die Meinung verbreitet, alle Onkel seien dumm. Diese Meinung ist aus zwei Gründen unvernüntig: 1) fast jeder Mensch ist gleichzeitig auch Onkel und folglich müßte man fast alle Menschen als dumm bezeichnen. 2) Onkel ist eine relative Größe, die einen Neffen voraussetzt. (der absolute Onkel ist ein fingierter Begriff oder doch zumindest so selten, daß es nicht lohnt, davon zu sprechen). Folglich ist die oben angefürte These folgendermaßen zu verstehen: Jeder Onkel ist dumm in Relation zu einem Neffen 2499 - nach den Gesetz 'actio gleich reactio' auch vice versa" 39 .

ad 2)

a) Obiges Zitat leitet unmittelbar über zum zweiten komischen Spannungsverhältnis: die wortreiche Onkeltirade hat in Lososinovs Onkel einen konkreten Anlaß. Dieser Onkel - ein Bauingenieur ist ein Mann der Aktivität, der lebenspraktischen Betätigung und als solcher für die Lososinovs, die ihrem Selbstrerständnis zufolge die Krönung der Schöpfung darstellen, schlicht: ein Idiot.

"Lososinov und sein Freund liebten den Onkel seiner Weltanschauung wegen (der Onkel ist Kommunist j.e.) nicht, und stepan Aleksandrovic hielt den Onkel überdies für einen Mußiggänger 'Hat drei Eisenbahnbrücken gebaut und ist darob sehr zufrieden', sagte er gewöhnlich von diesem Onkel; aber fragen Sie ihn, was eine 2489 jugatio perefrastica ist - und er wird es nicht wissen" 2487 .

Lososinov hofft, daß man im Gefolge der von ihm verbal-initiierten 'Renaissance' "bald nackt gehen wird"241). Den ironischen Einwand des Onkels "und das bei Frost und so"242) 'kontert' er: "Ohne auf Einwände einzugehen, brummelte Stepan Aleksandrovič irgend etwas von 'Idioten, die vor lauter Eisenbahnbrücken den Himmel nicht sehen', vor sich hin"243).

Aber: nicht nur dem 'idiotischen' Schaffenden 'wissen' sich die 
Lososinovs überlegen - selbst Koryphäen des Geistes werden von ihnen kurz erledigt:

"dąq 4 jst ja das Problem, daß man von der reichen russischen See$1 e^{244}$ nicht jene kleinbürgerliche Selbstsicherheit verlangen kann, die es Kant ermöglichte, sein ganzes Leben in Königsberg abzuhocken und die Dinge in seinem Inneren wiederzukäuen. Es ist charakteristisch, $94 \beta$ Lososinov Kant für einen mittelmäßigen Philosophen hielt" 245 ).

b) Und diesem aufgeblähten Übergelegenheitsanspruch 'korrespondieren' Ignoranz (Fichte als 'Flichte') und die Erbärmlichkeit ewig-geiler Automatenhaftigkeit, wie sie sich im stereotypen Tagesablauf der Lososinovs manifestiert: Aufwachen im Ehebett des Freundes, 'Praga', Oper, 'Praga' ('intellektuelles Gespräch' über immer dasselbe Thema in immer denselben Worten - und gleich anschließend ins) Bopdell: der Tagesablauf schöngeistiger Hurenböcke...

Der zweite Teil (Vollendete Vergangenheit'. Der Intellektuelle in der Bewährungssituation des bürgerlichen Krieges) steuert keine neuen Elemente zur Konstituierung der Lososinovs bei, setzt vielmehr ihre Verlachung lediglich durch Beibringung neuer Belege für die bereits eingefühten komischen Spannungsverhältnisse fort: Lososinov macht sich die Kriegsbegeisterung der 'Helden' spielenden 'Herren' zu eigen, artikuliert viel Patriotisches und kauft ("ich melde mich freiwillig"246)) eine Militärmütze ..... Zwar sonnt er sich im Ruhm, sich freiwillig gemeldet zu haben (was er faktisch erst zwei Jahre später tut) - bleibt aber in Moskau:

"Es ist unbekannt, was ihn dort festhielt. Einer Version zufolge konnte er um keinen Preis genau in Erfahrung bringen, wo Freiwilligenmeldungen entgegengenommen wurden; eine andere Version besagt, er sei von der ärztlichen Kommission ausgemustert worden, weil ihm irgeng $4 j^{j}$ sehr wesentliches Organ - wenn nicht gar die Milz - fehlte" 247 .

Endlich unterwegs, auf der Fahrt zur Etappe - die Front wird er nie zu sehen, den Krieg nie zu spüren bekommen: "der Abgrund, der den Weltkrieg von einem Wohltätigkeitsball trennte, schnurrte (für die intellektuellen Bourgeois-Söhnchen j.e.) auf das Maß eines kleinen Kanälchens zusammen"248) - setzt er sich mit 
dem F(1)ichteschen Idealismus auseinander und erklärt: "Flichte hätte wesentlich besser daran getan, wenn er - statt sich mit der Philosophie zu befassen - einen Wurstladen eröffnet hätte" 249? Konsequent entwickelt er sein eigenes hyperidealistisches Konzept, dessen Funktion die Vernichtung der Angst vor dem Krieg vermittels der Ignorierung unerwinschter Realität ist: "du (..), wie alles übrige, bist nur die Summe meiner Wahrnehmungen. Der Stein, der in der wiste liegt und den niemand wahrnimmt, existiert nicht. Verstehst du? .. Jetzt höre ... (..). Ein Mensch, der sich diese Weltsicht zu eigen gemacht hat, wird nichts mehr fürchten ... Was zum Teufel sollst du zum Beispiel eine heranfliegende Granate fürchten, $258^{n}$ du weißt, daß sie nur die Summe deiner Wahrnehmungen ist?" 250 ".

Fazit: der Krieg (nämlich der bürgerliche Krieg, der den bürgerlichen Intellektuellen alle Privilegien beläßt) stellt die realitätsabgelöste 'Ideen'-Lastigkeit der Lososinovs nicht auf die Probe, entläßt sie unversehrt - in eine qualitativ völlig neue Situation, die alle den Intellektuellen à la Lososinov erst ermöglichenden Privilegien vernichtet: die Revolution!

Der 'ideenlastige' Revolutionsbegriff der Lososinovs hat sich mit ihrer Qualifizierung der 'Philologisierung Rußlands' als 'etwas von der Art einer Revolution' bereits dokumentiert. Im dritten Teil ('Unvollendete Vergangenheit') manifestiert sich ihr weit vormarxistisches Revolutionsverständnis (zum Nachweis ihres Unverständnisses für den durch die Revolution herbeigefuhrten qualitativ neuen gesellschaftlichen Zustand) kontinuierlich:

"ein trauriger Mensch wollte wissen (..): 'was halten Sie von Lenin?' und erhielt die Antwort: 'meines Erachtens ist Maksimov besser. Denn damals meinf弓f pan mit Lenin gewöhnlich einen Schauspieler des Malyj Teatr"

"Stepan Aleksandrovic̈ akzeptierte die Revolution grundsätzlich" - er akzeptiert sie so, wie er sie versteht: dem 'signifiant' Oktoberrevolution assoziiert er H. Taine, assoziiert er die französische Revolution, d.h. die ihn - das Jeunesse doré-Mitglied in seiner privilegierten situation belassende bügerliche Revolution. Ungeachtet dieses gänzlich Realitäts-inadäquaten 'signi- 
fié' schreckt die Vokabel Revolution die Lososinovs lächerlicherweise dennoch. Lososinov liest der Frau seines Freundes aus Taine vor:

"Nina Petrovna wurde von dieser lektüre derart nervös, daß stepan Aleksandrovic ganze Tage mit ihr verbringen mußte und sie noch nicht einmal im Badezimmer verlassen durfte; denn seit sie die Geschichte Marats kennengelernt hatte, war Nina Petrovna ujbg5zeugt, man werde sie unbedingt in der Badewanne ermorden" 252 .

Der Erzähler kommentiert, porträtiert:

"Überhaupt war Stepan Aleksandrovic̈ hinter dem gesellschaftlichen Leben zurückgeblieben; er legte den Chalat nicht mehr ab, hatte sehr zugenommen und sich selbst irgendwie verloren. Das innere Feuer, das ihn sein ganzes Leben über verzehrt hatte, war plötzlich erloschen; unversehens wuchs ihm ein Doppelkinn und in entkleidetem Zustand glich er schon nicht mehr - wie früher - einem durchgeistigten Fakir, sondern einem Walroß. Zu einer Zeit, da ganz Rußland brannte und neu geboren wurde, wurde der geniale Mensch, ganz 25 m) Gegenteil, mickerig und verfiel gleichsam in Nichtigkeit" 253$)$.

Der Intellektuelle bleibt außerhalb der heroischen Zeit stehen: war er früher 'schöner' als die Gegenwart, weil er ihr in das schön-geistige Reich der 'Ideee an sich' enteilen konnte - so gerät er jetzt in den Kontrast der Häßlichkeit und Lächerlichkeit zu einer qualitativ neuen dynamisch-schönen Gegenwart. Hier wird ein stereotypes ${ }^{254}$ ) Verfahren der sowjetischen IntellektuellenSatire eingesetzt: Lososinov wird 'oblomovisiert' - er legt den Schlafrock nicht mehr ab, wird fett, verläßt das Haus nicht mehr, gibt sich nur noch der Reflexion über hohe Materien hin. Er wird zu einem 'Oblomov' - in einer Zeit, die die oblomovs nicht mehr akzeptiert (und materiell sicherstellt), die die Oblomovs durch Erschließung ungeahnter gesellschaftlicher Aktionsräume von tragischen zu eindeutig komischen Erscheinungen werden läßt.

In einer Zeit auch, die die Oblomovs-Lososinovs - 'wer nicht arbeitet, der soll auch nicht essen' - am Hungertuche knabbern läßt. Und so wird Lososinov nolens volens zum 'Sympathisanten', versucht er zumindest sich anzupassen:

"Mein Herz begann plötzlich, sozusagen unisono mit dem Herzen der Sowjetischen Regierung zu schlagen und plötzlichspggriff ich, welch mächtiges Glück darin beschlossen liegt!" 55 . 
Unt so wendet er sich als "bewußter Bürger"256) an das Volkskommissariat für Bildung mit einer 'genialen Idee', deren Präambel er - da er sich verbal (und nur verbal) bereits assimiliert hat - gar richtig formuliert:

"Es ist unsere Aufgabe, mit allen möglichen Mitteln die Errungenschaften der Revolution zu verfestiggn - mit der Waffe, mit dem gedruckten und ungedruckten Wort" 259 .

Die 'geniale Idee' selbst ist eine intellektuelle 'Idee an sich': "zuhöchst betrüblich ist der Fakt, daß die Genossen rote Kommissare genau so fluchen, wie in der 258 gn $^{2}$ Zeit blutrunstige Unteroffiziere und Polizisten fluchten" 258$)^{n}$.

Folglich beduirfe es der Entwicklung spezifischer roter Schimpfwörter - "z.B. schlage ich anstelle von 'Sollen dich Fliegen und Mücken fressen' vor 'Sollen dich S(ozial-) R(evolutionäre) und Menschenwiki fressen'"259) etc. - und zu diesem Zweck (er hat die Kürzel-Vorliebe der Roten richtig erkannt) fordert er die Einrichtung eines "Gosudarstvennyj institut brani (GIB)"260) (Staatliches Schimpfwortinstitut).

Die Roten akzeptieren seine 'Revolution' nicht - und so "war er sehr bald irgendwie vom Kommunismus enttäuscht und trat nicht in die Partei ein"261).

Da er zum Erhalt einer Lebensmittelkarte einer festen Anstellung bedarf, wird er Geschichtslehrer - und findet ein ausschließlich aus Seinesgleichen bestehendes Lehrerkollegium vor. Über ihr 'Intellektuellen-Sein' hinausführende Gemeinsamkeiten: absolutes fachliches, politisches und ideologisches Unqualifiziertsein für die Aufgaben eines Erziehers junger Sowjetbürger. Gemeinsam empfindet man die rote Gegenwart als Katastrophe, gemeinsam erwartet man die Restauration:

"Ach, schweigen Sie... das ist ein einziges Zuchthaus! - Und wissen Sie, wie man erzählt, soll Lenin gesagt haben 262): wir ${ }^{6}$ gुden abtreten, aber wir werden derart die Tür zuschlagen .." 2635 . "Ich habe die allerzuverlässigsten Informationen aus völlig vertrauenswürdiger Quelle, daß in zwei Wochen alles zu Ende sein wird .. Alle Brücken in der Moskauer Banlieue sind unterminiert, ebenso der Kreml 264) Nun, sollen sie sich noch zwei Wochen verlustieren ...."264). 
Nach einigen Wochen Lehrtätigkeit, d.h. nach einigen Wochen öffentlicher Ausbreitung seiner Ignoranz legt Lososinov vor versammeltem Kollegium und in Anwesenheit eines Schulinspektors 'In Erkenntnis' der Schändlichkeit seines Verhaltens ein volles peccavi ab:

"Ich nehme an, daß das Wichtigste in diesen (Erziehungs- j.e.) Fragen die ehrliche Einstellung zu seiner Arbeit ist (..) wir muissen uns direkt die Frage stellen: weshalb unterrichten wir?. Entweder weil uns die Bildungsarbeit fesselt (..) oder weil uns schlicht das Papierchen lockt, das uns vor dem Hauskomitee rettet (..). Ich weiß, daß jetzt viele den standpunkt vertreten 'je schlechter, desto besser' ... Soll doch, meinen viele, alles möglichst schnell zugrunde gehen und dann alles von Neuem erstehen ... Nun, sollen diejenigen so sagen, die meinetwegen mit dem Verkehrswesen oder der Produktion zu tun haben ... Wir aber, meine Herren, haben es mit Kindern zu tun .. Sie tragen doch nicht die Schuld daran, daß dem einen die Bolschewiken gefallen, dem andern eben nicht (...). Ich stelle mir jetzt die Frage .. Habe ich das Recht, hier zu bleiben und über die. Schulreform zu diskutieren? ... Und mutig antworte ich 'Nein!' Und er verließ den Saal, der in tödliche Stille verfallen war" ${ }^{265)}$.

Sein peccavi ist unecht, geborgt: es ist verbale, aus Versatzstücken der 'Reuiger Adliger' - Literatur zusammengestoppelte (und für die Sowjetgesellschaft völlig nutzlose!) Pose. Was die an die peccavi-Rede anschließende Szene noch unterstreicht: Lososinov betritt die Straße und verschenkt - ein Samariter - ungebeten und trotz bitterster Kälte seinen Pelz; und er 'erkennt weiterhin':

"Glauben Sie mir (..) - wenn alle Menschen absolut ehrlich wären und nur an die Gerechtigkeit denken würden, wie herrlich wäre dann das menschliche Leben (..). Und meines Erachtens ist das möglich .. Man muß nur die ganze Zeit daran denken .. Ich habe das ganze Leben über verschiedene Dinge nachgedacht ... über das Wichtige .. über das wichtigste aber habe ich nicht nachgedacht .. Jetzt) aber werde ich daruber nachdenken und etwas ausdenken ...."

Und er denkt eine 'Ideee an sich', deren 'Intellektuellenhaftigkeit' auch letzte Zweifel an der Posenhaftigkeit seines peccavi beseitigt:

"Ich, nehmen wir einmal an, werde sterben (..). Ist es im Grunde genommen nicht völlig gleich, ob man lebt oder tot ist? Wenn man alle Friedhöfe und Grabstätten in der ganzen Welt nimmt - so erweist es sich, daß es eine Million mal mehr Verstorbene als Lebende gibt. Wissen Sie, welcher Gedakkg)mir kam: die Lebendigen sind eine internationale Minderheit" ${ }^{67)}$. 
Der Roman schließt mit einer letzten Verlachung Lososinovs, der erklärt: "ich werde ein einfaches Madchen heiraten"268) - seine Pose des 'Reuigen Adligen' mithin zu einem Zeitpunkt beibehält, da veränderte sozio-ökonomische Bedingungen ihn - den brotlosen Intellektuellen - in einer Heirat 'reuiger Adliger' : 'einfaches Madchen' aus der Rolle des nobel Gebenden in die des materiell abhängigen Nehmenden verweisen würden!

Konstantes Merkmal des 'Intellektuellen': das Auseinanderklaffen von 'Idee' und 'Praxis'. Aber - die im Gefolge der Oktoberrevolution eingetretene Radikaländerung der gesellschaftlichen Verhältnisse bewirkt eine Umpolung des Spannungsverhältnisses zwischen

'Idee' und 'Praxis': Vor der Revolution - Vorhandensein einer 'Idee' bei völligem Fehlen einer ihr korrespondierenden gesellschaftlichen 'Praxis'. Nach der Revolution - gesellschaftliche 'Praxis' in einer gesellschaftlichen Schlüselposition (Bildungswesen) bei völligem Fehlen einer dieser 'Praxis' korrespondierenden 'Idee'. Aber - nicht nur eine Umpolung des 'Idee' : 'Praxis' - Spannungsverhältnisses findet statt; dieses Spannungsverhältnis wird jetzt vielmehr von einem lächerlichen widerspruch zu einem gefährlichen Widerspruch: der vorrevolutionäre Intellektuelle wird nur verlacht, der nachrevolutionäre Intellektuelle ist außerdem dargestelltermaßen negativ (Auch in den die beiden ersten Teile kennzeichnenden Verlachungswiderspruch ist Negativität selbstverständlich interpolierbar - der Intellektuelle als 'Schmarotzer' etc.. Aber: diese Negativität wird nicht dargestellt, nicht thematisiert. Dargestellt wird nur die Negativität des Intellektuellen unter den Bedingungen der sozialistischen Gesellschaft!). Der Grund: die neue Gesellschaft - 'wer nicht arbeitet, der soll auch nicht essen' - verlangt von dem Intellektuellen, daß er - früher nur verbalisierender Beobachter seiner Gesellschaft - sich in die gesellschaftliche Praxis integriert. Da sich der Intellektuelle im Gegensatz zu der Gesellschaft wesentlich nicht geändert hat, heißt 'Integration' aber: Tarnung des 'intellektuellen' Kerns unter der Fassade des loyalen Sowjetbürgers. Und genau dies praktizieren Lososinovs Kollegen mit Erfolg ${ }^{269)}$. 
Der Roman schliebt mit dem Nachweis der (an Lososinov herausgestellten) Lächerlichkeit und der (an den übrigen Mitgliedern seiner 'sozialen Gruppe' herausgestellten) Negativität der Intellektuellen im Bildungswesen der Sowjetgésellschaft. SchlieBt also mit dem indirekten Appell zur $\mho_{i s t k a}$ dieses relevanten Bereichs von konterrevolutionären ('sozial-gefährlichen'), bezüglich des Aufbaus der sozialistischen Gesellschaft indifferenten ('sozial-fremden') 'bürgerlichen Spezialisten'.

Die direkt betroffene Komsomolzen-Generation - die auch in diesem Roman, gemeinsam mit Lososinovs Ingenieur-Onkel (also dem 'Schaffenden') und einem Vertreter der Schulbehörde, der das Pauschalprogramm eines der veränderten gesellschaftlichen Situation entsprechenden, von humanistischem Ballast befreiten Unterrichts formuliert, die figurale positive Gegenposition besetzt - klagt ihre Rechte selbst ein, uberwindet also die Kluft zwischen 'Idee' (Unzufriedenheit mit den Verhältnissen an der Schule) und 'Praxis' (die politische Tat der Sprengung einer Konferenz ihrer konterrevolutionären Lehrer).

Thr Manifest:

"Mit Vorliegendem fordern wir:

Zum ersten : in der Schule ist eine Komsomol-Zelle zu gründen. Zum zweiten: wir wollen lernen wie befohlen.

Zum dritten: die Ikonen sind abzunehmen.

Zum vierten: das Brot ist von uns selbst, nicht von der wirtschafterin zu teilen. Auch ein solches Gesetz gibt es.

Wir erklären außerdem, daB wir wie die ubrigen Glieder dem Schul-Sowjet angehören wollen"270).

'Der Dritte Teil. Unvollendete Vergangenheit (Imperfectum)': das Problem der im Bildungssektor tätigen 'Intellektuellen' ist schon durch diese Titelgebung als noch aktuell ausgewiesen! 
Füfter Teil:

Satire des Innen-Bereichs (Eigener Bewußtseins-Haushalt)

Zur Erinnerung: Zur Gruppe 'Satire des Binnen-Bereichs' wurden satirische Romane zusammengefaßt, die (primär) negative soziale Verhaltensweisen präzis angesprochener sozialer Gruppen zentrieren sowie (sekundär) diese negativen Verhaltensweisen determinierende negative gruppenspezifische Denkmuster herausarbeiten und verlachen. Also: 1) negative gruppenspezifische soziale verhaltensweisen, 2) negative gruppenspezifische Denkmuster.

Unter die 'Satire des Innen-Bereichs' hingegen werden satirische Romane subsumiert, die die Entwicklung der sozialistischen Gesellschaft hemmende negative Denkmuster (Idealkonzeptionen, Ideologien: 'überbleibsel der Vergangenheit im Bewußtsein') zentrieren und verlachen. Diese negativen Idealkonzeptionen und Ideologien sind $n i c h t$ an präzisierte soziale Gruppen gekoppelt - vielmehr gerade als den Bewußtseinshaushalt einer $M$ e $h \quad r-$ $h$ e $i$ der Sowjetbürger (noch) belastende Faktoren ausgewiesen. Auf die Herausarbeitung negativer sozialer Verhaltensweisen (in der Sowjetgesellschaft!) wird in der 'Satire des Innen-Bereichs' generell verzichtet; ebenso auf die Einarbeitung einer (figuralen oder argumentativen) positiven Gegenposition - beides (und die überlegungen zur 'kommunikativen Funktion' werden dies zu verdeutlichen haben) aus gutem Grunde!

Nur drei Texte konstituieren die Gruppe 'Satire des Innen-Bereichs': A. Tolstojs 'Die Abenteuer Nevzorovs oder Tbikus' $(1924)^{1)}$, V. Kataevs 'Defraudanten' $(1926)^{2)}$ und M. Barkanovs 'Erzählung davon, wie Ivan Ivanovic̈ mit Ivan Nikiforovic̈ Frieden schloß' (1927) ${ }^{3)}$.

Diese drei Texte - ihre Autoren sind mit Ausnahme Barkanovs 4 ) Autoren sowjetischer 'Höhenkammliteratur' - differieren auf fast allen relevanten Textbefragungsebenen so stark, daß bewußt auf den Versuch der Erstellung eines Paradigmas verzichtet, die Prä- 
sentierung vielmehr in kurzen Einzelanalysen vorgenommen wird. Die Satiren Tolstojs und Kataevs sind so bekannt (und in jeder wissenschaftlichen Bibliothek zugänglich), daß ihre Dokumentation auf für die Rekonstruktion der Bewußtmachungs- und Verlachungsstrategie relevante Zitate beschränkt wird. Dies gilt nicht für die auch in der Sowjetunion nur sehr schwer zugängliche satirische povest' Barkanovs.

\subsection{Satire der Ideal-Zerstörung}

A. $T \circ 1$ s $t \circ j$ s 1924 entstandene satirische Großerzählung (ohne Genrebezeichnung) 'Die Abenteuer Nevzorovs oder Tbikus' ist wichtigster Vertreter der in den 'Innen-Bereich' des 'eigenen Bewußtseinshaushaltes' zielenden, $s$ a $t r e d e r$ I d e a $1-Z$ e r s t ör ung '.

Nevzorovs ('der Blicklose') einführende Konstituierung signalisiert die starke Generalisierbarkeit der seine 'intellektuelle Physiognomie' bestimmenden vergangenheitslastigen Idealkonzeptionen; signalisiert also, daß diese Idealkonzeptionen weitverbreitete 'Importe aus der Vergangenheit' - 'perežitki' - sind: "er arbeitete im Kontor eines Fuhrunternehmens. Mittlerer Wuchs, ganz liebes Gesicht, (..). Weder blonde noch braune Haare, vielmehr irgendwie so (..). Auf def) Straße verwechselt man ihn häufig mit irgend jemand anderem"

Seine Generalisierbarkeit wird wiederholt signalisiert - er wird laufend für andere gehalten (und zwar nicht nur für einen Kleinbürger - sondern für einen Revolutionär, einen Weißen etc.): er ist ein sowjetischer Herr $X$. Genauer: seine negativen Idealkonzeptionen, deren verlachende Bewußtmachung diese Satire intendiert, sind die (vielleicht uneingestandenen, vielleicht verdrängten, vielleicht unbewußten) Idealkonzeptionen vieler Sowjetbürger. Seine Idealkonzeptionen tragen (nach einer spielkarte) den Namen 'Ibikus'. Und die Satire endet mit dem Hinweis "Er (Nevzorov j.e.) ist selbst Tbikus" ${ }^{\text {) }}$ ": Nevzorov ist 'Ibikus', ist die Verkörperung bewußtzumachender und zu verlachender ne- 
gativer Idealkonzeptionen: Nevzorov ist das satirische Darstellungs-objekt für die satirischen Angriffs-objekte 'Faszination durch den Glanz einer aristokratischen Existenz' und 'Faszination durch eine privatunternehmerische Existenz großen Stils im Gelobten Land des Goldenen Westens'. Denn: da aristokratischer Glanz in der Sowjetunion entwertet und Nevzorov zudem nichtaristokratischer Provenienz ist, soll nicht Geburt, vielmehr in einem kapitalistischen Land erworbenes Geld das als Nachweis der Zugehörigkeit zu Nevzorovs Ideal-Klasse dienende blaue Blut durch seine Adern pochen lassen!

Nevzorovs Schwäche: "in den Zeitungen Berichte uber Aristokraten lesen"7). Er "träumte bei Tag und bei Nacht von aristokratischen Bällen, von aristokratischen five o clocks"8). Er erträumt sich selbst eine aristokratische Existenz:

"Ihn beherrschte der Traum von einem aristokratischen Salon, von Grafen und Gräfinnen (..), von sich selbst als einem blutarmen, schmachtenden Aristokraten, der mit einer üper die seidene Weste des Fracks herabhängenden Uhrkette spielt" 9 .

Und diese Wunschvorstellung ist immer verknüpft mit der Vorstellung $n$ a $k t$ e $r$ Aristokratinnen:

"Dort sind Gräfinnen und Fürstinnen, bis hierher nackt. Jeder brauche ich nur zuzuzwinkern - und schon ist das Kleid runter ${ }^{10)}$ ". Denn: "Der Gipfel der Zivilisation ist das luxuriöse Schlafzimmer einer sqhönen Frau, ein Tempel des Genusses. Alles übrige Vorurteile" 19 .

Die Revolution macht alle Hoffnungen zunichte, dieses Ideal in Rußland realisiert zu sehen (nicht: zu realisieren; denn: "um die Wahrheit zu sagen, rührte er keinen Finger, um den Lauf des Lebens zu ändern"12), ;

Und so

"kam die Gewißheit auf, ergab sich das Nahziel, sich einige Hunderttausend Rubel zu beschaffen (was inm per Diebstahl auch gelingt j.e.), den Dienst zu quittjeren und Petrograd zu verlassen. Genug Krieg, genug Revolution" liges Land, dachte Semen Ivanovic̈ (Nevzorov j.e.) und betrachtete mit Widerwillen (die "Flugblätter, Meetings, das Gedränge, den unverschämten Pöbel in schmutzigen Mánteln.. Ein Irrenhaus" " Pfui, ein für allemal. Ich sage mich los, vergesse mẹpe Herkunft. Zum Beispiel: Simon de Nézor - paßt glänzend" wer weiß6) dachte er, vielleicht bin ich tatsächlich Graf de Nézor'"16). 
Und so macht er sich - über die Ukraine (wo er sich schon als Hetman sieht) und Odessa ("Letzter Zufluchtsort für spekulanten und Weißgardisten"17), - auf den Weg in den Westen:

"für immer nach Europa fliehen. Dort ist das Leben, wenn man $18 Y^{-}$
tes Geld hat, ein einziger Genuß; er wußte das aus dem Kino" "paradiesische Länder, in denen es weder Revolutionen, noch Evakuierung gibt, wo es füfstöckige Geschäfte voll luxuriöser und billiger Kleidung gibt (..). Wo an jeder Kreuzung ein strenger und gerechter policeman steht und Tag und Nacht die Ruhe der Bürger und das heilige Eigentum bewacht (..). Wo man nicht aus Maschinengewehren schießt und nicht mit diesen verfluchten Flaggen rumläuft, wo man nicht an jeden gewöhnlichen Arbeiter ein mitfühlendes oder zuvorkommendes Lächeln hingrimassieren muß, wo man vielmehr im Bgyußtsein der eigenen Würde am Proletariat vorbeigehen kann" 19 .

"Er floh ins Ausland mit der festen Absicht, dort ein ruhiges und solides Plätzchen unter der Sonne zu finden. Die Auswahl des neuen Vaterlandes interessierte ihn nicht: kein Problem, dâs)
Geld wird mir schon zeigen, wo ich mich niederlassen soll" "Im Westę 19 ibt es keine Krämerseelen, keine Zyniker, keine
Schurken"

Die Idealkonzeptionen stehen fest - aristokratischer Glanz, Leben als Geldaristokrat. Fest stehen folglich auch die Antipathien: alles Rote, alles Proletarische..

Die Flucht aus dem proletarischen Rußland konfrontiert Nevzorov hautnah mit seinen Idealen: Aristokraten und Aristokratinnen (die mit ihm fliehen), 'Europa'. Und diese Konfrontation müßte Nevzorov die Augen öffnen - wenn er kein 'Nevzorov', kein 'Blinder' wäre. Denn: Aristokratie und 'Europa' korrespondieren so gar nicht den idealen Vorstellungen, die er sich von ihnen zurechtgeträumt hatte.

Auf dem Evakuierungsschiff (das Nevzorov 1919 von Odessa nach Istanbul verfrachtet)

"saßen auf Pritschen und Truhen erzürnte Generale, jeder von seinem eigenen stab umgeben, und diktierten Armeebefehle für alle verbindliche Resolutionen (..). Armeen im gewöhnlichen Sinne des Wortes hatten die Generale nicht mehr (..)." ${ }^{\text {: }}$ lächerliche Automaten!

Die den 'Gipfel der Zivilisation' innehabenden 'Gräfinnen': 
"- Gräfin, wie haben Sie geschlafen?

- Schrecklich, Semen Ivanovič, (die Wanzen) haben mich bei lebendigem Leibe aufgefressen,

- Sie gestatten, Gräfin, auf Threm ohr sitzt eine kleine Wanze. (..).

- Sie gestattģ) Lidija Ivanovna, auf Threr Brust sitzt eine kleine Wanze" ${ }^{23)}$ : häßliche, schmutzige Wanzenkolonien.

Die 'Europäer' empfangen sie keineswegs als Helden, als Märtyrer des Bolschewismus - sie lassen die Emigranten zunächst gar nicht an Land, rauben sie dann aus..

Die Verlachung der Nevzorovschen Ideale verfolgt vier Strategien: 1) Nevzorov ist durch seine ewigen Phantastereien von 'nackten Gräfinnen' als generell unreif ausgewiesen (satirische Pubertierung). 2) Es gelingt Nevzorov zwar, die Staffage seines Ideals in 'Europa' zu inszenieren; d.h. eine privatunternehmerische Existenz aufzubauen und sich in die Splitterbestände einer reinen Adelsgesellschaft (satirische Synekdoche) zu integrieren dies gelingt ihm aber nur, indem er einen bezüglich seines Erscheinungsbildes (!) gänzlich unaristokratischen Weg einschlägt: er wird Veranstalter von Küchenschaben-Rennen. Diese Tätigkeit ist nicht nur fundamental u $n$ i $t z$, sondern ebenso 1 äche $r l i c h$ - entspricht also, bei 'falschem Erscheinungsbild', dem Wesen seines Ideals (Komische Inkongruenz von Wesen und Erscheinung). 3) Der in seinem Selbstverständnis die große - politische wie kulturelle - bewahrende Gegenkraft darstellende Adel ist faktisch von lächerlicher Schwäche: in eine gesellschaft. liche Reduktionsstufe verwiesen, die es ihm verunmöglicht, a nd e $r$ e auszurauben, a $n$ e $r$ e zu vernichten, macht er sich selbst den Garaus (Automatenhaftigkeit + Autoliquidation). 4) Insbesondere aber resultiert die Verlachung aus der direkten Gegenüberstellung eines abstrakten Ideals mit seinen konkreten Einzelrepräsentanten: Die von ihren früheren - ihnen einen erborgten Glanz ermöglichenden - Geldquellen abgeschnittenen Aristokraten degenerieren blitzartig zu lächerlicher Häßlichkeit; bei ihren Versuchen, ihren Lebensunterhalt selbst zu verdienen, kommen ihnen ihre einzigen, in langer Praxis erworbenen Fähig- 
keiten zugute: betteln, stehlen, morden, sich prostituieren (Reduktion auf das wesentliche Negative). Das bürgerliche Ausland schließlich akzeptiert Nevzorov und die nun Seinesgleichen zwar schließlich - es akzeptiert sie aber nach seinem ungeschriebenen Grundgesetz: es beutet sie brutal aus!

'Die Abenteuer Nevzorovs..' verzichten - im Gegensatz zu den 'Satiren des Außen-Bereichs' und zu den 'Satiren des Binnen-Bereichs' - auf die Einarbeitung einer positiven Gegenposition, auf die Darstellung positiver Gegen-Figuren, auf direkte Ausformulierung positiver Gegenargumente. Dieser Verzicht ist in einer Satire, deren kommunikative Funktion die Bewußtmachung und Verlachung solcher negativer verschleppter Idealvorstellungen ist, die der Satiriker bei einer Vielzahl von Sowjetburgern - u n d bei einer Vielzahl seiner Rezipienten! - als gegeben ansetzt, durchaus begrüdet. Denn: eine (figurale oder argumentative) positive Gegenposition fungiert oder wirkt (auch) in einer Satire als Identifikationsangebot. Die (unerwinschte) kommunikative Konsequenz für eine in den 'Innen-Bereich' zielende Satire $m i t$ eingearbeiteter positiver Gegenposition ist evident: der Rezipient verlacht aus einer ihm (subjektiv oder objektiv) offerierten Überlegenheitsposition Negativa - als in a $n$ d e $r$ e $n$ angesiedelte Negativa. Die kommunikative Intention der Bewußtmachung, Verlachung und damit Integrierung nicht hinreichend bewußter (weil - z.B. - verdrängter) Belastungsfaktoren des e $i g$ e $n$ Bewußtseinshaushaltes ist somit nicht mehr realisierbar. Die ohne kritische Selbst-Reflexion übernommene Überlegenheitsposition - Vorschußlorbeeren!

Aus demselben Grunde verzichten die Satiren des 'Innen-Bereichs' auch auf die eindeutige Koppelung der zu verlachenden 'Denkmuster' an Repräsentanten präzis eingeengter sozialer Gruppen (die gruppenubergreifende Verwechselbarkeit Nevzorovs!), auf die zusätzliche Herausarbeitung sozialer Verhaltensweisen (in der Sowjetgesellschaft - s.u. Barkanov): beide Strukturen würden weitgehend die erwïnschte Referierung der verlachten Negativa auf den Bewußtseinshaushalt des Rezipienten selbst blockieren! 
Auch $v$. $K$ a $t$ a $v$ s 'Die Defraudanten' (1926) weisen eine in den 'Innen-Bereich' des eigenen BewuBtseinshaushaltes zielende $T$ e $n$ e $n z$ der satirischen Aggression auf. Auch diese'satirische' povest' läßt sich in die Nähe der 'Satire der Idealzerstörung' stellen - entzieht sich aber einer eindeutigen Zuordnung zu ihr; entzieht sich sogar einer zweifelsfreien Zuordnung zur $s$ a $t$ i $r$ s $h$ e $n$ Literatur.

Der hinsichtlich seines Bestehens junge, hinsichtlich seines Personalbestandes hoffnungslos uberalterte - weil fast ausschließlich 'Überbleibsel' beschäftigende - Sowjet-Apparat hat bereits eine höchst seltsame Tradition ausgeformt, deren bestimmendem Einfluß sich kein Angestellter zu entziehen vermag: mit turnushafter Regelmäßigkeit bemächtigen sich Lohnbuchhalter, Kassierer etc. sowjetischer Staats-Firmen zur Lohnauszahlung bestimmter Summen, um dann auf staatskosten eine Reise kreuz und quer durch die Sowjetunion anzutreten; eine Reise, die den Charakter einer Suche nach der verlorenen - grundsätzlich besseren vorrevolutionären - Zeit hat. So auch Filipp Stepanovič Prochorov und Vanečka Kljukvin, Buchhalter und Kassierer eines Staatsbetriebes - die Zentralfiguren der 'Defraudanten'.

Prochorov verfugt über eine Idealkonzeption - sein Ideal ist ein reichlich unbestimmtes kapitalistisch-nobles vergangenes, die schlechthin bessere Vergangenheit: er ist Sklave der Faszination, die die Erinnerung an den 'einzigen richtigen Menschen' (den Chef des Handelshauses, dessen Angestellter er einst war) sowie ein Satz auf ihn ausuben, dessen Herkunft und Bedeutung ihm dunkel sind: 'Graf Guido sprang auf sein Roß'. 'Der einzige richtige Mensch' und 'Graf Guido' machen - von einigen luxuriösen, meist verstümmelten Fremdwörtern und Kirchenslavismen abgesehen - seinen gesamten 'Wissens'-Vorrat aus; aus ihnen bezieht er auch seine "leichte Ironie, sein unmerkliches Gefühl der überlegenheit über die ihn umgebenden Menschen und Ereignisse, eine geduldige und harmlose Arroganz" 24 ).

Diese äußerst vage Idealkonzeption ist in den 'Defraudanten' von Anfang an als keiner Decouvrierung bedurftig, als von vornherein lächerlich ausgewiesen - anders als in den 'Abenteuer 
Nevzorovs..', wo-gerade die Verlachung einer präzisierten Idealkonzeption zentral steht. Verlacht wird in den 'Defraudanten' nur der Versuch, in der Sowjetgesellschaft Realisierungsräume für diese Idealkonzeption zu finden.

Dieser Versuch scheitert - und zwar sowohl an der Inkongruenz von (weitgehend implizit bleibendem) Ideal und sowjetischer Wirklichkeit, als auch daran, daß diese neue Realität das Bewußtsein Prochorovs und Vanečkas zwar noch nicht bestimmt, aber doch schon infiziert hat: sie imitieren ein Ideal, mit dem sie sich bereits nicht mehr voll identifizieren können, was zur Folge hat, daß sie kontinuierlich aus der Rolle, die sie eigentlich spielen wollen, herausfallen - lächerlich werden.

Thre Reise durch die Sowjetunion ist de facto eine Reise durch die aus der bürgerlichen Vergangenheit ererbten, noch nicht endgülig liquidierten Sumpfgebiete der Sowjetgesellschaft Ex-Aristokratie, NÖP-Milieu, dem Suff verfallene Provinz. Die gesellschaftliche Aktivität dieser 'Überbleibsel' konzentriert sich darauf, der gleichfalls ein Relikt aus vorrevolutionären Zeiten darstellenden 'Klasse' bürokratischer Defraudanten, die alle Züge, alle Hotels, alle Kutschen und alle Autos mit Beschlag belegen (satirische Synekdoche) und die einen gemeinsamen Angstgegner haben: den Satiriker Zoščenko, die Illusion der Zugehörigkeit zum harten Kern der 'Höheren (d.h. zaristischen) Gesellschaft' vorzugaukeln - m.a.W.: sie auszubeuten, zu ruinieren (Autoliquidation der 'Überbleibsel').

Dieses phantasmagorische RuBland ist ein Konglomerat in sich widersprüchlicher Erscheinungen, ein Konglomerat personifizierterOxymora: in einem als 'Sankt-Peterburg' apostrophierten Leningrad fungiert der authentische zaristische Adel als Komparserie für sowjetische antiaristokratische Filme; der "Genosse Lakai"25) führt dem "verstorbenen Imperator"26) "Gentlemen aus Moskau"27) zu, so "Graf Guido mit seinem Kassierer"28) etc... Deren Reise ist denn auch eine einzige Kette von Fehlschlägen, von Situationen, die Prochorovs 'Gefühl der überlegenheit über die ihn umgebenden Menschen und Ereignisse' ad absurdum führen 
- und damit zugleich auch die Hoffnung auf Realisierbarkeit seiner Idealvorstellungen unter den Bedingungen der Sowjetgesellschaft die 'Höhere Gesellschaft' zertrümert sein überlegenheitsgefühl unmittelbar (Prochorov stolpert von einem Fauxpas in den nächsten, aus einer Verlegenheit in die andere); das Nöp-Milieu quittiert den Versuch, mit Hilfe wahrer Rubel-ströme eine Erhöhung der Lebens-'Qualitä' in Prochorovs Sinne durchzusetzen, mit einer rein quantitativen Potenzierung der einzigen diesem Milieu verfügaren Lebens-'Qualität': schier unerträglicher Langeweile. Dieses Motiv des "Geldes, das keinen Wert hat"29), wird im "Goldenen Kälbchen. an zentraler stelle wiederbegegnen.

Der 'Sumpf', in dem Adel, Nöpmänner und Defraudanten gleich(un)wertig (satirische Demokratisierung) ihrem historischen Exitus entgegenvegetieren wird vom Ende der povest' her überstrahlt von der ihm als figurale positive Gegenposition opponierten jungen Komsomolzen-Generation: sie ist so grundlegend anders, so grundlegend positiv, daß selbst Vanečkas Exkurs in die Vergangenheit nur als verirrung eines kolossal naiven, fehlgeleiteten und in den Tiefschlaf einer verspäteten Pubertät versenkten Jünglings erscheint; seiner Besserung steht nichts im wege und sie wird am Ende auch angedeutet.

Die (unter dem Gesichtspunkt satirespezifischer kommunikativer Funktionen beurteilte!) kommunikative Schwäche dieser povest' ist evident: die Idealkonzeption der Zentralfigur wird weder präzisiert noch verlacht - ihre Lächerlichkeit wird vielmehr als offenkundig vorausgesetzt. Desgleichen findet eine Decouvrierung der aktuellen sozialen Negativität von Apparatschik, Bürokrat, Nöpmann etc. - eine Decouvrierung also ihres aktuellen. negativen Sozialverhaltens und/oder dessen ideell-ideologischer Prämissen - nicht statt, obwohl dieser Angriffs-Objektbereich figural präsentiert wird.

Die bescheidene Möglichkeit schließlich der Referierung der die vorrevolutionäre Vergangenheit zum pauschalen Goldenen Zeitalter 
glorifizierenden Idealkonzeption Prochorovs auf den 'eigenen Bewußtseinshaushalt' wird durch die Einarbeitung einer generationsspezifischen figuralen positiven Gegenposition abgeblockt: die Belastung des Bewußtseinshaushaltes sowjetischer Bürger (und Leser) durch Idealisierungen der bürgerlich-aristokratischen Vergangenheit wird zum Generationsproblem reduziert. Eine Aktivierung des Lesers (z.B. zu agitatorischen Maßnahmen unter 'befallenen' Mitgliedern der älteren Generation) wird weder direkt (Appelle) noch indirekt (die betreffende Aktivität demonstrierende figurale Leitbilder) gefordert.

Im Resultat sind Kataevs 'Defraudanten' - und die zeitgenössische Kritik hat das festgehalten - eher eine 'nur' belustigende Humoreske als eine auch aggressive (gegen sich oder andere aggressivierende) Satire; die humoristischen Qualitäten der 'Defraudanten' sind allerdings unbestritten, und auf sie ist der bis heute andauernde Erfolg der povest' und ihrer Bühnenbearbeitung zurückzuführen: das überwiegen humoristischer Merkmale als Totengräber satirisch-aggressiver und aggressivierender Aktualität und Garant langfristiger Rezipierbarkeit zugleich! (Womit keinesfalls eine 'Gesetzmäßigkeit' postuliert sein soll!) 


\subsection{Satire der Ideologie-Zerstörung}

1927 veröffentlichte M. Barkanov eine der reizvollsten sowjetischen satirischen Großerzählungen - 'Die Erzählung davon, wie Ivan Ivanovič mit Ivan Nikiforovič Frieden schloß'. Sie repräsentiert für die Entwicklung des sowjetischen satirischen 'Romans' die 'Satire der Ideologie-Zerstörung' .

Die Assozicerung der Gogol'schen 'Erzählung davon, wie Ivan Ivanovič sich mit Ivan Nikiforovič zerstritt' ist selbstverständlich gesteuert: vom Prädikat abgesehen identische Titelgebung, ähnliche Kapitelüberschriften, namenggleiche Haupt- und Nebenfiguren, skaz-Erzähler etc..

Der skaz-Erzähler selbst setzt sich eingangs mit dem erwarteten Vorwurf auseinander, sein 'Bericht' sei ein Unding, da Gogol' die beiden Ivany doch bereits beschrieben habe und diese zudem längst das Zeitliche gesegnet hätten:

"Das ist mir ja ein Vogel, dieser Gogol'! Wenn er sie beschrieben hat, soll auch gleich keiner sonst I.I. odefof.N. kennen. Was ist fr $_{1}$ denn uberhaupt, dieser Gogol'? Sogar 30 auf dem Denkmal, was in Moskau ist, sieht er nichts gleich. Ob da eine Alte eigep Strumpf strickt oder ob er Bauchweh hat - völlig unklar" ${ }^{\prime \prime}$.

Nach diesem Denkmalsturz, mit dem er sich zugleich als eindeutig komische Figur konstituiert, macht er sich $s$ e $1 \mathrm{~b} s$ (als wolle er dadurch die Alogik des obigen 'sogar' aufheben) an den Entwurf seines eigenen Denkmals:

"Nein, alles was recht ist, ich bitte schon... obwohl auch das nicht völlig bescheiden ist, aber der Leser wird, hoffe ich, einen derartigen Weitblick nicht verurteilen, ich will also darum bitten, mich auf dem Denkmal in einer Pose darzustelł̧̧⿻, wie sie einem Mannsbild geziemt: wenn möglich, auf einem Roß 3 , wenn das Roß aber nicht geht, dann halt jfgendwie so, daß die Figur Achtung einflößt: im Familienkreise ${ }^{349}$ oder sonst irgendwie,

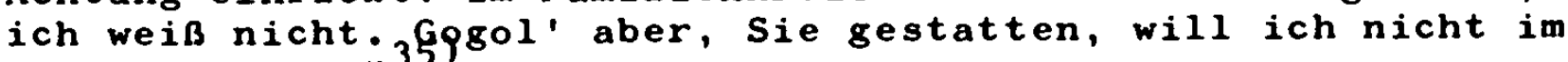
mindesten sein" 359 .

Indem er sich s o als denkmalverdächtiges Genie herausstellt, stellt er sich zugleich und wesentlich als intellektuelle und ideologische Instanz in Frage: der Leser ist somit aufgefordert, den Erzähler nicht einfach hinzunehmen, ihn - genauer: die von 
ihm vorgetragene Ideologie des Privat-Unternehmertums - vielmehr kontinuierlich (ideologie-) kritisch zu hinterfragen; der skaz, gerade in den 20-er Jahren häufig rein dekorativ eingesetzt, wird so hier zum rezeptionssteuernden Signalisierungsverfahren.

Die Handlung der 'Erzählung ....' fällt in die Jahre 1914-1921 und spielt in einer russischen Kleinstadt. Ivan Ivanovič und Ivan Nikiforovič, Fabrikant bzw. Gutsbesitzer, sind seit langem zerstritten - aufgrund eines Vorfalls, der bei Gogol' gerade zur Dokumentation gutnachbarlicher Beziehungen zwischen den beiden fungierte: die Kinder des einen spielten unerlaubt mit den Hunden des anderen und bezogen dafür Prügel - und führen einen sich auf alle gesellschaftlichen und wirtschaftlichen Bereiche erstreckenden Privatkrieg (der nur angedeutet wird). In das eingespielte Gefüge kleinstädtischer Verhaltensnormen brechen der erste Weltkrieg, Februar- und Oktoberrevolution, Kriegskommunismus ein, Ereignisse, die insbesondere die bürgerlichen und kleinbürgerlichen Schichten der Bevölkerung zur spontanen Reaktion auf sie zwingen und so, als Katalysatoren wirkend, den Kern ihres Sozialverhaltens (in der vorrevolutionären Gesellschaft!), ihrer Ideologie manifest werden lassen. Nicht Aktion vielmehr Reaktion auf historische Ereignisse - namentlich aber ihre Brechung im Bewußtsein des Erzählers - konstituieren Handlung und Makrostruktur der 'Erzählung ....': beide Ivany reagieren auf den Kriegsausbruch mit patriotischen Parolen und Gesten - und bringen als Kriegsgewinnler ihre Schäfchen ins Trockene; beide passen sich spontan an Republik und proletarische Diktatur an - und sind von deren baldigem Ende hoffnungsvoll überzeugt; sie denunzieren sich gegenseitig als Klassenfeinde - und landen gemeinsam im Gefängnis. Am Ende der 'Erzählung ....' ziehen sie - unter den Bedingungen des Kriegskommunismus - versöhnt durch die Dörfer: um zu 'hamstern'. Mit den Jahren des Kriegskommunismus schließt die 'Erzählung ....', nur der Erzählzeitpunkt -1924greift uber diesen Zeitraum hinaus, was insofern äußerst relevant ist, als er signalisiert, daß die Ideologie des Erzählers alle (sozio-) historischen Ereignisse (die er auf seine ganz spezifische Weise interpretiert) unbeschadet uberstanden hat: daß sein Bewußtsein mithin in gefährlicher Spannung zur Realität steht.

Die Konstituierung der beiden Ivany, die eine satirische Kollektivfigur bilden - fehlende Differenzierung, d.h. durchgehende übertragbarkeit der sozio-politischen Merkmale des einen auf den andern -, die den sozialen Typ 'privatkapitalistischer Unternehmer' repräsentiert, verzichtet auf individualisierende Charakterisierung, erfolgt durchgehend plakativ; sie entspricht somit 
den in der ersten Hälfte der 20-er Jahre gepflegten schablonenhaften Typisierungsverfahren. Unter dem Aspekt der Typisierung (der dargestellten Figuren!) ist die 'Erzählung ...' 1927 erschienen, wesentlich also ein Nachzügler. Genauer: sie wäre ein Nachzügler, gehörte sie tatsächlich in das von den dargestellten Figuren partiell suggerierte Paradigma der 'Satire der kapitalistischen Endzeit!!

Auf Individualisierung verzichtend, stellt die Typisierung Merkmale des (vorrevolutionären!) Sozialverhaltens zentral; Merkmale, deren satirische Darstellung sich durchgehend konstituiert aus der Spannung zwischen Schein und Sein, Phrase und Geste einerseits - wesentlicher Intention andererseits. Diese Spannung erscheint als $g$ e $n r$ e $l$ e $s$ Merkmal privatunternehmerischen Sozialverhaltens; die als Reaktion auf die verschiedenen sozio-historischen Ereignisse dargestellten $k$ o $k r e t e n$ sozialen Verhaltensweisen sind also nur noch Variationen zum Thema 'Privatunternehmer und Gesellschaft'.

Die Herstellung der Schein-Sein-Spannung erfolgt meist dergestalt, daß der Erzähler zunächst eine positive Etikette (Altruismus, Bildung, Patriotismus, etc.) zur Verfügung stellt und ihr dann zur Illustration ein kontraindiziertes Beispiel, eine 'Konkretisierung' der 'positiven' Grundeigenschaft anfügt, die in totalem Widerspruch zur Etikette stehen. Dies im Gegensatz zur erklärten Intention des Erzählers, der auf Rechtfertigung und Verherrlichung der beiden Ivany bedacht ist, die ihm Inbegriff alles Glanzes und aller Herrlichkeit des Privatunternehmertums, damit der stadt, damit der gesamten Menschheit sind (und der sich durch sein Unvermögen, 'Idee' und 'Realität' aufeinander abzustimmen, als intellektuell unbedarft und lächerlich autodecouvriert).

So erweist sich 'Altruismus' als seltsames Synonym für Pfandleihe an vom Ruin bedrohte Mitbürger. Der Etikette 'Bildung' korrespondiert faktische Ignoranz: I.I. durchblättert die Zeitung nur auf der Suche nach versteckten Prostitutionsannoncen; I.N. bevorzugt politischen Klatsch als 'billigere' Informationsmöglichkeit. Ähn- 
lich manifestiert sich privatunternehmerischer 'Patriotismus': I.I. ergeht sich in hochtrabenden patriotischen Phrasen, I.N. schwingt sich gar dazu auf, eine längst aufgetragene Hose zu spenden. Beide aber sehen den Krieg primär als Möglichkeit der Bereicherung auf Kosten vom Krieg unmittelbar betroffener Mitbürger: I.I. nimmt vom Staat evakuiertes Vieh in Pacht und ver-. kauft es auf eigene Rechnung; I.N. wird "aus Herzensgüe" 36) Armeelieferant und beliefert die Soldaten mit mieser Ware. Wie alle Bürger 'akzeptieren' auch die Ivany spontan die Februar-Revolution:

"Hingègen ist der Fakt sehr wohl der Erwähnung wert, daß es sich unmittelbar nach dem Umsturz herausstellte, daß die Bürger alle hinter der Republik standen: gib ihnen die Republik und sie wollen von nichts anderem mehr hören (...) er verließ nie anders das Haus als gij einem prächtigen Band von der Farbe einer gekochten Rübe" .

Noch 'titfer' wurzelt ihre ebenso spontan vollzogene Verankerung in der jungen Sowjetgesellschaft: zwar verstecken sie Vieh und Maschinen vor der roten Requisition - in Erwartung einer baldigen Restauration der "echten Republik"38) (d.h.: der den 'freien Unternehmer' privilegierenden Kerenskij-Republik) mithilfe intervenierender ausländischer Mächte; zwar hoffen sie auf baldige Liquidierung der Bolschewiken auf ihre grausame physische Vernichtung - was sie nicht daran hindert, ihre verbale Fassade den 'Roten' anzupassen - in Verfolgung höchst egoistischer Ziele. Diese Tarnung erfolgt aber so unvollkommen, daß sie unversehens in ihr Gegenteil umschlägt, zum Medium der Autodecouvrierung wird. In ihren an die örtliche C'K gerichteten gegenseitigen Denunziationsschreiben legen beide Ivany eine Detailkenntnis des revolutionären Jargons an den Tag - der Gegner erscheint als 'Hausbesitzer', 'Saboteur', 'Spekulant', "entstammt dem Adel und auch dem Popenstand"39), ja, er ist sogar "Schwarzhundertschaftler und SR" zugleich: diese indentierte Negativsteigerung ist eine faktische Autodecouvrierung, da sie dem Gegner zwei sich gegenseitig ausschließende politische Orientierungen zuschreibt, denen nur gemein ist, daß beide $v$ o der Revolution von den Bolschewiken bekämpft wurden; ihr Vermögen, die aktuelle politische situation zu beurteilen, ist also gleich Null. 
Die autodecouvrierende Denunziation findet ihren komischen Höhepunkt darin, daß sie dem Denunzierten politische Vorstellungen ankreidet, die versehentlich dem eigenen (nicht aber dem bolschewistischen) Negativkatalog entnommen sind und so das Demokratieverständnis der beiden Ivany evident machen: "Besagter Gutsbesitzer und Kapitalist, der auf der Plattform der allgemeinen, direkten, gleichen und geheimen Abstimmung steht, wird von mir beschuldigt"41). 'Von mir', d.h. von einem Antragsteller, der sich "selbst werktätig"42), "ein werktätiges Leben"43) führen sieht, das ihm "werktätiges Eigentum"44) eingebracht hat - ihm, einem "Genossen"45) resp. "Sympathisanten"46).

Die Intention der Denunzianten - den Gegner physisch zu vernichten und sich selbst in den Genuß seines Besitzes zu bringen wird nur partiell und so gar nicht im Sinne der beiden Antragsteller erreicht; beide werden zwar enteignet - aber zugunsten des Arbeiter- und Bauernstates; beide werden aus der Sowjetgesellschaft herauskatapultiert und finden sich im Gefängnis wieder, dessen "feste Mauern, die die Arrestanten von den ehrbaren Menschen trennen" 47 ), sie früher, als sie sich selbst "nicht ohne Ursache zu diesen zählte(n)"48), sehr zu schätzen wußten, in der gesellschaftichen Reduktionsstufe deklassierter Privatunternehmer: in Gesellschaft mithin von 'Wanzen'.

Denn, im Gefängnis träumt I.I. den Traum der Selbsterkenntnis: "Und zwar sah er sich als von seinen Mitbürgern zuhöchst geehrte Wanze von schmächtiger Körpergestalt zwar, aber von Achtung gebietenden Ausmaßen" 49 ). In diese Selbsterkenntnis-Vision schließt er nicht nur I.N., der "seiner Nachbarschaft das Blut aussaugte"50), sondern alle seine Standesgenossen mit ein, die mit ihm in seinem Traum eine Gesellschaft blutsaugender Schmarotzer formieren. Selbsterkenntnis und Einsicht in die endgütige hoffnungslose Situation in einer Gesellschaft, die seinen 'Saugrüssel' gekappt hat: I.I. schluchzte "wie ein neun Monate altes Kind in Erinnerung an die Süße der Muttermilch, die man ihm niemals mehr geben wird"51).

Noch im Gefängnis versöhnen sich die beiden Ivany: "Welchen Vor- 
teil finde ich in der Erniedrigung meines Feindes, wenn ich selbst emiedrigt und des vermögens beraubt bin"52) (im Klartext: wenn die sozio-historischen Veränderungen die Konkurrenzsituation zwischen uns beiden aufgehoben haben) - und das Ende der 'Erzählung ....' sieht sie vereint in der Bemühung, in den Dörfern der Umgebung Reste ihrer Habe gegen Lebenswittel einzutauschen (von Spekulation - also von einem negativen Sozialverhalten in der Sowjetgesellschaft - ist nicht die Rede!): Die beiden Ivany sind als 'Wanzen' endguiltig liquidiert, eine Möglichkeit der Integration in die Sowjetgesellschaft deutet sich nicht an.

Die 'Erzählung ....' erschien 1927. Den gesamten Zeitraum zwischen 1921 und 1927, mithin fast die gesamte Phase der NöP, läßt sie aber unberücksichtigt - einerseits liquidiert sie also auf der Ebene der dargestellten Figuren einen Gegner, der 1927 nicht nur sozio-ökonomisch wesentlich der Vergangenheit angehörte, der vielmehr auch satirisch längst erledigt war: den vorrevolutionären russischen Privatunternehmer; andererseits zeigt sie zwar die generelle virtuose Anpassungsfähigkeit des privatkapitalistischen Unternehmers an die jeweilige sozio-ökonomische und politische Konstellation auf - nicht jedoch das 1927 viel relevantere Problem der neuen (und neuen alten) Bourgeoisie unter den Bedingungen der NöP, das Problem der in den bürokratischen Apparat abgewanderten Bourgeoisie etc.

Der Vorwurf, die 'Erzählung ....' sei also bereits zum Zeitpunkt ihres Erscheinens so inaktuell gewesen, daß sie allenfalls noch als bloB erheiternde Humoreske rezipierbar gewesen sei, drängt sich mithin geradezu auf. Er wäre auch berechtigt - wenn nicht der Ersähler selbst als zentrale satirische Figur in Erscheinung träte!

Äußerst bescheiden sind die Angaben zur Person des Erzählers - er ist ein namenloser Mitbürger der beiden Ivany mit dem vorrevolutionären sozialen Status eines kleinen Beamten oder Angestellten: er ist, wie Tolstojs Nevzorov, ein der Kleinbur- 
ger-Schicht zumindest nahestehender (aber nicht ausdrücklich als Kleinbürger ausgewiesener: Erhaltung der starken Generalisierbarkeit!) sowjetischer Herr $X$, der keinerlei direkte Hinweise auf seinen aktuellen sozialen status, auf sein SozialVerhalten gibt (das aus der Darstellung also total ausgeklammert bleibt im Gegensatz zu den Texten der 'Binnen-Satire', die den Kleinbürger als eingeordnete Figur kennen!). Und ebenso wie Nevzorov ist er ein Blinder.

Sein Sprach-Verhalten weist viele Elemente der KleinbügerSatire auf: es ist charakterisiert durch Archaismen und Kirchenslavismen ("v ruce"53) "Eropkin sej obidelsja" 54), falschen Fremdwortgebrauch ("Was aber die Verjügung .... so ist das vorerst noch Mythologie"55). "Souvenir" statt "Service"56) etc. falsche grammatikalische Konstruktionen ("auf dem Denkmal, was in Moskau ist"), vor allem aber durch wildwuchernde Floskelhaftigkeit und Geschraubtheit ("I.I. versank ins Nirwana"57), "und bis auf den Tag erfreuen sie sich höchstpersönlich der Gesundheit" 58 ), die Ausfluß des Bemühens sind, Bildung, ästhetische Feinfühligkeit, Genialität unter Beweis zu stellen.

Viel wesentlicher aber ist die indirekte Autosozialcharakterisierung per Argumentations-Verhalten, durch die Ausbreitung konservativ-bürgerlicher Ideologie, die primäres objekt der satirischen Aggression der 'Erzählung ...' ist.

Die generellen Merkmale dieser Ideologie dokumentieren sich insbesondere im Geschichtsverständnis des Erzählers, dessen positive Kategorie, dessen Werthorizont die zur Idylle verklärte 'gute alte Zeit' ist. Über diese gute alte Zeit, in der "Ordnungsliebe, Achtung von Besitz und Verdiensten" ${ }^{59)}$, Frömmigkeit unverrückbare Werte waren, in der das "satte und ruhige Muhen des Hornviehs, das I.I. gehörte"60), die Abenddämmerung durchtönte, brach die Sowjetzeit mit "Finsternis und Verödung" 61 ) herein.

Seine Auffassung der Oktoberrevolution kleidet der Erzähler in eine Allegorie: in ein altes, festgefugtes - wenn auch windschiefes - Haus dringt ein neuer Bewohner ein, ernennt sich 
selbst zum Hausbesitzer und macht sich, von keinerlei Sachverstand getrübt, stürmisch an den Umbau des Hauses. Die Folgen liegen auf der Hand: nichts funktioniert mehr, selbst den Hühnern ist die Lust zum Legen vergangen. Die Beurteilung der zuküntigen Chancen des 'Eindringlings' (Sowjetmacht) läßt den Erzähler 'zynisch' werden:

"Unbekannt ist, was sich in ferner Zukunft abspielen wird. Vielleicht werden in ferner Zukunft bei uns Bananen wachsen, vielleicht wird man sogar eine Maschine zum Fangen von Flöhen erfinden, bis dahin aber in der frischen Luft zu leben und sich ausschließfjich von eben dieser Atmosphäre zu ernähren - habe die Ehre"

Diese schadenfroh-skeptische Charakterisierung der Perspektiven der Sowjetmacht mit den wirtschaftlichen Schwierigkeiten fertig zu werden, findet ihre letzte Konsequenz in der Konstruktion einer zyklischen Geschichts-'Theorie', die Kind des Wunsches nach Restauration des Goldenen Zeitalters ist:

"Hoffnung auf Rückkehr der glückseligen Tage keimt auf im von Verfolgungen beengten Geiste. Die Finger fügen sich zu der bekannten Kombination und die Lippen bringen hervor: Wer weiß, vielleicht wird $6 \xi 9$ sich noch einmal drehen, das Rädchen nämlich der Geschichte" 63 .

Die kleinbürgerlichen Mitbürger des Erzählers teilen diese Auffassung, die in der Sowjetzeit nur eine bedauerliche Entgleisung der Geschichte sieht, deren Folgen auszumerzen sind: Beauftragt, eine Hinweistafel čK-Büro anzubringen, findet ein Handwerker, der 'unnötige' Arbeit vermeiden will, folgenden Kompromiß:

$$
\begin{aligned}
& \text { Črezvy } \\
& \text { Č A J A J A } \\
& \text { Komissija }
\end{aligned}
$$

- so geschrieben, "um notfalls die Zusätze zuschmieren zu können"64).

Dieses Geschichtsverständnis konkretisiert sich in den Wertungen, die der Erzähler bei der Darstellung der Bourgeoisie einerseits, der Repräsentanten der Sowjetmacht andererseits vornimmt.

Der Erzähler formuliert die Ideologie des vor- und nachrevolutionären (Klein)Bürgertums, das - selbst in ärmlichen, abhängi- 
gen Verhältnissen lebend - sich mit verzückten Augen vom vergangenen (und gegenwärtigen) Glanz einer privatunternehmerischen Existenz blenden läßt. Der Unternehmer ist ihm Vater und selbstloser Erhalter Rußlands:

"Rußland, wer hat dich erschaffen? ... I.I. hat dich erschaffen, I.N. hat deine Paysage verziert. ... und nicht genug, daß sie selbst speisten - auch die andern ernährten sie. Und nicht ge-65) nug, daß sie selbst lebten - auch die andern ließen sie leben"65? Kurz: sie sind "Wohltäter der Menschheit"66).

Quelle ihres Reichtums ist aber nicht etwa die Arbeit Ausgebeuteter. Nein: "Quelle all seiner Reichtümer war nur die Natur"67) - "das Brot ist, sozusagen, gänzlich Produkt der Natur"68). Der Fabrikant "verdankt seinen Wohlstand ausschließlich eigenen Miihen, eigener Sparsamkeit"69).

Aus dieser idealisierenden, den Unternehmer als Vollstrecker naturimmanenter Gesetze glorifizierenden Darstellung der harmonischen bürgerlichen Gesellschaft und ihres Exponenten, des Privatunternehmers, ergibt sich zwingend die negative Gegenposition des Jetzt, die Bewertung der Sowjetgesellschaft und ihrer Kader: "Eine Zeit war und verging. Grimmige Tage brachen herein, das bürgerliche Leben verödete. Der freie Handel wurde untersagt, auf aufgeklärte Menschen wurde die Jagd eröffnet und (..) man beschnitt ihnen den Gebrauch der Luft, beraubte sie, sozusagen, der Atmosphäre: nach einer festgesetzten Stunde darf man nicht mehr auf die Straße gehen.. Finsternis breitet sich aus .. wird klirrend zerfetzt vom groben Gelächter einer Patrouille, einem Gelächter, das in der dem Bürger verbotenen Luft schwebt. In den leichten Schlaf unschuldiger Jungfrauen dringt zotiges Geschimgff .. es klopft .. Stöhnen des dem Tode geweihten Opfers" 109 .

Nicht besser als diese allgemeine Atmosphäre sind ihre Garanten: in der $\ddot{C} K$ "residierte hinter einem blutroten Tisch ein feurigrothaariger Genosse und unterschrieb schwungvoll Todesurteile.. wahrscheinlich"71). In der ausschließlich auf-Verteufelung der 'Roten' bezweckenden - konterrevolutionären Gerüchten basierenden Darstellung des Erzählers erscheinen die Bolschewiken als waffenstarrende, willkürlich-unberechenbare, brutale Sadisten mit Gangstermanieren: "Sie verhaften und liquidieren ... und ohne jeden Grund. Abrürung, Gewehr in Anschlag: eins, 
zwei, drei, päng! - und fertig"72). Das schlimmste Vergehen, das ihnen der Erzähler anzudichten weiß: mit vorgehaltener Waffe zwingen sie anständige Bürger - zum Judentum zu konvertieren (Kleinbürgerlicher Antisemitismus manifestiert sich wiederholt)!

Die Decouvrierung (Verlachung!) des erzählerischen Argumentationsverhaltens erfolgt ausschließlich als Autodecouvrierung. Die Argumentationsstrategie selbst ist brichig genug: sie opponiert einer idealisierten Vergangenheit, dem Mythos 'Privatunternehmer' - den Alptraum einer sozialistischen Gegenwart. Nicht also einer sozio-ökonomischen historischen Situation eine andere, vielmehr eine Schimäre einer anderen. Diese Opposition hat Aussagewert also nur bezüglich desjenigen, der sie, ignorant und passiv seinem konservativen wunschdenken ausgeliefert, durchführt.

Die Kompetenz des Erzählers, Urteile über historische und politische Vorgänge zu fällen, ist recht fragwiirdig: er erklärt wiederholt, er werde sich hüten, sich in Politisches einzumischen, Politisches auch nur zu berühren. In der Tat - Revolution, Bürgerkrieg haben für den Erzähler ihre Ursache nicht im Politischen der 'großen Welt': der Erzähler kennt nur seine 'kleine Welt' kennt nur ihrer Zerrperspektive adäquate Ursachen. Die 'bol'seviki': Parteigänger eines der beiden Ivany, "potomu čto u nich u vsech bol'šie そivoty"73). Die Revolution selbst resultiert aus einem neuerlichen Streitfall zwischen den beiden Ivany (ein bereits zum Braten aufgepfähltes Schwein flieht vom Hof des einen Ivan auf den desanderen und wird von diesem vereinnahmt :

"Ich stehe nicht an zu behaupten, der Umsturz" 74 ) sei unmittelbare Folge der seltsamen Geschichte mit I.N.'s Eberferkel (..) aber (..) es ergibt sich ein rätselhaftes Bild. Schon allein, daß es, sozusagen, Vorgänge gleicher Ordnung sind. Nie zuvor war der Wissenschaft bekannt, daß ein grunzendes Säugetier in aufgeprähltem Zustand eine Flucht realisieren konnte. Und ebenso nahm kein Mensch auf der Welt an, im Russischen Imperium könne eine Republik aufreten. Trotzdem wegff ich nichts behaupten, weil man darin Politik sehen könnte" 75 . 
Das Ende der 'Erzählung ....' versetzt den Erzähler ironisch ans Ziel seiner geheimsten Wünche - Seinesgleichen der Ivany zu sein: Philosophisch-geschwätzige überlegungen über die Vergänglichkeit privatunternehmerischen - d.h. für ihn aber: menschlichen - Ruhmes anstellend, gelangt er zu der Erkenntnis: "Tatsächlich, was sind wir, die wir uns Krönungen der Schöpfung wähnen? .. irgendwelche Wanzen"76). Als Wanzen freilich eingebettet in die Vorsehung des Höchsten, also mit der Legitimation ausgestattet, 'Wanze' zu sein - und zu bleiben!

Hier ergibt sich zugleich die wesentliche Differenz zur 'Wanze' Privatunternehmer und die bleibende satirische Relevanz der 'Wanze' Kleinbürger: Jene hat erkannt, daß ihre Zeit endguilig um ist, diese geht mit ungetrübtem Selbstverständnis - mit dem Selbstverständnis eines Möchtegern-Bourgeois - aus den revolutionären Ereignissen hervor. Den satirischen Feind 'Bourgeois' hat die neue Gesellschaftsordnung bereits liquidiert, das satirische Angriffsziel 'bürgerliche Ideologie' bedroht die Ausformung der sozialistischen Gesellschaft auch weiterhin, da sie die Integration der (im städtischen Bereich77), größten (!) gesellschaftlichen Gruppe in die Sowjetgesellschaft verunmöglicht: bewußtmachende Verhöhnung eben dieser - für viele kleinbürger und dem Kleinbürgertum nahestehende Leser nach wie vor attraktive - Ideologie ist denn auch eigentliche kommunikative Intention der 'Erzählung ....'.

Konsequent, da das eigentliche satirische Angriffsobjekt im 'Innen-Bereich' liegt, verzichtet die 'Erzählung ....' auf Einarbeitung einer figuralen oder argumentativen positiven Gegenposition. Protagonisten der neuen Gesellschaft treten nur episodisch in Erscheinung und auch dann nur durch die Perspektive des Erzählers verzerrt zu (im Sinne einer positiven Gegenposition) ideologisch neutralen Raufbolden. Indirekt freilich ist die positive Gegenposition in der zwischenzeitlich 'wider Erwarten' etablierten Sowjetgesellschaft der Rezipienten repräsentiert: Die Tatsache des 'Trotzdem' - Fortbestehens der Sowjetmacht stellt dem Rezipienten die wesentlichste Verlachungs- 
und Überlegenheitsperspektive zur Verfügung.

Der 'Erzählung ....' war kein Erfolg beschieden, obwohl sie über viele positive Qualitäten verfügt (sie ist auch eine der 'komischsten' sowjetischen Satiren der Zeit). Reaktionen der Kritik sind nicht feststellbar. Eine wissenschaftliche Bearbeitung unterblieb - Einzelbemerkungen bei Eršov und Vulis werden dem Text so wenig gerecht, daß die Frage, ob diese Autoren auch in diesem Fall auf eigene Text-Lektüre gänzlich verzichtet haben, durchaus berechtigt erscheint.

Die Gründe für diese stiefmütterliche Behandlung sind evident: die skaz-Konstruktion, deren Funktion es hier ist, die Rezeption nicht auf das Dargestellte, vielmehr auf den darstellenden Erzähler zu zentrieren, ist zu kompliziert: sie erzielt diese Intention erst bei wiederholter Lektüre; die Erstlektüre (und damit die Normallektüre) realisiert den skaz als erfreuliches 'schmickendes Beiwerk' - und konzentriert sich auf die Ebene der dargesteliten Figuren. Dann aber schlachtet die 'Erzählung ....' ein Goldenes Kalb ohne satirischen Aktualitätswert.

Ein weiterer Grund dafür, daß sich auch spätere Forschung der 'Erzählung ....' nicht annahm (oder sie in Fußnoten zum Gogol'Plagiat deklassierte), liegt in der oben herausgearbeiteten Spezifik der antisowjetischen Argumentation des Erzählers, der das Schreckbild einer bolschewistischen willkirherrschaft realisiert sieht, wie sie sich ein Jahrzehnt später faktisch als Stalinismus etablierte: der Kleinbürger als von der Geschichte bestätigter Visionär ..... 
Sechster Teil:

Satirische Totalisierung - Die Romane von I. Il'f und E. Petrov

Die beiden satirischen Romane von I. Il'f und E. Petrov -

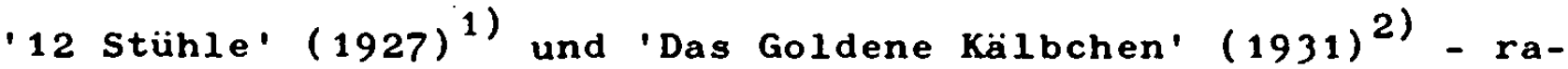
gen nahezu monolithisch aus dem Gesamtfeld sowjetischer satirischer Großerzählungen und Romane heraus; insbesondere 'Das Goldene Kälbchen' markiert einen der Höhepunkte der bisherigen sowjetischen satirischen Literatur (andererseits zugleich aber auch weitgehend einen vorläufigen Schlußpunkt ihrer Entwicklung). Beide Romane verfügen bis heute in allen sozialistischen Ländern über einen extraordinären Bekanntheits- und Beliebtheitsgrad und sind (von I. Érenburgs 'Julio Jurenito' abgesehen) die einzigen sowjetischen ${ }^{3)}$ satirischen Romane, die auch außerhalb des ostblocks einer breiteren Leserschaft bekannt wurden.

Beide satirischen Romane verfügen über eine in der sowjetischen Literatur beispiellose Vitalität - kein anderes Werk der sowjetischen Literatur ist (nun schon seit uber vier Jahrzehnten) derart tagtäglich gehandhabtes Gemeingut des Sowjetbürgers aller Nationalitäten und sozialen Schichten: auch heute noch werden ein raffiniert-sympathischer Gauner als ostap Bender, eine schnippische Schöne als Élločka, ein dümmlich-parasitärer Intellektueller als Lochankin etc. spontan apostrophiert und verspottet.

Die Vitalität beider Romane manifestiert sich nicht zuletzt auch darin, daß sie wiederholt inner- und außerhalb der Sowjetunion verfilmt wurden - so zuletzt im Jahre 1972 von 'Mosfilm' 12 Stühle'.

Popularität und Vitalität der satirischen Romane von Il'f und Petrov schlagen bis in die (quantitativ wie qualitativ uberaus bescheidene) an satirischen Großerzählungen und Romanen orientierte sowjetische Literaturgeschichtsschreibung durch, die sich mit derartiger Ausschließlichkeit auf diese beiden satiri- 
schen Romane konzentriert, daß - teilweise mit Ausnahme wiederum von 'Julio Jurenito, 4) die ubrigen Texte in aller Regel gerade noch registriert, als mehr oder minder mißlungene 'Präludien' zu den Romanen von Il'f und Petrov (die damit als impliziter Werthorizont fungieren) ab $-g e w e r t e t^{5)}$ werden.

Die sowjetische Literatur zu Il'f und Petrov weist eine erhebliche Quantität auf, läßt jedoch bis heute einen 'qualitativen Sprung' vermissen: fast alle einschlägigen Arbeiten sind methodisch konfuse, stark biographistische postume liebeserklärung an Il'f und Petrov - mehr leider nicht!

Die literatur zu Il'f und Petrov behandelt die beiden Romane fast ausnahmslos gemeinsam - behandelt sie als Fortsetzungs"Romane uber Ostap Bender"6). Dieses pauschalisierende Vorgehen ist bedenklich: Zum einen verstellt es den Blick auf die Tatsache, daß die beiden Romane unter den Aspekten 'Objekte der satirischen Aggression', 'Intensität der Aggressivität', insbesondere aber unter den Aspekten 'Konstitution und Funktion der Zentralfigur' und Sujetfügung' ganz erheblich differieren. Zun andern bedeutet dies in letzter Konsequenz zugleich, daß eine beide Romane pauschal abhandelnde Darstellung sich der Möglichkeit begibt, die alle früher für den 'Binnen-' $u n d$ 'InnenBereich' ausgeformten Darstellungs- und Angriffsobjekte und Konstitutionsverfahren totalisierende und zugleich etwas sehr Eigenständiges darstellende ganz extraordinäre leistung des 'Goldenen Kälbchens' begründbar herauszustellen.

\subsection{11 'f und E. Petrov '12 Stühle'}

Die ' 12 Stühle' sind so bekannt, daß sich eine breit dokumentierende Präsentierung hier erübrigt - zumal ihre Einordnung in die 'Satire des Sumpfes' sowie ihre partielle Absetzung von ihr keine Probleme aufwerfen. Da ferner alle vorliegenden Arbeiten zu I: 'f und Petrov ihr Schwergewicht auf $d i$ e $n$ Roman legen (und 
eine Arbeit, der es auf die in der bisherigen Literatur zum sowjetischen satirischen Roman nicht versuchte, an paradigmatischen Zusammenhängen orientierte Herausarbeitung von Entwicklungstendenzen und die diesen Zusammenhängen zugeordnete Bearbeitung besonders 'merkmalhaltiger'Einzel-Texte ankommt, darauf verzichten kann und - in Anbetracht der Materialfulle muß, als 'Forschungsbericht' getarnte Eulen nach Athen zu tragen); da schließlich eine akzeptable Analyse des 'Goldenen Kälbchens' bislang nicht vorliegt - verfolgt die Präsentierung der beiden 'Klassiker' des sowjetischen satirischen Romans hier in Abweichung von den Gepflogenheiten fer sowjetischen Il'fPetrov-literatur folgenden - den Schwerpunkt auf 'Das Goldene Kälbchen' verlagernden kontrastiven Weg:

1 a) Kurz-Präsentierung der ' 12 Stühle': Einordnung des Textes in die 'Satire des Sumpfes'; von der 'Satire des Sumpfes' absetzende Merkmale.

b) Analyse der Figur Ostap Benders in den '12 Stühlen'.

2 a) Präsentierung des 'Goldenen Kälbchens' unter den Aspekten 'Figurenbestand' und 'Figurenkonstitution' (satirische Darstellungs- und Angriffs-Objekte).

b) Analyse der Figur Ostap Benders im 'Goldenen Kälbchen' unter den Aspekten 'Konstitution' und 'rezeptionsteuernde Funktion': Ostap Bender - ein 'Schelm'?

Die Ende 1927 in knapp vier Monaten abgefaßten ' 12 Stüle' erschienen erstmals Anfang 1928 in den Nummern $1-7$ von ' 30 dnej', wurden noch im selben Jahr in Buchform veröffentlicht und erreichten allein von 1928-1932 sieben - sehr stark voneinander differierende - Auflagen.

Die story des Romans greift - parodistisch 7 ) - eine von vielen Abenteuerromanen eingesetzte Schablone auf: das Motiv miteinander konkurrierender, nach einem Plan auf Schatzsuche gehender Gruppen.

Am Sterbebett seiner Schwiegermutter erfährt der ehemalige Adelsmarschall und jetzige Standesbeamte Vorob'janinov, daß diese ihren gesamten Brillantenschmuck bei Ausbruch der Revo- 
lution in einem von zwölf stühlen versteckt hat. Der Pope und Möchtegern-Privatunternehmer Fedor teilt das Geheimnis. Vorob'janinov, zu dem bald der 'Held' des Romans - Ostap Bender - stößt, und Fedor machen sich auf getrennten, sich aber häufig kreuzenden Wegen auf die Suche nach den Stühlen, die die dynamische Zeit über ganz Rußland verstreut hat und die auch noch zum Zeitpunkt der Suche in Bewegung sind. Das Unternehmen endet mit einer totalen Pleite: Ostap Bender wird von Vorob'janinov ermordet, der Schmuck fällt - per Zufall bzw. historischer Notwendigkeit - in die Hände der jungen Sowjetgesellschaft. Die erzählte Zeit erstreckt sich über ein halbes Jahr von Frühjahr bis Herbst 1927 .

Der Figurenbestand der ' 12 Stüle' und die an diese Figuren gekoppelten Merkmale negativen (weil vergangenheitslastigen) sozialen Verhaltens und Denkens entsprechen wesentlich den aus der 'Satire des Sumpfes' vertrauten Verhältnissen: Ex-Adlige, ExBourgeois, Popen, Kleinbürger; antisowjetische Flüsterpropaganda, Diebstahl von gesellschaftlichem Eigentum; Restaurationshoffnungen, Privatunternehmerideologie etc.

E $i \mathrm{n}$ e Erweiterung weist der Figurenbestand freilich auf: der Bürokrat, der in allen anderen (zugänglichen) Romanen des 'Binnen-Bereichs' nicht in Erscheinung tritt. Aber: auch in den ' 12 Stülen' bleibt der Bürokrat Nebenfigur; genauer: eine bürokratische Arbeitseinstellung bleibt zumeist eingeordnetes Merkmal mancher Figuren (so Vorob'janinovs) oder wird als 'Bürokratismus' in einem sehr weitgefaßten sinne des Wortes an einem 'Bürokraten des Journalismus' (Ljapis) nachgewiesen, der alle seine Beiträge nach ein- und derselben Schablone verfertigt. "Fragen nach Liebe und Tod bewegten Ippolit Matveevič Vorob'janinov nicht, obschon er sich Kraft seines Amtes Tag für Tag von 9 Uhr morgens bis 5 Uhr abends - mit einer halbstiugigen Fruhstückspause - mit diesen Fragen zu befassen hatte" ${ }^{\prime}$.

Ein Element, das die' 12 Stühle' bedeutend gegenüber den meisten 'Satiren des Sumpfes' abhebt, ist die Füle rein humoristischer Episoden und Figuren: der Ingenieur ščukin, bei dem die Wasserleitung gerade in dem Moment versiegt, als er voll eingeseift unter der Dusche steht ..., die mannstolle Witwe Gricacueva etc. Dieses starke Hervortreten humoristischer Elemente findet seine Entsprechung in der Konstitution der Negativ-Figuren ('Negativ- 
Figuren' im Gegensatz zu rein humoristischen Figuren) und in der story. Alle Negativ-Figuren sind in einem viel stärkeren Maße lächerlich als negativ. Dies manifestiert sich schon in der durchgehend gehandhabten Bedeutungsnamengebung, die hier nicht als Mittel der indirekten Negativ-Charakterisierung fungiert, sondern als Mittel der Verlachung: Madam Petuchova, eine Uralt-Aristokratin (a: veraltete Anrede; b: der den Hahn (Petuch) assoziierende Name steht in komischem Kontrast zu ihrer Stimme, "um die sie Richard Löwenherz beneiden würde"9), ; Treuchov (Dreiohr'); Galkin, Palkin, Malkin, C̈alkin und Zalkin (deren Individualitäts-Anspruch sich auf jeweils ein einziges Phonem stürzt) etc.. Schließlich scheitern alle Negativ-Figuren noch in der story; sie scheitern aber nicht (wie in den meisten Texten der 'Binnen-Satire') an der überlegenheit der sozialistischen Gesellschaft und ihrer Exponenten - sie scheitern an Ostap Bender, der sie fast ausnahmslos übers Ohr hat, sie scheitern an ihrer eigenen Dummeit, Geldgier etc..

In seinen 'Erinnerungen an $\left.I l \cdot f,{ }^{+}\right)$teilt Petrov mit, in den ' 12 Stühlen' sei ihnen Ostap Bender gleichsam versehentlich zum Helden geraten, habe sich unter ihren Händen verselbständigt, nachdem er urprünglich als Nebenfigur konzipiert worden sei. Wie dem auch sei, obwohl ostap Bender erst im 5. (von insgesamt vierzig) Kapitel auftaucht, beherrscht er von da an so eindeutig die Szene, daß alle Passagen ohne seine unmittelbare Präsenz Exkurscharakter annehmen.

Ostap Bender wird eingefürt als "junger Mann von 28 Jahren"11),

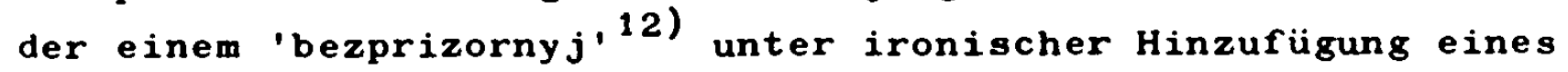
seiner vielen Leib- und Magenspriche - "soll ich dir vielleicht noch den Schlüssel der Wohnung geben, wo das Geld liegt?"13) einen Apfel schenkt. Dieser Kommentar ist ironisch und selbstironisch zugleich. Denn:

"Der junge Mann hatte gelogen: er hatte weder Geld noch eine Wohnung, wo es liegen könnte, noch einen Schluissel, mit dem man die Wohnung hätte aufschließen können. Er hatte noch nicht einmal einen Mantel. Die Stadt betrat der junge Mann in einem grü- 
nen auf Taille geschnittenen Anzug. Sein mächtiger Hals war einige Mal von einem alten Wollschal umschlungen, die Füße steckten in (..) orgygefarbenen Lachstiefeletten. Socken trug er darunter nicht" 14 ".

Hinweise auf Ostap Benders Herkunft und Vorleben, vor allem auf seine Klassenzugehörigkeit bleiben spärlich und sind - wo sie gegeben werden - durch ihren Kontext, namentlich dadurch, daß sie von Ostap Bender selbst in Form ironischer Selbstdarstellungsansätze geleistet werden, als von höchst bescheidenem Authentizitätsanspruch charakterisiert. Er erklärt, sein 'Papa' sei 'türkischer Untertan' gewesen - "nur diese eine Einzelheit pflegte er aus seiner Biographie mitzuteilen"15). Gegen Ende des Romans - eine Pechsträhne hat seinen ansonsten unerschüterlichen Optimismus leicht gedämpft - konzediert er sich selbst folgenden Epitaph:

"Der (..) Leichnam eignet einem jungen Mann von siebenundzwanzig Jahren. Er liebte und litt. Er liebte das Geld und litt unter seinem Mangel. Die hohe Stirn seines der Sonne zugewandten Kopfes umrahmten tiefschwarze Locken. Seine prächtigen Füße Schuhgröße 42 - sind aufs Nordlicht gerichtet (..) und in mein Denkmal wird eingemeiselt sein: 'hier ruht der bekannte Wärmetechniker und Jagdflieger Ostap-Sulejman-Berta-Marija-Bendobej, dessen Vater türischer Untertan war und starb, ohne seinem Sohn auch nur die Spur eines Erbes zu hinterlassen. Die Mutter des Verstorbenen war eine Gräfin YQG lebte von nicht durch eigene Arbeit erworbenen Einkünften"

Dieser Verzicht auf eine (ernstzunehmende) Benders Sozialprovenienz- und Zugehörigkeit verdeutlichende Konstruktion ist umso auffälliger, als alle andern Figuren hinsichtlich ihres vorrevolutionären oder aktuellen sozialen status genau festgelegt sind; die Durchbrechung dieser struktur ausgerechnet bei der Zentralfigur Ostap Bender ist ein relevanter intratextueller 'minuspriem.17), der signalisiert, daß der soziale status quo (ante) Ostap Benders ohne Bedeutung ist für das Verständnis dieser Figur!

Auch ein Bewußtsein seines Stellenwertes im Sozialgefüge der späten Nöp-Gesellschaft ist bei dem 'schönen Mann mit dem Tscherkessengesicht"18) nicht vorfindlich (ganz anders als später im 'Goldenen Kälbchen'). Desgleichen verfügt er weder über 
eine festumrissene 'Idee', eine bewußte und artikulierte ideologische Orientierung, noch über eine klar definierte Zielsetzung. Gewiß, mit "unerschöpflicher Energie und Fröhlichkeit" 19) beteiligt er sich als "technischer Direktor und Hauptfürer der Konzession"20) maßgeblich an der Diamantenjagd. Aber: das Geld hat für ihn (in diesem Roman!) nicht den für alle andern Figuren bestimmenden Fetischcharakter - er selbst versichert glaubhaft, das Geld nicht zu lieben, nur 'aus Prinzip' an der Diamantensuche zu partizipieren: "Tatsächlich spiegelt Benders Charakter nicht Zähigkeit und Verhärtung des Eigentumsstrebens (..) wieder - vielmehr verlocken ihn Gaunerstücke an sich"21).

Ostap Benders einziges Ziel ist es, sich 'auf Kosten anderer' - d.h. aber auf Kosten bornierter und vergangenheitsverhafteter Kleinbürger, Ex-Bourgeois und Ex-Aristokraten - ein lustiges und interessantes Leben zu machen, ohne selbst zu produktiver Arbeit gezwungen zu sein. Die Realisierung dieses Vorhabens fällt ihm umso leichter, als er die Achillesferse im Bewußtsein dieser von der Sowjetgesellschaft noch nicht integrierten gesellschaftlichen Elemente - eben ihr Verhaftetsein in bürgerlichen Denkmustern, ihren Traum von einer Restauration des Zarismus etc. - erkannt hat - und zwar ohne auch selbst mit dieser Achillesferse behaftet zu sein - und diese Erkenntnis auch weidlich zu nutzen versteht!

Nicht ein wie auch immer strukturiertes Bewußtsein charakterisiert also Ostap Bender in den ' 12 Stühlen', sondern - viel äußerlicher - unerschöpfliche Energie:

"Der Sohn des türkischen Untertanen wechselte während seines Lebens oft die Tätigkeit. Die Lebhaftigkeit seines Charakters, die es ihm unmöglich machte, sich irgendeiner Sache zu widmen und ihn beständig in die verschiedensten Ecken und Enden des Landes verschlug, war es, die ihn auch jetzt ohne Socken, ohne Schlüssel, ohne Wohnugg und ohne Geld nach Stargorod ('Altstadt' j.e.) gefürt hatte" 29 .

Diese seine 'Lebhaftigkeit' prägt namentlich auch sein Sprachverhalten: er läßt keine Gelegenheit ungenutzt, ein - seine Umgebung oft ironisch kommentierendes - oratorisches Feuerwerk abzubrennen, einen Exkurs über einen seiner ungezählten 'Bekannten' 
zu starten etc. Floskeln aller Art - juristische ebenso wie diplomatische, militärisches Befehlsvokabular und marxistische Grundbegriffe gehen ihm ebenso leicht über die Lippen wie fremdsprachliche Wendungen - mit einer Ausnahme freilich, die von der Forschung völlig ubbersehen wird, obwohl sie - gerade weil sie als Ausnahme ausdrucklich thematisiert wird - als Beleg dafür, daß in diesem Roman eine wesentliche Zuordnung Benders zu einer bestimmten sozialen Gruppe $n i c h t$ vorgenommen wird, relevant ist: die Floskeln der zaristischen hautevolee beherrscht er nicht: "Von all den luxuriösen Wendungen des Zarenregimes hatte er nur irgendsoein 'er geruhte gnädiglich zu befehlen' im Kopf"23).

Die in sowjetischen Arbeiten zu Il'f und Petrov abgedruckten Materialien zur - sehr kurzen - Entstehungsgeschichte dieses stark dem satirischen Feuilleton verpflichteten Romans (der im Grunde eher eine Aneinanderreihung ${ }^{24}$ einzelner, sich nicht auseinander entwicklender, auf der Basis von Notizenmaterial und fruheren satirischen Feuilletons etc. entstandener Einzelepisoden darstellt, die - von dem Motiv der Brillantensuche abgesehen nur durch das spätere Wiederauftauchen von Nebenfiguren verklammert sind) lassen den Schluß zu, eine Figur vom Zuschnitt Benders sei den Autoren nicht zuletzt zu dem Zwecke willkommen gewesen, viele in jahrelanger journalistischer Arbeit gesammelte witzige Sätze, Pointen etc. anbringen zu können.

Im Kontext der übrigen Figuren dominiert Bender - der 'bosjak' (Barfüßler) - eindeutig. Dies gilt zumal für seine stellung innerhalb der 'kleinen Welt' des Kleinbürgertums: sie alle, die auf eine so erbärmliche Weise lächerlich sind, daß ein Papagei gleichberechtigt ihre Ansichten zu teilen vermag, fühlen sich ihm so eindeutig unterlegen und ordnen sich ihm - von iberaus lächerlichen Emanzipierungsansätzen Vorob'janinovs abgesehen widerspruchslos unter.

Funktion der Figur Ostap Benders ist es in den' 12 Stülen' also nicht, a $n$ dieser Figur bügerliches Denken etc. bewußt zu machen, zu verlachen und zu verurteilen. Gewiß, er ist ein (sym- 
pathischer) Gauner, der über ein festes Repertoire "alter, erprobter"25) Gaunertricks - Namenwechsel, falsche Pässe, "1) einfache Bekanntschaft, 2) Liebesintrige, 3) Bekanntschaft mit Einbruch, 4) Tausch und 5) (..) Geld"26) - verfügt, und als solcher sicher alles andere als ein exemplarischer Sowjetbürger. Aber: nicht ihn, sondern Vorob'janinov (und mit ihm dessen aristokratische und bourgeoise Doppelgänger) konfrontieren die Autoren mit positiven Figuren wie dem - sehr blaß geratenen - Straßenbahningenieur Treuchov. Er hat in diesem Roman auch nichts 'Schelmenhaftes,27) an sich.

Vielmehr hat diese Figur zum einen die Funktion, durch die Konfrontation des Gauners und 'bosjak' Ostap Bender mit den sozial angeblich hoch über ihm stehenden Vorob'janinovs deren schale Lächerlichkeit umso deutlicher zu akzentuieren: zweitens kommt ihm als sympathischer Figur die Aufgabe zu, seine Umgebung mit ironischen Kommentaren zu decouvrieren. Nicht a $n$ Bender, sondern $m i t$ Benders Hilfe werden also die 'bürgerlichen überbleibsel' in der Sowjetgesellschaft verlacht.

Seine Haupt-Funktion ist aber zweifelsohne sujet-funktionaler Art: nämlich das "Motiv der Wanderung als primäres sujet-kompositorisches Prinzip" 28) zu ermöglichen. Er nämlich liefert als 'großer Kombinator' die allein das "Sujet mit den Stühlen, das nicht Basis des Romans, sondern nur Ursache, Anlaß dazu sein sollte, das Leben zu zeigen"29), in Bewegung haltende Energie für den Sprung von Stuhl zu Stuhl - und damit von einem Gesellschaftsauschnitt zum nächsten (wobei diese Ausschnitte sozialqualitativ kaum differieren). Mit dem Erreichen des letzten Stuhls hat er also auch ausgedient; die Autoren lassen ihn fallen bzw. ermorden. Dieser Mord ist keinesfalls - wie etwa Galanov meint - aus einer ernsthaften Evolution ${ }^{30)}$ des Mörders Vorob'janinov, der bei ostap Bender in die Lehre der "Unverschämtheit und Brutalität" 31) gegangen sei, zu verstehen; noch weniger kann man sich der von Vulis 32 ) vertretenen Auffassung anschließen, einziger Antrieb Ostap Benders sei seine Habsucht, sein Ende trete daher gesetzmäßig ein. Dieser Mord ist vielmehr 
ein - ansatzweise psychologisch motivierter (der gekränkte Vorob'janinov) - wenig überzeugender Verlegenheits-Kunstgriff der Autoren.

In seinen 'Erinnerungen an II' $f$ ' artikuliert Petrov selbst das Unbehagen der Autoren bezüglich dieses Schlusses:

"Es stimet, daB wir daruber stritten, sollten wir Ostap ermorden oder nicht. In der Tat habdn wir zwei Zettelchen vorbereitet. Auf einen von ihnen malten wir einen Schädel und zwei Knöchelchen auf. Und über das Schicksal der großen Kombinators wurde mit Hilfe einer kleinen Lotterie enţ̧̧⿻ieden. Später hatten wir diesen Leichtsinn sehr zu bedauern" 39 .

\subsection{Il'f und E. Petrov 'Das Goldene Kälbchen'}

In den Nummern 1-7 und 9-12 des Jahrgangs 1931 ebenfalls der Zeitschrift ' 30 dnej' - also drei Jahre nach dem Anlaufen des ersten Fünjahresplans (1928-1932) - wurde der zweite Roman von II'f und Petrov 'Das Goldene Kälbchen' erstmals veröffentlicht. Der ersten Buchausgabe von 1933 (bei 'Federacija') folgten bis 1942 sieben weitere, die den Text der Erstausgabe nicht mehr veränderten.

'Das Goldene Kälbchen' leistet die satirische Totalisierung der gesamten 'Überbleibsel'-Problematik. Alle Angriffsobjekte, die die sowjetische Satire der 20-er Jahre in 'Innen-' und 'BinnenBereich' aufs Korn genommen hatte, finden sich hier wieder: die 'überbleibsel der Vergangenheit im Bewubsein' ebenso wie aus der bürgerlichen Vergangenheit in die Sowjetgesellschaft verschleppte regative soziale Verhaltensweisen. Diese Materialfulle wird nicht nach dem üblichen Schema der als Reise motivierten Porträt- und Episodenreihung bewältigt; zwar 'reist' Ostap Bender auch hier - alle satirischen Figuren und Figurengruppen sind hier aber durch ein Geflecht karikaturistischer Wechselbeziehungen miteinander verknüpt, und im Knotenpunkt all dieser Interrelationen steht ostap Bender selbst.

Die fast ausschlieblich in der Provinz spielende Handlung fällt mitten in die Laufzeit des ersten Finf jahresplans. Ostap Bender erfährt von der Existenz des mehrfachen 'Untergrund-Millionärs' 
Korejko und beschließt, diesem - assistiert von seiner dreiköpfigen 'Mannschaft' - vermittels psychologischer Kriegsführung eine Million abzujagen, was ihm schließlich auch gelingt. Nicht jedoch gelingen will ihm die Realisierung seines eigentlichen Vorhabens, als Millionär - sei es in Sowjetrußland oder im kapitalistischen Ausland - zu leben.

Ostap Benders Verhältnis zur Sowjetgesellschaft der ersten NachNöP-Jahre ist so gestört, daß er nur noch die Möglichkeit sieht "wegzufahren (..) sehr weit wegzufahren" 34). Der Grund: "Sie will den Sozialismus bauen, ich aber will es nicht. Wie, bin ich etwa ein Maurer mit einer weißen Schüze" ${ }^{35)}$. Er langweilt sich in der Füf jahresplan-Gesellschaft, vor allem weil er sich der Möglichkeit beraubt sieht, in einer ganz am Kollektiv orientierten Gesellschaft seine $I n d i v i d u$ a $l i t$ ä $t$ voll und offen auszuleben; denn vor allem als Individuum, als absolutes Individuum versteht er sich: "Wie, gleiche ich etwa einem Menschen, der Verwandte haben kann? .. Ich habe keine Verwandten, ich bin einzig auf dieser Welt" ${ }^{36)}$. Benders Individualismus- und Intellektualismus-Anspruch ist in Lochankin ('der Waschzuber') eine Karikatur zugeordnet. Lochankin - eine ins Lächerliche verkehrte oblomov-Parodie - ist so realitätsentfremdet, daß er den Gebrauch prosaischer Umgangssprache verlernt hat: er redet in füffüßigen Jamben!

Der Negativposition 'Sowjetstaat' opponiert Bender als positive Gegenposition 'Rio de Janeiro' als Symbol der kapitalistischen Welt, mit der er einerseits die Vorstellungsreihe "Palmen, Mädchen (..) Platinzähne (..) und vor allem Ruhm und Macht, die das Geld verleiht" 37 ), andererseits aber auch den ansatzweise negativ gefaßten - weil mit den Wertungen 'Ausbeutung' und 'reaktionär' vage verknüpften - Begriff Privatunternehmertum assozicert. 'Ansatzweise': im Gegensatz zu vielen früheren eindimensionalen satirischen Figuren deutet sich bei Ostap Bender im 'Goldenen Kälbchen' eine Lern- und Dynamisierungsfähigkeit an - er ist entwicklungsfähig!

Zur Realisierung dieses Ideals einer privatunternehmerischen Existenz in 'Rio de Janeiro' - als Reserve-Ideal hält er eine Millionärsexistenz in Sowjetrußland auf Vorrat - konstituiert 
er sein Expeditionskorps in Gestalt seiner 'Mannschaft', bestehend aus Balaganov und Panikovskij - zwei geistigen Mikroben (Balaganov hält die Erde für eine Scheibe), die einer 'Konvention' angehören, deren Mitglieder als 'Söhne des Panzerkreutzerleutnants Schmidt' die Provinz bereisen und auf privatunternehmerischer Basis gutgläubigen Sowjetbürgern 'Anerkennungsprämien' abfuchsen - sowie Kozlevic, Besitzer eines Privatautos, allerletzter Privatunternehmer der Stadt Arbatov. Alle drei repräsentieren einerseits ein zu hilfloser Lächerlichkeit verurteiltes chancenloses Privatunternehmertum; andererseits sind sie Karikaturen des ihnen scheinbar haushoch überlegenen 'großen Kombinators'. Nur 'scheinbar', denn bei näherem Hinsehen erweist sich die qualitative Identität ihres gesellschaftichen Verhaltens, ihrer Zielvorstellungen: Sie $s$ i n d 'Privatunternehmer', Ostap $w i l$ es werden; gemeinsames Merkmal ihres Auftretens ist Maskerade, d.h. chamäleonhafte Anpassung der Fassade an die Sowjetgesellschaft, in der sie 'auf Kosten anderer' leben. Gemeinsam ist ihnen die Zielvorstellung 'viel Geld'. Gemeinsam stehen sie außerhalb aller Kollektive. Die Differenzierung ist rein quantitativ-ironischer Art: der zum Junggesellendasein verdammte heiratslustige Panikovskij hofft, dem Liebesglück mit einzelnen Goldzähnen nachhelfen zu können - Bender tut es nicht unter einem kompletten Platingebiß etc..

Die Bestimmung des tatsächlichen gesellschaftlichen standortes des nach ihrem Auto 'Antilopen'-Mannschaft genannten Expeditionskorps - mithin auch des von ihm karrikierten Benders - erfolgt wesentlich indirekt, nämlich durch ihre Verklammerung in die sich als 'große Welt' maskierende 'kleine Welt' der obyvateli, in der Marx und Engels 'Banditen' sind und die folgendermaßen charakterisiert wird:

"Womit sich die Leute nicht nur befassen! Parallel zur großen Welt, in der große Menschen und große Dinge leben, gibt es eine kleine welt mit kleinen Leuten und kleinen Dingen. In der großen Welt wurde der Dieselmotor erfun-den, wurden die 'Toten Seelen' geschrieben. In der kleinen Welt wurde die quietschende Blase 'geh-geh' erfunden, das Liedchen 'Ziegelsteinchen' geschrieben. In der großen Welt bewegt das Streben die Menschen glücklich zu machen die Leute. Die kleine Welt 
ist weit entfernt von so hohen Materien. Einziges Bestreben ihrer Bewohner: irgendwie leben ohne Hunger zu leiden. Die kleinen Leute eilen hinter den großen her. Sie begreifen, daß sie in Gleichklang mit der Epoche stehen müssen und daß nur dann ihre kümmerliche Ware Absatz finden kann. In der Sowjetzeit ist in der kleinen Welt eine Bewegung feststellbar, wenn in der großen Welt ideologische Bollwerke geschaffen werden. Unter all die erbärmlichen Erfindungen der Ameisenwelt schiebt sich die granitene Basis der kommunistischen Ideologie. Auf der Blase 'geh-geh' wird Chamberlain so dargestellt, wie er in der 'Izvestija' abgebildet ist. Und während in der großen Welt eine hitzige Debatte uber die Gestaltung des neuen Lebens gefuhrt wird, ist in der kleinen welt schon alles fertig: dort gibt es die Krawatte 'Traum $98 \%$ Stoßarbeiters', die Gipsstatuette 'Badende Kolchosarbeiterin!" 38 ).

Alle Wege zu Korejko - dem 'Untergrundmillionär', der sich während Kriegskommunismus und Nöp auf verbrecherische Weise bereichert hat und nun, getarnt als unscheinbares Bürokratenmäuschen, des Zusammenbruchs des Sowjetstaates harrt, um Genuß aus seinen jetzt wertlosen (weil verborgen bleiben mussenden) Millionen ziehen zu können - führen in den 'Herkules', in den bürokratischen Apparat, und damit zu einem der zentralen Themen der sowjetischen Satire: $B \ddot{u} r \circ k r$ a $t s m u s$.

Die Beschreibung des 'Büro'-Gebäudes allegorisiert die Charakteristik seiner Insassen:

"Wie sehr sich die oft wechselnden Chefs auch bemuihen mochten, dem 'Herkules' den Hotel-Geist auszutreiben, es wollte ihnen keinesfalls gelingen. Die Hausmeister mochten noch so oft die alten Aufschriften übertünchen, überall kamen sie doch wieder zum Vorschein. Bald sprangen einem in der Warenabteilung die Wörter 'Chambres separés' in die Augen, bald machten sich auf der Milchglastür des Maschinenraums die Wasserzeichen 'Diensthabendes Zimmermädchen' bemerkbar, bald traten auf den wänden

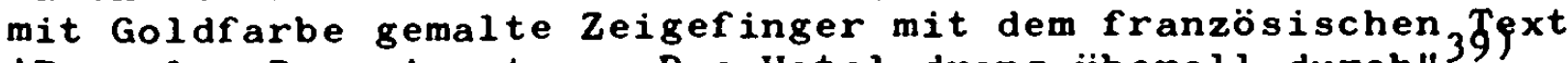
'Pour les Dames' zutage. Das Hotel drang uberall durch" 39$)^{\circ}$.

D.h. aber: der 'Herkules' ist nichts anderes als ein bürgerliches Etablissement, das sich als Sowjetunternehmen tarnt: er ist die bürgerliche Vergangenheit, die im Bewußtsein der Bürokraten (Ex-Adlige, Ex-Bourgeois, 'bürgerliche Spezialisten', die den Privatbesitz an Produktionsmitteln auch weiterhin befürorten) die Gestalt eines Mythos vom verlorenen Paradies angenommen hat und die sich unter dem fadenscheinigen Mäntelchen absoluter Sowjetloyalität verbirgt. Tarnung, Anpassung 
der Fassade an die Sowjetgegenwart, Simulieren ist denn auch die Maxime des Verhaltens der Bürokraten der neuen Gesellschaft gegenüber.

Der 90-jährige 'Sitzpräsident. Funt signalisiert das Verwurzeltsein der Bürokraten in tiefer Vergangenheit. Zugleich markiert er aber auch den nabtlosen übergang vom Bürokratismus zum Verbrechen: Funts 'Sitzpräsidenten'-Tätigkeit bestand nämlich darin, die meiste Zeit seines Lebens als Ersatz-Delinquent für die Flecken auf der nur scheinbar weißen Weste der Bürokraten hinter Gittern zu verbringen. Funt:

"Während des Kriegskommunismus habe ich, um die Wahrheit zu sagen, uberhaupt nicht gesessen, der alte Handel war verschwunden, es gab keine Arbeit (für mich j.e.). Wie ich dafür aber während der NÖP saß ... Das waren die besten Jahre meines Lebens. Während

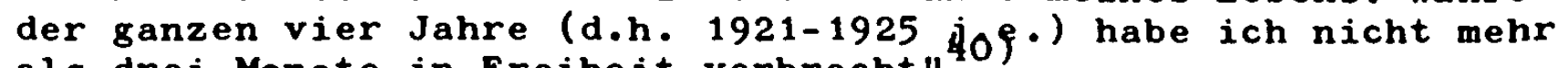
als drei Monate in Freiheit verbracht" 40$)^{\circ}$.

Grund: die unentwirrbare, der Umleitung von Staatsgeldern in private Aktiengesellschaften dienende Verfilzung von bürokratischem Apparat und privatkapitalistischem Sektor.

An der Figur des 'Herkules'-Chefs Polychaev werden die - neben Simulieren, Vergangenheitsverhaftetsein, Kriminalität - wesentlichen, den bürokratischen Apparat und die hinter ihm stehende Geisteshaltung kennzeichnenden Bürokratie-Merkmale herausgearbeitet: A $m$ t $s$ c $i m m$ e $l$ e $i$ und Privateigentumsdenken. In seinem Bemühen, die bürokratischen 'Arbeits'-Gänge zu vereinfachen, hat es Polychaev zu beachtlicher Perfektion gebracht; ja, das von ihm entwickelte Gerät ist so perfekt, daß es sich bereits zu Polychaevs - und mit ihm jedes Bürokraten - Karikatur verselbständigt. Ausgehend von einem mit seiner Unterschriftsfaksimile versehenen Stempel war Polychaev nämlich auf die Idee eines alle Geschäftsvorgänge erfassenden 'Universalstempels' verfallen:

"Dies war ein herrlicher Gummigedanke, den Polychaev jedem beliebigen Fall des Lebens anpassen konnte. Abgesehen davon, daß er die Möglichkeit erschloß, sofort auf die Ereignisse zu reagieren, befreite er sogar von der Notwendigkeit, jedesmal erst quälend zu denken. Der stempel war so bequem (..) konstruiert. daß es genügte, den in ihm freigelasseqg9 Raum auszufuilien, um jede beliebige Resolution zu erhalten" 
Aber: dieses Verfahren wird nicht etwa in den Dienst der eigentlichen Arbeit des 'Herkules' gestellt. Weit gefehlt: die 'Herkulesser' pervertieren ihren Betrieb zum Privateigentum und kämpfen unter Einsatz der gesamten Arbeitszeit, vor allem aber ihres Stempels dagegen an, daß IHR 'Herkules' wieder seiner eigentlichen Bestimmung - nämlich Hotel zu sein - zugeführt wird; die (ohnehin unberuhrten) Aktenordner stapeln sich also auch weiterhin auf Betten, unter Gummibäumen, nehmen also - wie ihre ebenso leeren Herren - eine ihnen nicht gemäße Position ein.

Korejko hat das, was Ostap Bender als Reservezielvorstellung vorschwebt - nämlich als 'Ein Millionär in Sowjetrußland,42) zu leben - formal realisiert. Die inhaltliche Fülung dieses Millionärsdaseins steht indes in denkbar krassem Widerspruch zu Benders Erwartungen: anstelle von 'Macht und Ansehen', anstatt aus dem Vollen leben, anstatt seine 'Individualität' voll entfalten zu können, heißt das: erbärmliches, "von ewigem Warten erbittertes" 43 ) und durch die Angst vor Entlarvung vergälltes Dahinvegetieren auf dem Existenzminimum, totale Vereinsamung.

Auf die ständige Konfrontation mit seiner Karikatur Korejko (unter dem Aspekt des Geld = Macht + Ansehen-Wunschdenkens) reagiert Ostap zwar mit der Erkenntnis, seine Suche nach dem Goldenen vlies seien "Tagträumereien eines Idioten"44), die Einsicht jedoch, daß ein Rußland nach seinem gusto - ein Rußland, das in Anbetung des Goldenen Kalbes (das hier längst zum harmlosen 'Goldenen Kälbchen' degenerierte) versunken wäre nicht mehr existiert, bleibt - zunächst - aus. Die Million, in einer kollektivorientierten Gesellschaft in Händen eines Individuums wertlos, wird ihm bald physisch und psychisch lästig, macht ihn zum sozial Aussätzigen. Aber erst nachdem er das Gelobte Land des Kapitalismus erreicht und von seinen Glaubensbrüdern ihrer gemeinsamen Heilslehre gemäß empfangen - nämlich brutal ausgebeutet wurde - dämmert ihm die Erkenntnis auf: 
"Keine Ovationen! Zu einem Grafen von Monte Christo habe ich es nicht gebracht. Werde ich mich halt zum Hausverwalter umqualifizieren müssen"45), die Möglichkeit der Integration Benders in die Gesellschaft der 'Maurer des Sozialismus' deutet sich an ...

Die figurale positive Gegenposition ist im letzten Teil des Romans durch Repräsentanten vor allem der jungen Generation - Studenten, Bauarbeiter etc. - vertreten. Der direkte Kontakt zwischen negativem und positivem Lager - seine Mitglieder sind durchweg naiv-forsche Aufbautypen und von stolz auf IHRE Gegenwart erfült und treten nur als Kollektive in Erscheinung - ist gleich Null; nur über Ostap Bender kommt er zustande - solange er sich als Sowjetmensch maskiert. Indirekt freilich ist das positive lager im negativen durch dessen simulierende proformaAusrichtung, d.h. aber Reaktion auf jenes permanent präsent. Auch eine direkte Auseinandersetzung findet nicht statt - ist auch gar nicht erforderlich. Denn: die 'Überbleibsel' der alten Gesellschaft bilden ein in sich total verfilztes Knäuel, dessen Einzelelemente sich selbst gegenseitig den Garaus machen. (Autoliquidation der 'gesellschaftlichen Überbleibsel', bei der Bender als Katalysator fungiert).

Mit $\dot{\text { El }}$ 'sbergs Charakterisierung positiver Figuren in sowjetischen Satiren - "In der sowjetischen Satire kann der positive Held völliger Durchschnitt sein, sofern er sich aktiv am Aufbau des Sozialismus beteiligt"46) - sind diese positiven Figuren, die Lunačarskij "zu den besten Seiten des Romans"47) zählt, sehr genau zu fàssen.

Unter kommunikativen Gesichtspunkten sind sie problematisch: Mit Gaier schafft die Satire (oft j.e.) "das gesichtslose Drohende ${ }^{48}$ ) (z.b. bürgerliche Bewußtseinsinhalte) in einen definierten Gegner um, in ein Darstellungs-objekt also, das diese negativen Bewußtseinsstrukturen repräsentiert: satirische Repräsentanzobjekte.

Wenn nun der Satiriker das Positive, für das er sich einsetzt, in einem Neuen, nämlich in einer neuen Gesellschaft sieht, ihm 
die Restbestände des Alten - namentlich auch dessen im Bewußtsein hinterlassene (genauer: in das Unbewußte verdrängte) Spuren als 'Bedrohung' erscheinen, kann er die satirischen Repräsentanzobjekte per Synekdoche, die die gesellschaftliche Realität auf ihre negativsten - weil die Entwicklung nicht mitvollzogen habenden - Elemente reduziert, aus dieser gesellschaftlichen Wirklichkeit selbst gewinnen.

In diesem Fall stehen die satirischen Repräsentanzobjekte zwar a $u$ c $h$ für die von der früheren Gesellschaft zurückgebliebenen negativen Einschüsse in der neuen gesellschaftlichen Realität selbst, repräsentieren aber zugleich diesen Einschüssen konsekutiv zugeordnete integrationsbedurftige Bewußtseinsinhalte.

So auch die Figuren der Negativreihe des 'Goldenen Kälbchens': sie sind eindimensionale, d.h. je eine bürgerliche Bewußtseinsstruktur repräsentierende Repräsentanzobjekte, die der zentralen Figur ostap Bender, die alle diese Bewußtseinsinhalte in sich bündelt, als Karikaturen zugeordnet sind (s.u.).

In den positiven Figuren ist die mit der Eindimensionalität der negativen Figuren gekoppelte Rückübersetzung-Strategie (aus der Ebene figuraler satirischer Repräsentanzobjekte in die der gemeinten negativen - bügerlichen - Bewußtseinsinhalte) durchbrochen. Damit ist aber die Gefahr verbunden, daß auch die negativen Figuren nur als Repräsentanten für im gesellschaftichen Raum unmittelbar vorfindliches Negatives, nicht jedoch als Repräsentanten auch für im Bewußtseinshaushalt des Rezipienten selbst situierte satirische Angriffsobjekte aufgefaßt werden.

Diese Gefahr wird noch dadurch gesteigert, daß die positiven Figuren im letzten Teil des Romans stark hervortreten, was den Eindruck eines puren überwechselns aus einem (negativen) in einen anderen (positiven) Ausschnitt der Gesamtgesellschaft erzeugt, den Eindruck folglich, als gelte die satirische Aggression des Romans nur gesellschaftichen Gruppen, nicht auch - und vor allem - negativen Bewußtseinsinhalten! 
Sowohl die sowjetischen Arbeiten zu Il'f und Petrov als auch die westdeutsche russistische Literaturgeschichtsschreibung achen es sich - offenbar in der Annahme, die bloße Anwendung von Etiketten wie "ein echter Schelmenroman und gehört somit zum allgemeinen Typus des Abenteuerromans"49) oder "satirischer Schelmenroman (..) Hochstapler (..) Glücksritter (..) 'positiver Gauner' (..) unverwistlicher Schelm (..) Verwandl ungskuinstler"50) etc. vermöchten, ohne daß die gemeinte inhaltliche Füllung dieser Termini auch nur angedeutet wirde, bereits Klarheit zu schaffen sowohl hinsichtlich der (letztlich irrelevanten) Genrebestimmung der beiden Romane von Il'f und Petrov, als vor allem auch hinsichtlich der Beurteilung der für die Ermittlung der kommunikativen Funktion des 'Goldenen Kälbchens' ausschlaggebenden Figur Ostap Benders sehr leicht. Namentlich die Begriffe 'Schelm' und 'Schelmenroman' geistern ungeklärt durch sämtliche Arbeiten.

Hierzu ist zu bemerken: 1. Wie oben nachgewiesen wurde, sind der Bender der ' 12 Stühle' und der des 'Goldenen Kälbchens' so verschieden konzipiert, daß eine typologische Bestimmung, die beide 'Helden' undifferenziert über einen Kamm schert, nichtssagend - um nicht zu sagen: falsch - ist. 2. Wenn ein sich an Romanen vom Typ des 'Gil Blas' von Lesage (und damit an der novela picaresca) orientierendes (bzw. auf diesen Roman-Typ zutreffendes) Schelmenroman-Verständnis zugrundegelegt wird, sind beide Romane mit Gewißheit keine Schelmenromane - auch wenn (im Gegensatz etwa zu v. Wilpert) die 'Ich-Form' der Erzählung nicht als unverzichtbare Grundstruktur des Schelmenromans angesehen wird: Bender ist zwar eine "antiheroische, listenreiche Zentralfigur"51) - damit aber noch lange kein Schelm, denn in echten Schelmenromanen ist diese 'antiheroische, listenreiche Zentralfigur" eine "sozial'Tiefstehende"52), die als 'Diener vieler Herren' ein durch seine spezifische "Perspektive von unten"53) konstituiertes satirisches Bild seiner Gesellschaft erstellt. Während der echte Schelm also in dienender stellung steht und oft - wie Gil Blas - innerhalb der bestehenden Gesell- 
schaftsordnung einen echten Aufstieg realisiert, sind Bender (im 'Goldenen Kälbchen'!) seinerseits i h $n$ karikierende 'Diener' zugeordnet; hinzu kommt, daß das, was Bender als soziales Avancement vorschwebt, de facto - nämlich nach überwindung der bürgerlichen Gesellschaft - ein sozialer Abstieg ist: auch hinsichtlich seiner sozialen Stoßrichtung ist ostap Bender also kein Schelm: "Il'f und Petrov benützen also die uralte Tradition des Schelmenromans, um sie zu begraben" ${ }^{4}$ ).

Mit den Kriterien hingegen, die C.G. Jung - auf der Text-Grundlage nicht von Schelmenromanen, sondern von indianischen Schelmenmythen - in seinem Aufsatz 'Zur Psychologie der Schelmenfigur.55) entwickelt hat, ist die rezeptionspsychologische Funktion von Bender (im 'Goldenen Kälbchen'!) sehr genau zu fassen - unter der Voraussetzung freilich, daß Bedeutungsmodifikationen vorgenommen werden, die die Jungschen Kategorien eindeutig aus dem archetypischen in den sozio-historischen Bereich verlagern!

Alle mythischen Gestalten - so auch der Schelm - sind nach Jung zu verstehen als Entsprechungen zu inneren Erlebnissen, als ursprüngliche Resultate psychischer Vorgänge; der Schelm ist also ein 'Psychologema', d.h. eine archetypische psychische Struktur höchsten Alters. Die Frage nach der Funktion dieses Phänomens beantwortet Jung folgendermaßen:

Persönlichkeitsspaltungen - Dissoziationen - gehören zu den frühesten psychopathologischen Beobachtungen uberhaupt: der IchPersönlichkeit ist in komplementärer oder kompensatorischer Relation eine abgespaltene Persönlichkeit zugeordnet, die gleichsam eine Personifikation von Charaktereigenschaften darstellt, die entweder besser oder - meist - schlechter als die der IchPersönlichkeit sind. Diese nirgends fehlende 'inferiore' Persönlichkeit, die einer früheren Bewußtseinsstufe entspricht, die der Ich-Persönlichkeit - dem Ich-Bewußtsein - unsympathisch ist und von ihr folglich in das Unbewußte verdrängt wird, bezeichnet Jung als 'Schatten'. 
Das in allen Mythologien anzutreffende 'Phantasma' des Schelms ist - so Jung - die personifizierte Widerspiegelung dieser früheren - verdrängten - Bewußtseinsstufe und zwar - im Gegensatz zu der "wohldefinierten Gestalt"56), die der individuelle Schatten etwa in Träumen annimit, eine kollektive Personifikation, die "Summierung aller individuellen inferioren Charaktereigenschaften"57). Hieraus, nämlich aus ihrer Teilhabe an der Psyche jedes einzelnen 'Zuschauers', resultiert die Wirkung dieser Schattenfigur.

Merkmal der Schelmengeschichte ist es nun, daß sie diese kollektive Schattenfigur - also die Personifikation der kollektiven früheren inferioren Bewußtseinsstufe - nicht etwa inkompatibel oder unsympathisch, vielmehr interessant, vergnüglich, sympathisch ausgestaltet und damit bei ihren 'Zuschauern' nicht verdrängung auslöst, sondern Bewußthaltung initiiert und so die Voraussetzung für die kritische Auseinandersetzung mit dem Inhalt des Schattens schaff.

Diese in der Lösung der Verdrängung bestehende Überwindung des früheren Bewußtseinszustandes, die bewirkt, daß "das Bewußtsein sich von der Faszination des übels befreien kann und nicht mehr genötigt ist, es zwanghaft mitzuerleben"58), deutet sich innerhalb einer Schelmengeschichte oft in der partiellen Bewußtwerdung des Schelmen selbst an.

Funktion des Schelmenmythos ist somit seine psychotherapeutische Wirkung: er hält dem superioren Bewußtsein den früheren Zustand vor Augen, "damit es nicht vergesse, wie das Gestern aussah"59). Hierbei wirken zwei gegensätzliche Tendenzen, nämlich einerseits die, aus dem fruheren Zustand herauszukommen, andererseits aber die seiner Bewußthaltung.

In einer Fußnote nimmt Jung eine für diese Intentions-überlegungen höchst relevante Ergänzung vor: "Verständlicherweise beeinflußt die Auseinandersetzung mit dem Schatten die Beziehungen des Ich zu inneren und äußeren Gegebenheiten aufs nachhaltigste, denn die Integration des Schattens bewirkt eine Persönlichkeitsveränderung" 60 ). 
Der ganz an der "letzten bestehende Ordnung"61) orientierte Bender des 'Goldenen Kälbchens' kann - mit Jung - hinsichtlich seiner kommunikativen Funktion als personifizierte Widerspiegelung der dieser Ordnung zugeordneten früheren - bürgerlichen Bewußtseinsstufe, d.h. als kollektive burgerliche Schattenfigur aufgefaßt werden. Dieser kollektive Schatten nimmt in ostap Bender (in genauer Entsprechung zu Jung) keine inkompatible, unsympathische Gestalt an - wie es seinem negativen, weil bürgerlichen Gehalt entspräche - ist vielmehr, ganz im Gegenteil, ausgesprochen interessant und vergnüglich - verdrängungslösend aufbereitet: Bender ist intelligenter, gebildeter etc., vor allem aber ungleich witziger und sympathischer als alle andern der alten Gesellschaft zugeordneten Figuren.

Funktion dieses dem kollektiven bürgerlichen Schatten in seiner liebenswerten Personifikation zugeteilten sympathievorschusses ist es, ihn dem an diesem Schatten teilhabenden Leser gleichsam 'schmackhaft' zu machen, dem Leser eine zumindest teilweise Identifikation mit dieser Personifikation nahezulegen - um ihm dann, nach der hieraus resultierenden Aufhebung der Verdrängung, den "Kampf mit den überbleibseln des Kapitalismus in (seinem j.e.) Bewußtsein"62) zu ermöglichen - "denn in jedem von uns gibt es die einen oder andern Züge von Kleinbürgertum, Eigentumsdenken" 63).

Dieser einem Bewußtwerdungprozeß entsprechende 'Kampf' wird durchaus gesteuert - und zwar dadurch, daß dem kollektiven Schatten Ostap Bender, genauer seinen einzelnen Komponenten, die "sich in einem Helden vereinigen"64) (Habgier, Individualismus, Intellektualismus, Ausbeutertum etc.), in Gestalt der eindimensionalen Negativfiguren der Bürokraten, der 'kleinen Welt', der 'Antilopen'-Mannschaft, Lochankin, Korejko u.a. Karikaturen zugeordnet sind, die so eine fortgesetzte Konfrontation des in der Figur Ostap Benders sympathisch eingekleideten kollektiven bürgerlichen Schattens mit seinem eigentlichen, negativen Gehalt ermöglichen. 
Abschließend soll das Problem der 'Darstellung des Positiven in der Satire' - die wohl kontroverseste Frage der aktuellen sowjetischen Satire-Diskussion - kurz reflektiert und einer Lösung zumindest angenähert werden.

Die Analyse-Ergebnisse der hier vorliegenden literaturhistorischen Untersuchung ermöglichen eine von normativen 'Wesens'-Behauptungen (gemeinsamer Nenner: die sozialistische Gesellschaft hat die objektiven Bedingungen für die figurale/argumentative Einarbeitung des Positiven in sowjetische Satiren geschaffen während diese Möglichkeit der vorrevolutionären Satire aufgrund objektiver Bedingungen der vorrevolutionären Gesellschaft verwehrt war) freie Sichtung der Frage: Ist das Positive (die positive Gegenposition) in der Satire (unmittelbar) repräsentierbar? Oder umgekehrt: Ist das Positive der Satire 'wesensfremd'?

Die hier anzustellenden überlegungen, die diese Frage keineswegss erschöpfend behandeln, vielmehr wesentliche Denkanstöße vermitteln wollen, sind rezeptionspsychologisch-kommunikationstheoretisch orientiert, gehen aus von der oben vorgenommenen BereichsKlassifizierung der Angriffsobjekte der sowjetischen Satire und finden ihr implizites Belegmaterial in der überwiegenden Mehrzahl der analysierten Texte.

Angriffsobjekte der Satire sind generell negative - im Ursachenoder Erscheinungsbereich - gesellschaftliche objekte, die entweder die Ausformung des gesellschaftlichen Ideals, für das sich der Satiriker einsetzt, behindern oder aber einen bestehenden gesellschaftlichen Zustand, den der Satiriker für verteidigenswert erachtet, bedrohen.

Während nun die sowjetische Satire-Theorie diese objekte zumeist sehr pauschal als 'überbleibsel' kennzeichnet, schien dem Verfasser eine das Negative in verschiedenen Wirklichkeitsbereichen ansiedelnde Differenzierung erforderlich; diese Differenzierung war relevant für die Interpolation der kommunikativen Funktionen und ist ausschlaggebend für die rezeptionspsychologische Klärung des Problems der 'Darstellung des Positiven'. 
Für die sowjetische Satire wurde als Bereichs-Klassifizierung vorgeschlagen:

1 Außen-Bereich - Die eigene vorrevolutionäre soziopolitische Vergangenheit

- Das kapitalistische/imperialistische Ausland

- Der Gegner in Bürgerkrieg und Weltkrieg II

2 Binnen-Bereich - Konterrevolutionäre Klassen

- Behindernde/gefährdende gesellschaftliche Gruppen, Typen

3 Innen-Bereich - Bürgerliche, aristokratische Idealkonzeptionen

- Bügerliche Ideologien

Basis-Intentionen für alle Angriffs-Bereiche sind die Bewußtmachung einer 'Behinderung', 'Bedrohung' (die Herstellung eines Problembewußtseins) und die Verlachung des anvisierten sozio-politischen Negativen. Über diese Gemeinsamkeiten hinaus ergibt sich folgende Intentions-Klassifizierung:

1 Außen-Bereich - Der Gegner $k$ a $n$ bekämpft werden + er $m$ u B bekämpft werden (Aktionsappell) oder/und

- Legitimierung/Bestätigung der eigenen Gesellschaftsordnung per Nachweis der Negativität des kapitalistischen systems

2 Binnen-Bereich - Appell zur gesellschaftpolitischen und propagandistischen Bekämpfung (politische Ausschaltung oder gesteuerte Integration in die Sowjetgesellschaft)

3 Innen-Bereich - Destruierung verschleppter oder importierter negativer gesellschafticher Bewußtseinsinhalte

Die Konsequenzen für die 'Darstellung des Positiven', für die Einarbeitung der positiven Gegenposition liegen auf der Hand: 
wenn die Satire im AuBen-oder Binnen-Bereich angesiedeltes Negatives anvisiert, ihre Intention also primär darin besteht, einen (als militärischer Gegner, Klassenfeind etc.) faßbaren Gegner als Bedrohung bewuBt zu machen, ihn als der Bekämpfung bedürftig und zugänglich zu decouvrieren - kann sie durchaus sinnvoll direkt zur Aktion auffordern und figurale Leitbilder dazu zur Verfügung stellen (Etwa in Gestalt der den 'gesellschaftlichen Überbleibseln' opponierten Komsomolzen).

Verfolgt die Satire hingegen primär die Intention der Bewußtmachung eigener negativer Bewußtseinsinhalte (insbesondere also: 'Überbleibsel' bürgerlicher Ideologie im Bewußtsein von Sowjetbürgern) - so gefährdet ein figurales positives Identifizierungsangebot die Realisierung dieser Intention: Der Rezipient identifiziert sich mit der positiven Figur, solidarisiert sich mit ihr - verzichtet also auf die intendierte selbst-Bewußtmachung. Denn: indem er sich mit dieser positiven Figur identifiziert, verlacht er auch die negativen Figuren, verlacht er andere nicht sich selbst, faßt er die 'Behinderung', 'Bedrohung' nicht als Element seines eigenen Bewußtseinshaushaltes auf, vielmehr lediglich als in anderen Individuen, Gruppen etc. vorfindlich. Anders gesagt: anstatt sich in die Nesseln der selbsterkenntnis zu setzen, läßt er sich im Fauteuil selbstzufriedenen überlegenheitsdükels nieder. 
Zusammenfassung

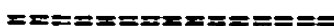

\section{Intention und Vorgehen}

Intention der vorliegenden Untersuchung war die Herausarbeitung der - Tendenzen der Entwicklung des sowjetischen satirischen Romans (1919 1931)'. Dieser Zeitraum wurde nicht willkürlich festgelegt; vielmehr umfaBt er die Zeitspanne zwischen dem Erscheinen des ersten sowjetischen satirischen Romans und der Veroffentlichung des 'Goldenen Kälbchens' von I. Il'f und E. Petrov. Dieser Roman ist nicht nur eine der Spitzenleistungen des sowjetischen satirischen Romans; er ist auch (von wenigen in den letzten Jahren unternommenen und fast ausschlieblich nur auBerhalb der UdSSR veroffentlichten Versuchen abgesehen) der letzte eindeutig dem Genre 'sowjetischer satirischer Roman' zuzuschlagende Text.

Diese Untersuchung bemūhte sich zwar um eine möglichst umfassende Beschreibung des sehr umfangreichen (63 ermittelte/28 zugăngliche Texte) Materials, zentrierte aber zwei Aspekte: die Modifikationen, denen Bestand und Konstitution der Darstellungsobjekte des sowjetischen satirischen Romans wăhrend der 20er Jahre unterworfen waren, sowie zweitens die Diachronie der kommunikativen Funktionen.

Als Instrumentarium zur Textbeschreibung wurde eingangs ein BeschreibungsModell entworfen, das sich an den zentral-K a $t$ e g $r$ i e $n$ des sowjetischen Satire-Begriffs orientierte und für alle Texte einen gemeinsamen Frage-Horizont konstituierte: 'Negativ-Position', 'Positive Gegenposition', 'Historische Perspektive', 'Kommunikative Funktion' und 'SujetKonstruktion'.

Die ermittelten und zugănglichen satirischen Romane wurden nun aber

- in der Regel - nicht etwa Einzel-Analysen unterzogen (dieser Darstellungsmodus schied schon aufgrund der sehr großen zahl von Texten aus). Vielmehr wurde das gesamte verfügbare (und als 'sowjetische satirische Romane' 'akzeptierte') Material einer doppelten Gliederung unterworfen: Namlich erstens einer Grobgliederung nach Maßgabe der Wirklichkeitsbereiche, in denen die satirischen Angriffsobjekte angesiedelt sind (der sowjetische Leser der 20er Jahre als Lieferant der Zuordnungs-Perspektive): 1) 'AuBen-Bereich (der zeit, des Raums und der zeit, des Raums); 2) 'Binnen-Bereich' (des eigenen Sozial-Haushalts); 3) 'Innen-Bereich' (des eigenen Bewubtseins-Haushalts) Diese drei GroBgruppen ('Satire des AuBenbereichs' etc.) wurden sodann einer Feingliederung unterzogen, die Texte mit gemeinsamen Parstërg Ebding - 9783954792788 
gemeinsamen kommunikativen Funktionen etc. zu Untergruppen zusammenfaßte, die entweder - bei hohem Klischierungsgrad u $\mathrm{n} d$ groBer Zahl von Texten als 'Paradigmen', oder - bei hohem Klischierungsgrad a b e r geringer Zahl von Texten - als 'typologische Erscheinungsformen' beschrieben wurden. Nur in einigen wenigen Fảllen waren Einzeltexte Gegenstand von Analysen; nămlich dann, wenn es sich entweder um exponierte Texte handelte, die sich um Uberwindung, Modifikation bestehender 'Paradigmen' bemūhten - oder aber um Texte, die so isoliert standen, daß sie sich einer sinnvollen Eingliederung in andere Untergruppen entzogen.

\section{Ergebnisse}

1919 erschien mit O. L. D'Ors 'Russischer Geschichte bei Warăgern und Vorăgern' der erste sowjetische satirische Roman. Schon er reprasentiert nicht nur die am frühesten einsetzende und bis 1927 eindeutig dominierende Gruppe sowjetischer satirischer Romane, sondern zugleich auch die mit Abstand produktivste Gruppe: mit Sicherheit nicht weniger als 40 Romane sind dieser 'Satire des AuBen-Bereichs' zuzuschlagen, deren Angriffsobjekte zeitlich und/oder răumlich a u B e $r$ h 1 b der Sowjetgesellschaft liegen: Nämlich 1) im Bereich der eigenen sozio-historischen Vergangenheit ('Satire der aristokratischen Agonie'), 2) im in naher Zukunft angesiedelten Bereich der bürgerlichen Gesellschaft 'der letzten Tage' ('Satire der kapitalistischen Endzeit') und 3) im Bereich der zeitgenōssischen kapitalistischen Staaten ('Satire der bourgeois-faschistischen Fratze').

Diese Untergliederung ist aber nicht nur eine Typologisierung nach MaBgabe gemeinsamer Darstellungsmuster etc.. sondern zugleich auch eine Periodisierung nach Maßgabe der jeweils vorherrschenden typologischen Möglichkeiten bzw. Paradigmen: O. L. D'Ors 'Russische Geschichte...' ist der einzige mit Sicherheit identifizierbare und verfügbare Roman der 'Satire der aristokratischen Agonie'. Zwischen 1922 und 1925 dominiert die 'Satire der kapitalistischen Endzeit', zwischen 1925 und 1927 die 'Satire der bourgeois-faschistischen Fratze'. Diese beiden letzteren Textgruppen konkurrieren zwar mit Satiren anderer

'Bereiche', jedoch nicht untereinander!

Weitgehend gemeinsam ist diesen beiden Textgruppen der Figurenbestand: Reprăsentanten der okonomischen und politischen Macht der kapitalistischen Gesellschaft (Bosse, konservative Politiker) sowie deren als 'Prostituierte' ausgewiesene ideologische und exekutive Helfershelfer (Presse, Kunst, Wissen- 
schaft, Milită, Polizei); die 'Satire der bourgeois-faschistischen Fratze' bringt als wesentliche Erweiterung den Faschisten. Gemeinsam sind ihnen auch die Konstitutionsverfahren: plakative Zweidimensionalitat - der BoB ist nur - pauschal - ausbeuterisch, und er ist häBlich: er ist stereotyp eín von Fettwūlsten überquellendes gesichtslos-fettes Schwein (also: totale Korrespondenz von sozialem Wesen und physischem Erscheinungsbild) - allenfalls erweitert um die Dimension der Angst vor der (Welt-) Revolution. Die 'Satire der bourgeoisfaschistischen Fratz' überwindet die Pauschalitat dieser Negativ-Konstituierung und thematisiert insbesondere das politische Verhalten der 'Bosse'.

Die beiden Paradigmen differieren relativ stark bezüglich positiver Gegenposition und kommunikativer Funktion. Die 'Satire der kapitalistischen Endzeit' kontrastiert dem häBlichen $B O B$ als Exponent der Negativ-Position die Positiv-Figur eines kommunistischen Arbeiterführers, der den Merkmalen des Bosses - Brutalităt, Häblichkeit, Angst - die Merkmale (Kinder-) Liebe, sympathisches physisches Erscheinungsbild, das Wissen um und die feste Uberzeugung vom unmittelbar bevorstehenden Sieg der Weltrevolution entgegensetzt. Diese figurale positive Gegenposition wird erweitert um eine argumentative positive Gegenposition: der Arbeiter der kapitalistischen Lănder identifiziert sein gesellschaftliches Ideal mit dem soziopolitischen status quo der UdSSR. Die Interpolation der kommunikativen Funktion der 'Satire der kapitalistischen Endzeit' muB ausgehen von der kommunikativen situation des zeitgenössischen sowjetischen Rezipienten - d. h. aber insbesondere von seiner okonomischen und ideologischen situation: von der ăußerst problematischen Wirtschaftslage in den ersten nachrevolutionăren Jahren, die vielen grundsătzlich prosowjetisch orientierten die Identifikation mit der jungen Sowjetgesellschaft erschwerte. Anders gesagt: die Sowjetgesellschaft bedarf noch in starkem MaBe der Legitimierung, der Glorifizierung zur Stărkung der Identifikationsbereitschaft ihrer Bürger - beides intendieren die 'Satiren der kapitalistischen Endzeit'. Sie gehen aus von der expliziten These der Unausbleiblichkeit der siegreichen proletarischen Weltrevolution; diese von der exponierten Positivfigur vorgetragene These erfahrt in der im Siegder (Welt-) Revolution gipfelnden story dieser Romane ihre Bestătigung. Mit der Bestătigung der Weltrevolutionsthese ist zugleich auch der status quo der Sowjetunion legitimiert: er ist Resultat einer mit GesetzmäBigkeitscharakter erfolgten historischen Entwicklung, ist notwendige (weil gesetzmaBig eintretende) Ubergangsstufe zur formierten sozialistischen Gesellschaft.

Die letzten Texte der 'Satire der kapitalistischen Endzeit' erscheinen 1925. Sie wird abgelöst durch die 'Satire der bourgeois-faschistischen Fratze', die

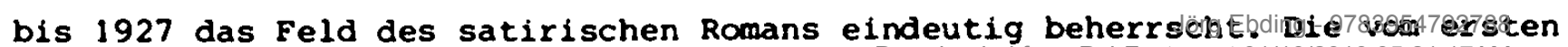


zum zweiten Paradigma erfolgten Modifikationen sind Resultate der verănderten auBen- und innenpolitischen Situation, Resultat der Neupolarisierung innerhalb der Ideologiediskussion: die Weltrevolutionserwartung der frühen 20er Jahre hatte sich nur nicht bestătigt, wurde vielmehr durch die faktische Rechtsentwicklung in vielen kapitalistischen Staaten desavouiert. Die der 'Satire der kapitalistischen Endzeit' zugrunde liegende These war somit unglaubmirdig geworden. 9ie war darüber hinaus innenpolititsch und ideologisch diskreditiert: der nach 1924 verstärkt erfolgende Ausbau der Roten Armee stellte eine in das Budget jedes Sowjetbürgers durchschlagende ökonomische Belastung dar, die der propagandistischen Legitimierung auch mit satirischen Mitteln bedurfte; die Ideologiediskussion schlieblich hatte zur Dominanz des Leninschen 'Sozialismus in einem Lande' gegenüber der Trockijschen Konzeption der Weltrevolution geführt.

Diesen Modifikationen der kommunikativen Situation, der intendierten kommunikativen Funktion trăgt die 'Satire der bourgeois-faschistischen Fratze' Rechnung. Bei wesentlich unverăndertem Figurenbestand und, wie oben angedeutet, modifizierten Konstitutionsverfahren verlagert sie die Handlung aus der nahen zukunft des $\mathrm{N}$-Irgendwo in das kapitalistisch-faschistische Europa der Mitte der 20 er Jahre, ersetzt die Weltrevolutions-Story durch eine Reihung von Kapitalistenund Faschistenportrats, ersetzt den siegreichen Proletarier (alle Romane des ersten Paradigmas enden mit der siegreichen proletarischen Revolution!) durch den verhäßlichten unterdrũckten - aber unbeirrt an seiner Revolutionshoffnung festhaltenden - Proletarier.

Und die Rōte am Horizont der 'Satire der bourgeois-faschistischen Fratze' ist nicht mehx das Morgenrot des sozialistischen Weltbrandes, ist vielmehr antizipierender Hinweis auf den imperialistischen $\mathrm{Krieg,} \mathrm{mit} \mathrm{dem} \mathrm{die} \mathrm{kapitalistischen}$ Staaten die Sowjetunion bedrohen. Denn: der BOB hat sich vom Anti-Kommunisten zum Anti-Bolschewisten gemausert. An die Stelle dynamischer Agonie sind statische antisowjetisch-aggressive HăBlichkeit - und Gefăhrlichkeit! - getreten.

1925 erschloB sich der satirische Roman, der bislang ausschlieBlich die 'zagraničnaja tematika' ('Auslands-Thematik') der HăBlichkeit, Agonie und (mit der ebenfalls 1925 einsetzenden 'Satire der bourgeois-faschistischen Fratze') Gefährlichkeit des kapitalistischen Systems kultiviert hatte, einen objektbereich, für den kleine satirische Formen (u. a. Majakovskijs und Bednyjs Verssatiren, zoscenkos Kurzerzăhlungen) bereits einen festen Bestand an Figuren, Konstitutionsmustern entwickelt hatten.

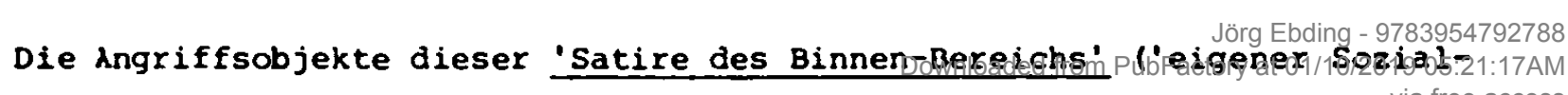
Haushalt'), die zunächst noch (bis 1928) mit 'Satiren der bourqeois-faschi-' 
stischen Fratze' konkurriert, dann bis zum vorlaufigen Erlöschen des sowjetischen satirischen Romans um 1932 das Genre beherrscht: ' S 02 I 0 R E L I K T E. .

'Sozio-Relikte' heiBt einerseits: die aktuelle gesellschaftliche Negativitat dieser Angriffsobjekte - Kleinbürger, SpieBer, Bourgeoisie, Ex-Aristokratie, Bürokrat, Apparatschik, Nöpmann, Intellektueller - wird kausal zurūckgeführt auf den gesellschaftlichen Status, den diese sozialen Gruppen bzw. Typen in der vorrevolutionăren Gesellschaft innehatten. M. a. W.: sie werden dargestellt als Importe aus der bürgerlichen Vergangenheit: als 'Uberbleibsel'.

'Sozio-Relikte' heiBt andererseits: die Darstellung dieser Angriffsobjekte zentriert negative soziale Verhaltensweisen, zentriert nicht diese Verhaltensweisen determinierende, aus der Vergangenheit importierte Denkmuster (Ideologien, Idealkonzeptionen): diese sind Angriffsobjekte der 'Satire des Innen-Bereichs' ('eigener Bewritseins-Haushalt').

Die 'Satire des Binnen-Bereichs' hat drei typologische Moglichkeiten entwickelt: 1) 'Satire des Sumpfes', 2) 'NOP- und Apparatschik-Satire', 3) 'IntellektuellenSatire'.

'Satire des Sumpfes': dieser 'Sumpf' ist die in tiefster Provinz angesiedelte soziale Reduktionsstufe in die Sowjetgesellschaft nicht integrierter, nicht integrationswilliger, nicht integrationsfahiger gesellschaftlicher Gruppen und Typen. Der 'Sumpf' enthălt, die 'Satire des Sumpfes' thematisiert alle von der 'Satire des Binnen-Bereichs' überhaupt erfaBten gesellschaftlichen Negativ-Erscheinungen innerhalb der jungen Sowjetgesellschaft. Die 'Satire des Sumpfes' enthalt also bereits den gesamten Figurenbestand auch der beiden anderen typologischen Moglichkeiten der 'Binnen-Satire'. 'Satire des Sumpfes' einerseits, 'NOP' - und 'Intellektuellen-Satire' andererseits setzen auch ahnliche Typisierungs- und verlachungsstrategien ein.

Drei Tendenzen charakterisieren die Entwicklung innerhalb der 'Satire des Binnen-Bereichs' :

1) Von der 'Totalen' (die 'Satire des Sumpfes' erfaBt alle Angriffsobjekte des 'Binnen-Bereichs') zum Einzelaspekte (der Intellektuelle) oder aktuell zeitspezifische Erscheinungen (der Nöpmann) zentrierenden Zugang.

2) Vom etikettierend-pamphletistischen zum darstellend-verlachenden zugang: Unter dem Gesichtspunkt 'Darstellung oder Benennung' der Negativităt fuhrt die Entwicklung von stark 'benennender' ('Schmarotzer') Pamphlethaftigkeit (Lukašin, 1925) zu völligem Verzicht auf Etikettierung, zu intensivstem Einsatz von Verlachungs-Strategien (Buchov, 1930). Diese Tenderatikeninetohnet//nizohto5nur 7 die 
Entwicklung der 'Satire des Binnenbereichs', vielmehr die des sowjetischen satirischen Romans ganz generell.

3) vom die positive Gegenposition global ansprechenden Zugang ('Satire des Sumpfes':'die junge Generation') zum problemspezifisch appellierenden Nachweis politisch konkretisierter Möglichkeiten zur Lösung der verlachten Negativa:Kommunikative Basis-Funktion der 'Satire des Sumpfes' ist Bewußtmachung bzw. BewuBthaltung des Problems der sozialen 'Uberbleibsel', ihres negativen Sozial-Verhaltens, ist Stärkung des Vertrauens in die positive gesellschaftliche Entwicklung (Generations-Spezifik), schließlich Propagierung der

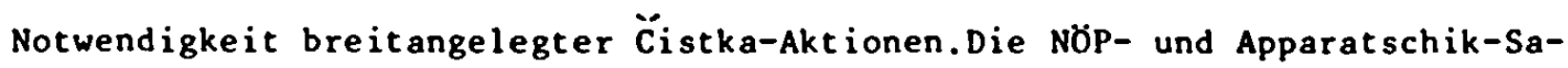
tire' und die 'Intellektuellen-Satire' sind auf drei zentrale kommunikative Funktionen ausgerichtet:a)Begrindung/Popularisierung einer sich auf den staatswirtschaftlichen Apparat konzentrierenden $\ddot{C} i s t k a-P o l i t i k, b)$ Begründung/Popularisierung der beschleunigten Ablösung der Nöp, des beschleunigten ('bergangs zur zentralistischen $\mathrm{Planwirtschaft,c)Bewußtmachung}$ der Gefährlichkeit nur angepaßter 'bürgerlicher Spezialisten' im Bildungswesen, Aufforderung zur $\ddot{C} i s t k a$ dieses Bereichs.

Buchovs antiklerikale Kapitel schließlich propagieren Maßnahmen zur Verbesserung der politischen Bildung und zur Behebung des kulturellen Defizits in der Provinz.

Die 'Satire des Innen-Bereichs' ist die am schwächsten repräsentierte Gruppe sowjetischer satirischer Romane; nur zwei Texte sind eindeutig zuzuordnen: A.Tolstojs 'Ibikus' (1924) und M.Barkanovs 'Erzählung davon,wie Ivan Ivanovic mit Ivan Nikiforovič Frieden schloß'(1927).

Während Angriffsobjekte der 'Satire des Binnen-Bereichs' negative soziale Verhaltensweisen präzis angesprochener sozialer Gruppen bzw. Typen sind,zentriert und verlacht die 'Satire des Innen-Bereichs' vergangenheitslastige Denkmuster (Idealkonzeptionen, Ideologien:'Uberbleibsel der Vergangenheit im Bewußtsein'), die der Entwicklung der sozialistischen Gesellschaft hinderlich sind.Diese negativen Idealkonzeptionen sind $n i c h t$ an präzisierte soziale cruppen gekoppelt (z.B.'für Intellektuelle typische Denkmuster'), vielmehr gerade als den Bewußtseinshaushalt einer $M$ e $h$ r $h$ e $t$ der Sowjetbuirger noch belastende und $z u$ neutralisierende bzw. zu integrierende Faktoren ausgewiesen. Die Referierung der Darstellungsobjekte auf im Bewußtseinshaushalt einer gruppenübergreifenden Mehrheit der Sowjetbiirger angesiedelte Angriffsobjekte wird in der 'Sa- 
tire des Innen-Bereichs' durch zwei 'minus-Verfahren' gesteuert:zum einen wird generell auf die Herausarbeitung negativer sozialer Verhaltensweisen (in der Sowjetgesellschaft!) verzichtet;ebenso generell wird zum andern keine (figurale oder argumentative) positive Gegenposition eingearbeitet, werden dem Rezipienten keine positiven Identifikationsangebote zur Verfügung gestellt.

Zwei typologische Möglichkeiten sind für die 'Satire des Innen-Bereichs' zu identifizieren. Nämlich 1)die 'Satire der Ideal-Zerstörung', die durch A.Tolstojs satirische Großerzählung 'Ibikus' (und, mit großen Einschränkungen, durch V.Kataevs 'Defraudanten') repräsentiert ist.'Ibikus' zerstört, verlacht zwei Idealkonzeptionen,zwei Faszinationen:die 'Faszination durch den Glanz einer aristokratischen Existenz'(zur Verlachung dieser Faszination wird das abstrakte Ideal -'aristokratischer Glanz'- konkreten Vertretern einer absolut glanzlosen Aristokratie konfrontiert) und die 'Faszination durch eine privatunternehmerische Existenz im Goldenen Westen' (auch hier erfolgt die Konfrontation Ideal:Wirklichkeit).

2)Zweite typologische Möglichkeit ist die 'Satire der Ideologie-Zerstörung'. Kommunikative Funktion von A.Barkanovs 'Erzählung davon,wie Ivan Ivanovic̈ mit Ivan Nikiforovič Frieden schloß' ist die Verlachung der Ideologie des alliberlegenen, gottgegebenen Privatunternehmertums. Auch hier ist $\mathrm{e} i \mathrm{n}$ der Decouvrierungs-Strategien die Konfrontation von Schein und Sein, Anspruch und Einlösungs vermögen... Insbesondere erfolgt die Verlachung dieser Ideolgie jedoch über die Verlachung ihres Apologeten (des Erzählers), der mit seinem Argumentationsverhalten seine Unfähigkeit zur Beurteilung politischer und ökonomischer Vorgänge auto-decouvriert.Auch er also (wie A.Tolstojs Nevzorov) ein 'Blickloser'; auch er (wie Nevzorov) Darstellungsobjekt zu Demonstration und Verlachung von Angriffsobjekten im Bewußtseins-Haushalt des sowjet ischen Herrn $X:$ des Lesers.

Den $A b s c h l u B$ der hier nachzuzeichnenden Entwicklungslinie des sowjetischen satirischen Romans der 20-er Jahre bilden die beiden auch außerhalb der UdSSR populären satirischen Romane von I.Il'f und E.Petrov:'12 Stüle' (dieser erstmals 1927 erschienene satirische Roman läßt sich bezüglich Figurenbestand, Konstitutionsmustern,kommunikativer Funktion weitgehend der 'Satire des Sumpfes' subsumieren, hebt sich von den dort analysierten Texten aber durch höhere 'literarische Qualität', starke Einbeziehung humoristischer Elemente und die Einfihrung einer Zentralfigur -der 'große Kombinator' Ostap Bender- $a b$ ); 'Das Goldene Kälbchen'. 
Dieser letzte Roman aus dem Jahre 1931 leistet die satirische Totalisierung der gesamten 'Uberbleibsel'-Thematik.Alle Angriffsobjekte,die die sowjetische Satire der 20-er Jahre in 'Binnen-' wie 'Innen-Bereich' aufs Korn genormen hatte,finden sich hier wieder:aus der bürgerlichen Vergangenheit in die Sowjetgesellschaft verschleppte negative Verhaltensweisen ebenso wie -insbesondere'Uberbleibsel der Vergangenheit im Bewußtsein'.

Die Zentralfigur dieses Romans -ein qualitativ never Ostap Bender- ist eine 'kollektive Schattenfigur' (der C.G.Jungsche Terminus wird hier aus dem archetypischen in den sozio-historischen Bereich verlagert), ist liebenswerte Personifikation des 'kollektiven bürgerlichen Schattens' des zeitgenössischen sowjetischen Lesers.Diese 'kollektive (birgerliche) Schattenfigur' Ostap Bender steht im Knotenpunkt eines Geflechtes karikaturistischer Wechselbeziehungen: alle anderen Figuren dieses Romans (von nur im letzten Teil vorfindlichen positiven Figuren abgesehen) sind Karikaturen einzelner Komponenten dieses 'bürgerlichen Schattens' (Habgier, Individualismus, Intellektualismus, Ausbeutertum etc.). Und eben diese Konfrontation von liebenswerter Zentralfigur einerseits, sie umzingelnden satirischen karikaturistischen Demonstrationsfiguren andererseits steuert den BewußtwerdungsprozeB der Rezipienten dieses Romans.

Neu sind aber nicht nur die in diesem Roman eingesetzten Verfahren der Figurenkonstitution- und Konstellation.Neu (für die Geschichte des sowjetischen satirischen Romans!) ist auch eines seiner zentralen Angriffsobjekte:der Bürokratismus, in anderen sowjetischen satirischen Genres zu diesem Zeitpunkt längst dominierende Thematik.Auch er wird als 'Uberbleibsel der Vergangenheit' ausgewiesen.

'Satirische Totalisierung':während,wie oben festgehalten wurde, die generelle Entwicklungslinie des sowjetischen satirischen Romans in 'Binnen-' und 'InnenBereich' von einer den gesamten objektbestand dieser beiden Bereiche pauschal erfassenden 'Total'-Perspektive zur Zentrierung von Einzel-objekten (der Intellektuelle etc.) füht, steht an Ende dieser Entwicklungslinie wieder eine 'Total'-Perspektive auf den Gesamtbereich der 'Uberbleibsel'; eine Perspektive, deren Resultat freilich grundverschieden ist von den satirischen Romanen des 'Binnen-Bereichs':am Ende steht nicht mehr eine satirische 'Pauschalisierung', am Ende steht vielmehr eben eine satirische 'Totalisierung'. 


\section{Sch luBbemerkung}

'Das Goldene Kälbchen' kennzeichnet -wie erwähnt- einerseits einen der Höhepunkte der bisherigen sowjetischen satirischen Literatur, andererseits aber auch weitgehend einen vorläufigen Schlußpunkt ihrer Entwicklung. Anfangs der 30-er Jahre setzt sich eine satire-feindliche Literaturpolitik durch;das 'bürgerliche lberbleibsel' Biirökratismus ist seit Jahrzehnten dominierender Themenbereich der sowjetischen Satire. Das weitgehende Ausbleiben einer Produktion aggressiver satirischer Literatur wird zwar von allen neueren sowjetischen Satire-Bearbeitern konstatiert und beklagt; die Frage nach den Grüden dieses Auableibens bleibt aber meist ungestellt -dabei sind sie evident.

Der Produktionsspielraum, der dem sowjetischen Satiriker von Kritik und Literaturtheorie zugestanden wird und dessen Grenzen die Negativbegriffe 'Harmlosigkeit', 'fehlende Aggressivität' einerseits, 'Verleumdung', 'Entstellung der Sowjetrealität' andererseits markieren,ist eng;so eng,daß der Weg des Satirikers nur als schwindelerregende Gratwanderung zwischen diesen beiden Abgruinden zu beschreiben ist. 'Abstürze' sind häufig.

Ein signifikantes Beispiel hierfür ist -in jüngerer Zeit-auch L.Lenc̈,der mit seiner Erzählung 'Teure Gäste' (in: 'Trudnaja služba.Satiričeskie i jumorističeskie rassakzy'. M.1967) eine scharfe Apparatschik-Satire vorlegte:Die 'teuren Gäste' sind Kontrolleure einer für den Gaststättenbereich zuständigen Behörde, die ihr Amt dazu mißbrauchen, sich qua passiver Bestechung durchzuschmarotzen; ein von allen Beteiligten durchschauter Amtsmißbrauch-gegen den indes nicmand vorgeht, da man Schwierigkeiten mit der Biirokratie befirchtet. Diese Satire verurteilt Ja. $\dot{l}$ l'sberg ('Voprosy teorii satiry',S.289) mit der Begrüdung,hier werde der Apparat so dargestellt, als produziere er durch sein bloßes Vorhandenund Sosein negative Erscheinungen wie die 'teuren Gäste'.Diese seien vielmehr -wie alle 'bürokratischen Auswüchse'- 'Uberbleibsel der Vergangenheit'.

Sehr treffend charakterisiert I. Érenburg diese Tendenz, die 'tberbleibsel' zum primären Sündenbock für negative Erscheinungen zu machen:

"Wenn wir über die Schattenseiten unseres Lebens sprechen, fügen wir manchmal erläuternd hinzu,es handle sich dabei um 'Uberbleibsel des Kapitalismus'. Zuweilen trifft das zu, zuweilen nicht. Nehmen wir das geläufigste Beispiel: den Bürokratismus... Sollte die Aufblähung der Registratur,die Hypertrophie der Instanzen wirklich nur ein Uberbleibsel sein?Ich halte dafir,daB diese Auswiichse, die zu guter Letzt verschwinden können und müssen, mit dem Ausbau der Organisation, der Statistik, der Produktionskontrolle, mit lauter positiven Dingen also, zusammenhängen."

('Menschen, Jahre, Leben') 
Die aus dieser Kritik zu ziehenden Folgerungen sind von erheblicher Konsequenz für Theorie und Produktion sowjetischer Satire:Basisintention der Satire ist es, die therwindung negativer Erscheinungen in ihren gesellschaftichen URSACHEN zu ermöglichen,zu befördern.Sie ist also ausgerichtet auf einen (noch) besseren gesellschaftlichen Zustand, der die kritisierten negativen Erscheinungen nicht mehr hervorbringt:sie ist also (mit K.Mannheim) 'seinstranszendierend' angelegt.M.a.W.:ihr eignet ein utopischer_Impetus! Eine Satire hingegen, die negative Erscheinungen nur als Importe aus der Vergangenheit anspricht, decouvrier Ursachen nicht, verschleiert sie vielmehr $-w$ e $n$ objektiv von der bestehenden Gesellschaftsordnung hervorgebracht werden;sie ist also nicht (im oben erwähnten Sinne) utopisch, vielmehr ideologisch, d.h.aber:im Interesse der politischen Führung ursachenverschleiernd -damit 'seinskonservierend' ausgerichtet.Stellt also ein im Spannungsfeld zwischen Utopie und Ideologie geborenes lebensunfähiges Zwitterwesen dar. 


\section{Zitatnachwe ise, Anmerkungen}

Vorbemerkung : Ein hinter dem Zitatnachweis stehendes + weist darauf hin,daB dieses zitat zusätzlich zur im Text der Arbeit stehenden deutschen thersetzung im Anhang $z u$ diesen $2 i t a t n a c h w e i s e n$ und Anmerkungen im russischen Originaltext geboten wird. Die $\mathrm{Ziffer}$ des $\mathrm{Zitatnachweises}$ und die des russischen Originalzitates sind -um das Auffinden des Originalzitates zu erleichternjeweils identisch.

Im Gegensatz zu sonstigen slavistischen Dissertationen, die Zitate entweder nur transliteriert oder transliteriert und ubersetzt geben (wobei Transliteration und Ubersetzung im Text der Arbeit unmittelbar aufeinander folgen) wurde hier dieser Modus gewählt. Und zwar aus folgenden Grüden : Diese Arbeit muß, da sie größtenteils außerhalb der UdSSR unzugängliche Texte behandelt, häufig und breit dokumentieren. Da umfangreiche transliterierte $Z$ itate die Geduld des Lesers uber Gebüh strapaziert, ihnen immer hinzugefügte Ubersetzungen den Umfang der Arbeit unerträglich ausgeweitet hätten, werden die $\mathrm{Zitate}$ im Text der Arbeit grundsätzlich in eigener wörtlicher tbersetzung und nur sehr schwer zu ubersetzende (skaz-) Zitate im Anhang zusätzlich in russischer Sprache und kyrillischer Schreibung geboten.

\section{Erster Teil : Voraussetzungen}

1) A.Vulis 'Sovetskij satiriceskij roman.Evoljucija żánra v 20-30-e gody'. Taskent 1965.

2) ebenda S. 5 .

3) L.Eršov 'Sovetskaja satiricéskaja proza 20-x godov'.M.-L. 1960.

4) A.Vulis a.a.0. S. 5 .

5) A.Vulis' Arbeit leidet insbesondere darunter, daß sie -anstatt die satirischen Romane der 20-er und 30-er Jahre nach Maßgabe eines zuvor definierten Fragehorizontes zu b e $s$ c $r e i b$ e $n$ und sie einer die damaligen Produktionsvoraussetzungen mitreflektierenden Analyse ihrer $d$ a m a 1 i $g$ e $n$ kommunikativen Funktion $z u$ unterziehen- sich ganz auf die we $r$ t $n g$ dieser Romane verlegt. Vulis' Wertmaßstab konstitutieren die Romane von I.Il'f und E.Petrov.

6) Es sei nur an D.Bednyj erinnert, der vom hochdekorierten'Barden der Revolution' zum 'Verleumder' der sozialistischen Gesellschaft 'degradiert' wurde.

7) Ja.El'sberg 'Voprosy teorii satiry'. M. 1957.

8) ebenda S. 8.

9) ebenda S. 9.

10)Außerdem führt E.Hyperbel, Allegorie, Groteske, Karikatur, Parodie an. Man sieht: keine saubere Trennung 2 wischen 'objektiver Qualität' (das Komische) und Verfahren der Darstellung negativer Erscheinungen. 
11) N.G.Tschernyschewskij 'Die ästhetischen Beziehurgen der Kunst zur Wirklichkeit'. (Diss. 1855). Berlin 1954. S.141.

12) Ja.El'sberg a.a.0. S.164.

13) ebenda S.163.

14) ebenda S.17 (geschrieben 1957!).

15) ebenda S.18.

16) ebenda S.19.

17) V.Blum 'Vozroditsja li satira?'. In:'Literaturnaja gazeta',1929,6 (27.5.).

18) Zitiert nach Ja.El'sberg a.a.0. S.149.

19) V.Bljum a.a.o.

20) Nach: I.Eventov 'Lirika i satira'. M.1968. S.230.

21) Ebenda.Ausführlicher in: I.Eventov 'Sila sarkazma.Satira i jumor $v$ tvordéstve M.Gor'kogo'. M.1973.

\section{Zweiter Teil : Satire des AuBen-Bereichs (Kapitalismus)}

O) O.L.D'Or 'Russkaja istorija pri varjagach i vorjagach'. Petrograd (Izd.avtora) 1919.

1) A.Vulis a.a.0. S.35.

2) D'Or a.a.o. S.98.

3) ebenda S.102.

4) ebenda S.106.

5) ebenda S.106.

6) ebenda S.55.

7) ebenda S.115.

8) ebenda S.116.

9) ebenda S.119.

10) V.Giršğorn i I.Keller 'Sorvanec Džó.Povest' '. L.-M. 1924. S.13/14. +

11) M.Kozyrev 'Neulovimyj vrag.Amerikanskij roman'. Char'kov (Molodoj rabocij) 1923. S.7.

12) Ju.Okunev 'Katastropha.Social 'no-satiričskaja povest' '. M.-L. (Molodaja guardija) 1927. S.89

13) I.Zlobin 'Zemlja v pautine. (Dal'nie priključenija sibirjaka Chožalova). Povest'v trech cástjach'. M.-L. (ZIF) 1926. S.7.

14) Kozyrev a.a.0. S.3. +

15) ebenda S.36.

16) A. ̈̈ंško 'Gospodin Antichrist'. M.-L. (ZIF) 1926. S.4. 
17) Giršgorn i Keller a.a.0. S.14.

18) ebenda s.17.

19) S̈isko 'Antichrist..'. S.41.

20) Kozyrev a.a.0. S.8.

21) Giršgorn i Keller a.a.0. S.20./21.

22) ebenda S.49.

23) ebenda S.20.

24) Zlobin a.a.0. S.101.

25) Kozyrev a.a.0. S.8.

26) S̈isko 'Antichrist..'. S.77.

27) ebenda S.124.

28) Girşgorn i Keller a.a.0. S.21.

29) ebenda S.20.

30) Vs.Ivanov 'Cudesnye pochożenija portnogo Fokina.Povest' '. L. (Gosizdat) 1925. S.22.

31) Kozyrev a.a.0. S.19.

32) ebenda s.20.

33) Giršgorn i Keller a.a.0. S.50.

34) Kozyrev a.a.0. S.25.

35) S̈iško 'Antichrist..'.S.124.

36) V.Kataev 'Ostrov Erendorf (Jumorticeskij parodijnyj roman)'. (Ural'skij raboclj) 1924. S.7-8.

37) B.Lavrenev 'Krušenie Respubliki Itl' '.(Zvezda) 1925.S.3-6. Zitiert nach :B.Lavrenev 'Sobr.sod'v 6-i tomach'.M.1954,T.4

38) Z.B. die Saginjan-Romane 'Prikljucenie damy iz obscestva.Malen'kij roman' (1923). 'Mess-Mend,ili Janki v Petrograde.Roman-skazka' (1923-1924).

39) Kataev a.a.0. S.498.

40) ebenda S.499.

41) ebenda S.575.

42) S. Anm. 37).

43) P.Medvedev in : 'Vstupitel'naja stat'ja k sobraniju soclnenij B.Lavreneva',T.1. (GIChL) 1931. S.23.

44) A.Lezhev in: 'Pec: i rev.',1926,6. S.208.

45) Etwa 20 Romane, die vermutlich diesem Paradigma zuzuordnen sind,konnten bibliographisch ermittelt werden.Allerdings waren nur wenige Titel verfügbar. 
46) S̈iško 'Antichrist..', s.45.

47) 'Porträt' im Sinne von 'Darstellung des physischen Erscheinungsbildes'.

48) Siško 'Antichrist..', s.33.

49) ebenda S.28-30.

50) A. ̈̈iško 'Konec zdravogo smysla.Fantotičsskaja povest' '. M.-L. (ZIF) 1927. S.105.

51) Sišsko 'Antichrist..', S.46.

52) S̈iško 'Konec..', S.105.

53) S̈iskko 'Antichrist..', S.60.

54) ebenda S.45.

55) ebenda S.87.

56) Sisko 'kone c..', S.80.

57) S̈iško 'Antichrist..', S.78.

58) Sisḱo 'Konec..', S.67.

59) Siško 'Antichrist..', S.81.

60) ebenda S.73.

61) ebenda s.73.

62) ebenda S.106.

63) Sis̀ko 'Konec..', S.95.

64) ebenda S.96.

65) Ivanov a.a.0. S.13/14.

66) Siško 'Antichrist..', S.73.

67) ebenda S.88.

68) ebenda S.44.

69) ebenda S.44.

70) Zlobin a.a.0. S.185. +

71) Ivanov a.a.0. S.52/53.

72) L.Nikulin 'Prodavcy tajn.Satiričskij roman'. M. (Molodaja gvardija) 1928. S.122.

73) Dieses Element ist wohl, nicht paradigmatisch:In den verfügbaren Texten findet es sich nur in Sisko 'Antichrist..'.

74) Siško 'Antichrist..', S.60.

75) Siskro 'Konec..', S.104.

76) Ja.El'sberg a.a.0. Siehe Anm.7 (Teil 1).

77) Ju.Borev 'O komiçskom'. M.1957.

Deutsche Ausgabe Berlin (Aufbau-Verlag) 1960. 
78) S̈isḱo 'Konec..', s.7.

79) S̈iško 'Antichrist..', s.33.

80) ebenda S.4.

81) Sisḱo 'Konec..', S.105.

82) Siehe Exkurs unten $\mathrm{S} .167 \mathrm{ff}$.

83) So in: S.Bel jaev 'Kak Ivan Ivanyc' ot bol'sévikov begal.Formennaja vesc' v duuch cástjach'. L. (Rabočée izdatel'stvo 'Priboj') 1926.

84) Im Vorwort (S.4) zu diesem Roman.

85) Siehe Anm.30 (Teil 2).

86) Ivanov a.a.0. S.48.

87) ebenda S.3.

88) ebenda S.3.

89) ebenda S.3/4.

90) Fokins 'lange Leitung' bei der Einsicht in historische Vorgänge!

91) Der Autor teilt dem Leser zuvor mit, daß Fokin nie 'gekämpft' hat.

92) Ivanov a.a.0. S.6.

93) ebenda S.6.

94) ebenda S.6.

95) ebenda S.10.

96) Komisch vor allem auch per Rückkoppelung auf den 'intelligent', der damit in den 'Kleinbürgermief' -dem er sich unendlich überlegen wähnt- herabgezerrt wird.

97) Ivanov a.a.0. S.9.

98) ebenda S. 28.

99) ebenda S. 35 .

100) ebenda S. 35.

101) ebenda S. 39.

102) ebenda S. 40.

103) ebenda S. $41 / 42$.

104) ebenda S. 33.

105) ebenda S. 48.

106) ebenda S. 49.

107) ebenda S. 46.

108) ebenda S.48/49.

109) ebenda S. 49. 
110) ebenda S. 50.

111) ebenda S. 53.

112) ebenda S. 21.

113) ebenda S. 15.

114) ebenda S.15.

115) ebenda passim S. 42-46.

116) ebenda S. 42 .

\section{Dritter Teil : Sonderfall Erenburg}

1) I.Erenburg - 'Neobycájnye pochożenija Chulio Churenito i ego učénnikov...' . Berlin 1922 .

- 'Trèst D.E. Istorija gibeli Evropy'. Berlin 1923.

-'Burnaja ż́zn' Lazika Rojt 'švaneca'. Berlin 1929.

2) J.Holthusen 'Russische Gegenwartsliteratur I ', Berlin-Minchen 1962. S.135.

3) I.Erenburg 'Sobr.soc': v 9-i tomach',M.1962.

4) Il ja Ehrenburg 'Die ungewöhnlichen Abenteuer es Julio Jurenito und seiner Jünger....'. München 1957.

5) Erenburg 'Sobr.soc'...', T.1, S.219.

6) Ohne Zweifel stand I.Erenburg um 1920 stark unter dem Finfluß der Kulturund Geschichtsphilosophie 0.Spenglers ('Der Untergang des Abendlandes. Umrisse einer Morphologie der Weltgeschichte'. 1918-1922).

7) Unten wird -der leichteren Lesbarkeit wegen und um die Nationalität der Figuren nicht immer eigens signalisieren zu mussen- die hier in Klammer stehende Graphie gegeben.

8) Erenburg a.a.0. S.11.

9) ebenda S. 12 .

10) ebenda S. 12.

11) ebenda S. 219.

12) ebenda S. 10.

13) ebenda S. 38.

14) ebenda S. 19.

15) ebenda S. 115.

16) ebenda S. 5 .

17) ebenda S. 66 .

18) ebenda S. 65. 
19) ebenda S. 69.

20) ebenda S. 81.

21) ebenda S. 82 .

22) ebenda S. 82 .

23) ebenda S. 112.

24) ebenda S. 112.

25) ebenda S. 156.

26) ebenda S. 156.

27) ebenda S. 176.

28) ebenda S. 216.

29) ebenda S. 174.

30) ebenda S. 164.

31) ebenda S. 177.

32) ebenda S. 160.

33) ebenda S. 141.

34) I.Ehrenburg 'Die ungewöhnlichen Abenteuer...'.

35) ebenda S. 236.

36) ebenda S. 236.

37) ebenda S. $239 / 240$.

38) ebenda S. 241.

39) ebenda S. 242.

40) I.Erenburg 'Sobr.sod:' S.217.

41) ebenda S.217.

42) ebenda S.219.

43) ebenda S.219-220. Es sei nochmals auf Julio Jurenitos paradoxe Argumentationsweise hingewiesen:er verabscheut die bestehenden 'Staatsleviatane' und opponiert ihnen visionär 'gigantische Staaten' mit einer 'Architektur' -einer 'Kultur' also- die nur per Hyper-Organisation produzierbar ist.

44) ebenda S. $220 / 221$.

45) ebenda S. 34.

46) ebenda S. 280.

47) ebenda S. $231 / 232$.

48) ebenda S. 228.

49) Siehe auch unten : 'Desorientierend und desorientiert'.

50) V.Kataev 'Ostros...'.'. (Siehe Anm. 36, Teil 2), S. 533.

51) ebenda S. 532 .

52) ebenda S. 587 . 
53) ebenda S. 604.

54) ebenda S. 604.

55) ebenda S. 524.

56) ebenda S. 586.

57) I.Ehrenburg 'Menschen, Jahre, Leben' (1961-1965), S. 506.

58) ebenda S. 507.

59) I.Erenburg 'Sobr.soc':' S.5.

60) Die Arboit an 'Julio Jurenito..' nahm nur einen Monat (Mitte Juni bis Mitte Juli 1921 im belgischen Exil nach der Ausweisung aus Frankreich) in Anspruch!

61) I.Erenburg 'Sobr.soc::',S. 7.

62) ebenda S. 304.

63) ebenda S. 252.

64) ebenda S. 259.

65) ebenda S. 270.

66) ebenda S. 383 .

67) ebenda S. 380 .

68) ebenda S. 248.

69) ebenda S. 248.

70) ebenda S. $272 / 273$.

71) ebenda S. $370 / 371$.

72) ebenda S. 346.

73) ebenda S. 252.

74) ebenda S. $347 / 348$.

75) Nachwort in:I.Erenburg 'Sobr.so'c:', S.528-532.

76) ebenda S. 251.

77) ebenda S. 296.

78) ebenda S. 378.

79) Nur L.Vulis befaßt sich a.a.0. mit Lazik'Rojšvanec'.

80) Was keinesfalls besagt, daß sich I.Erenburg die Ideologie antibolschewistischer revanchistischer Emigrantengruppen (die er vielmehr in 'Julio Jurenito' wie in 'Lazik Rojtśvanec' verhöhnt) zu eigen gemacht hätte!

81) I.Erenburg 'Lazik Rojtš́anec..', Berlin 1929. S. 248.

82) ebenda S. 34 .

83) ebenda S. 258.

84) ebenda S. 261.

85) ebenda S. 260.

86) ebenda S. 262. 
Vierter Teil: Satire des Binnen-Bereichs (Eigener Sozial-Haushalt

1) A.Tolstij 'Pochoždenija Nevzorova ili Ibikus' (1924). S.u.

2) I.Lukašin 'Gorod Perepljuj.Povest' '. Izd.'Proletarij'. (ohne Jahr,ohne Ort.Erstausgabe laut Vulis in der Reihe 'Nedra', Kniga vos'maja 1925).

3) Wie bi den Roman-Satiren des Außen-Bereichs.

4) Irmer mit dem Vorbehal: de: bibliographischen Ermittelbarkeit

5) Zum Begriff des 'obyvatel' 's.u. Anm.14.

6) S.u. unter 'Verlachungs-Strategien'.

7) A.Buchov 'Tstorija trech svjatych i netotarych postaronni:ch.Satiriceskij roman'.M. (Akcionernoe izdatel'stvo 'Bezboznik') 1930

8) ebenda S. 13.

9) Beide Romane von I.Il'f und E.Petrov bleiben in diesem Kapitel unberiicksichtigt!

10) Lukaš in a.a.0. S. S.

11) Ju.Slezkin 'Kozel v ogorode.Povest' '. 'Moskovskoe tovariscestvo pisatelej', 1927 .S. $72 / 73$.

12) Buchov a.a.0. S. 74 .

13) abenda s. 53.

14) 'Obvvatel'' wird hier Bleichresetzt mit 'gesellschaftliche Uberbleibsel': in diesem Wortgebrauch iberlanden sich die beiden Grundbedeutungen von 'obvvatel'' (nach Ozerov) : l.Einwohner des zaristischen Rußlands; 2. Soießbuirger-die 'Uberbleibsel' sind eben die sewesenen 'Einwohner..' (genauer: deren privilegierte Schichten). die unter veränderten historischen Bedinsungen zu'Soießern' degenerieren.

15) 'Istoriia SSSR s drevnejšich vremen do našich dnej v duch serijach i 12-i tomach'. M. 1967.T.VIII.S. 66.

16) Lukašin a.a.0. S. 7.

17) Buchov a.a.0. S. 114 .

18) ebenda S. 116.

19) ebenda S. 114.

20) ebenda S. 44.

21) Lukašin a.a.0. S. 127.

22) ebenda S. 127.

23) ebenda S. 69.

24) Buchov a.a.0. S. 116. 
25) Lukašin a.a.0. S. 94.

26) ebenda S. 82.

27) Buchov a.a.0. S. 114 .

28) ebenda S. 121.

29) s.u. 'Zolotoi telenok'.

30) Slezkin a.a.0. S. 56.

31) ebenda S. 61 .

32) ebenda S. 57.

33) So ein heute in der UdSSR kursierender Spottvers.

34) Lukašin a.a.0. S. 41/42.

35) N.Nikitin 'O byvsem kupce Chropove ob Olimpiade Ivanovne $i$ o veselom chudoznike Mokine.Povest''. M.-L. (Cosizdat) 1926. S.27

36) Lukaš in a.a.0. S. 26.

37) Hier wird ein Motiv angesprochen, das die antiklerikale Satire (s.u.) breit thematisiert, das aber auch in allen 'Satiren des Sumpfes' zu finden ist : das Motiv des 'obyvatel'" - Glaubens an 'Zeichen'.

38) Lukas in a.a.0. S. $8 / 9$.

39) ebenda S. 79.

40) ebenda S. 26.

41) ebenda S. 26.

42) ebenda S. 4.

43) N.Gogol' 'Ženit'ba': 'Soč. v dvuch tomach', M. 1966 ,T. 2 s.130.

44) Lukasin a.a.0. S. 57.

45) Slezkin a.a.0. S. 83.

46) Buchov a.a.0. S. 112.

47) Lukašin a.a.0. S. 27.

48) ebenda S. 64.

49) Nikitin a.a.0. Dassim S.3-5.

50) Buchov a.a.0. S. 69.

51) Lukašin a.a.0. S. 128.

52) Buchov a.a.0. S. 123.

53) Lukašin a.a.0. S. 40.

54) ebenda S. 46/47.

55) ebenda S. 127.

56) Buchov a.a.0. S. 43. 
57) ebenda S. 44.

58) ebenda S. 114.

59) Zum NöP-Begriff s.u. Exkurs S.167 ff.

60) Es sei daran erinnert,daß unter 'Decouvrierung' hier nicht 'Aufdeckung der Negativität' verstanden wird,vielmehr grundsätzlich 'Aufdeckung der Lächerlichkeit etc.' der Negativ-Figuren.

61) Lukas in a.a.0. S. 79.

62) Slezkin a.a.0. S. 58.

63) ebenda S. 141.

64) ebenda S. 105.

65) ebenda S. 58.

66) Slezkin a.a.0. S. 79.

67) ebenda S. 130.

68) Lukašin a.a.0. S. 30.

69) N.Nikitin

70) S.u. 'Zolotoi telenok'.

71) Lukašin a.a.0. S. 48 .

72) ebenda S. 79.

73) Slezkin a.a.0. S. 61.

74) Lukašin a.a.0. S. 86.

75) V.Majakovskij 'O drjani'. In ders. 'Satira', M. 1962 ? S. 9.

76) Lukašin a.a.o. S. 27.

77) Ungeachtet starker Uberfrachtung mit satirischen Angriffs-objekten.

78) Buchov a.a.0. S. 4.

79) ebenda S. 31 .

80) ebenda S. 33.

81) ebenda S. 32 .

82) Sprecher ist der Vorsitzende des Gorsovet einer Provinsstadt.

83) Buchov a.a.0. S. 130.

Zapachins einziges Fronterlebnis bestand darin,daß er von Soldaten -denen er Durchhalte-Reden hielt- im Schützengraben verprügelt wurde.

84) Lukašin a.a.0. S. 46.

85) ebenda S. 77.

86) Buchov a.a.0. S. 78.

87) ebenda S. 116.

88) Lukašin a.a.0. S. 82.

89) ebenda S. 47. 
90) ebenda S. 84.

91) ebenda S. 94.

92) 1924.

93) ebenda S. 94.

94) ebenda S. 94.

95) ebenda S. 134.

96) ebenda S. 85.

97) ebenda S. 87.

98) S.Zajaickij 'Yiznȩopisanie Stepana Aleksandroviča Lososinova. Tragikomiceskoe socinenie'. M.-L. (Gosizdat) 1928.

99) So ein Provinzarzt bei Slezkin -dieser ist zugleich allseits geschätzter Arzt und lächerlicher Schwafler : "ein enger Spezialist ohne ideologische Basis" (a.a.0. S. 146.).

100) 'Im engeren Sinne des Wortes' : im heutigen sowjetischen Sprachgebrauch ist der 'obyvatel" nicht mehr Spießer u n d sozio-politisches 'Uberbleibsel'; er ist nur noch der 'Spießer'.

101) Slezkin. S.u. unter 'Sujetkonstruktion'.

102) Genauer: als harmlos dargestellte.

103) Lukašin a.a.0. S. 100.

104) S.u.

105) Der am intensivsten 'verlachende' (s.u.) Roman iber den 'Sumpf'.

106) Slezkin a.a.0. S. 144.

107) Lukašin a.a.0. S. 84 .

108) ebenda S. 86.

109) ebenda S. 67.

110) Slezkin a.a.0. S. 149.

111) Lukas in a.a.0. S. 54.

112) Lukašins exponierte Positivfigur Anton ist Lieferant all dieser Etiketten.

113) ebenda S. 67.

114) Slezkin a.a.0. S. 72 .

115) ebenda S. 73 .

116) Lukašin a,a.0. S. 48.

117) ebenda S. 75 .

118) Dieser 'Decouvrierungs'-Begriff ist so allgemein, daß er nichtssagend ist: insbesondere legt er nicht fest, ob unter 'Decouvrierung' Merkmale der Textkonstitution oder eine mehr oder wenig zufällig (durch undefinierte Konstruktionsprinzipien) erzielte Rezeptionswirkung zu verstehen ist. 
119) Siehe insb. Ju. Mann 'Komedija Gogolja 'Revizor' '. M. 1966.

120) U.a. aus diesem Grunde sind 'Krokodil', 'Perec' etc., die einen sehr engen Themenkreis monokultivieren,zu wesentlicher Wirkungslosigkeit verurteilt.

121) Nach 1925 ! -erst jetzt setzt die Produktion von satirischen Romanen des 'Binnen-Bereichs' ein.

122) So Lukašin.

123) So Buchov.

124) Es versteht sich von selbst, daß auch eine Satire ohne intratextuelle Negativ-Decouvrierung extratextuell -nach Maßgabe des Erwartungshorizontes des Rezipienten- decouvrierende', ihm bisher nicht bekannte oder bewußte etc. Problemstellungen 'aufdeckende' Wirkung haben kann. Diese Wirkung ist aber keine satire-spezifische,kann vielmehr von beliebigen 'Textsorten' erzielt werden.Hier interessieren aber gerade satire-spezifische Rezeptionswirkungen,d.h. solche Wirkungen, die von Text mit spezifischen Mitteln satirischer Text-Konstitution gesteuert werden.

125) Die 'Roten' sind auch 'schöner'. S.u. unter 'positive Gegenposition'.

126) Insbesondere die Herstellung dieser historischen Distanz ist im Verein mit dem problemharmonisierenden Schluß der 'Geschichte...' problematisch: sie legt es nahe, das (insbesondere im 3.Teil) thematisierte Problem als historisch erledigt anzusehen -dort nur zu lachen, wo auch gekämpft werden müßte (Aufgabe der Aktivierungspotenz der Satire).

127) Die satiretheoretische Literatur läßt m.W. eine einigermaßen vollständige Katalogisierung der wichtigsten satirischen Vernichtungsverfahren vermissen;dabei ist das Repertoire einigermaßen stabil.

128) Lukašin a.a.0.

129) ebenda.

130) ebenda.

131) ebenda.

132) ebenda.

133) Buchov a.a.0. S. 65.

134) Lukasin a.a.0. S. 10/11.

135) Buchov a.a.0. S. 47.

136) ebenda S. 121.

137) ebenda S. 130.

138) ebenda S. 83.

139) Lukašin a.a.0. S. 48.

140) Buchov a.a.0. S. 67.

141) ebenda S. 103. 
142) ebenda S. 140.

143) Eine der bei Buchov iberaus seltenen direkten Negativ-Benennungen.

144) ebenda S. 151.

145) Diese Koppelung wird bis zu 'Zolotoj telenok' unverändert beibehalten.

146) Slezkin a.a.0. S. 166.

147) ebenda S. 136.

148) Versatzstiuck der gesamten 'Binnen-Satire' der 20-er Jahre.

149) Slezkin a.a.0. S. 146.

150) Buchov a.a.o.

151) ebenda S. 72.

152) Lukas in a.a.0. S. 58.

153) ebenda S. 68.

154) ebenda S. 53.

155) ebenda S. 154.

156) Diese positive Wendung, mit der der Roman schließt,bleibt freilich rein deklarativ: die story selbst endet mit der Niederlage der exponierten Positivfigur (mit dem Sieg also der 'obyvateli), und es bleibt unklar, wodurch jene 'geschwächt' worden sein sollen. Bitterböse story und aufgesetzte optimistische Schlußdeklaration stehen also in uniberbrückbarem widerspruch.

157) ebenda S. 135.

158) Negativfiguren proletarischer Herkunft gibt es in keinem der satirischen Romane des 'Binnen-Bereichs'.

159) Wie bereits erwähnt, umspannt Buchovs dargestellter Zeitraum die zehn Jahre von 1914-1925. Fir die 'Satire des Sumpfes' relevant ist insbesondere der $1923 / 24$ spielende 2 .Teil.

160) Nach dem Ideologie-Begriff von K. Mannheim: 'Ideologie und Utopie', Frankfurt 1952 (3. Auflage).

161) V.Majakovskij .Siehe Anm 18) (1.Teil).

162) Vulis a.a.0.

163) Buchov a.a.0. S. 74.

164) Der Leser weiß längst, daß die 'heilige.Frau' de facto ein diebisches Flittchen ist.

165) ebenda S. $75 .+$

166) ebenda S. 77.

167) ebenda S. 78.

168) ebenda S. $120 / 121$.

169) ebenda S. 147.

170) ebenda S. 164. 
171) ebenda S. 164 .

172) ebenda S. 147 .

173) ebenda S. 123.

174) R.Lorenz 'Anfänge der bolschewistischen Industrienolitik'. Köln 1965. S. 15.Anm. 2 .

175) Zahlenansaben nach K. -H. Ruffmann (Sowietrußland -Struktur und Endfaltunp einer Weltmacht'. München 1971 (3.Auflare).S. 101.

176) ebenda S. 102.

177) Zahlen nach Ruffmann a.a.0. S. 103.

178) Zahlen nach 'Sowjetgesellschaft im Wandel. RuBlands Wer zur Industrieresellschaft'. Hrsp. B.Meissner. Stut trart 1968. S. 37.

179) B.S.E..M. 1949.T.30.S. 66.

179a) S.Anm. 15 (4.Teil)

180) B.S.E.a.a.O. S. 66 .

181) Istori ia SSSR.S. 66.

182) B.S.E. a.a.O. S. 66.

183) L.Grabar' 'Lachudrin Dereulok.Povest' '. L. (Proboi) 1926.

184) Ju.Berzin 'Ford. Roman!

L. (Priboj) 1928 (2.Auflage)

185) Ein positiver Nöpmann ist natürlich undenkbar -hier stellt sich dieses Konstitutionsproblem also nicht.

186) Berzin a.a.0. S. 23-28.

187) Die NöP-Satire gerät hier auf widerspruchsvolles Terrain: einerseits verlacht sie den kleinbirgerlichen Antisemitismus, andererseits sind ihre Nöpmänner fast ausnahmslns Juden.

188) Die 'Bürschchen' sind Nöpmänner des zweiten Tvps; Sprecher ist ein Nöpmann ersten Trps.

189) Gome ' $^{\prime}$ ist im satirischen Roman der 20-er Jahre stereotyd d i e Hochbure iüdischen Kleinbüreertums (s.z.B. auch I.Erenburg 'Lazik roitsvanec').

190) Berzin a.a.o. S. $9 / 10$.

191) Ein 'Petrograd' qibt es 1925 nicht mehr -es wurde 1924 in 'Leningrad' umbenannt: der Nöpmann hinkt hinter der Zeit her.

192) Berzin a.a.0. S. 10.

193) Grabar' a.a.0. S. 25.

194) Berzin a.a.o. S. 39.

195) ebenda S. 66.

196) ebenda S. 72.

197) Grabar'a.a.o. S. 28. 
198) Berzin a.a.0. S. 173.

199) Ford bleibt aber Randfigur und ist insbesondere für eine an komunikativen Funktionen orientierte Interpretation -von seiner KommentatorFunktion abgesehen- irrelevant.

200) Grabar' a.a.0. S. 37.

201) Berzin a.a.0. S. 22.

202) ebenda S. 117.

203) ebenda S. 117.

204) Ford hat natülich Ford (Henry) im Auge.

205) ebenda S. 59.

206) ebenda S. 51.

207) Der positive Kommissar stellt die Frage.

208) ebenda S. 101.

209) S.Anm. 118,124 (4.Teil).

210) Grabar' a.a.o.

210a) Diese Vorliebe signalisiert zugleich die Vergangenheitslastigkeit dieses 'Denkens'.

211) Garbar' a.a.0. S. 4.

212) Ihre Funktion in einer NöP-Satire wird die Analyse der Komissare ergeben.

213) Andere relevante Gründe für dis spyte Erschließung der Dorf-Thematik fuir die Satire: der Bauer (zum größten Teil noch analphabetisch) kommt aus objektiven wie subjektiven Gründen als Rezipient satirischer fomane noch 7 icht in Frage;der Bauer muß aufgrund der schlechten Lage auf dem Nahrungsmittelmarkt geschont (bei Produktionslaune gehalten) werden.

214) Die Bauern treten episodisch als Kollektivfigur in Erscheinung -es gibt keine einzige exponierte Bauern-Figur;ihre Negativität wird durchgehend direkt benannt.

215) B.Meissner a.a.0. (Anm. 178,4.Teil) gibt den Anteil von Bauern und Heimarbeitern an der Cesamtgesellschaft für $1928 \mathrm{mit} 72,9 \%$ an.

216) Es sei betont, daß die Etikette 'Apparatschik' abweichend vom bürgerlichen Wortgebrauch wertfrei die funktionale Zugehörip,keit zum Apparat (Leitungsorgane in Wirtschaft und Verwaltung) bezeichnet.

217) Berzin a.a.0. S.15-17.

218) 1926 -die NöP ist noch nicht offiziell liquidiert-geschrieben!

219) Berzin a.a.0. S. 74.

220) ebenda S. 56.

221) ebenda S. 78 .

222) Sprecher ist Ford.

223) ebenda S. 102 . 
224) S.auch u. unter 'Kommunikative Funktion'.

225) Ein 'Argument' liefert Berzin: "Die neue Bourgeoisie dringt uberall ein...verdirbt den staatlichen Apparat... Massenprozesse.. Bestechungen.... Veruntreuungen". (a.a.0. S. 173).

226) Alle Angaben sind textbezogen -nicht Projektionen historischer Informationen auf die Texte!

227) Berzin a.a.o. S. 193.

228) ebenda S. 32 .

229) V.Chomutov 'Kassir Kol'cugin.Roman'. M.-L. (ZIF) 1927.

230) Berzin a.a.o. S. 191.

231) So subsumiert A.Vulis etwa folgende ( 40 Oktav-Seiten umfassengde) Erzahlung unter den 'satirischen Roman': Sven i Al.Grigorovic ' Cudo na syrych bolotach. Satiriceskaja chronika'. L. (Veselaja biblioteka Begemota) 1926.

232) 'Intelligent' bedeutet im $h$ e u $t$ i 8 e $n$ sowjetyischen Sprachgebrauch: 'ein Mensch,der der intelligencija angehört' (Ozegov).

'Intelligencija' wiederum bedeutet: 'Soziale Schicht,die aus Geistesarbeitern besteht, die über Bildung und Spezialwissen auf den verschiedenen Gebieten von Wissenshcaft, Technik und Kultur verfügen' Ozegov). Dieser 'intelligent'-Begriff darf hier nicht angesetzt werden.' Intelligent' wird also zur Vermeidung von Mißverständnissen nicht mit 'Intelligenzler' sondern mit 'Intellektueller' ibersetzt.

233) Slezkin a.a.0. S. 105.

234) ebenda S. 100.

235) ebenda S. 99.

236) s.Anm. 98 (Teil 4).

237) Ort der Handlung ist vorwiegend Moskau.

238) Zajaickij a.a.0. S. 16-22. Man beachte den intellektuellen RevolutionsBegriff.

239) ebenda S. 19-20.

240) ebenda S. 20.

241) ebenda S, 21 .

242) ebenda S. 22.

243) ebenda S. 22.

244) Das Gefasel von der 'reichen russischen Seele' ist gängiges Versatzstück der sowjetischen Intellektuellen-Satire.

245) ebenda S. 22

246) ebenda S. 53.

247) ebenda S. 62.

248) ebenda S. 79.

249) ebenda S. 77.

250) ebenda S. 79. 
251) ebenda S. 122 .

252) ebenda S. 122. Stereotypes Verfahren der sowjetischen IntellektuellenSatire ist die Selbst-Stilisierung der Intellektuellen nach historischen oder -vorzugsweise- literarischen Vorbildern :'Literarisierung der Existenz'.

253) ebenda S. 122/123.

254) So z.B. auch Lochankin in 'Zolotoj telenok' (s.u.).

255) ebenda S. 141.

256) ebenda S. 143.

257) ebenda S. 144.

258) ebenda S. 144 .

259) ebenda S.144.

260) ebenda S. 144 .

261) ebenda S. 144.

262) Diese Äußerung stammt natürlich gerade $n i c h t$ von Lenin-sondern von Trockij.

263) ebenda S. 158.

264) ebenda S. 166.

265) ebenda S. $177 / 178$.

266) ebenda S. 182.

267) ebenda S. 183.

268) ebenda S. 184.

269) Während der Roman offen läßt, ob Lososinov eine lebensgefährliche Erkältung,die er sich als Folge seiner Samariter-Pose zugezogen hat, überleben wird, macht er deutlich,daß seine Intellektuellen-Kollegen auch weiterhin den Lehrkörper sowjetischer Schulen stellen.

270) Zajaickij a.a.0. S. 166.

Auch dieser satirische Roman verzichtet also nicht auf eine leicht ironisierende Konstituierung der figuralen positiven Gegenposition -das im Kontext 'deplacierte' Brot-Teilungs-Anliegen- zur Reduzierung des die positive Gegenposition oft kennzeichnenden Pathos. 
Fünfter Teil: Satire des Innen-Bereichs (Eigener Bewußtseins-Haushalt)

1) A.Tolstoj 'Pochoždenija Nevzorova ili Ibikus', 1924.

2) V.Kataev 'Rastratciki', 1925.

Zitiert nach: V.Kataev'Sobr.soč. v 9-i tomach'. M. 1969.T. 3.

3) M.Barkanov 'Povest' o tom kak pomirilsja Ivan Ivanovič s Ivanom Nikiforovicen'. M.-L. (Gosizdat), 1927.

4) Barkanov ist ein literaturhistorisch völlig unbeschriebenes Blatt; Angaben zu Person und (eventuell sonstigem) Werk konnten nicht ermittelt werden.

5) Tolstoj a.a.0. S.344.

6) ebenda S. 471 .

7) ebenda S. 345 .

8) ebenda S. 430.

9) ebenda S. $467 / 468$.

10) ebenda S. 359.

11) ebenda S. 447 .

12) ebenda S. 345 .

13) ebenda S. 353.

14) ebenda S. 355.

15) ebenda S. $366 / 367$.

16) ebenda S. 373.

17) ebenda s. 410.

18) ebenda S. 384.

19) ebenda S. 410.

20) ebenda S. 417.

21) ebenda S. 425 .

22) ebenda S. 424 .

23) ebenda S. 443/444.

24) V.Kataev 'Rastratčiki',a.a.0. S. 13.

25) ebenda S. 56.

26) ebenda S. 58 .

27) ebenda S. 56 .

28) ebend a S. 59.

29) L.Eršov 'Sovetskaja satiričeskaja proza 20-x godov' (s.Anm.3,3.Teil), S.246. 
30) Eine völlig unlogische Steigerung -als sei Gogol für die Gestaltung seines Denkmals verantwortlich zu machen.

31) Grammatik-Fehler, der mangelhafte Bildung signalisiert.

32) Barkanov a.a.0. S. $7 / 8$.

33) a)Spießer-Ästhetik; b) Stibruch.

34) Symbol der 'kleinen Welt'.

35) Barkanov a.a.0. S. 8.

36) ebenda S. 31 .

37) ebenda S. $51 / 52$.

38) ebenda S. 71.

39) ebenda S. 73.

40) ebenda S. 88.

Die 'Schwarzhundertschaftler' - 'Cernosotency' - waren eine vorrevolutionäre politische - rechtsradikale- Gruppierung.

41) ebenda S. 88 .

42) ebenda S. 77 .

43) ebenda S. 78.

44) ebenda S. 78.

45) ebenda S. 78.

46) ebenda S. 79.

47) ebenda S. 99.

48) ebenda S. 99.

49) ebenda S. 102.

50) ebenda S. 103.

51) ebenda S. 105.

52) ebenda S. 117.

53) ebenda S. 101.

54) ebenda S. 6.

55) ebenda S. 61 .

56) ebenda S. 11 .

57) ebenda S. 13.

58) ebenda S. 8.

59) ebenda S. 41.

60) ebenda S. 71 .

61) ebenda S. 71.

62) ebenda S. 66.

63) ebenda S. 124. 
64) ebenda S. 81.

65) ebenda S. 66/77.

66) ebenda S. 16.

67) ebenda S. 14.

68) ebenda S. 15.

69) ebenda S. 15.

70) ebenda S. 91.

71) ebenda s. 83.

72) ebenda S. 92.

73) ebenda S. 62.

74) Die Vokabel 'Revolution' wird euphemistisch vermieden. Ähnlich: "Die Sowjetmacht da.Sie entschuldigen diesen Ausdruck...". (S. 44.).

75) ebenda S. 51.

76) ebenda S. 101.

77) 'im städtischen Bereich': ein Integrationsproblem also, das den größten Teil des potentiellen Rezipientenkreises betrifft!

Sechster Teil: Satirische Totalisierung (Die Romane von I.Il'f U.E.Petrov)

1) '12 stul'ev'. Erstausgabe in ' 30 dne j',1928,1-7. Zitiert nach : I.Il'f-E.Petrov '12 stul'ev',M. 1968. (Im Folgenden kurz ' $12^{\prime}$ )

2) 'Zolotoj telenok'. Erstausgabe in 30 dne j',1931,1-7 + 9-12. Zitiert nach: I.Il'f i E.Petrov 'Zolotoj telenok', New York 1954. (Im Folgenden kurz 'Z.T.)

3) In den letzten Jahren entstandene Dissidenten- und Samisdat-Satiren bleiben unberücksichtigt.

4) S.o.

5) So insbesondere A.Vulis a.a.0. und ders. in I.Il'f - E.Petrov 'Očerk tvorcestva', M, 1960.

6) A.Vulis 'sovetskij satiričeskij roman....', S. 175.

7) Die Parodierung dieser Schablone besteht darin,daß die -durch den Popen repräsentierte- Konkurrenzgruppe gleich zu Anfang auf eine falsche Fährte und damit für die Schatzsuche außer Gefecht gesetzt wird. 
8) ' 12 ', S. 9 .

9) ebenda S. 20.

10) I.II'f,E.Petrov 'Sobr.soč.v 5-i tomach',M. 1961, T. 2.

11) '12', S. 39 .

12) Damit ist eines der großen sozialen Probleme der 20-er Jahre angesprochen: das Problem der Jugendlichen, die während der Bürgerkriegs jahre ihre Eltern verloren und als -oft kriminelle-Banden von 'Obdachlosen' durch die Provinz vagabundierten ( S. Makarenko 'Pedagogiceskaja poèma').

13) '12', S. 39 .

14) ebenda S. 39.

Bender ist ein verkappter 'bosjak' -'Barfüßler'.

15) ebenda S. 34.

16) ebenda S. 298.

17) Im Lotmanschen Sinne.

18) ' 12 ', S. 210.

19) L.Janovskaja 'Počemu vy pišete smešno ? Ob Il'fe i Petrove,ich žizni i ich jumore'. M. 1961, S. 93.

20) '12', S. 73 .

21) Ja.El'sberg a.a.0. S. 335 .

22) ' 12 ', S. $42 / 43$.

23) ebenda S. 121.

24) Die Erstueröffentlichung in ' 30 dnej' erfolgte mit der Genre-Bezeichnung 'Roman-chronika'.

25) ' 12 ', S. 186 .

26) ebenda S. 186.

27) S.u. unter 'Funktion O.Benders in 'Z.T.'.

28) 'Istorija russkogo sovetskogo romana', M. 1965, T.1, S. 268.

29) L.Janovskaja a.a.0. S. 42.

30) B.Galanov 'Il'ja Il'f i Evgenij Petrov.Žizn'.Tvorcěstvo'. M. 1961 .

Vorob'janinovs tatsächliche 'Evolution' besteht darin,daß er sich nach und nach 0staps Sprüche -stotternd (und dadurch wird er nur noch lächerlicher)- aneignet;sprachliche Improvisational la Ostap gelingt inm aber nach wie vor nicht:" I.M. wollte irgendeine Gemeinheit sagen und hatte zu diesem Zweck sogar schon den Mund geöffnet, aber es fiel ihm nichts ein" ('12', S. 98).

31) B.Galanov a.a.0. S. 137 .

32) A.Vulis 'l.Il'f....', S. 193.

33) I.Il'f ,F.Petrov 'Sobr.soc.....'s. $513 / 514$.

34) 'Z.T.', S. 34 . 
35) ebenda S. 35.

36) ebenda S. 35 .

37) ebenda S. 178.

38) ebenda S. 110.

39) ebenda S. 129.

40) ebenda S. 187.

41) ebenda S. 231.

42) Titel der deutschsprachigen Erstausgabe,Berlr:Wien-Leipzig 1932.

43) 'Z.T.', S. 117 .

44) ebenda S. 347.

45) ebenda S. 403.

46) Ja.El'sberg a.a.0. S.338.

47) A.Lunaçarskij 'Stat'i o sovetskoj literature',M. 1958,S. 459/460.

48) U.Gaier 'Satire.Studien zu Neidhard,Wittenwiler,Brant und zur satirischen Schreibart', Tübingen 1967, S. 343.

Der Absolutsetzung der Struktur 'Repräsentanzobjekte' für 'gesichtslos Drohendes', die Gaier als überhistorisches Wesensmerkmal des Satirischen ansieht, kann ich mich jedoch ebensowenig anschließen wie der absoluten Festlegung satirischer Konstitutionsverfahren (Verzerrungsverfahren etc.) auf die Funktion von Rückübersetzungssignalen : der Bourgeois etwa wird in der sowjetischen Satire nicht zu einem gesichtslos-fetten Schwein verzerrt um so ein Rückübersetzungssignal zu setzen; diese Verzerrung intendiert vielmehr seine Verlachung.intendiert die Suggestion von Superioritätsbewußtsein etc.!

49) W.Lettenbauer 'Russische Literaturgeschichte', Wiesbaden 1958 (2.Auflage), S. 304 .

50) J.Hol thusen a.a.O. Bd. I, S. 131.

51) G.v.Wilpert 'Sachwörterbuch der Literatur', Stuttgart 1969 ( 5 . Auflage), S. 683 .

52) J.Striedter 'Der Schelmenroman in Rußland. Ein Beitrag zur Geschichte des russischen Romans vor Gogol' ', Berlin 1961, S. 31.

53) v.Wilpert a.a.0. S. 683.

54) 'Istorija russkogo sovetskogo romana', S. 275.

55) C.G.Jung,K.Kerény.j,P.Radin 'Der göttliche Schelm -ein indianischer Mythenzyklus', Zürich 1954.

56) ebenda S. 205.

57) ebenda S. 204 .

58) ebenda S. 200.

59) ebenda S. 201.

60) ebenda S. 206.

61) ebenda S. 174 .

62) B.Gorbatov 'O sovetskoj satire i jumore.Zametki pisatel.ja'. In: 'Novy.i mir',1949,10,S.215-229; S.217.

63) Malachov 'Smech' . In:'Literaturnaja gazeta' 1939,15.4Jörg Ebding - 9783954792788

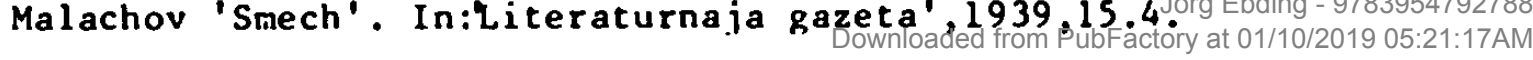




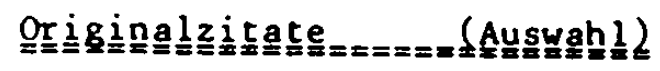

Zweiter Teil: Satire des Außen-Bereichs (Kapitalismus)

IO Hav известно, что вы и ненормальный фантазер Смирнов мечтаете

о раскрепощения рабочих от каписталистического ига...

Сначала $я$ и мои коллеги по всемирной кампании "Капитал" смеялись над небольшими заметками, просачивающимися в мутнуо грязь бульварных газет, и двумя болванами...созидарщими пуниверсальные јучи", пель которых ....... я can не знак, что..... Но если половина из того, что пишут газеты правда, то.... я сам не знар, что!...

I4 Мистер Бебеп известен на всех островах, полуостровех и континентах старого и нового света, но мало кто видел мистера Бебеша. И если мы позволим себе маленькуо нескромность и заглянем в его кабинет /.../ - то мы все равно не увидим мистера Бебеша: мы видим только /.../ огромнуо кучу из брок, сортука, галстука и белоснекного воротничка, -и на всей этой куче- розовуо пирамиду, своим основанием опирапщуося на белоснежный воротничек.

Пирамида зта лишена абсолотно всякой растительности и на ней нельзя различить никаких углубленй или возвыпений, которые давали бы намек на существование у мистера Бебеша глаз или носа, и нухно потратить порядочное время на изучение географии этой головы, чтобы с первого взгляда узнавать, где находится у мистера Бебеша передняя часть или лидо и где - задняя часть или так называемый затылок.

70 В приемной "правителя" было дупно и тихо. Генералы в орденах и штатские одеты тщательно и старокодно, и даже разные старухи-просительницы "тянулись" невероятно.

Теряя под собой почву, они стали теперь .. во много раз "превосходительнее" и "милостивогосударнее" .

В приемной было тихо, несмотря на толпу. Гула голосов не было, стоял какой-то почтительный шум, похохй не на гудение пчел, а на тарахани порох в теплом месте за печьр.

-Bame пре..ство...

-Его пр..сход......

-Его выс.. пре..ход...

88 Портно Фокин сидел все время спокойо. Был он сутул, как павлодарские заборы, криворук, и на один глаз косил, да и все на нем было на один бок, так что удивлялись павлодарские комиссары: И откуда у него такая достоверность в игле?!

89 И вот накануне вербного воскресенья сидит Фокин, Иван Петрович, у себя на верстаке, хозяйка квартирная вербы ему принесла, рыбой праздничной пахнет, а на верстаке й стульях френчи накроены, неимрверное количество френчей. Со всего уезда, а мохет со всего семипалатинского округа, заказывали Фокину френчи. 
Смотрит Фокин на френчи зти и говорит хозяйке: -А как вы полагаете, Гликерия Егоровна, долго мне придется шить френчи?

-А Френчи вам, Иван Петрович, я полагар, шить долго придется, так как воина не окончилась.

-Как так, Гликерия Егоровна, вонна не окончидась,? Чан, завтра вербное воскресенье дваддать третьего года, а последним-то кто с нами воевал? Поляки, -это в котором Году было? Вов попу, сказывают, какой-то племянник из столицы коробку папироснуо прислал, и можно различить на ней градданские иоды... -Так ведь это картинки, Иван Петрович, а вам-то все заказывапт Френчи. Кабы воина закончилась, зачем заказывать им бы френчи? Оглянулся Фокин, и точно: вся комната френчами заросла, дахе будто дышать трудно.

92 -А если, говорит Фокин, -если я, Гликерия Егоровна, Френчи пить откахусь?

-Через почему вы зто откахетесь, Иван Петрович?

-А через потому, что не хочу я воевать больше, Гликерия Егоровна, через потому, что хочу пить грахданские фасоны./.../ Тут через тюрьму все граддане прошли, мохет и Јенин прошел, которые создали росефесоре и иир народам. Вы ке, грахдане, продолжаете шить френчи, не переходите на мирное положение, втайне надеясь на воину! А я воины не хочу и вам, мирным лодям, Френчи шить не буду, я портной штатский и вду от вас штатских заказов..."

І03 Плюнул и пошел тихонько от дворда./.../ Счастье я думал найт, братишки, товарищи, в птатских фасонах. Получается кругом кукиш или, по-сибирски, фига. Наблюдар я, наблюдаб, и мутит меня от Штатского платья, которое дошло вплоть до охоты на свиней, не говоря о худшвх мелочах.

IC9 -Так, -протянейше сказал Фокин: -а комитет вам, часом, не заявлял, когда он власть в наши руки передаст? -Позвольте, Иван Петрович... -Нет уж вы мне позвольте, Генадй̆ Семеныч, по порядку дня и постольку, поскольку мы являемся представителями Советского Союза, и когда за нами -да....ы к этим делам насчет организапии привыкли и завсегда непорядки видим так как представители рабочих и крестьян.Скахем первое слово, заседание хорото. А при чем тут бал и бессмысленное расходование народного имущества? Загогулина!

II -Піепчет совсем смятенно Фокин /.../ :

-Парень, да ведь это сплошь контр-револодия и возор..

тут ведь так влипнуть мохно.. Нет, брат, пойдем/.../ от греха подальше: тут такой заговор, тут такая игра, что мне ни один комиссар, не только что френча, подштанники не закахет. 
II5 -Ребятишки, товарищи, вы на меня надейтесь, я, ребятишки, не выдам, я всем там скаку про вас, -так, мол, и так видел, мол, все портной Фокин и решил, -хдать невозмохно /.../ . Я, может быть, самому Владимиру Ильичу скаху так, я всей красной армии и, мохет быть, за сввные их охоты, чека скаху /.../ И с радости начал тут Фокин врать, и врал так, что самому страшно до оснобы стало, и оглядывался он очень часто... /.../ ... что пятьдесят миллионов пролетариев, одетых в одехду, придуманнуо им, Фокиньм, и вооруяенных танками, пойдут скоро на Европу, разденут догола всех буркуев и заселят ими киргизские степи, что Тродкий в мундире, спитом Фокиньм, хдет, когда приготовят достаточное количество химического газа, который обладает способностью вытравливать всех не советских русских, живущих заграницей и придумывающих заговоры.

Vierter Teil : Satire des Binnen-Bereichs (Eigener Sozial-Haushalt)

76 Как вы относитесь к советской власти, спративают...

Меня, господа товарими, трудно пойнать. $K$ примеру, оно хотя и мелочь, что я пишу в деловых записках "господин", а не "грахданин, а для меня это совсем не мелочь. Вопрос -как чувствуо: "Г", тире и "н"... Придепись подалуй....

І65 Из Рязанской губернии к нам прибыл /.../, -великие чудеса там сделал...Исделенные толпами ходили за ним.. Слепых лечил, хромых лечил, припадочных.. В лесах хитался, воду ключевуо пил .../.../. А с ним и уверовавшие в него кивут.. Женщина одна святая .. - Анна-мученнида, да слепед Василий... -Слепед, говоришь...

-Слепед. Теперь все видит, а раньше слепдом был.. .Святой Игнатий и испелил.. - Бросился слепед Василй ему в ноги и говорит: "Отеп Игнатй, прозреть хочу". А тот спокойненько так: "Прозри,отрок..."..

- Да что ты, говоришь .... Отрок, значит? ...

-Ну да, отрок.Раньше отроком был, а теперь уже не отрок...

I73 то есть и сволочь же народ /.../. Еыл я в зтой самой ихней Лысовке... Есть у них в сельсовете два таких оголтелых... Партейды.. Добегались, дохлопотались -им амбулаторию выстроили, больнида такая, что хоть в город ее. И доктора два, молодые, толковые. Лечат, что называется, на ять... И всегда полно, а вот находятся такие, что сода лезут... Ословєе племянники... А ведь смотрите, Игнатий Анемподистович, взрослые люди.. От больницы $x$ графским лепепкам бегут... Зубным порошком лечатся да лошадиным пометом... Эх, люди, дюдешечки... 
270 Настоящим мы требуем:

Первым на перво: организовать при школе комячейу. Вторьм на перво: чтоб учиться как сказанно.

Третьи на перво: иконы снять.

Четвертьм на перво: хлеб делить самим, а не экономке. Такой есть тохе закон.

И вообще чтоб в школьном совете состоять, как прочие члены.

Fünfter Teil: Satire des Innen-Bereichs (Eigener BewuBtseins-Haushalt)

32 Подумаешь, какая птида-Гоголь! Если он писал, так будто никто другой ухе не знает И.Н. или И.Н. Что он, в сущности, Гоголь? Даке на памятнике, что в Носкве -никакого вида: Баба ли вяхет чулок, хивот ли у него болит -ничего понять невозмохно.

35 Нет ух, я попрошу..хотя и зто не вполне скромно, но читатель, надеюсь, не осудит такую дальновидность, я попрошу на памятнике изобразить меня в приличествующей муху позе: если мохно -на коне, а если нельзя коня, как-нибудь так, чтобы фигура внупала уважение: в семейном хругу или еше как-нибудь, я не знаю. А Гоголем,узвольте, ни малейшего хелания не имер быть.

37 Зато вполне достоин упоминания тот факт, что грахдане тотчас хе после переворота оказались все за республику: давай им республику, и больше ни о чем слушать не хотят... /он / не иначе выходил из дому как с пышным бантом цвета вареной свеклы.

62 В отдаленном будудем неизвестно, что произойдет. Мохет быть, в отдаленном будущем у нас бананы будут расти, мохет быть, дахе машину для ловли блох изобретут, но хить до зтого на вольном воздухе и той хе единственной атмосферой питаться -благодарствуйе.

63 Надехда на возврат бдагополучных дне рохдается в стененном гонениями уме. Персты складываотся в известнур комбинадир, и уста произносят: неизвестно еще, как оно, колесикото истории повернется.

65 Россия, кто тебя созидал? И.И. тебя созидал,И.Н. украшал твой пейзах.. и мало что сами кушали -других кормили.

И мало что хили -другим давали хить. 
70 Была пора и прошла. Настали суровые дни, и заглохла гралданская хизнь. Свободнуго торговдо запретили, на просвещенных лодей открыли гонение и .. ограничили в употреблении воздуха, атмосферы, так сказать, лишили: после полохенного часу не на ухпу выйти .. стелется тишина .. с треском рвется грубым хохотом патруля, повисатщи в запрещенном для грахдан воздухе. В чуткий сон невинных дев вторгается похабная ругань .. стучит .. стон обреченной жертвы.

75 Я не буду утверхдать, что переворот явился прямњ сдедствием странноН истории С И.И.-чевым боровом..но.. получится картина загадочная. Хотя бы уже то, что оба происшествия, так сказать, одного порядка. Никогда до того не было в науке известно, чтобы млекопитахее и хрокаюе могло совершить побег в заколотом виде. Й так де совершенно никто в мире не предполагал, чтобы в россйской империи могла оказаться республика. Все-таки не буду ничего утверхдать, потому что в этом погут усмотреть политику.

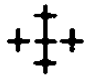




\section{Lit ther}

\section{Primärliteratur}

\section{a) B Behandel tre_Texte}

Wo nicht die unten angefürten Originalausgaben verwendet werden konnten, finden sich Angaben über die benutzten Werkausgaben in den jeweiligen Anmerkungen $(s .0$.$) .$

Barkanov,M. 'Povest' o tom kak pomirilsja Ivan Ivanovic s Ivanom Nikiforovicem'. M.-L. 1927.

Beljaev,S. 'Kak Ivan Ivanyç ot bol'ševikov begal. Formennaja vešc' v dvuch castjach'. L. 1926.

Berzin,Ju. 'Ford.Roman'. 1928 (2.Auflage).

Buchov,A. 'Istorija trech svjatych i nekotorych postoronnich.Satiriceskij roman'. M. 1920.

Erenburg,I. - 'Neobyčajnye pochoždenija Chulio Churenito i ego učennikov...' Berlin 1922.

- 'Trèst D.E.Istoriia gibeli Evronv'. Berlin 1923.

- 'Burnaia zizn' Lazika Rojsvaneca'. Berlin 1929.

Ciršgorn.V. i Keller.I. 'Sorvanec Džo. Povets' '. L.-M. 1924.

Grabar'.L. 'Lachudrin dereulok.Povest' '. L. 1926

Il'f.I. i Petrov.E. -'12 stul'ev'.1928.

$$
\text { -'Zolotoi telenok'. } 1931 .
$$

Ivanov.Vs. 'Zudesnve Dochoždeni ia Dortnozo Fokina. Povest' '. L. 1925.

Kataev.v. -'Ostrov Erendorf (Jumorističeski; Darodijnyj roman)'. 1924. -'Rastratčiki'. 1925.

Kozyrev,B. 'Neulovimyj vrag.Amerikanskij roman'. Char'kov 1923.

Lavrenev,B. 'Krǔ̌enie Respubliki Itl' '. 1925.

Lukašin, I. 'Gorod Perepljuj. Povest' '. 1925.

Nikitin,N. 'O byysem kupce Chropove ob Olimpiade Ivanovne $i$ o veselom chudoznike Mokine. Povest' '. M.-L. 1926.

Nikulin,L. 'Prodavcy tajn. Satiričeskij roman'. M. 1928.

Okunev,Ju. 'Katastrofa.Social'no-satiričeskaja povest' '. M.-L. 1927.

D'Or,0. 'Russkaja istorija pri varjagach i vorjagach'. Petrograd 1919.

Slezkin,Ju. 'Kozel v ogorode. Povest' '. M. 1927.

Suchotin,P. 'Višni dl ja kompota.Roman'. M.-L. 1927 
Siško,A. -'Gospodin Antichrist'. M.-L. 1926.

-'Konec zdravogo smysla.Fantasticeskaja povest' '. M.-L. 1927.

Tolstoj,A. 'Pochoždenija Nevzorova ili Ibikus'. 1924.

Zajaickij,S. j'̌izneopisanie Stepana Aleksandroviča Lososinova.Tragikomiceskoe sočinenie'. M.-L. 1928.

Zlobin,I. 'Zemlja v pautine. (Dal'nie priključenija sibirjaka Chožalova). Povest' v trech castjach'. M.-L. 1926.

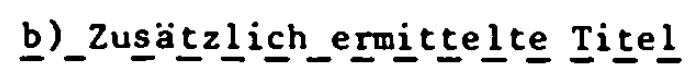

Bibliographisch ermittelte Texte, die nicht zugänglich waren. Diese Literaturangaben erfolgen mit dem Vorbehalt, daB die unten angefühten Texte von Forschung, Satire-Theorie und Bibliographien zwar als 'satirische Romane' klas-

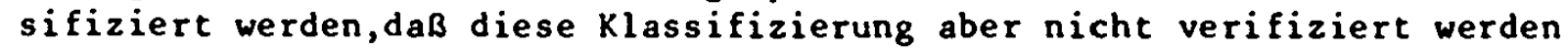
konnte.Dieser Vorbehalt hat umso mehr Gewicht,als es sich bei einer ganzen Reihe von Texten, die insbesondere A.Vulis 'als 'satirische Romane' ausweist, herausstellte, daß es sich bei ihnen (auch bei großzügigem Begriffs-Verständnis) keinesfalls um satirische Romane handelt.

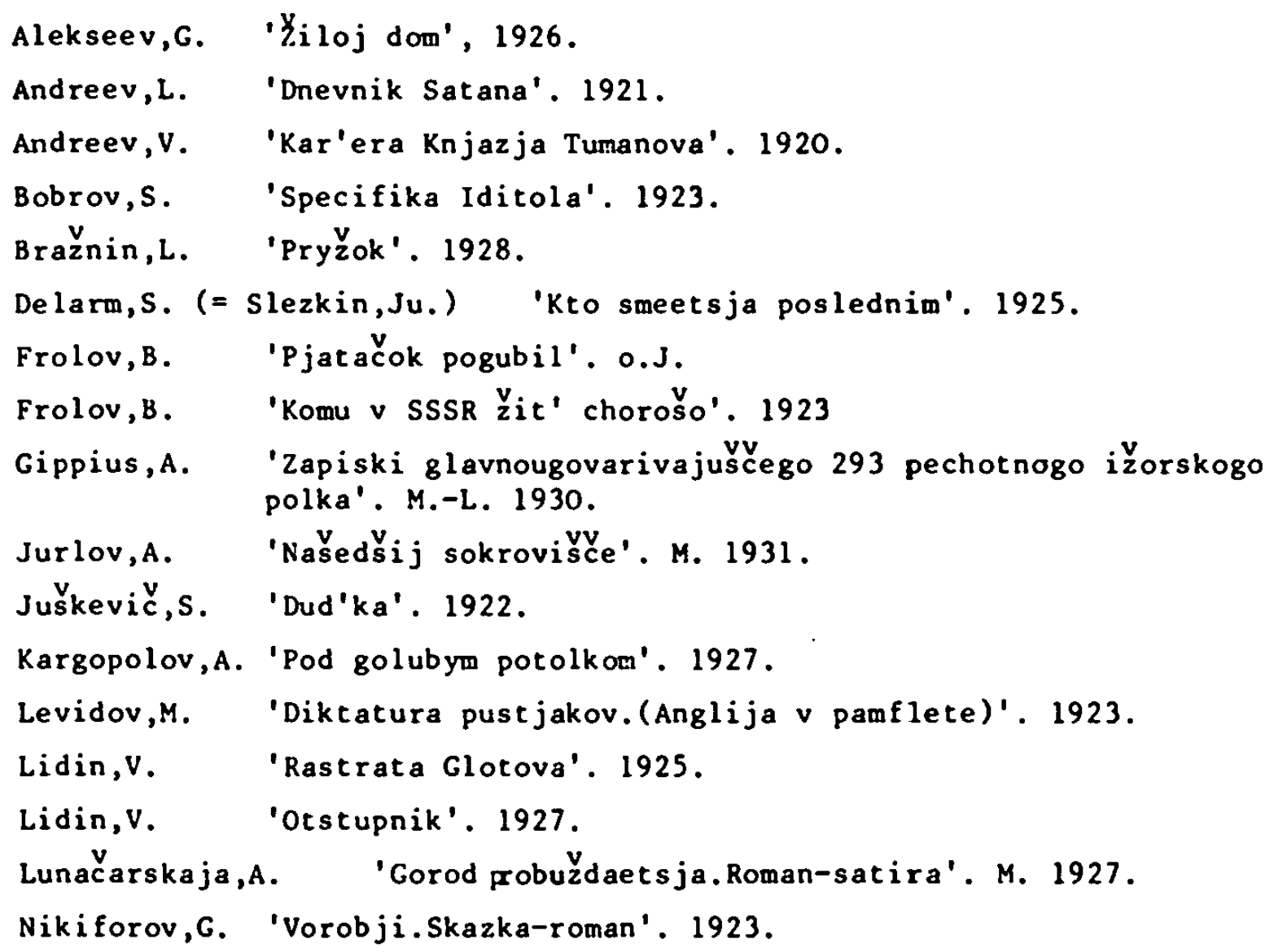




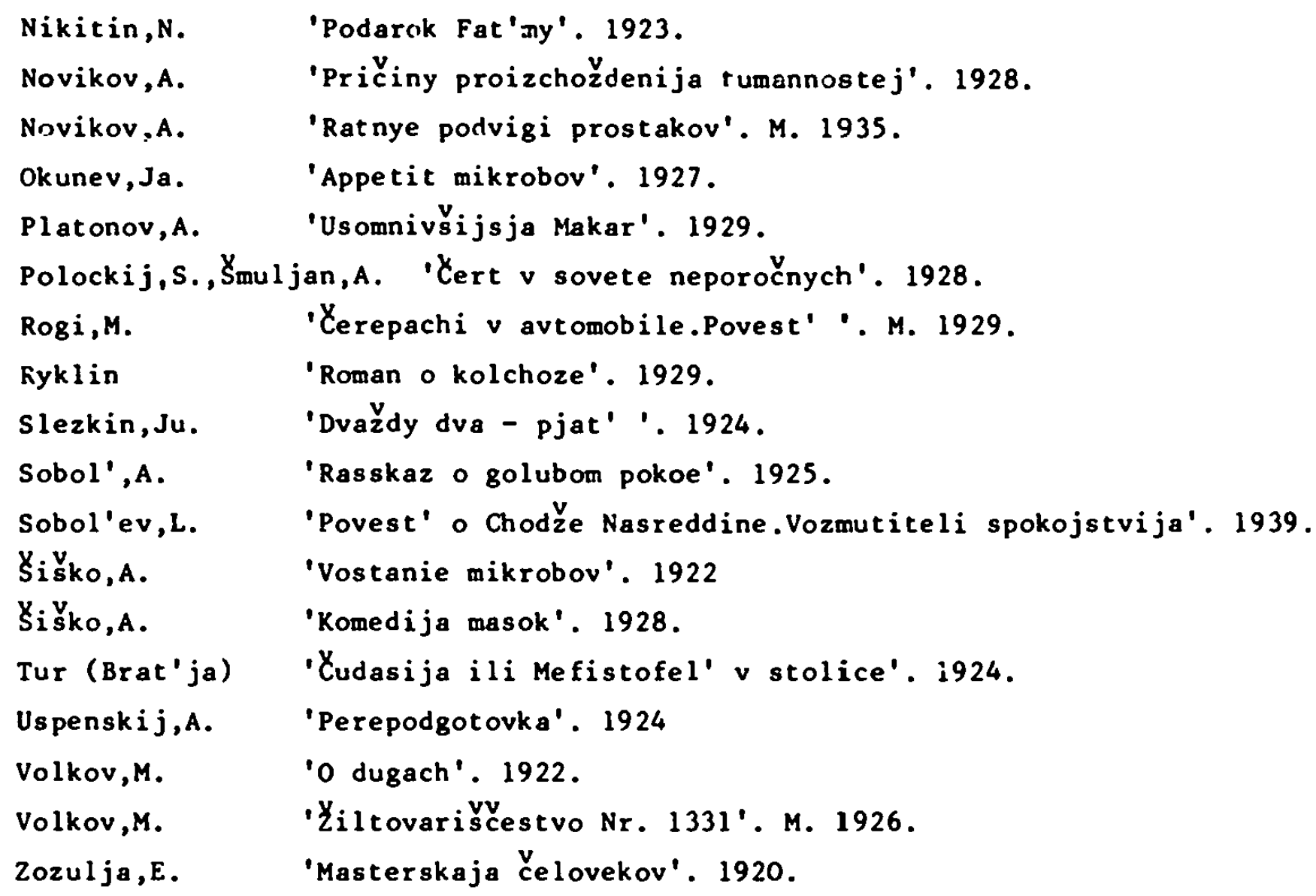

\section{Spezial-Bibliographie}

Ozmitel',E. 'Sovetskaja satira.Seminarij.Posobie dlja studentov'.M.L. 1964.

\section{Sowjetische Satire- und Komiktheorie, Satire- und Komikdiskussion}

a) Monographien

$\begin{array}{ll}\text { Borev,Ju. } & \text { 'O komičskom'. M. } 1957 . \\ \text { Dzeverin, I. } & \begin{array}{l}\text { 'Problemy satiry v revoljucionno-demokratičskoj èstetike'. } \\ \text { Kiev } 1965 .\end{array} \\ \text { Galjavin,A. } & \text { 'Jumor i satira v sovetskoj poèzii!.Ul'janovsk 1960. } \\ \text { El'sberg,Ja. } & \text { 'Nasledie Gogolja i Scedrina i sovetskaja satira'. M. } 1954 . \\ \text { El'sberg,Ja. } & \text { 'Voprosy teorii satiry'. M. } 1957 \\ \text { Eventov, I. } & \text { 'Lirika i satira'. L. 1968. }\end{array}$


Nikolaev,D. 'Smech - oruzie satiry'. M. 1962.

Safir,Ja. 'Ot ostroty do pamfleta'. L. 1925.

Dzemidok,B. 'O komiceskom'. (Aus dem Polnischen). M. 1974.

Neubert,W. 'Die Wandlungen des Juvenal. Satire zwischen gestern und morgen'. Berlin (DDR) 1966.

b) - Auf $\underline{\text { äg }}$ ze

Diese Auswahl wird zur Verdeutlichung der Entwicklungstendenzen der SatireDiskussion in chronologischer Anordnung gegeben.

Bcgdanov,A. 'Tajna smecha'. Molodaja gvardija, 1923, 2, 175-180.

Kryneckij,N. 'O krasnom smeche.K diskussii o fel'etone'. Krasnaja pecat', 1923, 20,7-10 (17.7.).

Safir, Ja. 'Počemu my nye umeem smejat's ja?' Krasnaja pecat' $, 1923,17,6-8$.

Tynjanov,Ju. 'Literaturnoe segodnja'. Russkij sovremennik, 1924, 1, 301.

Safir,ja. 'Komiceskie i satiriceskie priemy (k charakteristike satiriçeskoj zurnalistiki 17-ogo goda)'. Zurnalist, 1924, 9-10, 25-27.

Bek, A. 'Lico rabocego citatelja'. Rabocij citatel', 1925,6, 16 .

Maevic , A. 'Jumor i satira'. Zurnalist, $1925,4,45-46$.

Zurbina,E.

'Sovremennyj fel'eton (Opyt teorii)'. Pecat' i revoljucija, 1926, $7,18-35$.

Gusev,S. 'Predely kritiki (0 paskviljach,poklepach,klevete i kontrrevoljucii)'.

Izvestija CIK sSSR i V'̌IK,1927, 100, 6.5.

Safir,Ja. 'Razoblacitel'nye priemy "Pravdy" v 1927 godu'.

Peçat' i revoljucija, $1927,6,5-17$.

Bekker,M. 'Nužna 1 i nam basnja?'.

Na literaturnom postu, 1928, 13-14 + 90-92.

'Epopeja ili fel'eton.Materialy diskussii'.

'itatel' i pisatel', 1928, 13,5 (24.3.).

Bl jum,V. 'Vozroditsja li satira?'.

Literaturnaja gazeta, 1929,6 (27.5.). 
Bl jum,V. 'O putjach sovetskoj satiry'.

Literaturnaja gazeta,1929,13 (15.7.).

Le żnev,A.

'Na puti k vozroždeniju satiry'.

Literaturnaja gazeta, 1929,1 (22.4.).

Rogi,M. 'Puti sovetskoj satiry'.

Literaturnaja gazeta,1929,14 (22.7.).

Safir,Ja. ' $K$ voprosu o satiričskom romane'.

Peçat' i revoljucija, 1929, 12, 31-39.

Jakubovskij,G. 'O satire našich dnej'.

Literaturnaja gazeta, 1929, 1 (8.7.)

Litegraturnaja gazeta, 1930, (13.1.) Referat uber den Disput:

'Nuzna li nam satira?'.

Kut , A.

'Nǔ̌na li nam satira?'

Vecernaja Moskva, 1930,(9.2.).

Bojčevskij,v. 'Puti sovetskoj satiry'.

Zemlja sovetskaja, 1931, 1, 143-149.

Nusinov, I. 'Voprosy Zanra v proletarskoj literature'.

Literatura $i$ iskusstvo, 1931, 2-3,41.

Kol'cov,M. 'Ocerk i pamflet'.

Literaturnyj kritik, 1934,7-8.

Kol'cov,M. (Rede auf d.Schriftstellerkongreß).

Literaturnaja gazeta, 1934, 24.8 .

Zurbina, E. 'Roždenie smecha'.

Literaturnaja gazeta, 1936, 20.5 .

Eventov, I. 'Smech pobeditelej.Dvadcat' let sovetskoj satiry'.

Literaturnyj sovremennik, 1937, 7, 223-242.

Gorbatov,B. 'O sovetskoj satire i jumore.2ametki pisatelja'. Novyj mir, 1949, 10,214-229.

Kirpotin, v. 'Satira Sčedrina i sovremennost' '. Okt jabr', 1951,1, 162-172.

Plotkin, L. 'O pravde zizni'. Zvezda, 1952, 8, 135-145.

Borev,Ju. 'Oružija ljubimejšego rod (Zametki o komičeskom)'. Teatr, 1953, 7, 51-64.

El'sberg, Ja. 'Nasledie Gogolja i Šcedrina i sovetskaja dramaturgija'. Teatr, 1953, 2, 54-70.

Gural'nik,U. 'Smech smechu rozn'. Satiričeskij rasskaz v zurnale "Krokodil" '.

Okt jabr', 1953, 2, 177-183.

Gural'nik, U. 'Russkaja revoljucionno-demokratičeskaja kritika i voprosy satiry'.

Izv. AN SSSR, otd.1it. i jaz., 1953, 12, vyp. 3, 237-246. 


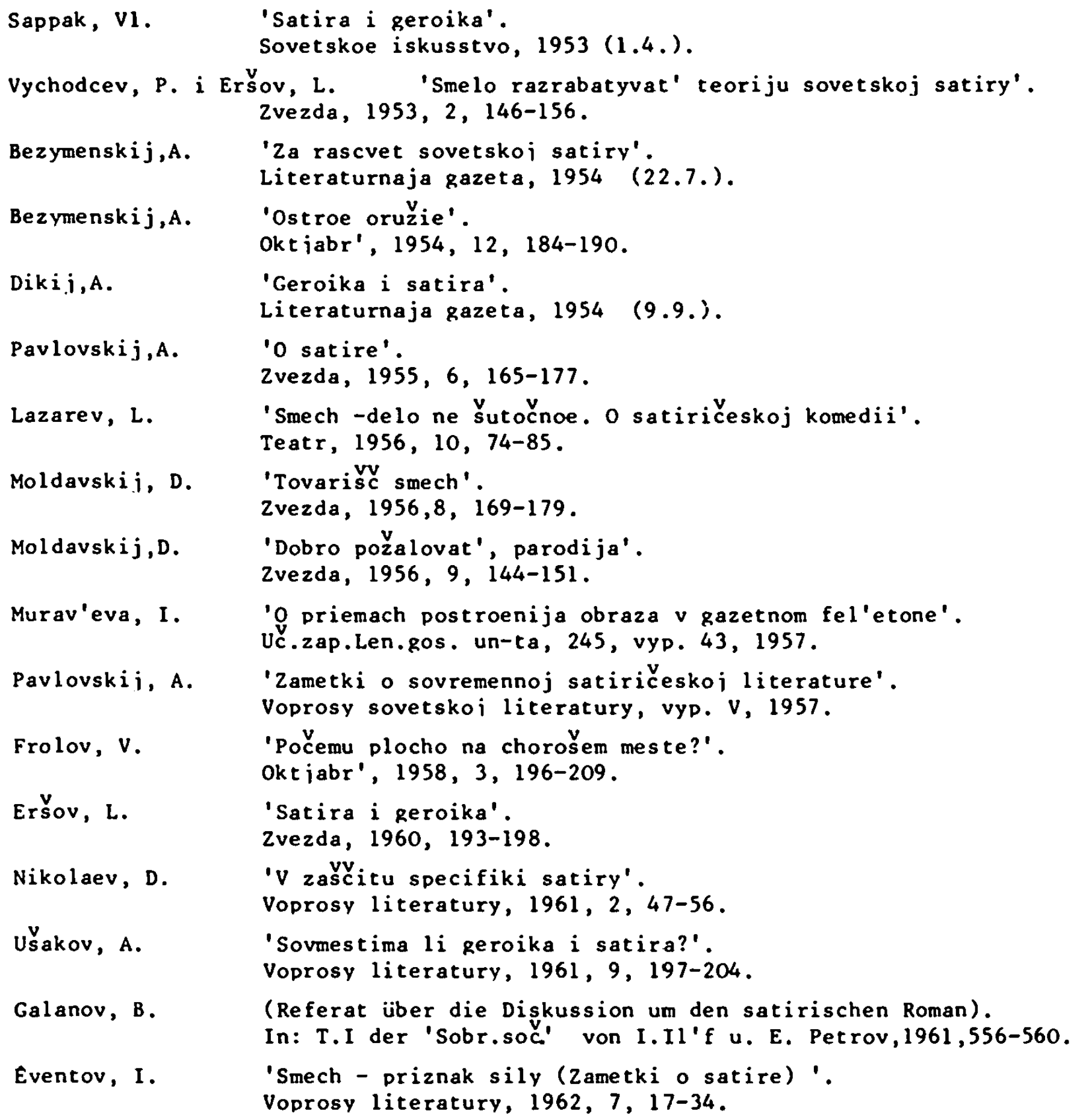

\section{Zur Geschichte des sowietischen satirischen Romans}

Eršov, L. 'Sovetskaja satiričeskaja proza 20-ch godov'. M. -L. 1960.

Eršov, L. 'Sovetskij satiriceskij roman $v 20-e$ gody'. Voprosy sovetskoj literatury, T.IX, izd.AN SSSR, 1961,357-396. 
Ersơv, L.

'Sovetskaja satiričeskaja proza'.

M. -L. 1966.

Ersov, L.

'Iz istorii sovetskoj satiry. M.zošcenko i satiričskaja proza 20 - 40-ch godov'.

L. 1973

Eventov, I.

'Sila sarkazma. Satira i jumor v tvorcestve M.Gor'kogo'. L. 1973.

Galanov, B.

'Il'ja Il'f i Evgenij Petrov.Žizn'.Tvorcestuo'.

M. 1961 .

Janovskaja, L. 'Počemu vy pišete smešno? Ob Il'fe i Petrove, ich žizni i ich jumore'.

M. 1969 .

Muratova, D. 'Gor'kij i sovetskaja satira (1919-1936)'.

Voprosy sovetskoj literatury, vyp.v, 1957.

Stykalin, S. i Kremenskaja, J. 'Sovetskaja satiričeskaja pečat' 1917$1963^{\prime}$.

M. 1963.

Vulis,A. II.Il'f i E. Petrov. Očerk tvorcestva'. M. 1960 .

Vulis,A. 'Sovetskij satiričeskij roman.Evoljucija žanra v 20-30-e gody'.

Taskent 1965 . 
105. Pogað̌nik, J.: Von der Dekoration zur Narration. Zur Entstehungsgeschichte der slovenischen Literatur. 1977. $165 \mathrm{~S}$.

106. Bojić, V.: Jacob Grimm und Vuk Karadżć. Ein Vergleich ihrer Sprachauffassungen und ihre zusamenarbeit auf dem Gebiet der serbischen Grammatik. 1977. $257 \mathrm{~S}$.

107. Vintr, J.: Die ältesten Zechischen Evangeliare. Edition, Textund Sprachanalyse der ersten Redaktion. 1977. $367 \mathrm{~S}$.

108. Lohff, U. M.: Die Bildlichkeit in den Romanen Ivan Aleksandrovie Goncarovs (1812-1891). 1977. XVI, $244 \mathrm{~S}$.

109. Regier, Ph. R.: A Learner's Guide to the Old Church Slavic Language. Part 1: Gramnar with Exercises. 1977. XLIV, $368 \mathrm{~S}$.

110. Worth, D. S.: On the Structure and History of Russian. Selected Essays. With a Preface by Henrik Birnbaum. 1977. X, 276 S.

111. Schulte, B.: Untersuchungen zur poetischen Struktur der Lyrik von Sima Pandurović. Posmrtne pocasti.1977. $345 \mathrm{~S}$.

112. Albert, H.: Zur Metaphorik in den Epen Zivana, Medvjed Brundo, Utva und Ahasver des kroatischen Dichters vladimir Nazor. 1977. $171 \mathrm{~s}$.

113. Slavistische Linguistik 1976. Referate des II. Konstanzer Slavistischen Arbeitstreffens (5.-7.10. 1976). Herausgegeben von W. Girke und H. Jachnow. 1977. $261 \mathrm{~S}$.

114. Matuschek,H.: Einwortlexeme und Wortgruppenlexeme in der technischen Terminologie des Polnischen. 1977. VIII, $417 \mathrm{~s}$.

115. Schreier, H.: Gogol's religiöses Weltbild und sein literarisches Werk. Zur Antagonie zwischen Kunst und Tendenz. 1977. $123 \mathrm{~S}$.

116. Beiträge und Skizzen zum Werk Ivan Turgenevs. 1977. $142 \mathrm{~S}$.

117. Neureiter, F.: Geschichte der kaschubischen Literatur. Versuch einer zusammenfassenden Darstellung. 1978. $281 \mathrm{~S}$.

118. Russel, M.: Untersuchungen zur Theorie und Praxis der Typisierung bei I. A. Goncarov. 1978. $401 \mathrm{~S}$.

119. Referate und Beiträge zum VIII. Internationalen slavistenkongreb Zagreb 1978. 1978. $451 \mathrm{~S}$.

120. Slavistische Linguistik 1977. Referate des III. Konstanzer Slavistischen Arbeitstreffens Bochum. 27.9.77 - 29.9.77. Herausgegeben von W. Girke und H. Jachnow. 1978. $260 \mathrm{~S}$.

121. Muller, V.: Der Poetismus. Das Programm und die Hauptverfahren der tschechischen literarischen Avantgarde der zwanziger Jahre. 1978. VI, $215 \mathrm{~S}$.

122. Pailer, W.: Die frühen Dramen M. Gor'kijs in ihrem Verhältnis zum dramatischen Schaffen A. P. Cechovs. 1978. VIII, $210 \mathrm{~S}$.

123. Thomas, G.: Middle Low German Loanwords in Russian. 1978. $269 \mathrm{~S}$.

124. Lehfeldt, w.: Formenbildung des russischen Verbs. Versuch einer analytisch-synthetisch-funktionellen Beschreibung der Präsens- und der Präteritumflexion. 1978. $114 \mathrm{~S}$.

125. Schön, L.: Die dichterische Symbolik V. M. Garšins. 1978. VI, $203 \mathrm{~S}$.

126. Berg, R.: Die Abstrakta auf -nie/-tie, -ka/-ok, -ost', -stvo/ -stvie, -ie/-be in den "Pis'ma i Bumagi" Peters des GroBen. 1978. IV, $352 \mathrm{~S}$.

127. Stricker, G.: Stilistische und verbalsyntaktische Untersuchungen zum Moskovitischen Prunkstil des 16. Jahrhunderts. 1979. XIV, 678 S., 3 Tabellen. 
128. Heim, M. H.: The Russian Journey of karel Havlícek Borovský. 1979. XII, $194 \mathrm{~S}$.

129. Malingoudis, J.: Die Handwerkerbezeichnungen im Alttschechischen. 1979. IV, $221 \mathrm{~s}$.

130. Roth, J.: Die indirekten Erlebnisformen im Bulgarischen. Eine Untersuchung $z u$ ihrem Gebrauch in der umgangssprache. 1979. VIII, $186 \mathrm{~S}$.

131. Nitsch, E.: Thema und Anweisungsstruktur im Text. Mit einer Analyse des ersten Abschnittes aus "Noc s Hamletem" von Vladimir Holan. 1979. VIII, $178 \mathrm{~s}$.

132. Hock, Ch.: Zur syntaktischen und kommunikativen struktur slavischer Partizipial- und Gerundialkonstruktionen. 1979.X, $283 \mathrm{~S}$.

133. Slavistische Linguistik 1978. Referate des IV. Konstanzer Slavistischen Arbeitstreffens Tubingen 26.-29. Sept. 1978 . Herausgegeben von Jochen Raecke und Christian Sappok. 1979. $276 \mathrm{~s}$.

134. Breitschuh, W.: Die Feoptija V. K. Trediakovskijs. Ein physikotheologisches Lehrgedicht im RuBland des 18. Jahrhunderts. 1979. VIII, $523 \mathrm{~S}$.

135. Gallant, J.: Russian Verbal Prefixation and Semantic Features: an Analysis of the Prefix Bз-. 1979. $460 \mathrm{~S}$.

136. Jachnow, H. (u.a.): Zur Erklärung und Modellierung diachroner Wortbildungsprozesse (anhand russischer substantivischer Neologismen). 1980. IV, $230 \mathrm{~S}$.

137. Breu, W.: Semantische Untersuchungen zum Verbalaspekt im Russischen. 1980. X, $231 \mathrm{~S}$.

138. Slavistische Linguistik 1979. Referate des V. Konstanzer Slavistischen Arbeitstreffens Zürich 25. - 27. Sept. 1979. Herausgegeben von Daniel Weiss. 1980. $259 \mathrm{~S}$.

139. Franz, N.: Groteske Strukturen in der Prosa zamjatins. Syntaktische, semantische und pragmatische Aspekte. 1980. $312 \mathrm{~S}$.

140. Baer, J. T.: Arthur Schopenhauer und die russische Literatur des späten 19. und frühen 20. Jahrhunderts. 1980. VIII, $194 \mathrm{~S}$.

141. Lempp, A.: Das zusammengesetzte Verbalprädikat mit "da" im Neubulgarischen. 1981. IV, $102 \mathrm{~S}$.

142. Stephan, H.: "Lef" and the Left Front of the Arts. 1981. XIV, $242 \mathrm{~S}$.

143. Kempgen, S.: "Wortarten" als klassifikatorisches Problem der deskriptiven Grammatik. Historische und systematische Untersuchungen am Beispiel des Russischen. 1981. X, $309 \mathrm{~S}$.

144. Peters, J.: Farbe und Licht. Symbolik bei Aleksandr Blok. 1981. VIII, $315 \mathrm{~S}$.

145. Ebding, J.: Tendenzen der Entwicklung des sowjetischen satirischen Romans (1919-1931). 1981. VI, 294 S.

146. Schreiber, J.: Jerzy Andrzejewskis Roman "Ciemności kryja ziemię" und die Darstellung der Spanischen Inquisition in Werken der fiktionalen Literatur. 1981. VIII, $308 \mathrm{~S}$.

147. Slavistische Linguistik 1980. Referate des VI. Konstanzer Slavistischen Arbeitstreffens Hamburg 23. - 25. Sept. 1980. Herausgegeben von Peter Hill und Volkmar Lehmann. 1981. $243 \mathrm{~S}$.

148. Hartenstein, K.: Das erklärend-kombinatorische wörterbuch im "Smysl $\leftrightarrow$ Tekst"-Modell. Studien zu den lexikologischen Grundlagen der Bedeutungsexplikation und ihrer lexikographischen Verwendbarkeit. 1981. VIII, $277 \mathrm{~s}$. 